\title{
Inflation-output trade-offs and the implications for monetary policy
}

Citation for published version (APA):

Lammertsma, A. (1997). Inflation-output trade-offs and the implications for monetary policy. [Doctoral Thesis, Maastricht University]. Universiteit Maastricht. https://doi.org/10.26481/dis.19971106al

Document status and date:

Published: 01/01/1997

DOI:

10.26481/dis.19971106al

Document Version:

Publisher's PDF, also known as Version of record

\section{Please check the document version of this publication:}

- A submitted manuscript is the version of the article upon submission and before peer-review. There can be important differences between the submitted version and the official published version of record.

People interested in the research are advised to contact the author for the final version of the publication, or visit the DOI to the publisher's website.

- The final author version and the galley proof are versions of the publication after peer review.

- The final published version features the final layout of the paper including the volume, issue and page numbers.

Link to publication

\footnotetext{
General rights rights.

- You may freely distribute the URL identifying the publication in the public portal. please follow below link for the End User Agreement:

www.umlib.nl/taverne-license

Take down policy

If you believe that this document breaches copyright please contact us at:

repository@maastrichtuniversity.nl

providing details and we will investigate your claim.
}

Copyright and moral rights for the publications made accessible in the public portal are retained by the authors and/or other copyright owners and it is a condition of accessing publications that users recognise and abide by the legal requirements associated with these

- Users may download and print one copy of any publication from the public portal for the purpose of private study or research.

- You may not further distribute the material or use it for any profit-making activity or commercial gain

If the publication is distributed under the terms of Article $25 \mathrm{fa}$ of the Dutch Copyright Act, indicated by the "Taverne" license above, 


\section{Inflation-Output Trade-Offs and the Implications for Monetary Policy}





\title{
Inflation-Output Trade-Offs and the Implications for Monetary Policy
}

\author{
PROEFSCHRIFT \\ ter verkrijging van de graad van doctor \\ aan de Universiteit Maastricht, \\ op gezag van de Rector Magnificus, Prof. Mr. M.J. Cohen, \\ volgens het besluit van het College van Decanen, \\ in het openbaar te verdedigen \\ op donderdag 6 november 1997 om 16.00 uur
}

door

Alexander Lammertsma 


\section{Promotores:}

Prof. dr. C.G. Koedijk

Prof. dr. C.J.M. Kool

Prof. dr. J. Muysken

\section{Beoordelingscommissie:}

Prof. dr. F.C. Palm (voorzitter)

dr. R.M.W.J. Beetsma

Prof. dr. E. de Jong (Katholieke Universiteit Nijmegen) 


\section{Preface}

This thesis is the result of four years of research while I was employed as a research assistant (AiO) at the Economics Department of the Faculty of Economics and Business Administration of Maastricht University. Without the continuing support of my supervisors Kees Koedijk, Clemens Kool, and Joan Muysken this dissertation would never have been completed. I would like to thank them for their trust and stimulating comments on the papers I wrote in the past four years.

As chairman of the examining committee, Franz Palm offered useful suggestions to improve the thesis. The remarks of Roel Beetsma and Eelke de Jong also contributed to further improvements of the thesis. Several colleagues in the Economics and the Finance department offered valuable comments on parts of this thesis. I would like to thank them not only for their recommendations, but also for the pleasant environment they created to write the thesis.

Furthermore, I would also like to thank Lilian Raetsen, Tilly Loth, and Anke Wijnen for their secretarial assistance. Finally, I thank my family for their interest in the progress of this thesis.

\section{Alex Lammertsma}

August, 1997 


\section{Contents}

\section{Preface}

List of Tables

List of Figures

Chapter 1 Introduction

1.1 Background

1.2 Aim of this thesis

1.3 Outline of this thesis

Chapter 2 Inflation-Unemployment Trade-offs and Aggregate Demand Policy: A Survey

2.1 Introduction

2.2 Forerunners of the Phillips curve

2.3 The Phillips curve and its extensions

2.4 New microeconomic foundations

2.5 Price-misperception theories

2.5.1 The Lucas (1973) model

2.5.2 The Barro (1976) model

2.5.3 The open-economy extensions of Lucas (1973)

Price stickiness theories

2.6.1 Price adjustment costs

2.6.2 Nominal rigidities

2.7 Conclusion

Chapter 3 Asymmetry, Non-neutrality and Persistence: Evidence from the United States and Germany

3.1 Introduction

3,2 The Lucas (1973) model 25

3.3 Asymmetry, non-neutrality, and persistence $\quad 26$

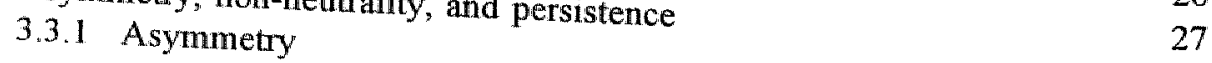


3.3.2 Non-neutrality 28

$\begin{array}{ll}\text { 3.3.3 Persistence } & 28\end{array}$

$\begin{array}{lll}3.4 & \text { Model } & 29\end{array}$

3.5 Data 31

\begin{tabular}{ll}
3.6 & Empirical analysis \\
\hline
\end{tabular}

3.6.1 Symmetry test 33

3.6.2 Structural neutrality test 37

3.6.3 Non-persistence test 38

$\begin{array}{lll}3.7 \text { Conclusion } & 41\end{array}$

Appendix 3A Construction of $t$ and $w t \quad 42$

Chapter 4 The Evidence on International Output-Inflation Trade-Offs: An Evaluation $\quad 45$

4.1 Introduction $\quad 45$

4.2 The Lucas model and the Lucas variability hypotheses 46

4.3 Empirical evidence on the Lucas variability hypotheses 47

4.4 A correction for supply responses $\quad 53$

4.5 Conclusion 55

Appendix 4A Estimation periods of Lucas variability studies $\quad 56$

$\begin{array}{lll}\text { Appendix 4B } & \text { Developed countries in Lucas variability studies } & 57\end{array}$

Appendix 4C Developing countries in Lucas variability studies $\quad 58$

Chapter 5 The Effects of Systematic Policy in a Price Stickiness Model: the Alogoskoufis Model

Revisited

5.1 Introduction 61

5.2 Alogoskoufis-Smith (1991) model 63

5.2.1 The demand for goods 64

5.2.2 Price-setting behaviour of firms 64

5.2 .3 The demand for money 65

5.2.4 The supply of money 66

$\begin{array}{ll}\text { 5.2.5 The demand for labour } & 67\end{array}$

5.2.6 The supply of labour $\quad 68$

$\begin{array}{ll}5.2 .7 & \text { Equilibrium conditions }\end{array}$

5.3 Average model $\quad 69$

5.4 Relative model $\quad 74$

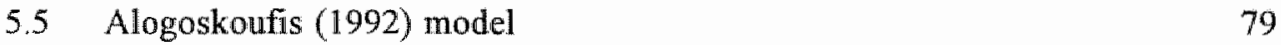

$\begin{array}{lll}5.6 \text { Conclusion } & 81\end{array}$ 
Appendix 5A Price adjustment cost model

Appendix 5B Solution of the average Alogoskoufis-Smith (1991) model

Appendix 5D Solution of the average Alogoskoufis (1992) model

Appendix 5E Solution of the relative Alogoskoufis (1992) model

\section{Chapter 6 The Effects of Systematic Policy in a} Price-Misperception Model

6.1 Introduction

6.2 Basic model

6.2. I The demand for goods

6.2.2 The supply of goods

6.2.3 The demand for money

6.2.4 The supply of money

6.2.5 The nominal and the real exchange rate

92

6.2.6 Equilibrium conditions

6.3 Average price-misperception model

6.4 Relative price-misperception model

6.5 Conclusion

Appendix 6A Derivation of the aggregate supply function

Appendix 6B

Derivation of the relative price-misperception model given a modified exchange rate equation

Appendix 6C Solution of the average price-misperception model

Appendix 6D Solution of the relative price-misperception model

\section{Chapter 7 Inflation Convergence and Exchange Rate Policy:}

\section{A Case Study for Spain and Italy}

7.1 Introduction

7.2 Main economic developments in Spain during 1975-1995

7.3 Main economic developments in Italy during 1975-1995

7.4 Methodology

7.4.1 Model

7.4.2 Structural breaks

$\begin{array}{ll}7.6 .1 & \text { Tests for unit roots and co-integration } \\ 7.6 .21\end{array}$

7.6.2 Structural break analysis

7.6.2.1 Depreciation period: $1975: 1-1985: 2$

7.6.2.2 Depreciation period and stable period: 1975:1-1992:3 
7.6.2.3 Whole period: $1975: 1-1995: 1$

7.6.2.4 Main results for Spain 125

$\begin{array}{lll}7.7 & \text { Empirical results for Italy } & 128\end{array}$

$\begin{array}{ll}\text { 7.7.1 Tests for unit roots and co-integration } & 128\end{array}$

$\begin{array}{lll}7.7 .2 & \text { Structural break analysis } & 130\end{array}$

7.7.2.1 Depreciation period: 1975:1-1986:4 130

7.7.2.2 Depreciation period and stable period: $1975: 1-1992: 3 \quad 130$

7.7.2.3 Whole period: 1975:1-1995:1 131

$\begin{array}{ll}7.7 .2 .4 & \text { Main results for Italy } \\ & 132\end{array}$

$\begin{array}{lll}7.8 \text { Conclusion } & 135\end{array}$

Appendix 7A Derivation of the inflation convergence model 136

Appendix $7 \mathrm{~B} \quad$ Construction of the real exchange rate and the European price index $\quad 136$

$\begin{array}{lll}\text { Chapter } 8 & \text { Summary and Suggestions for Further Research } & 139\end{array}$

$\begin{array}{lll}\text { 8.1 Summary and conclusions } & 139\end{array}$

$\begin{array}{ll}8.2 & \text { Suggestions for further research } \\ & 146\end{array}$

$\begin{array}{ll}\text { References } & 147\end{array}$

$\begin{array}{lr}\text { Samenvatting } & 155\end{array}$

$\begin{array}{ll}\text { Curriculum Vitae } & 161\end{array}$ 


\section{List of Tables}

3.1 Cumulated effects of positive and negative shocks for the United States 34

3.2 Cumulated effects of positive and negative shocks for Germany 35

3.3 Symmetry tests for the United States 36

3.4 Symmetry tests for Germany 36

3.5 Structural neutrality tests for the United States 37

$\begin{array}{ll}3.6 & \text { Structural neutrality tests for Germany } \\ 3.7 & 38\end{array}$

3.7 Non-persistence tests for the United States 39

3.8 Non-persistence tests for Germany 40

4.1. Cross-section averages of $\sigma_{\Delta x}^{2}$ for developed countries, developing countries, and all countries (developed and developing countries) $\quad 49$

4.2 Cross-section averages of $\sigma^{2}$ for developed countries, developing countries, and all countries (developed and developing countries)

4.3 Cross-section averages of $\pi$ for developed countries, developing countries, and all countries (developed and developing countries) 50

4.4 Simple cross-country correlations for developed countries 51

4.5 Simple cross-country correlations for developing countries 51

4.6 Simple cross-country correlations for all countries 52

4.7 Average simple correlations across studies $\quad 52$

4.8 Behrens-Fischer tests on simple correlations 53

4.9 Average partial correlations across studies $\quad 55$

4.10 Behrens-Fischer test on partial correlations 55

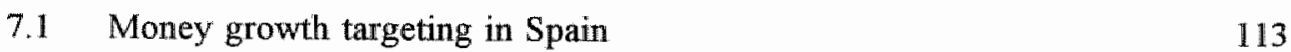

7.2 Augmented Dickey-Fuller tests for Spain with constant, trend, and four lags (1975:1-1995:1)

$\begin{array}{lll}7.3 & \text { Models for the change in Spanish inflation }\left(\Delta \pi_{s p, t}\right) & 127\end{array}$

7.4 Augmented Dickey-Fuller tests for Italy with constant, trend, and four lags (1975:1-1995:1)

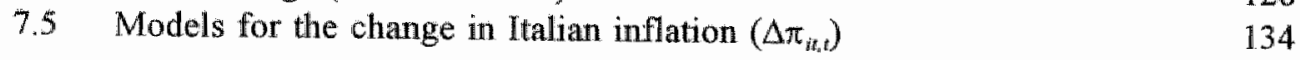

8.1 Theoretical output effects of unsystematic and systematic policy 141

8.2 Theoretical effects of unsystematic policy on the slope of the short-run inflation-output trade-off

8.3 Theoretical inflation effects of systematic monetary and exchange rate policy 


\section{List of Figures}

5.1 Output effects of a change in systematic monetary policy in the average Alogoskoufis-Smith (1991) model

5.2 Output effects of a change in systematic exchange rate policy in the relative Alogoskoufis-Smith (1991) model

6.1 Output effects of a change in systematic monetary policy in the price-misperception model

6.2 Restrictions in the average price-misperception model due to the saddlepath assumption

6.3 Output effects of a change in systematic exchange rate policy in the price-misperception model

7.1 Exchange rate of the Spanish peseta per Deutschmark (EPSDM), the lower EMS band (LBPSDM), and the upper EMS band (UBPSDM) 114

7.2 Exchange rate of the Italian lira per Deutschmark (ELIDM), the lower EMS band (LBLIDM), and the upper EMS band (UBLIDM)

7.3 Spanish (PSP) and core European (PEUR) inflation (percentage price increase relative to the corresponding quarter of the previous year)

7.4 Difference between Spanish and core European inflation

7.5 Recursive speed of inflation convergence for Spain (model (7.6))

7.6 Italian (PIT) and core European (PEUR) inflation (percentage price increase relative to the corresponding quarter of the previous year)

7.7 Difference between Italian and core European inflation

7.8 Recursive speed of inflation convergence for Italy (model (7.10)) 


\section{Chapter 1}

\section{Introduction}

\subsection{Background}

After the collapse of the Bretton Woods system of fixed exchange rates in 1971 and the experience with divergent economic policies in the snake arrangement since April 1973, the German and French initiative at the end of 1978 to form a zone of monetary stability resulted in the establishment of the European Monetary System (EMS) in March 1979; the EMS replaced the snake arrangement." The main element of the EMS is its Exchange Rate Mechanism (ERM). It is a fixed-exchange rate mechanism with fixed but adjustable parities. Until 1983 the participating currencies were frequently realigned. From 1983 on, however, the frequency of realignments dropped and the ERM became an asymmetric system with Germany as leader. Each of the participating countries attempted to borrow the credibility of the Bundesbank by committing themselves firmly to fixed exchange rates; the purpose of these policies was to fight inflation (see Giavazzi and Pagano, 1988). This attitude was confirmed by the Basle-Nyborg agreement in 1987 which developed a new procedure to withstand speculative attacks (see Bakker, 1996). Instead of largescale interventions, interest rates should be used to defend the exchange rate and the realignments should be small. As a result, the exchange rate parity remained unchanged for a long time untill 1992.

Besides monetary integration, economic integration also progressed. By the end of 1992 the European Community was to be a single market with free movement of persons, goods, services, and capital. One of the first measures was to lift all capital controls by July 1990 . In order to reap the full benefits of the internal market, the European Commission stated in 1990 in its report "One Market, One Money" that a common currency was necessary. Such a common currency, or monetary union resolves the dilemma that free trade, full capital mobility, fixed exchange rates, and independent national monetary policies are inconsistent (see Padoa-Schioppa, 1988:376). To propose concrete steps for such a monetary union, the Delors committee was established, and it was on the report of that committee that in 1991 the Maastricht treaty was written. In this treaty it was agreed that if a country wants to join the European Monetary Union it has to fulfil certain criteria. First of all, the

\footnotetext{
1 For an extensive overview of the history of the process of European monetary integration see, for example, Gross and Thygesen, 1992, and Collignon, 1994, or Kenen, 1995.
} 
government deficit has to be less than 3 per cent of gross domestic product and its debt has to be no more than 60 per cent. Second, inflation rates and interest rates must converge around the average of the lowest three. Finally, a country must have a stable exchange rate for at least two years before entry; this implies that it has not changed its exchange rate parity in the ERM for at least two years.

In February 1992 when the Maastricht treaty was signed, it was thought that the ERM had already evolved into a kind of quasi monetary union. The crisis in the EMS in September 1992, however, ended this wishful thinking. Speculation was directed at overvalued currencies like the Italian lira and the British pound. As the exchange rate parity could not be defended by large-seale interventions, and capital controls were lifted, both currencies had to leave the exchange rate mechanism. About one year later, the exchange rate margins in the ERM had to be widened to 15 percent as the market doubted whether countries with high unemployment rates like France and Spain would still increase their interest rates to defend the exchange rate parity. ${ }^{2}$

Despite these difficulties in the process of monetary integration, most European countries, except the United Kingdom and Denmark, want to join the European Monetary Union that is most likely to start in January 1999. Even Austria and Finland joined the EMS in January 1995 and October 1996 respectively; Italy rejoined ERM in November 1996. To enter the European Monetary Union in January 1999, each country has to satisfy the Maastricht criteria; this will be examined in the spring of 1998 by the European Monetary Institute (EMI), the predecessor of the European Central Bank (ECB). Of these criteria, the budgetary ones are the most difficult to fulfil, for to achieve them, spending cuts are necessary in many countries. Moreover, these spending cuts must be even higher due to the stability pact. This pact agreed in June 1997 obliges countries to submit stability programmes. These stability programmes must contain plans to achieve a budget deficit of around zero or even have a small budget surplus. Furthermore, countries with a deficit exceeding 3 per cent will be forced to hold a non-interest earning deposit at the ECB between 0.2 and 0.5 per cent of their gross domestic product. The purpose of this stability pact is to help the ECB to maintain its prime goal of price stability.

\subsection{Aim of this thesis}

With the European Monetary Union approaching, countries like France, Italy, and Spain fear that European monetary policy will be so strict that it may lead them into a recession. The main reason for this fear is that the prime goal of the future ECB is to maintain price stability. Moreover, the ECB has to build up an anti-inflation reputation, similar to that which the Bundesbank has now, which may lead to

Only the bands between the Dutch guilder and the Deutschmark kept 2.25 per cent. 
extra tight monetary policy. Finally, the ECB will be unable to serve national goals of high economic growth and low unemployment as this will jeopardize the ultimate goal of price stability.

While a less strict monetary policy may temporarily lead to a lower unemployment rate, it generally implies a higher rate of inflation in the long run. Whether such a trade-off between output and inflation can and should be exploited by monetary policy, or more generally, by aggregate demand policy, depends on a number of issues. First, it is contigent on the magnitude and persistence of the unemployment reduction after an expansionary policy. The longer the unemployment effects last and the larger the decrease in unemployment, the more effective such a policy is. Second, if an expansionary policy mainly leads to a higher inflation, and a contractionary policy does not cause serious disinflation but mainly results in an increase in unemployment, the costs of countercyclical demand policy increase. Third, if a policy change is announced, this may not have real effects if economic agents have the ability to incorporate a policy change in their decisions. Fourth, the potential of macroeconomic demand policies may be conditional on the explanation of the trade-off between inflation and unemployment. Finally, the output and the inflation effects may depend on the type of aggregate demand policy which is used to exploit the trade-off between inflation and unemployment.

The aim of this thesis is to review the theoretical explanations for a trade-off between inflation and output growth, to investigate whether the output and inflation effects of aggregate demand policies differ from one inflation-output theory to another, to investigate for which explanation empirical support can be found, and to investigate whether aggregate demand policies can be used to increase output growth and to reduce inflation.

\subsection{Outline of this thesis}

In chapter 2 the literature on the trade-offs between inflation and unemployment is reviewed in historical order. The first explanations were given by Hume (1752), Thornton (1802), Attwood (1816), and Mill (1833). These explanations, though, were of a descriptive nature. Because data were scarce, it took untill 1926 before Irving Fisher carried out the first empirical investigation. He found a correlation between anticipated inflation and the change in employment of 0.9 . The empirical analysis of the trade-off between inflation and unemployment, however, really started in the $1950 \mathrm{~s}$ with Phillips (1958) as the major breakthrough. Phillips found a clear trade-off between unemployment and wage inflation in the form of a convex curve; Samuelson and Solow (1960) labeled it the Phillips curve.

The Phillips curve stimulated much empirical work. Especially the lack of stability of the curve tumed out to be a problem. First, it was thought to be an omitted variables problem, but later Phelps (1967) and Friedman (1968) stressed that insta- 
bility was due to the exclusion of expectations. According to them there is only a trade-off in the short run, in the long run it is absent; this is the natural rate hypothesis. To understand the natural rate hypothesis better, new microeconomic explanations were provided.

Two explanations for the natural rate hypothesis are the price-misperception theories and the price stickiness theories. According to the price-misperception theories, there is a short-run trade-off because suppliers have imperfect information on the nature of shocks that occur: the more a shock is thought to be real, the more output will respond. In the long run, however, the trade-off vanishes. With respect to aggregate demand policy, unsystematic policy and systematic policy need to be distinguished. Unsystematic policy influences the economy by policy-induced shocks, whereas systematic policy runs through changes in policy rules. The pricemisperception model predicts that unsystematic (unexpected) policy affects output; whereas systematic policy does not. The latter is the structural neutrality hypothesis. Furthermore, the price-misperception models imply that positive and negative shocks have the same effect on output (symmetry hypothesis), and that shocks have only a real effect in the period in which they occur (non-persistence hypothesis). Besides these three properties, Lucas (1973) also derives three cross-country hypotheses from the misperception theory. These are commonly known as the Lucas variability hypotheses: the more uncertain economic agents are about inflation, the less they will adjust output. Second, the larger the variance of demand shocks, the larger the variance of inflation. Third, the more variable aggregate demand shocks are, the less output will respond to these shocks.

According to the price stickiness theories, there are price adjustment costs or other nominal rigidities that cause nominal demand changes to have real effects. This implies again that there is a short-run trade-off, but no long-run trade-off. One of the main differences with the price-misperception theories is that in the price stickiness theories systematic policies can affect real output (non-neutrality hypothesis). Furthermore, the effect of negative shocks is larger than that for positive shocks (asymmetry hypothesis) in the price stickiness theories, whereas it is symmetric in the price-misperception models. Finally, shocks have a persistent effect on output in the price stickiness models, that is, shocks not only have real effects in the period in which they are initiated, but also in later periods (persistence hypothesis), whereas they are not persistent in the price-misperception models.

These differences between the price-misperception theories and the price stickiness theories with respect to unsystematic policy can be used to test whether the empirical evidence favours price-misperception theories or price stickiness theories. Therefore in chapter 3 a simple price-misperception model is extended to allow the symmetry hypothesis, the non-persistence hypothesis, and the structural neutrality hypothesis to be tested against the alternatives of asymmetry, persistence and nonneutrality. It is found that in general the non-persistence hypothesis as well as the 
structural neutrality cannot be rejected for the United States and Germany over the period 1973:1-1992:4; the evidence for the symmetry hypothesis was mixed. So, it is hard to reject the price-misperception model with respect to unsystematic policy.

If unsystematic aggregate demand policy is exploited to increase output growth, the price-misperception model predicts that its real effect is reduced if it is used more frequently. To examine this, the Lucas variability hypotheses are investigated in chapter 4 . The available empirical evidence for these predictions in previously published studies is mixed concerning the question whether these predictions differ between developed and developing countries. Addison et al. (1986) and Odedokun (1991), for example, found that the potential role of aggregate demand policies in developing countries is larger than for developed countries, whereas Jung (1985) and Katsimbris (1990) find the reverse. To investigate whether the Lucas variability hypotheses are valid for developed and developing countries, the available crosscountry investigations are re-analysed in a meta-study in chapter 4 . It is known that the structure of developing economies differs from those of developed countries. If this difference is measured by the supply response and the correlations are corrected for a different supply response, it is found that the third Lucas variability hypothesis that a higher variance of demand shocks leads to a lower output effect of a demand shock should be rejected for the group of developed countries; the other two hypothesis could not be rejected.

Whereas chapters 3 and 4 concentrated on unsystematic policy, chapters 5,6 , and 7 focus on systematic policy. To have real effects of changes in systematic policy it is usually assumed that prices are sticky. There are only a few models that investigate how systematic policy, or rules for adjusting, for example, the money stock or the exchange rate, affects output growth as well as inflation in such price stickiness models. The most advanced models in this line are the two-country models of Alogoskoufis and Smith (1991) and Alogoskoufis (1992). Nevertheless, both studies have three disadvantages: first, they do not show how output growth is affected; second, they do not show through which channels a change in systematic policy is transmitted; and third, they make a crucial mistake in deriving the consequences for the persistence of inflation of changes in systematic exchange policy changes. Chapter 5 not only illustrates the output growth effects by way of a graphical analysis, it also clarifies through which channels a change in systematic policy is transmitted, and provides the correct solutions for both models.

A change in systematic policy in these models has several effects on output growth. First of all, systematic policy changes are non-neutral in the short run. It takes time for firms to adjust their pricing policies to the new systematic policy. Therefore, a change in systematic policy has real effects even if the change is expected. Second, a change in systematic policy affects output growth only in the short run; in the long run the output growth effects disappear. Third, changes in 
systematic policy have symmetric effects on output growth; that is, a decrease in the degree of monetary accommodation or exchange rate accommodation has an equal effect on economic growth as an increase. ${ }^{3}$ Fourth and finally, changes in systematic policy have persistent effects on economic growth; that is, the effects of a change in systematic policy occur not only in the period when systematic policy is changed, but also in later periods.

In order to derive the effects of a change in systematic monetary policy on inflation, all variables are averaged over both countries. If the model is solved, it is found that a higher degree of monetary accommodation increases the persistence of average inflation. An increase in the degree of monetary accommodation decreases the average real interest rate and increases the demand for goods through the real interest rate channel. This increase in demand for goods implies higher wage claims; thus, a higher rate of average inflation results. And as long as the effect on output growth persists, average inflation will keep rising.

For the effects of a change in systematic exchange rate policy, the difference of each variable is taken between both countries and consequently the model is solved. If the model is correctly solved, which Alogoskoufis and Smith (1991) and Alogoskoufis (1992) did not do, an ambiguous relation between the degree of exchange rate accommodation and the persistence of relative inflation is found. An increase in the degree of exchange rate accommodation is transmitted not only through the real interest rate channel, but also throught the real exchange rate and the wage cost channel. The fact that the relation between the degree of exchange rate accommodation and the persistence of relative inflation is not strictly positive is due to the fact that a higher degree of exchange rate accommodation causes an increase in the persistence of relative inflation through the real interest rate channel and the real exchange rate channel, but a decrease through the wage cost channel. Under reasonable parameter values, that is, if the real interest elasticity of the demand for goods and the unemployment elasticity of wages are low, the relation will be positive.

Whereas most theoretical models investigate systematic policy within a price stickiness model, it is interesting to investigate how systematic policy can affect output growth and inflation in a price-misperception model. Therefore a flexible price, misperception version of the price stickiness models of Alogoskoufis and Smith (1991) and Alogoskoufis (1992) is built in chapter 6. This is an innovative element in this thesis. It is found that systematic policy changes are non-neutral in the short run; in the long run, however, systematic policy does not affect economic growth. Second, changes in systematic monetary as well as exchange rate policy have symmetric effects on output. Finally, a change in systematic policy has persis-

This symmetric result is due to the transformation of the Alogoskoufis models to first differences; if they are stated in levels, systematic policy changes have asymmetric instead of symmetric effects on output growth as for unsystematic policy. 
tent output effects. With respect to systematic monetary policy, it can be derived that a higher degree of monetary accommodation increases the persistence of average inflation; with regard to systematic exchange rate policy, it is found that a higher degree of exchange rate accommodation increases the persistence of relative inflation and reduces the speed of inflation convergence.

Chapters 5 and 6 provide the hypothesis that a decrease in the degree of exchange accommodation lowers the persistence of relative inflation. The lower the persistence of relative inflation is, the higher the speed of inflation convergence. Thus, the lower the degree of accommodation, that is the harder the peg of a currency with respect to a low inflation currency like the Deutschmark is, the faster the speed of inflation convergence becomes. Alternatively, the borrowed credibility hypothesis predicts that joining a fixed exchange-rate regime like the Exchange Rate Mechanism (ERM) of the European Monetary System (EMS) is enough to increase the speed of inflation convergence. In chapter 7 it is investigated which of these two hypotheses is true for Spain and Italy. It is found for both countries that a hard peg causes a significant increase in the speed of inflation convergence, but that joining the ERM does not affect the speed of inflation convergence. This supports the hypothesis of chapters 5 and 6 , but rejects the borrowed credibility hypothesis.

Finally, chapter 8 contains a summary as well as suggestions for further research. 


$$
\begin{array}{ll}
\therefore & \\
\therefore \quad
\end{array}
$$




\section{Chapter 2}

\section{Inflation-Unemployment Trade-Offs and Aggregate Demand Policy: A Survey}

\subsection{Introduction}

Almost every government prefers to have a lower unemployment rate at the same rate of inflation, or a lower inflation rate accompanied by the same unemployment rate. However, a government generally is unable to lower unemployment and inflation at the same time: lowering unemployment by stimulating aggregate demand policy will increase inflation, whereas a disinflation policy will increase unemployment. Thus, in general there is a trade-off between inflation and unemployment: the higher inflation is, the lower unemployment must be and vice versa.

Whereas the debate on the trade-off between inflation and unemployment is often thought to have started in 1958 with the publication of the famous empirical analysis in the article by A.W. Phillips, it does in fact run back to David Hume and John Stuart Mill. Phillips (1958) was indeed a major breakthrough, but it did not provide a theoretical model for the trade-off found. Lipsey (1960) was the first to provide such a model. The introduction of inflationary expectations and the distinction between the short-run trade-off and the long-run trade-off by Phelps (1967) and Friedman (1968) was, nevertheless, more important for the theoretical debate. According to them, there is only a negative relation between unemployment and inflation in the short run; in the long run it is absent. Consequently, government cannot permanently lower unemployment through demand policies. "This is the natural rate hypothesis. To understand this hypothesis better, new theories for having a negative short-run trade-off and no long-run trade-off were developed in the 1970s. They can be divided into intertemporal labour supply theories, pricemisperception theories, search theories, and price stickiness theories.

The purpose of this cliapter is to provide an overview of the developments on the area of the trade-off between inflation and unemployment. Therefore the early explanations of Hume (1752) and Mill (1833) for a trade-off between inflation and unemployment are reviewed in section 2.2. This is important because it shows that the notions of the division between the short-run and the long-run trade-off and the relevance of unperceived price changes were already available long before Phelps (1967) and Friedman (1968). Section 2.3 describes how the trade-off developed from Phillips (1958) to the natural rate representation of Phelps (1967) and Friedman (1968). Then in section 2.4 the various new microeconomic developments like 
the intertemporal labour supply theories, price-misperception theories, search theories, and price-stickiness theories are discussed. As the rest of this thesis mainly builds on price-misperception theories and price stickiness theories, they are described in more detail in section 2.5 and 2.6 respectively. Finally section 2.7 contains a conclusion.

\subsection{Forerunners of the Phillips curve ${ }^{1}$}

The theoretical literature on the trade-off between inflation and unemployment runs back to classical writers such as Hume (1752) and Thornton (1802). Both Hume and Thornton described a trade-off between inflation and unemployment. According to Hume, this trade-off is due to the fact that the perceived price level adjusts slowly to the actual price level. Suppose that the money stock increases. Then the perceived price level remains initially unchanged. Consequently consumers think that the real value of their money has risen; that is, they suffer from money illusion, and demand more goods; therefore, the demand for labour will be higher and unemployment will be lower. Given the extra demand for goods; prices will increase one by one and the perceived price level will rise. If the increase in money is absorbed fully and all prices have been adjusted, the perceived price level stops rising and the perceived and the actual price level will be equal. Then the trade-off will vanish.

In Hume's view, it was desirable to exploit this trade-off in order to lower unemployment permanently. To achieve this, the money stock had to be continually increasing because this would keep actual prices above the perceived prices. Furthermore, the speed of adjustment of the expected price level towards the actual price level had to be low because this gives a rather flat trade-off between inflation and unemployment. Such flat trade-off is necessary to generate a large decrease in unemployment.

Whereas Hume's explanation of the trade-off was based on money-illusion, Thornton based his explanation on a consistent lag in the response of wages to price changes. ${ }^{2}$ His reasoning for a trade-off was the following. Suppose that the money stock increases continually. Then inflation will rise, and the real wage rate will fall as there is a lag in the response of wages to price changes. Given this decrease in the real wage, the demand for labour rises and unemployment falls.

Contrary to Hume, Thornton rejected the exploitation of this trade-off. This rejection was based on two arguments: first, stimulating aggregate demand policy leads only to a small reduction in unemployment and too large an increase in infla-

This section mainly draws upon Humphrey (1986).

2 A clear drawback of Thornton's reasoning is that it is not explained why the lag in the response of wage to price change persists and why wage inflation does not catch up with inflation. 
tion; second, the high inflation that results from stimulating aggregate demand policy is bad for the economy because it increases uncertainty. Thus, Thornton's impression was that the slope of the trade-off was very steep. Another difference with Hume is that Thornton did not inclide inflationary expectations in his tradeoff between inflation and unemployment.

The debate about the trade-off was continued in the nineteenth century by Attwood (1816) and Mill (1833). Attwood thought that there was a stable trade-off between unemployment and the price level: the higher unemployment is, the lower prices are and vice versa. Such a trade-off can be explained in that firms do not produce if prices are not high enough to match production costs. The higher the price level is, the more profitable it is to produce, given unchanged wages. According to Attwood, the government should use inflationary monetary policy to obtain a zero rate of unemployment. Doing this would support the prosperity of the nation most. However, this implies that employees can be fooled continuously about their real wages. Mill, on the other hand, rejects this claim. In his eyes, inflationary policy can only temporarily decrease unemployment as money illusion is only temporary. When the expected price level equals the actual price level again, unemployment returns to its original rate.

Whether or not it is sensible to exploit the trade-off between inflation and unemployment, as Hume and Thornton suggested, depends on the slope of the trade-off. If the slope is flat, the costs of a unit decrease in unemployment are low; if the slope is rather steep, the costs of a unit decrease in unemployment are much higher. Hume and Thornton, as well as Attwood and Mill, however, did not investigate how steep the trade-off between inflation and unemployment actually was. Irving Fisher (1926) was the first to present some statistical evidence for a trade-off between inflation and unemployment. He found a correlation of 0.9 between anticipated inflation and the change in employment. ${ }^{3}$ His explanation for this trade-off was that a rise in inflation increases the receipts of a firm more than it increases the firm's expenses. The reason for this slower increase in expenses is that expenses like the interest on bonds, rents and wages are fixed in contracts. Thus a rise in inflation increases profits, and this increases employment in turn. On the other hand, deflation lowers profits, and increases the number of firms going bankrupt; consequently, unemployment increases. Further empirical trade-offs were found by Tinbergen (1936), Klein and Goldberger (1955) and Brown (1955); see Humphrey (1986).

3 Anticipated inflation was measured as a distributed lag of inflation. 


\subsection{The Phillips curve and its extensions}

The empirical analysis of the trade-off between inflation and unemployment became a major research topic only after the publication in 1958 of A.W. Phillips" analysis for the UK. ${ }^{4}$ It was especially the fact that Phillips drew a curve through the scatter diagram of wage growth and the unemployment rate that made it catch the profession's eye. This curve, which was two years later called the Phillips curve by Samuelson and Solow (1960), had a downward sloping, convex shape: it was rather steep in the inflationary zone and flatter in the deflationary zone. Phillips attributed this asymmetric shape to downward wage rigidity: employees are not willing to accept nominal wage decreases if the demand for labour is low. If, instead, the demand for labour is high, employers raise wages to attract employees. Thus, the slope is steeper.

Another argument for the success of Phillips (1958) was that Lipsey (1960) provided a theoretical underpinning for Phillips' empirical result. The trade-off in Lipsey's model was based on two relations. First, Lipsey assumed a linear relation between the excess demand for labour and the wage increase: the higher the demand for labour is relative to the supply of labour, the more wages must rise. Second, the excess demand for labour and unemployment were assumed to be inversely related: the higher the excess demand for labour, the lower unemployment is and vice versa. Combining both relationships gives the curve found by Phillips.

With the new attention for the trade-off between inflation and unemployment, the issue of exploiting it by aggregate demand policy arose again. Two years after the publication of Phillips (1958), Samuelson and Solow (1960) suggested that the Phillips' curve offers a menu for policy choice: given the relative preferences for inflation and unemployment the Phillips curve determines the optimal combination between inflation and unemployment. ${ }^{6}$ To obtain this optimal combination the government only had to use monetary and fiscal policy to move along the Phillips curve to this optimal point. This requires that the position of the Phillips curve remains unchanged over time; that is, it has to be stable.

However, the empirical trade-off that Phillips (1958) and Lipsey (1960) found was not stable. Initially this was thought to be an omitted variables problem: to solve it, price changes, productivity and profit were added as explanatory variables

4. For an overview of this literature see Santomero and Seater (1978).

s Brown (1955) had already presented a statistical scatter diagram between wage growth and the rate of unemployment, but had not drawn a curve through these data (see Humphrey, 1986).

- Samueison and Solow (1960) rewrite the relation between wage inflation and unemployment as a relation between inflation and unemployment by assuming that prices are determined by a fixed mark-up over unit-labour costs. 
(see Santomero and Seater, 1978). Later, in the mid-sixties, Phelps (1967) and Friedman (1968) attributed the instability to the exclusion of expected inflation. If expected inflation is taken into account, only a short-run trade-off between inflation and unemployment remains, not a long-run trade-off.

This short-run trade-off between inflation and unemployment comes about as follows (see Friedman, 1975). Suppose that a government wants to decrease unemployment at the cost of a higher rate of inflation by a stimulating aggregate demand policy. Then firms will raise their selling prices given the extra demand for goods; wages, however, respond more slowly to the increase in aggregate demand than selling prices. Consequently, the real wage rate goes down and labour demand increases. Employees in turn evaluate the new higher wage rates at the old price level, and thus think the real wage has gone up. As a result, employment increases and unemployment falls. But as soon as employees observe that prices are going up and their real wage has gone down, they will expect a higher rate of inflation. This in turn shifts the Phillips curve upwards. In the long-run, expected inflation and actual inflation will be equal and unemployment will be equal to its natural rate for every rate of inflation. ${ }^{7}$ Thus; only in the short run will there be a negative trade-off between inflation and unemployment; in the long run unemployment is only determined by real forces and thus there is no permanent trade-off between inflation and unemployment; this is the natural rate hypothesis.

The natural rate hypothesis modifies the Phillips curve in four ways (see Humphrey, 1986, and Leeson, 1997). First, excess demand is specified as the deviation of unemployment from its natural rate where the natural rate is that rate of unemployment which represents full employment equilibrium in the labour market. Second, expected inflation was included in the inflation equation with a unit coefficient, whereas Phillips (1958) omitted expected inflation. Third, the adaptive expectations mechanism was provided for adjusting expected inflation. ${ }^{8}$ Finally, Lipsey's model that is consistent with the empirical results of Phillips (1958) and Lipsey (1960) is misrepresented in Friedman (1975) as a trade-off between wage growth and unemployment with a slope that is equal in the inflationary zone and in the deflationary zone.

Given the natural rate hypothesis, aggregate demand policy can only achieve a permanent reduction of unemployment below the natural rate if the government is willing to increase the rate of inflation continually. This is the accelerationist hypothesis. It can be interpreted as a modification of the reasoning of Hume. Whe-

The natural rate of unemployment is that rate of unemployment which is consistent with equilibrium in the labour market. It is positive because workers continuously move into and out of the labour force and between jobs.

\& Adaptive expectations construct the expected rate of inflation as a weighted awerage of past rates of inflation (see Frisch ${ }^{1} 1983$ ). 
reas Hume supposed that the speed of adjustment of inflationary expectations is slow and constant at every rate of inflation, it must rise according to the accelerationist hypothesis in order to keep unemployment below the natural rate. Consequently, the trade-off between inflation and unemployment becomes steeper than in Hume.

\subsection{New microeconomic foundations}

The implications of the natural rate hypothesis for policy making are quite clear. Aggregate demand policy cannot be effectively used to lower unemployment permanently; the more policy tries to exploit the short-run trade-off, the higher the costs become in terms of inflation. That is, the more costly it becomes to keep unemployment low. In order to understand these implications of the natural rate hypothesis better, economists provided new explanations for having a negative short-run trade-off and no long-run trade-off (see Santomero and Seater, 1978). These theories can be divided in four categories: intertemporal labour supply theories, price-misperception theories, search theories, and price stickiness theories.

The first type of theories for a short-run trade-off between inflation and unemployment are the intertemporal labour supply theories (see for example Lucas and Rapping, 1969a, Lucas and Rapping, 1969b). In these theories individuals believe that wages and prices have some normal levels to which they will return if they deviate from their normal level. ${ }^{9}$ These normal levels adjust only slowly. Furthermore it is assumed that a rise (fall) in the actual rate of inflation causes a less than proportionate rise (fall) in the nominal interest rate. Finally, the substitution effect of a change in the perceived real interest rate on the supply of labour, that is the effect that arises because it is more attractive to supply more labour now and to pass the proceeds to the next period, dominates the income effect, that is the effect that a rise in the real interest rate increases current income and thus decreases the supply of labour.

Now the short-run Phillips curve emerges in the following way. Suppose that the price level rises. As the normal price adjusts only slowly, the individual perceives an unexpectedly high price level relative to its normal level. Given that the price level is assumed to return to its normal level, he expects the price level to fall and thus a deflation. And as the nominal interest rate does not change in proportion to the change in inflation, the real interest rate is expected to rise. Finally, this increase in the perceived real interest rate causes individuals to increase their current supply of labour and the current money savings as the substitution effect outweighs the income effect. Thus, there is a short-run trade-off between unem-

\footnotetext{
The nomal price level is defined as the expected future price level; it is generated by adaptive expectations.
} 
ployment and inflation. In the long run expected and actual inflation will be equal, and consequently there is no trade-off.

This explanation of a short-rin trade-off, nevertheless, has two drawbacks. First; Lucas and Rapping (1969a, 1969b) based it on adaptive expectations; as is well-

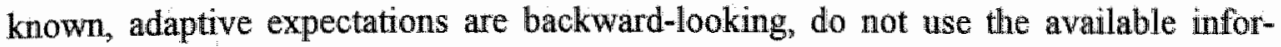
mation optimally to forecast inflation, and generate systematic forecast errors. Second, it is a rather indirect explanation; if one of the underlying assumptions does not hold, there will be no short-run trade-off.

The second type of short-run Phillips curves, the price-misperception theories (see for example Lucas, 1972, Lucas, 1973, and Sargent and Wallace, 1975), eliminate these two drawbacks by replacing adaptive expectations by rational expectations and providing a direct, imperfect information explanation for the output-inflation relationship inside Lucas and Rapping (1969a). This explanation is based on the Phelps' islands paradigm (see Phelps, 1970); it states that if a demand shock occurs, the individual is uncertain whether the relative demand for his products has increased or whether the aggregate price level has risen. Only to the degree that the expected relative price for their products has risen, will the individual increase his output. The uncertainty about the aggregate price level is eliminated by the publication of the general price index. Consequently, an unexpected increase in aggregate demand only has a real effect for one period. Thereafter this effect is gone, Thus, only shocks in aggregate demand, or unsystematic aggregate demand policy affects real output; systematic aggregate demand policy, like monetary policy rules, do not affect real output. However, this results is based upon the assumption that there are no non-neutralities in the price-misperception model. If there is, however, at least one non-neutrality in the model, systematic policy can affect real output growth even in a flexible price, misperception model; chapter 6 builds such a model and shows the consequences for output growth and inflation.

The third type of theories for a short-run trade-off between inflation and unemployment are search theories (see Kim, 1991, and Zaretsky and Coughlin, 1995). In these theories an individual has imperfect information about the wages that are offered by various employers. If he engages in job search he can increase his lifetime income. This job-search will continue as long as the wage offered is lower than his acceptance wage ${ }^{10}$ If the wage rate offered is higher than this acceptance wage, the job will be accepted.

In these search theories a short-run Phillips curve emerges only if inflationary expectations adjust slowly to changes in inflation. Suppose that the nominal wage rate rises due to an increase in inflation. As potential employees adjust their inflationary expectations only slowly, the increase in nominal wage rate is perceived as an increase in the real wage rate. The rise in the perceived real wage increases the

10 The acceptance wage is that wage which equates the marginal costs and gains from search. 
probability of finding a job and consequently decreases unemployment (see Mortensen, 1970 , and Santomero and Seater, 1978). In the long-run expected inflation will equal actual inflation, and thus there will be no long-run trade-off between inflation and unemployment. The division between the short-run and the long-run trade-off is in line with the natural rate hypothesis. Note that this result crucially depends on the assumption about the slow adjustment of expected inflation. If inflationary expectations adjusted immediately, even the short-run trade-off would become vertical.

A drawback of the search theories is that they are silent about how the expectations about inflation are formed. As a consequence, this theory for a short-run trade-off did not receive much attention as an explanation for a short-run trade-off between wage inflation and unemployment. Nevertheless, search theory can provide a basis for price stickiness, the fourth type of inflation-output theories. ${ }^{11}$

In the price stickiness theories systematic as well as unsystematic policy can influence real output. Such real effects can come about if for example prices are set one period in advance (see Phelps and Taylor, 1977), or if long-term contracts exist (Fischer, 1977, Ahmed, 1987). In the long run, however, price will adjust to the change in systematic policy, and the short-run output effects will disappear. To show the consequences of changes in systematic policy for output growth as well as inflation, and to see how changes in systematic policy are transmitted, chapter 5 reinterprets the price stickiness models of Alogoskoufis and Smith (1991) and Alogoskoufis (1992). Besides systematic policy, unsystematic policy can also effect real output in the short run (see Ball, Mankiw, and Romer, 1988; DeFina, 1991). If prices are sticky, however, positive and negative shocks have a different effect on output growth, that is they are asymmetric (see Ball and Mankiw, 1994); furthermore, shocks will have a persistent effect on output growth (see Haltiwanger and Waldman, 1989; Laidler, 1990).

In order to be able to investigate whether expansionary and contractionary aggregate demand policy is effective in reducing unemployment or inflation, aggregate demand policy is divided into unsystematic and systematic policy. Given the four inflation-output theories above, the price-misperception theories and the price stickiness theories provide more predictions for unsystematic and systematic policy than the search theories and the optimal labour supply theories. However, it is clear from the above discussion that the four inflation-output theories are related. More specifically, the price-misperception theories developed out of the optimal labour supply theory, and the price stickiness theories out of the search theories. The optimal labour supply theory, however, has the drawbacks that it is based on adaptive expectations and that it is an indirect explanation; the search theories in turn

11 Examples of such theories are the customer market theory (see Phelps and Winter, 1970, and Okun, 1975, 1981) and the theory of strategic complementarity (see Diamond, 1982, and Oh and Waldman, 1994). See also section 2.6 . 
lack an assumption about the specification of expected inflation. Because of these interrelations, and the disadvantages of the optimal labour supply theory and the search theory, this thesis restricts the attention to the price-misperception theories and price stickiness theories. In section 2.5 the price-misperception theories are described in more detail followed by the price stickiness theories in section 2.6.

\subsection{Price-misperception theories}

In this section three kinds of price-misperception theories are distinguished: first, the Lucas (1973) theory in section 2.5.1, then that of Barro (1976) in section 2.5.2. Finally, the open-economy extensions of Lucas (1973) are briefly mentioned in section 2.5.3.

\subsubsection{The Lucas (1973) model}

The first major price-misperception model developed is that of Lucas (1973). It assumes that prices are flexible, markets clear instantaneously, and expectations are made rationally. The short-run inflation-output relation in this model results from imperfect information: suppliers in each market only increase their output above their normal output if they expect that the price for their goods has risen relative to the general price index. ${ }^{12}$ Aggregating these surprise-supply function over all goods markets gives the aggregate surprise-supply function. Finally a unit-elastic demand function is added to complete the model.

Then, solving this model by setting aggregate supply equal to aggregate demand, three intra-country and three cross-country properties follow. The first intracountry hypothesis is that the output response is symmetric for an unexpected decrease and an unexpected increase in aggregate demand. This is the symmetry hypothesis. Phillips (1958) and Lipsey (1960), however, found a clear asymmetric pattern in their inflation-output trade-off. To investigate which is true, chapter 3 tests whether the response of output is equal for positive and negative shocks. The second intra-country hypothesis states that output only responds to unanticipated demand changes, not to anticipated demand changes. This is the structural neutrality proposition. It is the second test performed in chapter 3. The third and final intracountry hypothesis is that shocks in aggregate demand are not persistent; that is, it predicts that the real effect of a shock disappears one period after its initiation. This is the non-persistence hypothesis; it will be tested also in chapter 3.

Besides these three intra-country properties, the Lucas model provides three cross-country properties, the so-called Lucas variability hypotheses. These hypotheses follow from the response of output to an unexpected change in nominal

12 Normal output is assumed to follow a linear trend. 
demand and the definition of the variance of prices. The first Lucas variability hypothesis states that the more uncertain economic agents are about inflation, the less they will adjust output. The second states that the larger the variance of demand shocks is, the higher the variance of inflation will become. And finally the third hypothesis states that the more variable aggregated demand shocks are, the less output will respond to demand shocks.

Note that the first hypothesis is in line with the accelerationist hypothesis. According to the accelerationist hypothesis unemployment can only be kept under the natural rate if inflation is rising faster and faster. This implies that the short-run trade-off should be very steep. The accelerationist hypothesis, however, did not prove that the slope becomes steeper. The Lucas variability hypotheses, instead, do provide a theoretical basis for such a steeper trade-off. Suppose that the variability of inflation and inflation itself are positively related (see Friedman, 1977). Then a rise in inflation increases the variability of inflation, which, according to the first Lucas variability hypothesis, lowers the real effect of an unexpected increase in demand; consequently, the slope of the trade-off between inflation and unemployment becomes steeper.

To investigate these three relationships empirically, the various coefficients and statistics are calculated for a number of countries and cross-country correlations are calculated. In a number of studies (see for example Jung, 1985, and Odedokun, 1991) the set of countries is divided into developed and developing countries; the available evidence is unclear whether the Lucas variability hypotheses can or cannot be rejected for developed and developing countries. Therefore we re-analyse the available evidence in chapter 4 . Note that the three Lucas variability hypotheses depend on the assumption that the variance of relative prices, and the supply response to the expected relative price in each market, are identical across countries; therefore the computed correlations are corrected for differences in supply response of each country in chapter 4.

\subsubsection{The Barro (1976) model}

The second major price-misperception model is that of Barro (1976). The major difference with Lucas (1973) is that it introduces money as a wealth variable in the supply and demand equations for each market besides the expected relative prices. ${ }^{13}$ Furthermore, the Barro (1976) model includes supply and demand shocks in contrast to Lucas (1973). Examples of such demand and supply shocks are unanticipated changes in the trade-volume, the terms of trade and the oil-price. We will include these variables in our empirical analysis in chapter 3.

13 Another way to introduce money is to split nominal income into money and money velocity (see Demery, 1984, or Christensen and Paldam, 1990). A drawback of such a procedure is that money is included in an ad hoc fashion. 
If the Barro model is solved, four properties follow: ${ }^{14}$ i) positive and negative money shocks have an equal effect on real output (symmetry hypothesis); ii) only unanticipated money affects real output; anticipated money does not (structural neutrality bypothesis); iii) money shocks have an effect on real output only during one period (non-persistence hypothesis); iv) the higher the variance of unanticipated money growth, the less output changes due to an unexpected money growth shock (Barro variability hypothesis). These hypotheses are similar to those of the Lucas (1973) model. In chapter 3 the first three hypotheses are also investigated for the Barro model. The difference between developed and developing countries is, however, not analysed in chapter 4 for the Barro variability hypothesis. This is due to the fact there are only three studies available that test the Barro variability hypothesis ${ }^{15}$; to investigate the difference between developed and developing countries at a meta level more studies are necessary.

\subsubsection{The open-economy extensions of Lucas (1973)}

The third and final type of price-misperception models are the open-economy extensions of Lucas (1973) such as Leiderman (1979), Parkin, Bentley and Fader (1981) and Neumann and von Hagen (1988). The main difference with Lucas (1973) is that in these models the relevant price level is a weighted average of the domestic and the foreign price level whereas it is the domestic price level in Lucas (1973). This sets the stage for the terms of trade to explain output. Changes in terms of trade influence domestic real output because an increase in terms of trade, that is a relative increase of domestic prices over foreign prices, makes foreign output relatively cheaper. This induces domestic consumers to substitute foreign output for domestic output. In chapter 3 the terms of trade is used as an additional variable to explain output movements.

The predictions of these open-economy models are comparable to those of the Lucas (1973) and the Barro (1976) models. Besides symmetry for the effect of positive and negative shocks, they also imply structural neutrality and non-persistence of shocks. With respect to the cross-country predictions, however, the Parkin, Bentley and Fader (1981) model does not provide a theoretical link between the variability of aggregate demand shocks and the response of output to unexpected changes in aggregate demand. This is due to the complex, non-linear structure of this response. Nevertheless, the model does predict that the larger the variance of

\footnotetext{
14. In order for an unexpected increase (decrease) to have a positive (negative) effect on output, it is assumed that the effect on supply of a change in expected relative prices and the wealth effect on demand are the domimant effects.

15 These studies are: Attfield and Duck (1983), Kormendi and Meguire (1984), and Christensen and Paldan (1990).
} 
foreign inflation and the real terms of trade are under fixed exchange rates, the steeper the short-run trade-off between inflation and output will be; under flexible exchange rates no such prediction follows from the model.

\subsection{Price stickiness theories}

In the price-misperception theories competition is assumed to be perfect and the short-run trade-off between inflation and unemployment is based on imperfect information. If competition is imperfect, however, this alone is not enough for aggregate demand to affect output (see Blanchard and Kiyotaki, 1987). Only if other distortions are added to explain price stickiness, can changes in aggregate demand have real effects. Price adjustment costs and nominal rigidities are such distortions (see Dixon and Rankin, 1994). These are discussed in section 2.6.1, and 2.6 .2 respectively.

\subsubsection{Price adjustment costs}

The first group of distortions consists of price adjustment costs. There are two kinds of price adjustment costs: fixed price adjustment costs, or menu costs, and variable price adjustment costs. Within the fixed price adjustment cost models there is a static and a dynamic approach. In the static approach a monopolistic firm faces fixed costs of adjusting prices. It has to decide either to adjust its price or to ration given an increase in demand. Only if the increase in profits outweighs the lump sum price adjustment costs, is the price for the firms product adjusted; otherwise, demand is rationed (see Mankiw, 1985, Lucke, 1995). Whereas the static approach pays attention to the welfare aspects of menu costs, it does not to the price-strategy.

The difference of the dynamic approach of fixed price adjustment costs compared to the static approach is that it does focus on the price-strategy (see Sheshinski and Weiss, 1977, Caplin and Spulber, 1987, and Caplin and Leahy, 1991). In this approach firms adjust the nominal price if the real price has fallen to some lower bound; in that case the nominal price is increased so much that the real price is equal to some upper bound. Thereafter the nominal price is not adjusted until it reaches the lower bound again. Given such costs of adjusting prices, a short-run trade-off between inflation and unemployment comes about (see for example Naish, 1986, Naish, 1988, and Konieczny, 1990). Only under specific assumptions about the firm's profit function and its demand function, is the trade-off vertical. A drawback of the fixed price adjustment cost models is that they do not distinguish between the short-run and the long-run trade-off.

Within this dynamic approach Ball, Mankiw and Romer (1988) developed two tests to find out whether the trade-off between output and inflation is due to pricemisperception or to price adjustment costs. According to the price-misperception- 
model of Lucas (1973) the output response to a shock in aggregate demand is independent of the level of inflation; the price adjustment cost model of Ball, Mankiw, and Romer (1988), however, predicts that this response decreases if inflation if higher; the higher inflation, the faster price are adjusted and the lower the real effect of a shock. This is the first test. The main critique with respect to this test is that it falls apart if the inflation and the variance of inflation are highly correlated (see Akerlof, Rose, and Yellen, 1988). Furthermore, the Ball et al. model is a microeconomic model; testing it with aggregate data like Ball et all. (1988) and DeFina (1991) do, is not appropriate. The second test verifies the relation between the response of output to aggregate demand shocks and the variance of relative prices is positive or negative. According to the new-classical Lucas (1973) model the response of output to an aggregate demand shock rises if the variance of relative prices increases, because it raises the proportion of the shocks that are misperceived as real; the Ball et al. (1988) model, however, predicts that it should be negative because a higher variance of relative prices increases frequency of price adjustment. One of the main difficulties of this test is that it requires disaggregated data. Another difficulty lies in the construction of the price variance. There are a lot of ways to construct the price variance, but it is not certain whether economic agents anticipate the constructed price variance. Finally it is hard to measure relative price variance and to distinguish it from the variance of prices.

In the variable price adjustment costs models, price adjustment costs vary with the change in prices. Examples of such models are Rotemberg (1982), Tsiddon (1991), and Konieczny (1993). ${ }^{16}$ An argument for variable price adjustment costs is the costs of market response. These costs consist of i) customer switching, and ii) more aggressive pricing behaviour by competitors.

The customer market explanation for the costs of market response runs as follows (see Bils, 1989, Nishimura, 1989). Customers have to incur search costs as they are imperfectly informed about competitors' prices and current demand. As long as the prices of the current supplier change slowly, the customer will not switch because the search costs are too high. If the price changes were relatively large in the eyes of the customer, he will break the relation with the supplier and look for another, cheaper supplier. For the supplier it will be hard to convince the customer that he will not raise prices unexpectedly. Thus, firms in customer markets are hesitant to raise prices. Thus an increase in nominal demand will increase real output (see Nishimura, 1989, and Lye and Sibly, 1994).

\footnotetext{
16 The advantage of the Rotemberg (1982) model is that it includes the deviation of the actual price from the optimal price that would maximize profits as an extra cost of price adjustment besides the change in prices whereas Tsiddon (1991) and Konieczny (1993) do not include it. Consequently, a firm has to choose an optimal price-strategy given both costs. In chapter 5 the Rotemberg modell is used to introduce price stickiness.
} 
The aggressive pricing explanation for the costs of market response is the following (see Slade, 1989, Slade, 1990). If one firm in some market reduces its supply prices, it will attract a larger proportion of the whole market. Given that the volume of the market is unchanged, other suppliers will lose some of their market share. To regain the lost market share, competitors must bid more aggresively. Given this extra competition, the profit for the initiator of the price run will be lower. And whether the profit of the initiator will increase depends furthermore on the priceelasticity of the good. If it is low, he may even lose money. Therefore, large changes in prices can be rather costly.

\subsubsection{Nominal rigidities}

The second group of distortions are small nominal rigidities. Here we discuss two of such nominal rigities: strategic complementarity (Haltiwanger and Waldman, 1989. Ball and Romer, 1990, and Oh and Waldman, 1994), and staggered prices (Blanchard, 1983, Cecchetti, 1985).

An economy with strategic complementarity is one where the higher aggregate output is, the larger the incentive is for individual agents to produce. The presence of such strategic complementarity entails that an economy can be characterized by multiple equilibria. An increase in aggregate demand will cause the economy to jump from one equilibrium to another and thus may cause output to increase. Furthermore, an increase in aggregate demand will have longer real effects, depending on the strength of strategic complementarity (see Oh and Waldman, 1994).

In the case of staggered prices, prices are fixed by multi-period contracts which are negotiated at different times. At each point in time a fraction of the contracts is renegotiated, the rest remain unchanged. ${ }^{17}$ If a new contract is negotiated, the contracts still in force must be taken into account as must be the expected future price and output levels during the new contract. Given an increase in aggregate demand, output will increase because it takes time before all contracts are renegothated. In section 5.5 staggered wages are used as an alternative way introduce price stickiness; in the rest of chapter 5 the Rotemberg (1982) model is used to generate price stickiness.

\footnotetext{
This kind of infrequent renegotiation can be rationalized by fixed real costs of adjustment or negotiation (see Sheshinski and Weiss, 1983).
} 


\subsection{Conclusion}

Whereas the Phillips curve debate is often thought to have started with Phillips (1958), or sometimes with Fisher (1926), it goes back to classical authors like David Hume (1752) and John Stuart Mill (1833). Hume and Mill asserted that it is necessary for a short-run trade-off between inflation and unemployment that the perceived price level differs from the actual price level and that the speed with which they become equal determines the period for which such a trade-off will exist. If the perceived price level has become equal to the actual price level, the trade-off is vertical. Phelps (1967) and Friedman (1968) only rediscovered this distinction and labeled it the natural rate hypothesis. It implies that there is only a short-run trade-off between inflation and unemployment and no long-run trade-off.

To understand this implication of the natural rate hypothesis better, four kinds of microeconomic inflation-output trade-off models were developed: intertemporal labour supply theories, price-misperception theories, search theories, and price stickiness theories. These four inflation-output theories, however, are related. More specifically, the price-misperception theories developed out of the optimal labour supply theory, and the price stickiness theories out of the search theories. The optimal labour supply theories, however, are based on adaptive expectations and provide an indirect explanation for the trade-off whereas the price-misperception theories are based on rational expectations and use the direct, imperfect information explanation. A drawback of the search theories is that they do not specify how expected inflation is constructed. Given these relations, and the drawbacks of the optimal labour supply theories and the search theories, this thesis restricts the attention to the price-misperception theories and price stickiness theories.

According to the flexible price, misperception theories unsystematic policy has symmetric effects on output growth, that is, positive and negative shocks have the same effect (symmetry hypothesis). Furthermore, output does not respond to expected demand changes (structural neutraliy hypothesis). Finally, shocks in aggregate demand have only one period a real effect, thereafter it disappears (non-persistence hypothesis). The price stickiness models, however, predict that shocks in aggregate demand have an asymmetric effect on output growth. Furthermore, expected changes can affect output growth as long prices do not have adjusted yet. Finally, shocks in aggregate demand will persist due to the fact that it take time to adjust prices. Therefore, in chapter 3 the symmetry-hypothesis, the structural neutralityhypothesis and the non-persistence hypothesis are tested.

If unsystematic policy is used often, this may reduce the real effect of shocks. The Lucas variability hypothesis provide a theoretical framework for this intuition. In chapter 4 the available evidence for these hypotheses is analysed in a metastudy. It is tested whether the results are different for developed countries and deve- 
loped countries and whether a correction for the supply response affects these results.

Then in chapters 5,6 , and 7 systematic policy is analysed. First in chapter 5 a price stickiness model is built to investigate the effects of systematic policy for output growth and inflation. Then chapter 6 investigates systematic policy in a price-misperception model. The results for output growth and inflation are compared to those of the price stickiness model of chapter 5. Finally, chapter 7 tests the inflation effects of systematic exchange rate policy for Spain and Italy. 


\section{Asymmetry, Non-neutrality, and Persistence: Evidence from the United States and Germany}

\subsection{Introduction}

In chapter 2 three kinds of price-misperception models were described: the Lucas (1973) model, the Barro (1976) model, and the open economy extensions of Lucas (1973), see section 2.5. From these models three predictions follow. First, the size of the response of output is the same for both an unexpected increase and an unexpected decrease in aggregate demand. That is, the response to a demand shock is symmetric. The empirical evidence, however, often rejects a symmetric response in favour of an asymmetric response. Phillips (1958) and Lipsey (1960), for example, found that the trade-off between unemployment and inflation was rather steep in the inflationary regime but flatter in the deflationary regime. Nevertheless, they did not explicitly test the symmetry hypothesis. De Long and Summers (1988), Cover (1992), and Rhee and Rich (1995) do perform symmetry tests. They find that the size of the response of real output to positive demand shocks is small and not significant whereas it is large and significant for negative demand shocks; this is consistent with the asymmetry found by Phillips and Lipsey. The implication of such an asymmetric trade-off is that a central bank cannot effectively use aggregate demand shocks to stimulate the economy or to reduce inflation.

The second prediction is that expected changes in aggregate demand do not affect real output. This is the structural neutrality hypothesis. If this hypothesis is true, it implies that systematic policy is ineffective. That is, an anticipated increase in aggregate demand will not affect output because economic agents have taken this increase in demand into account. The empirical evidence, however, generally supports non-neutrality instead of neutrality (see Mishkin, $1982 \mathrm{a}$, 1982b; Driscoll et al, 1983; Cecchetti, 1987; Darrat, 1987, 1991; and Shelley and Wallace, 1995).

The third prediction is that shocks in aggregate demand are not persistent, that is, an aggregate demand shock has a real effect in the period when it occurs, but not in later periods. This is the case in the Lucas model when lagged demand shocks do not affect real output given a significant coefficient for lagged real income, and when lagged demand shocks are signficant but the coefficient of lagged real income is insignificant. The non-persistence hypothesis, howewer, has received little attention in the framework of the price-misperception theories. Only Sheffrin (1979) paid attention to this issue. He found that lagged money-shocks do 
have a significant impact on real output given a significant coefficient for lagged real income.

Given the evidence for an asymmetric response of output to aggregate demand shocks, for non-neutrality of expected aggregate demand, and for persistence in the response to lagged aggregate demand shocks, it must be doubted whether the Lucas (1973) specification for the business cycle is adequate. However, most empirical work pays little attention to the question why there should be asymmetry, non-neutrality, and persistence. Furthermore, only one specification is normally used for generating expectations; the results, however, may be dependent on the way expectations are specified. Finally, the tests may be biased by omitting important variables like the oil-price (see Lawrence, 1983; Froyen and Waud, 1985), the terms of trade (see Leiderman, 1979; Parkin et al., 1981), and the volume of worldwide trade (Argy and Spitäller, 1980; Fratianni and Nabli, 1985).

The purpose of this chapter is to review the theoretical arguments for asymmetry, non-neutrality, as well as non-persistence and to investigate whether the symmetry hypothesis, the structural neutrality hypothesis, and the non-persistence hypothesis can be rejected for the United States and Germany. The main contributions of this chapter are threefold. First, it tests all three hypotheses instead of only one of them; second, the tests are performed under three specifications of expectations in order to check whether the results are sensitive to the chosen specification. Third, the oil-price, the terms of trade, and the volume of worldwide trade are included as important variables that are standardly omitted in other research.

This chapter is arranged as follows. Section 3.2 presents the Lucas (1973) model briefly and shows that it implies symmetry, structural neutrality and non-persistence. Then, section 3.3 briefly restates the theoretical explanations for asymmetric effects of shocks, structural non-neutrality, and persistence of shocks. After presenting an extended Lucas model in section 3.4 that allows the symmetry hypothesis, the structural neutrality hypothesis, and the non-persistence hypothesis to be tested, the data sources are reported in section 3.5. Section 3.6 tests the three hypotheses. Finally, section 3.7 contains a summary and the main conclusions.

\subsection{The Lucas (1973) model}

The Lucas (1973) model states that the deviation of output from its trend, or cyclical output, $y_{s, t}$, depends on unexpected aggregate demand, and lagged cyclical output: 


$$
\begin{gathered}
y_{c, i}=\alpha_{1}+\alpha_{2}\left(x_{t}-E_{i-1} x\right)+\lambda y_{i, j-1}+\varepsilon_{i}, \\
0 \leq \alpha_{2} \leq 1 \quad|\lambda|<1,
\end{gathered}
$$

where $x_{r}$ is the log of nominal aggregate demand, $E$ the expectations operator, and $\varepsilon_{t}$ a normally distributed error term. It is assumed that output adjusts not more than proportionately to aggregate demand shocks and that cyclical output is stationary.

Model (3.1) implies three hypotheses. First, the size of the effect of positive and negative demand shocks on cyclical output must be equal; that is, if $x_{t}-E_{t-1} x_{\mathrm{f}}$ is positive, then cyclical output increases by $\alpha_{2}\left(x_{i}-E_{i, 1} x_{i}\right)$, and if it is negative, cyclical output decreases by the same amount. This is the symmetry hypothesis. Second, expected aggregate demand does not affect cyclical output as it is absent in equation (3.1). This is the structural neutrality hypothesis. Third, shocks in aggrem gate demand are not persistent. This non-persistence hypothesis can be stated in two ways. First, if lagged aggregate demand shocks are added to equation (3.1); it states that these lagged aggregate demand shocks are not significant, given that lagged cyclical income, $y_{c_{n} t-1}$, is significant. Second, if equation (3.1) is written as a distributed lag of past and aggregate current demand shocks, significant lagged shocks are consistent with the non-persistence hypothesis as long as lagged cyclical income, $y_{c, 1}$, is insignificant:

\subsection{Asymmetry, non-neutrality and persistence}

Whereas the Lucas model in section 3.2 implies symmetry, structural neutrality and non-persistence, there are theoretical arguments for the reverse. These are explained in sections $3.3 .1,3.3 .2$, and 3.3 .3 respectively.

\subsubsection{Asymmetry}

Phillips (1958) and Lipsey (1960) assumed that the asymmetric shape of the Phillips curve was due to downward price rigidity, see section 2.3 . However, they did not provide a thorough theoretical foundation for an asymmetric response of output to aggregate demand shocks. Caballero and Engel (1992), Tsiddon (1993), and Ball and Mankiw (1994) do provide such a theoretical foundation. Suppose that a firm has to pay price adjustment costs or menu costs if it changes its prices and that there is a positive trend in inflation. If the firm faces a negative shock in the demand for its product it does not have to incur menu costs. This is because the decrease in relative prices that is necessary to match the unexpected decrease in demand is mainly accomplished by the rise in the general price level. As the nominal price is not adjusted, the decrease in demand will reduce output. If there is instead a positive shock in the demand, the relative price for the firms' product must rise. Given that the relative price is falling, the deviation of the actual price 
from the desired price becomes larger, and it is more likely that the firm will increase the price for its product. Consequently, the increase in demand will increase prices more quickly and thus the output effect will be smaller. This implies that the aggregate supply curve is convex the higher output is, the steeper the supply curve. Thus, a positive shock in aggregate demand will have less impact on output than a negative shock in aggregate demand.

\subsubsection{Non-neutrality}

Whereas the price-misperception models assume that expected aggregate demand does not affect real output, non-neutralities can arise in two cases. First of all, if competition is imperfect, expected aggregate demand will be non-neutral if prices are sticky. Price stickiness in turn may be due to price adjustment costs, or nominal rigidities like strategic complementarity and staggered contracts (see section 2.6). Second, expected aggregate demand can be non-neutral if certain assumptions are not met. Two models that specify such assumptions are Sidrauski (1967) and Begg (1980). In the Sidrauski (1967) model money is neutral if economic agents optimize and live infinitely long, if the real money stock does not influence real output, if labour supply is inelastic, and if the discount factor to compare utilities over time is constant. If one of these conditions does not hold, expected money is not neutral (see Fischer, 1980). The Begg (1980) model provides two other conditions. First, for neutrality the real money stock must not affect real consumption; that is, there must be no real balance effect. Second, the real demand for money must be independent of the nominal interest rate. If these conditions are violated, then expected. aggregate demand will affect real output.

\subsubsection{Persistence}

The Lucas (1973) model predicts that shocks in aggregate demand do not persist. However, a number of arguments exists for persistent effects of shocks on real output. The first argument is strategic complementarity (Haltiwanger and Waldman, 1989; Oh and Waldman, 1994). Given strategic complementarity (see section 2.6.2), a shock in aggregate demand will cause aggregate output to jump from one equilibrium to another. This takes more than one period. Therefore, aggregate demand shocks last for more than one period.

The second argument for persistent aggregate demand shocks comes from the staggered (wage) contracts approach (see Taylor, 1979, 1980; Kempf, 1987). Given a demand shock, prices can only be adjusted in the contracts that are currently renegotiated and not in the contracts that are still in force. Thus an aggregate demand shock will affect real output in the period the shock occurs. In the next period, however, not all remaining contracts are adjusted. So, there will still be a real output effect. Consequently, the demand shock persists. 
The third argument for persistence is given by the existence of inventories (Blinder and Fischer, 1981). Given an unexpected increase in aggregate demand, the stock of inventories will go down. However, it will take time to replenish inventory to the desired level. Therefore, a demand shock can induce persistent output effects.

Fourth and finally, persistence can be caused by lags in the acquisition of information (see Lucas, 1975). In the Lucas (1975) model an unexpected increase in aggregate demand causes some producers to increase the production capacity as they view the increase in demand as a real signal. This extra capacity will imply an increase in labour demand and increase output. Given that the lag in the acquisition of information, it takes time to verify whether the increase in demand was indeed a real signal. In the meantime, the effect on output will persist.

\subsection{Model}

In this section the basic model of section 3.2 is extended to provide a framework to test the symmetry hypothesis, the structural neutrality hypothesis and the nonpersistence hypothesis. Before this is done, equation (3.1) is amended to allow the oil-price, $p_{\text {oit, }}$, the terms of trade, $t t_{t}$, and the volume of worldwide trade, $w t_{t}$ to affect output. The oil-price measures supply effects on real output: the higher the oil-price, the less profitable it is to produce given the current technology, and the lower output will be. The terms of trade measure the substitution effect between foreign and domestic output: an increase in the terms of trade, that is an increase in the domestic price level relative to the foreign price level, makes domestic goods more expensive compared to foreign goods; consequently, the demand for domestic goods will fall. And finally the volume of worldwide trade is a proxy for the foreign demand for domestic output: the higher the volume of worldwide trade, the higher domestic output will be. Furthermore, aggregate demand is measured alternatively as nominal income as well as money supply. ${ }^{1}$ This allows the Lucas as well as the Barro predictions (see section 2.5.2) to be investigated. Given these modifications equation (3.1) becomes:

$$
\begin{aligned}
& y_{c, t}=\alpha_{1}+\alpha_{2}\left(\phi_{t}-E_{t-1} \phi_{t}\right)+\alpha_{3}\left(p_{o i t, t}-E_{t-1} p_{o t t_{t} t}\right)+ \\
& \alpha_{4}\left(t t_{t}-E_{t-1} t t\right)+\alpha_{5}\left(w t_{t}-E_{t-1} w t_{t}\right)+\lambda y_{t, t-1}+\varepsilon_{t}
\end{aligned}
$$

where the aggregate demand variable $\phi_{t}$ is either nominal income, $x_{n}$, or the money stock, $m_{n}$.

An argument for preferring money supply instead of nominal income as an indicator of nominal aggregate demand is that nominal and real income are closely related (see Kormendi and Meguire, 1984). 
To be able to investigate symmetry, structural neutrality, and non-persistence, model (3.2) is modified in the following way. First, the various shocks are split into positive and negative shocks in order to test asymmetry. Second, the expected series that are used to calculate the shocks are added as separate variables to investigate structural neutrality. Third, lagged shocks are introduced to verify whether shocks are non-persistent. This gives: ${ }^{2}$

$$
\begin{aligned}
& y_{a, t}=\alpha_{1}+\sum_{k=0}^{q} \alpha_{2 p, k} D_{1, k}\left(\Delta \phi_{t-k}-E_{t-1-k} \Delta \phi_{t-k}\right)+\sum_{k=0}^{q} \alpha_{2 \pi, k}\left(1-D_{1, k}\right)\left(\Delta \phi_{t-k}-E_{t-1-k} \Delta \phi_{i-k}\right)
\end{aligned}
$$

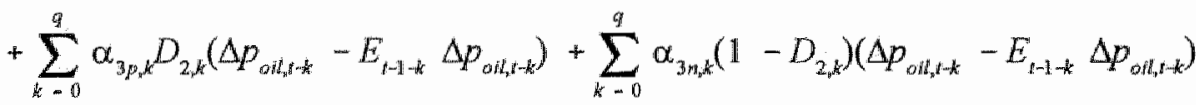

$$
\begin{aligned}
& +\sum_{k=0}^{q} \alpha_{4 p, k} D_{3, k}\left(\Delta t t_{t-k}-E_{t-1-k+k} \Delta t t_{t-k}\right)+\sum_{k=0}^{q} \alpha_{4 m, k}\left(1-D_{3, k}\right)\left(\Delta t t_{t+k}-E_{t-1-k} \Delta t t_{t-k}\right) \\
& +\sum_{k=0}^{q} \alpha_{s_{p, k}, k} D_{i, k}\left(\Delta w t_{t-k}-E_{t-1-k} \Delta w t_{t-k}\right)+\sum_{k=0}^{q} \alpha_{s n, k}\left(1-D_{4, k}\right)\left(\Delta w t_{t-k}-E_{t-1-k} \Delta w t_{t-k}\right) \\
& +\alpha_{6} E_{t-1} \Delta \phi_{t}+\alpha_{7} E_{t-1} \Delta p_{o i t, t}+\alpha_{8} E_{t-1} \Delta t t_{t}+\alpha_{9} E_{t-1} \Delta w t v_{t} \\
& +\lambda y_{c, r-1}+\mathbf{e}_{t},
\end{aligned}
$$

where

$D_{l, k}=1$ if $\Delta \phi_{t-k}-E_{t-1-k} \Delta \phi_{t-k} \geq 0$ and 0 if $\Delta \phi_{t-k}-E_{t-1-k} \Delta \phi_{t-k}<0$,

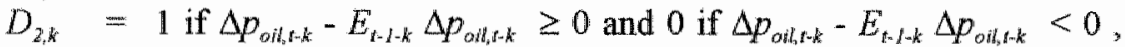

$D_{3, k}=1$ if $\Delta t_{t-k}-E_{t-1-k} \Delta t t_{t-k} \geq 0$ and 0 if $\Delta t t_{t-k}-E_{t-1-k} \Delta t t_{t-k}<0$, and

$D_{t, k}=1$ if $\Delta w t_{t-k}-E_{t-k-k} \Delta w t_{p-k} \geq 0$ and 0 if $\Delta w t_{t-k}-E_{t-k-k} \Delta w t_{t-k}<0$.

Given model (3.3) the symmetry-hypothesis, the structural neutrality hypothesis and the non-persistence hypothesis can be formalized. With respect to the symmetryhypothesis it is difficult in the short run to reckognize whether aggregate demand is unexpectedly low or high; in the longer run more information is gathered and it is more easy to take a production decision. Therefore, the symmetry hypothesis is

2 Note that shocks are defined in growth rates instead of in levels. This has no effect on the series for the shocks because the shocks are equal in levels and in growth rates. This can be proved easily, for example for an aggregate demand shock $\phi_{t}$ :

$\phi_{t}-E_{k-1} \phi_{t}=\phi_{t}-\phi_{t-1}-E_{t-1}\left(\phi_{t}-\phi_{t-1}\right)=\Delta \phi_{t}-E_{t-1} \Delta \phi_{t}$.

Furthermore, the expected series of aggregate demand, the oil-price, and so on are introduced as expected growth rates. 
stated in terms of long-run elasticities. More specifically, it states that the cumulated effect of positive shocks is equal to the cumulated effect of negative shocks:

$$
\sum_{k=0}^{q} \alpha_{p, k}=\sum_{k=0}^{q} \alpha_{k, k} .
$$

The structural neutrality implies that the expected changes in aggregate demand, oil-prices, terms of trade, and the volume of world wide trade are equal to zero. Thus, $\alpha_{6}=0, \alpha_{7}=0, \alpha_{8}=0$, and $\alpha_{9}=0$. The non-persistence hypothesis can be stated in two ways. First, it implies that lagged positive or negative shocks have no effect on real output if lagged cyclical real income, $y_{0,4-1}$, is significant. Thus:

$$
\alpha_{p_{t} k}=0, \alpha_{n, k}=0 \quad \forall k=1,2, \ldots, q
$$

Second, if the model is rewritten as a distributed lag of past and present shocks, significant lagged shocks are consistent with the non-persistence hypothesis if lagged cyclical real income, $y_{c, t-1}$, is not significant. Now, the non-persistence hypothesis is tested as follows. First it is investigated whether the coefficient of the lagged cyclical real income, $\lambda$, is significant or not. If it is not significant, the non-persistence hypothesis cannot be rejected; if it is, then the answer depends on the significance of the lagged shocks. If some lagged shocks are significant given a significant $\lambda$, then the non-persistence hypothesis must be rejected; otherwise, it cannot be rejected.

\subsection{Data}

In order to estimate model (3.3) the nominal gross national product $(X)$, the real gross national product (Y), and the nominal money stock $(M)$ for the period 1970:11992:4 were obtained from DATASTREAM. ${ }^{3}$ The oil-price series $(P)$ is the HWWA energy price index in US dollars. The terms of trade are calculated by dividing the domestic price level by the foreign price level (see appendix $3 \mathrm{~A}$ ). Finally, the volume of worldwide trade (WT) is calculated as a weighted series of foreign real imports (see appendix 3 A). All series have been seasonally adjusted.

3 For Germany M2 is used as money stock variable, and for the United States M1.

4. This index was kindly provided by the Dutch Central Bank (DNB) 


\subsection{Empirical analysis}

Before model (3.3) can be estimated, three things have to be determined. First, cyclical output has to be constructed. The most common ways to construct cyclical output are detrending real output, and using output growth. Detrending real output by a linear trend, is hard to defend because it gives a non-stationary cyclical output series; furthermore, this procedure does not provide reliable cyclical output series if there are serious structural breaks in real gross national product. Therefore, real output growth, $\Delta y_{t}$, is used as the indicator of cyclical real output.

Second, the number of lags has to be specified. In our empirical analysis we restrict the number of lags to four quarters. Given that equation (3.3) is estimated over 80 observations, and that it contains 46 variables if the number of lags is 4 , this leaves only 34 degrees of freedom. Increasing the number of lags for example to 6 , the number of degrees of freedom reduces to 18 . Because a slight increase in the number of lags decreases the number of degrees of freedom considerably, the number of lags is restricted to four.

Third, expectations have to be specified. To generate expectations, three procedures are used. This allows to investigate whether the results are sensitive to the chosen specification of expectations. The first specification used here is the naive random walk forecast. In this case the expected value of a variable is equal to the last observation of the variable. The shock in the level of the variable is then equal to the change in the variable. The expected growth rate, however, is then equall to zero. Second, the multi-state Kalman Filter method is used to generate truly ex ante expectations. Third, Box-Jenkins models are identified and estimated for each of the explanatory variables. ${ }^{5}$ The fitted values are interpreted as expectations, while the residuals serve as innovations. As such the naive random walk is nested in the BoxJenkins model. The difference between the Box-Jenkins forecasts and the Kalman forecast is that as the latter method uses less information for its forecasts, the variance of its forecast errors may be higher; furthermore, the Kalman method is more flexible than the Box-Jenkins method in the sense that it can cope with temporary outliers and changes in economic structure whereas the Box-Jenkins method cannot.

To test the symmetry hypothesis, the structural neutrality hypothesis, and the non-persistence hypothesis, a three-step procedure is used. First, the expected nominal income, money stock, oil-prices, terms of trade, and volume of worldwide trade are determined for Germany and the US. Given these expected series, the unexpected series can be computed immediately. Subsequently, each time series of unex-

5 More specifically, for the United States the following models were fitted for the series $x_{t}, m_{n}$, $p_{\text {oin, },}, t_{t}, w t_{t}:(1,2,1),(1,2,1),(1,1,1),(1,2,3)$, and $(3,1,2)$ respectively; for Germany we estimated for the same variables the models: $(2,2,4),(1,2,1),(1,1,1),(1,2,1)$, and $(2,1,2)$ respectively. These models were identified with likelihood ratio tests. 
pected shocks is split into a positive and a negative series. Second, model (3.3) is estimated using ordinary least squares techniques on quarterly data for the United States and Germany for the period 1973:1-1992:4. The observations from 1970:11972:4 are used to generate the Kalman expectations. Third, F-tests and t-tests are performed for the three hypotheses. The results of these tests are described in sections 3.6.1, 3.6.2, and 3.6.3.

\subsubsection{Symmetry test}

To see whether positive and negative shocks have a real effect on output growth, their effects are cumulated for current and lagged shocks. Furthermore an F-test is performed to investigate whether these cumulated effects are different from zero at the five percent significance level. Table 3.1 reports the results for nominal income as well as money supply as demand shift variable for the United States. In the case that aggregate demand is measured as nominal income, positive as well as negative shocks have a significant effect on real growth. If aggregate demand is specified as money supply, positive and negative shocks are only significant with Kalman filter expectations. With respect to oil-prices, the table shows that in general only positive shocks influence output, whereas negative shocks do not. Furthermore, positive and negative terms of trade shocks do not affect real growth. Finally, shocks in the volume of worldwide trade are only significant if aggregate demand is measured as nominal income and expectations are generated by the Box-Jenkins method.

Table 3.2 shows the cumulated effects of positive and negative shocks for Germany. It shows that if aggregate demand is determined by nominal income, positive and negative shocks in aggregate demand have a significant impact on real growth, as in the case for the United States. If money supply is the aggregate demand variable, only positive shocks affect real growth; negative money shocks do not exert at significant impact. Furthermore, only positive oil-price shocks significantly influence real output growth, negative oil-price shocks do not; for the United States we found the same result (see Table 3.1). With respect to significance of terms of trade shocks Table 3.2 shows that it depends on the aggregate demand variable as well as the specification of expectations. Finally, shocks in the volume of worldwide trade do not in general have a significant impact on real growth.

To test whether these cumulated effects of positive and negative shocks are symmetric, F-tests are performed. Table 3.3 describes the results of these tests for the United States. It shows that nominal income shocks have an asymmetric effect on real economic growth. Combining this result with Table 3.1 it follows that negative income shocks have a larger impact on real growth than positive income shocks. This is in line with the Phillips-Lipsey evidence. For money supply shocks asymmetry is also found. But in the only case where the cumulated effects of money shocks are significant, that is if expectations are generated by Kalman filters, positive as well as negative money shocks exert a positive influence on real 
economic growth (see Table 3.1). Thus, the asymmetric results for nominal income growth are more intuitive than those for money growth. With respect to oil-price shocks an asymmetric effect is also found: only positive shocks in the oil-price affect real growth; negative shocks do not. Finally Table 3.3 shows that the symmetry hypothesis cannot be rejected for shocks in the terms of trade and the volume of worldwide trade.

Table 3.1 Cumulated effects of positive and negative shocks for the United States

\begin{tabular}{|c|c|c|c|}
\hline & $\begin{array}{l}\text { Naive } \\
\text { random walk }\end{array}$ & $\begin{array}{l}\text { Kalman } \\
\text { Filter }\end{array}$ & $\begin{array}{l}\text { Box- } \\
\text { Jenkins }\end{array}$ \\
\hline$x_{\text {piosilitive }}$ & $0.21^{\text {..* }}$ & 0.66 & $0.32^{* * *}$ \\
\hline$x_{\text {mogstiven }}$ & 6.38 & $0.82^{* * *}$ & $1.47^{\ldots} \ldots$ \\
\hline$p_{\text {oilt, passitive }}$ & $-0.04^{* \ldots *}$ & -0.02 & $-0.09^{\cdots *}$ \\
\hline$p_{\text {oil, magativi }}$ & 0.01 & 0.03 & $-0.05^{* *}$ \\
\hline$t_{\text {pasultive }}$ & -0.38 & -0.00 & -0.64 \\
\hline$t t_{\text {magation }}$ & 0.18 & 0.41 & 0.37. \\
\hline$W t_{\text {piositive }}$ & 0.03 & 0.12 & $-0.01 \ldots$ \\
\hline$W t_{\text {meg gative }}$ & -0.02 & 0.03 & $-0.08^{\cdots *}$ \\
\hline$m_{\text {pasistive }}$ & 0.02 & $1.28^{* * *}$ & $1.10^{\circ}$ \\
\hline$m_{\text {ruggafitite }}$ & 0.18 & $-1.20^{* *}$ & -0.88. \\
\hline$P_{\text {aill, parsitive }}$ & -0.08 & $-0.06^{\circ}$ & $0.07^{\circ *}$ \\
\hline$p_{\text {oxit, nowgative }}$ & 0.01 & -0.00 & 0.19 \\
\hline$t t_{\text {pasitiva }}$ & -0.36 & 0.78 & -0.33 \\
\hline$\| t_{\text {nigatives }}$ & -0.35 & -0.49 & 2.86 \\
\hline$W \|_{\text {possititise }}$ & -0.08 & 0.05 & -0.20 \\
\hline$W t_{\text {negigatrive }}$ & 0.19 & 0.03 & 0.11 \\
\hline
\end{tabular}

Note:**, and indicate that the test-statistic is significant at the 10,5 , and the 1 per cent level.

\footnotetext{
6 An explanation for this result may be that if money growth is unexpectedly high, the wealth effect on aggregate demand and the effect of the change in expected relative prices are so strong that they dominate the wealth effect on aggregate supply and the expected relative price effect on aggregate demand; thus, the positive money shock causes an increase in real economic growth. In the case of an unexpected decrease in money growth, however, these effects may be reverse. Then, the negative money shock causes an increase in economic growth (see section 2.5.2, and Barro, 1976).
} 
Table 3.2 Cumulated effects of positive and negative shocks for Germany

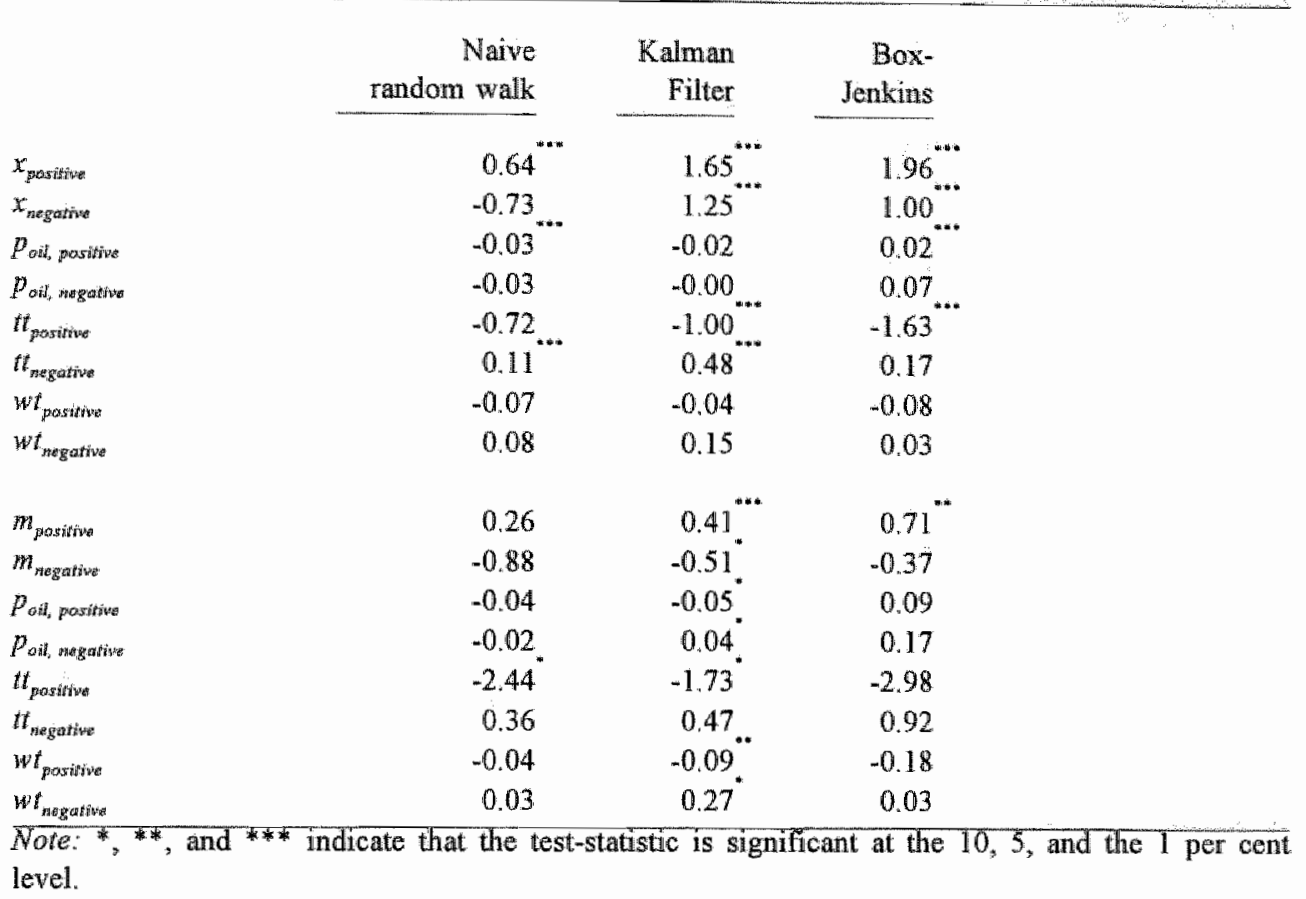

Table 3.4 reports the F-tests for symmetry in the case of Germany. The first result that follows from this table is that nominal income shocks have a symmetric effect on real growth, whereas money shocks have an asymmetric effect. The asymmetry for money shocks is, however, the other way around compared to Cover (1992) and Rhee and Rich (1995): only positive money shocks have a significant positive impact on real growth, whereas negative money are insignificant. This implies that Germany monetary policy could effectively influence the economy without large costs during the 1970s and the 1980s. Furthermore, there is evidence that the terms of trade shocks are asymmetric: positive shocks in the terms of trade exert more impact on real growth than negative shocks. This may be interpreted as follows. Given an unexpected increase in the terms of trade, German firms cannot adjust their prices, they become less competitive and production falls. If the terms of trade are unexpectedly low, it will only cause profits to be higher: given that the terms of trade are not permanently lower, it is too costly in terms of hiring and firing costs to adjust production; the extra demand is matched by lowering the stock of produced goods. Finally, Table 3.4 shows that the symmetry hypothesis cannot be rejected in general for the oil-price and the volume of worlwide trade; this 
result, however, depends on the specification of expectations and the chosen demand variable.

Table 3.3 Symmetry tests for the United States

\begin{tabular}{|c|c|c|c|}
\hline & $\begin{array}{r}\text { Naive } \\
\text { random walk }\end{array}$ & $\begin{array}{r}\text { Kalman } \\
\text { Filter }\end{array}$ & $\begin{array}{l}\text { Box- } \\
\text { Jenkins }\end{array}$ \\
\hline$x$ & 6.23. & 0.21 . & $9.44 \cdots$ \\
\hline$p_{\text {out }}$ & $7.33^{\circ *}$ & $3.39^{\circ}$ & $7.23^{\circ}$ \\
\hline tt & 1.82 & 0.55 & $3.24^{\circ}$ \\
\hline$w i$ & 0.54 & 1.47 & 1.07 \\
\hline$m$ & 0.00 & $10.63^{\circ * * ”}$ & $6.59^{\circ *}$ \\
\hline$p_{\text {ail }}$ & $4.63^{* *}$ & 1.12 & $4.67^{\circ}$ \\
\hline$t$ & 0.00 & 0.63 & 1.96 \\
\hline$w t$ & 1.38 & 0.02 & 1.15 \\
\hline
\end{tabular}

Nore: * ${ }^{* *}$, and ${ }^{* * *}$ indicate that the test-statistic is significant at the 10,5 , and the 1 per cent level.

Table 3.4 Symmetry tests for Germany

\begin{tabular}{|c|c|c|c|}
\hline & $\begin{array}{r}\text { Naive } \\
\text { random walk }\end{array}$ & $\begin{array}{l}\text { Kalman } \\
\text { Filter }\end{array}$ & $\begin{array}{r}\text { Box- } \\
\text { Jenkins }\end{array}$ \\
\hline$x$ & 0.32 & 0.90 & 1.44 \\
\hline$p_{\text {oit }}$ & 0.08 & $0.99 \ldots$ & $4.43^{*} \ldots$ \\
\hline$t i$ & $4.27^{\circ *}$ & $8.04^{\cdots}$ & $9.07 \times$ \\
\hline$w t$ & $3.46^{\circ}$ & $5.96^{*}$ & $2.94^{\circ}$ \\
\hline$m$ & $6.75^{\circ *}$ & $8.50^{\circ .}$ & $10.06^{6 * * *}$ \\
\hline$p_{\text {oil }}$ & 0.30 & $5.59^{\circ}$ & 2.56 \\
\hline Ir & $7.92^{\circ}$ & $2.97^{\circ}$ & $3.72^{\prime \prime}$ \\
\hline$w t$ & 0.12 & 2.59 & 1.12 \\
\hline
\end{tabular}

It can be concluded from Tables 3.1 to 3.4 that for the United States the symmetry liypothesis must be rejected for nominal income growth, money growth and the oilprice; it cannot be rejected for the terms of trade and the volume of worldwide trade. This conclusion, however, is dependent upon the specification of expectation for nominal income growth and money growth. For Germany the symmetry hypothesis cannot be rejected for nominal income growth, the oil-price, and the volume 
of worldwide trade; for money growth and the terms of trade it must be rejected. For the oilprice and the volume of worldwide trade, however, this result depends on the chosen specification of expectations and the demand variable.

\subsubsection{Structural neutrality test}

Another implication of the Lucas model is that expected changes in aggregate demand, the money supply, and so on, do not have a significant impact on real growth. To test this hypothesis, t-tests are performed for the expected change in aggregate demand, the oil-price, the terms of trade and the volume of worldwide trade. The results of these tests for the United States are reported in Table 3.5. The effect of all expected changes on real growth is insignificant except for the expected terms of trade. The significant negative effect of the expected terms of trade may be due to the fact that the terms of trade change only slowly over time. In contrast to other reported evidence (see section 3.1), the structural neutrality hypothesis cannot be rejected for nominal income growth, money growth, oil-price changes and the volume of worldwide trade. It can, however, be rejected for the terms of trade.

Table 3.5 Structural neutrality tests for the United States

\begin{tabular}{|c|c|c|}
\hline & Kalman Filter & Box-Jenkins \\
\hline$x$ & $\begin{array}{c}0.16 \\
(1.07)\end{array}$ & $\begin{array}{c}0.36 \\
(1.64)\end{array}$ \\
\hline$p_{\text {oil }}$ & $\begin{array}{c}-0.02 \\
(-0.90)\end{array}$ & $\begin{array}{c}0.13 \\
(0.49)\end{array}$ \\
\hline$t t$ & $\begin{array}{c}0.06 \\
(0.44)\end{array}$ & $\begin{array}{c}-0.24{ }^{* *} \\
(-2.39)\end{array}$ \\
\hline$w t$ & $\begin{array}{c}-0.03 \\
(-0.72)\end{array}$ & $\begin{array}{c}0.04 \\
(2.00)\end{array}$ \\
\hline$m$ & $\begin{array}{c}-0.09 \\
(-0.38)\end{array}$ & $\begin{array}{c}-0.08 \\
(-0.22)\end{array}$ \\
\hline$P_{\text {oit }}$ & $\begin{array}{c}-0.03 \\
(-0.62)\end{array}$ & $\begin{array}{c}-0.97 \\
(-1.20)\end{array}$ \\
\hline$\pi t$ & $\begin{array}{c}-0.811^{*} \\
(-2.53)\end{array}$ & $\begin{array}{c}-1.32 \\
(-3.73)\end{array}$ \\
\hline$w t$ & $\begin{array}{c}-0.08 \\
(-0.98)\end{array}$ & $\begin{array}{c}0.01 \\
(0.12)\end{array}$ \\
\hline
\end{tabular}

Note: ${ }^{*}, *$, and ${ }^{* * *}$ indicate that the test-statistic is sigmificant at the 10,5 , and the 1 per cent level; $\mathbf{t}$-value between parentheses. 
The results of the structural neutrality test for Germany are reported in Table 3.6. It shows that all expected changes are not significant impact except the expected growth of nominal income. Thus, except for nominal income growth, the evidence for Germany supports the structural neutrality hypothesis.

Table 3,6 Structural neutrality tests for Germany

\begin{tabular}{|c|c|c|}
\hline & Kalman Filter & Box-Jenkins \\
\hline$x$ & $\begin{array}{c}0.65^{\cdots *} \\
(4.20)\end{array}$ & $\begin{array}{c}0.67^{\cdots} \\
(7.00)\end{array}$ \\
\hline$p_{\text {oil }}$ & $\begin{array}{c}-0.01 \\
(-0.82)\end{array}$ & $\begin{array}{c}-0.31 \\
(-1.13)\end{array}$ \\
\hline$t$ & $\begin{array}{c}-0.04 \\
(-0.48)\end{array}$ & $\begin{array}{c}-0.11 \\
(-1.03)\end{array}$ \\
\hline$w t$ & $\begin{array}{c}-0.01 \\
(-0.41)\end{array}$ & $\begin{array}{c}-0.07 \\
(-0.76)\end{array}$ \\
\hline$m$ & $\begin{array}{c}-0.00 \\
(-0.03)\end{array}$ & $\begin{array}{c}-0.06 \\
(-0.40)\end{array}$ \\
\hline$p_{\text {oil }}$ & $\begin{array}{c}-0.02 \\
(-0.53)\end{array}$ & $\begin{array}{c}-0.71 \\
(-1.02)\end{array}$ \\
\hline$\|$ & $\begin{array}{c}0.20 \\
(1.03)\end{array}$ & $\begin{array}{c}0.20 \\
(0.59)\end{array}$ \\
\hline$w t$ & $\begin{array}{c}-0.06 \\
(-0.95)\end{array}$ & $\begin{array}{c}-0.15 \\
(-0.60)\end{array}$ \\
\hline
\end{tabular}

Note: ${ }^{*},{ }^{*}$, and $* * *$ indicate that the test-statistic is significant at the 10,5 , and the 1 per cent level; twalue between parentheses.

\subsubsection{Non-persistence test}

The third and final test that is performed here is that for non-persistence. First, it is investigated whether the coefficient for lagged real income, $\lambda$, is significant for the United States. Table 3.7, however, shows that, in general, the estimated coefficients for lagged real income are not significant. Only for the combination of the narve random walk specification of expectations and nominal income growth as demand variable it is significant. In this case persistence is only found for nominal income growth shocks and oil-price shocks. In general, however, we cannot reject the nonpersistence hypothesis. Second, the non-persistence test is also performed for Germany. For Germany, the estimated coefficients for lagged real income are reported 
in Table 3.8. It shows that all coefficients for lagged real income are insignificant, and thus the non-persistence hypothesis cannot be rejected.

Table 3.7 Non-persistence tests for the United States

\begin{tabular}{|c|c|c|c|}
\hline & $\begin{array}{r}\text { Naive } \\
\text { random walk }\end{array}$ & $\begin{array}{r}\text { Kalman } \\
\text { Fillter }\end{array}$ & $\begin{array}{r}\text { Box- } \\
\text { Jenkins }\end{array}$ \\
\hline$x_{\text {paritive }}$ & $10.60^{m=*}$ & 1.45 & 0.75 \\
\hline$x_{\text {Heg gative }}$ & 1.74 & $2.22^{\circ}$ & $3.71^{* \ldots}$ \\
\hline$p_{\text {aill, positivia }}$ & $5.89^{* * *}$ & 1.09 & $16.11^{* \cdots *}$ \\
\hline 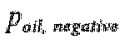 & 1.07 & 0.72 & 1.85 \\
\hline th trasitive & $2.23^{\circ}$ & 1.22 & 1.60 \\
\hline$t_{\text {Magative }}$ & 1.12 & 0.62 & 1.00 \\
\hline$w t_{\text {posinitive }}$ & 1.50 & 1.58 & $2.37^{\circ}$ \\
\hline$w t_{\text {megative }}$ & 0.78 & 0.58 & 1.84 \\
\hline$\lambda$ & $0.35^{* *}$ & 0.21 & -0.04 \\
\hline$m_{\text {positive }}$ & 1.50 & $3.11 \ldots$ & $2.73^{* *}$ \\
\hline$m_{\text {raggaivive }}$ & $0.23 \ldots$ & $3,37$. & 2.06 \\
\hline$P_{\text {oil pasitive }}$ & 4.12 & $3.00^{\circ "}$ & $8.65^{\circ *}$ \\
\hline$P_{\text {oild, negative }}$ & 0.94 & 0.43 & 0.80 \\
\hline$t_{p \text { pasitive }}$ & 0.79 & 1.29 & 1.20 \\
\hline$t_{\text {megativet }}$ & 0.26 & 0.81 & 0.68 \\
\hline Wht pasitive & 1.12 & 0.44 & 1.06 \\
\hline$W t_{\text {Hagafivet }}$ & 1.65 & 0.81 & 1.15 \\
\hline$\lambda^{2}$ & 0.16 & 0.08 & -0.03 \\
\hline
\end{tabular}

Nore: ${ }^{*}{ }^{*}$, and ${ }^{* * *}$ indicate that the test-statistic is significant at the 10,5 , and the 1 per cent level. 
Table 3.8 Non-persistence tests for Cermany

\begin{tabular}{|c|c|c|c|}
\hline & $\begin{array}{r}\text { Nave } \\
\text { random walk }\end{array}$ & $\begin{array}{l}\text { Kalman } \\
\text { Filler }\end{array}$ & $\begin{array}{l}\text { Box- } \\
\text { Jenkins }\end{array}$ \\
\hline$x_{\text {posinvion }}$ & 0.88 & 1.75 & 1.62 \\
\hline$x_{\text {segságrivia }}$ & $0.36 \ldots$ & 0.78 & $1.07 .$. \\
\hline$p_{\text {oilt, pasitive }}$ & $6.21^{\circ 00}$ & 1.32 & $4.79^{\circ *}$ \\
\hline$p_{\text {oil, soggative }}$ & 1.27 & 0.35. & 0.37 \\
\hline$t_{\text {positivas }}$ & 0.66. & $3.51^{\circ .}$ & 3.76 \\
\hline$t_{\text {ntgattive }}$ & $9.12^{* * 1 *}$ & $7.17^{* * *}$ & 1.42 \\
\hline$w t_{\text {possititios }}$ & 0.66 & 0.77 & 0.60 \\
\hline$w t_{\text {megalive }}$ & 1.15 & 2.00 & 0.31 \\
\hline$\lambda$ & 0.21 & $-0,20$ & -0.12 \\
\hline$m_{\text {jiosititiwe }}$ & 1.29 & $4.58^{\circ . *}$ & $3.58^{* \bullet}$ \\
\hline$m_{\text {sorgengativat }}$ & 0.90 & $2.67^{*}$ & 1.14 \\
\hline$P_{\text {oil, }}$ pestiver & $2.20^{\circ}$ & $2.77^{\circ *}$ & 1.68 \\
\hline$p_{\text {call, magartive }}$ & $0.75 \ldots$ & $2.57^{\circ}$ & 1.43 . \\
\hline$U_{\text {positiver }}$ & $2.75^{\circ}$ & $2.27^{*}$ & $2.28^{\circ}$ \\
\hline$i_{\text {Megutive }}$ & 1.48 & 1.44 & 1.13 \\
\hline$w t_{\text {passitive }}$ & 0.94 & $3.15^{* *}$ & 1.44 \\
\hline$w t_{n e \text { gatsivg }}$ & 0.65 & 1.47 & 0.25 \\
\hline$\lambda$ & 0.07 & -0.11 & -0.05 \\
\hline
\end{tabular}




\subsection{Conclusion}

The price-misperception models imply three hypotheses. First, positive and negative shocks have an equal effect on real income (symmetry hypothesis). Second, expected changes in for example aggregate demand do not influence real output (structural neutrality hypothesis). Third, shocks only have an impact on real output in the period in which they occur; thereafter their effect is zero (non-persistence hypothesis).

Earlier empirical evidence, however, suggests that shocks are asymmetric, that structural neutrality should be rejected, and that shocks are persistent. In order to understand these phenomena, theoretical explanations for asymmetry, non-neutrality, as well as persistence were reviewed: asymmetry can result from price adjustment costs, structural neutrality only holds under very specific assumptions, and persistence may be due to strategic complementarity, staggered contracts, inventories, and lags in the acquisition of information.

Then the three hypotheses were tested for the United States and Germany over the period 1973:1-1992:4. These tests were not only performed for aggregate demand shocks but also for important missing variables like oil-prices, terms of trade, and volume of worldwide trade. Furthermore, the tests were performed for three specifications of expectations in order to check whether the results were sensitive to the chosen specification.

With regard to the symmetry hypothesis it was found that it depends on the type of shocks whether shocks have symmetric or asymmetric effects on real economic growth; furthermore the results may differ between countries. For the United States, for example, shocks in nominal income growth, money growth, and oil-prices had asymmetric effects, whereas shocks in the terms of trade and the volume of worldwide trade had symmetric effects. The conclusion for nominal income growth and moeny growth, however, is sensitive to the specification of expectations. For Germany it was found that shocks in money growth and the terms of trade had asymmetric effects on real economic growth, whereas nominal income growth, oilprices and the volume of worldwide trade had symmetric effects. The result for oilprices and the volume of worldwide trade, however, is dependent on the chosen specification of expectations.

Note that the results are opposite for nominal income shocks, oil-price shocks, and terms of trade shocks. Whereas nominal income shocks had an asymmetric effect on economic growth for the United States, they had a symmetric effect in the case of Germany. A possible explanation for this is that in the United States prices are adjusted more frequently if demand is high, than when demand is low, but that in Germany this frequency is independent of the sign of demand shocks. With respect to oil-price shocks the effect on real growth was asymmetric in the United States, but symmetric for Germany. This may be due to the fact that hiring and 
firing costs were higher in Germany than in the United States. Given an increase in the oil-price, output decreases in both countries as the production costs increase and profitability falls given that firms are not able to pass on the increase in production costs given competition and their pricing policies. The other way around a fall in price of oil should increase profitability and thus increase output and employment. If employers, however, are uncertain whether the oil-prices are permanently lower, and hiring and firing costs are high, they might not respond fully to the change in oil-prices. Consequently, the response to oil-price shocks will be asymmetric. Finally, terms of trade shocks have a symmetric effect on real economic growth for the United States, but have an asymmetric effect for Germany. This may be also due to differences in hiring and firing costs. If the terms of trade are low, profits will be higher. If it is uncertain whether the favourable competitiveness position will last for some while, it may be very costly to adjust output and employment to the change in terms of trade; the extra demand may be matched by adjusting the stock of produced goods.

With respect to the structural neutrality hypothesis it is found that, in contrast to the earlier empirical results, the structural neutrality hypothesis cannot be rejected for the United States except for the terms of trade; for Germany it cannot be rejected except for nominal income growth. Finally, in general the non-persistence hypothesis could not be rejected for the United States as well as Germany independent of the specification of expectations.

\section{Appendix 3A Construction of $t$ and $w t$}

The terms of trade for country $i, t t_{i}$, is determined by the domestic price level, $P_{i}$, and the foreign price level in domestic currency, $P F_{i, i}$ :

$$
t_{i}=\ln P_{i}-\ln P F_{i, i} .
$$

The foreign output price level, $P F_{i, i}$, in turn is constructed as an exchange rate adjusted sum of nominal income divided by the exchange rate adjusted sum of real income: $^{\text {? }}$

$$
P F_{i, i}=\frac{\sum_{j=1}^{n} X_{j, j}\left(e_{s_{i} /} / e_{s, i}\right)}{\sum_{j=1}^{n} Y_{j, j}\left(e_{s_{j} / e_{s, i}}\right)} \text { with } j \neq i,
$$

See Parkin et al. (1981). 
Where

$P F_{i, i}^{*}=$ foreign output price of country $i$ denoted in currency of country $i_{s}$

$X_{j,}=$ nominal gross national product of country $j$ in millions of the currency of country $\dot{j}$,

$Y_{J j}=$ real gross national product in 1985 prices of country $j$ denoted in millions of the currency of country $j$, and

$e_{\$, i}=$ exchange rate of the US dollar with respect to the currency of country $i$ [US dollar/ currency of country $i]$.

The set of countries $j$ which has been used to compute the foreign price level consists of the United States, Japan, Germany, France, the United Kingdom and the Netherlands. The GNP data obtained from DATASTREAM for these countries were already seasonally adjusted for France, Japan and for the United States, so we also seasonally adjusted the GNP data for Germany, the United Kingdom and the Netherlands using the multiplicative algorithm of MicroTSP version 7.0d. For the Netherlands data were combined from DATASTREAM, De Nederlandsche Bank (1986) and Kwartaalrekeningen, CBS (various issues). Furthermore, the necesssary end of period dollar exchange rate were acquired from DATASTREAM.

The volume of worldwide trade for country $i, w t_{j}$, is determined by geographically weighting real imports:

$$
\begin{gathered}
W t_{i}=\ln \left(W T_{i, j}\right), \\
W T_{i, j}=\sum_{j=1}^{k}\left(\frac{B_{j j}}{B_{i}}\right) Z_{j, j}\left(e_{S_{j} j} / e_{j, i}\right) \quad j \neq i, \\
B_{j}=\sum_{j=1}^{k} B_{i j}, \\
\sum_{j=1}^{k} \frac{B_{i j}}{B_{i}}=\frac{1}{B_{j}} \sum_{j=1}^{k} B_{i j}=1,
\end{gathered}
$$

where

$W T_{i, f}=$ geographically weighted volume of worldwide trade of country in millions of the currency of country $i$ (prices 1985),

$B_{i j}=$ exports (including energy) of country $i$ to country $j$ in million US dollars,

$B_{i}=$ exports (including energy) of country $i$ in million US dollars, and

$Z_{j j}=$ real imports of country $j$ in millions of the currency of country $j$ in prices of 1985 .

To callculate $w t_{\text {; }}$ additional data were obtained for the period 1970:1-1992:4. First, the bilateral export flows, $B_{i j}$, between ten countries were extracted from various 
issues of the Directions of Trade Statistics (IMF) as well as their total exports and imports. ${ }^{8}$ Third, the nominal value of imports and the import price indices were obtained for 20 countries from DATASTREAM. Finally, the end of period dollar exchange rates that were not yet available were acquired from DATASTREAM.

To construct the geographically weighted volume of worldwide trade (WT) first the non-seasonally adjusted real imports $Z_{j, j}$ were calculated for these 20 countries in millions of domestic currency. ${ }^{10}$ Second, the domestic real import volumes were multiplied by the dollar exchange rate $e_{s, t}$ to get real imports in US dollars. Third, the export shares have to be calculated. Therefore, annual trade-matrices have been constructed. ${ }^{11}$ This is done as follows. Given the difference between the total exports (imports) to a country and the exports (imports) to the ten above countries, the exports (imports) to the rest of the world is calculated. Then the export share of the export from country $i$ to $j$ in the total exports of country $i, B_{i j} / B_{i}$, was calculated.

In our analysis we define the imports of the rest of the world as the sum of the real imports of the other ten countries (Australia, Austria, Canada, Finland, Greece, Ireland, New Zealand, Norway, Sweden and Switzerland). Then formula (3A.4) has been applied. Note that the trade-weights are implemented with a year lag: for example the trade-matrix of 1969 is used in calculating the volume of worldwide trade for the quarters 1970:1 until 1970:4 and so on. The resulting series for Germany were restated in Deutschmarks and those for the United States remained in dollars. Then both series were seasonally adjusted.

\$ These ten countries are: Belgium, Germany, the Netherlands, France, the United Kingdom, Italy, Spain, Denmark, Japan and the United States.

9 These 20 countries are: Belgium, Germany, the Netherlands, France, the United Kingdom, Italy, Spain, Denmark, Japan, the United States, Australia, Austria, Canada, Finland, Greece, Ireland, New Zealand, Norway, Sweden and Switzerland.

10. For the period 1970:1-1971:4 import prices were not available for Belgium, France, Italy,

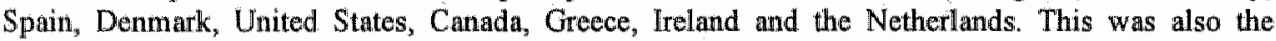
case for Spain during the period 1987-1992. For the Netherlands import price-series were extended to 1970 and 1971 using the non-seasonally adjusted series of import prices from DNB (1986). For the other countries this gap was filled by linearly interpolating the yearly import prices from the International Financial Statistics Yearbook 1993 (IMF). Furthermore the last quarter of 1992 import prices of Greece and Sweden were not available; these two fourth quarter import prices were approximated by combining the 1992 import price index in the IFS Yearbook 1993 with the three available quarterly figures from DATASTREAM.

"The advantage of using yearly trade matrices instead of quarterly trade matrices is this avoids introducing extra seasonality via trade weights. 


\section{The Evidence on International Output-Inflation Trade-Offs: An Evaluation}

\subsection{Introduction}

In chapter 2 six properties of the Lucas (1973) model were described: three intracountry and three cross-country properties. Of these, the intra-country hypotheses were investigated in chapter 3 . The cross-country hypotheses or Lucas variability hypotheses are the subject of the current chapter. These state the following. First, the more uncertain economic agents are about inflation, the less they will adjust output. Second, the larger the variance of demand shocks is, the larger the variance of inflation. Third, the more variable aggregate demand shocks are, the less output will respond to demand shocks.

These variability hypotheses are important because they cast doubt on the effectiveness of demand policies. Whereas the use of demand policies to stimulate the economy was a popular tool of economic policy in the 1950 s and $1960 \mathrm{~s}$, its effectiveness came under attack in the seventies. It was argued that systematic attempts by governments to lower unemployment below its natural (long-run) level would only result in more inflation and inflation uncertainty in the end. The latter would affect people's perceptions of future policy and deprive future demand policies of their short-run effects.

The Lucas variability hypotheses have been extensively tested; however, the results are mixed. In particular, no consensus exists about the extent to which inflation-output trade-offs are sensitive to active demand policies and whether these sensitivities differ between developed and developing countries. Addison et al. (1986) and Odedokun (1991), for example, find that the potential role of demand management in developing countries is larger than in developed countries, whereas Jung (1985) and Katsimbris (1990) reject this claim. There are two arguments why the sensitivity to demand policy may differ between these groups. First, the lack of aggregate price-data in developing countries compared to developed countries may make it more difficult to distinguish between nominal and real shocks and may therefore enlarge the real effect of aggregate demand policy (see Ram, 1984). Second, the presence of mass illiteracy, predominance of small-scale peasant primary production and other market imperfections, can make aggregate demand policy more effective in developing countries (see Odedokun, 1991). 
The purpose of this chapter is to investigate the validity of the Lucas variability hypotheses for developed and developing countries. Therefore a meta-study is performed of ten previously published inflation-output studies, that differ widely in sample periods and choice of countries. In combining and processing the information across studies, we may arrive at more robust conclusions than is possible for individual studies.

This chapter is structured as follows. First, section 4.2 restates the Lucas (1973) model and the variability hypotheses. Then section 4.3 distinguishes between the group of developed countries on the one hand, and the group of developing countries on the other, and empirically tests the variability hypotheses using cross-sectional correlation coefficients. Section 4.4 repeats the analysis of section 4.3 , allowing for structural differences between developing and developed countries. Finally, section 4.5 contains a short conclusion.

\subsection{The Lucas model and the Lucas variability hypotheses}

The Lucas (1973) aggregate supply model results in an exploitable inflation-output trade-off, depending on the confusion between general and relative price shocks:

$$
\begin{gathered}
y_{c, t}=\pi\left(\Delta x_{r}-\delta\right)+\lambda y_{c, t-1}+\varepsilon_{r}, \\
\text { with } 0 \leq \pi=\frac{\theta \gamma}{1+\theta \gamma} \leq 1 ; \varepsilon_{r} \sim N\left(0, \sigma_{\varepsilon}{ }^{2}\right),
\end{gathered}
$$

where $y_{c, t}$ is cyclical output, $\left(\Delta x_{t}-\delta\right)$ the unexpected increase in nominal demand, $\pi$ the trade-off parameter, $\lambda$ the adjustment speed, $\theta$ the fraction of total individual price variance due to relative price variation $\left(\theta=\tau^{2} /\left(\sigma^{2}+\tau^{2}\right)\right)$ wherein $\tau^{2}$ is the the variance of market specific demand shocks and $\sigma^{2}$ the price variance, and $\gamma$ the supply response to changes in the expected real price level in each individual market.

The Lucas variability hypotheses follow from the response of output to an unexpected change in nominal demand, $\pi$. First, the definition of the fraction of price variance in a market due to relative price variance, $\theta$, is substituted in the formula for $\pi$ :

$$
\pi=\frac{\gamma \tau^{2}}{\sigma^{2}+\tau^{2}(1+\gamma)}
$$

Then the first derivative of $\pi$ with respect to the price variance $\sigma^{2}$ is defined by: 


$$
\frac{\partial \pi}{\partial \sigma^{2}}=-\frac{\gamma \tau^{2}}{\left(\sigma^{2}+\tau^{2}(1+\gamma)\right)^{2}}<0 .
$$

Given that the variance of market specific demand shocks, $\tau^{2}$, and the supply response, $\gamma$, are constant, equation (4.4) states that the more uncertain economic agents are about inflation, the less they will adjust output. This is the first Lucas variability hypothesis. The second one follows from the definition of the price variance, $\sigma^{2}: !$

$$
\frac{\partial \sigma^{2}}{\partial \sigma^{2}}=\frac{1}{(1+\theta y)^{2}}>0
$$

Equation (4.5) states that the larger the variance of demand shocks is, the higher the variance of inflation will become. This is the second Lucas variability hypothesis. The third and final hypothesis follows from combining (4.4) and (4.5):

$$
\frac{\partial \pi}{\partial \sigma_{\Delta x}^{2}}=\frac{\partial \pi}{\partial \sigma^{2}} \frac{\partial \sigma^{2}}{\partial \sigma_{\Delta x}^{2}}<0
$$

which states that the more variable aggregate demand shocks are, the less output will respond to demand shocks.

\subsection{Empirical evidence on the Lucas variability hypotheses}

In this chapter the empirical evidence of ten previously published inflation-output studies is combined. The studies that are used in the investigation are Lucas (1973), Koskela and Viren (1980), Alberro (1981), Ram (1984), Jung (1985), Addison et al. (1986), Ball et al. (1988), Ram (1990), Katsimbris (1990), and Odedokun (1991). The sample periods for which the Lucas variability hypotheses are analysed differ widely across these studies (see appendix 4A). Note that Addison et al. (1986) as well as Ram (1990) separately analyse two sub-periods; the full period results in these studies are not used here to avoid double-counting.

The first step in the analysis is to catagorize each country as either developed or developing. Therefore each country used in any of the ten studies is classified as either developing or developed, consistent with the classifications of Jung (1985), Addison et al. (1986), Katsimbris (1990) and Odedokun (1991). Out of a total of

1. The price variance $\sigma^{2}$ is defined as: $\sigma^{2}=\frac{\sigma^{2} \Delta x}{(1+\theta y)^{2}}$ where $\sigma_{\Delta x}^{2}$ is the variance of nominal demand growth (see Lucas, 1973). 
141 countries across all studies, 21 are uniformly classified as developed, and 89 as developing. ${ }^{2,3}$

For two countries, Israel and South Africa, the classifications were not fully consistent. Israel is classified as developed by Addison et al (1986), but as developing by Jung (1985) and Odedokun (1991) and South Africa as a developed country by Addison et al. (1986), but as a developing country by the other three investigators. In order to be as consistent as possible with Jung (1985), Addison et al. (1986), Katsimbris (1990), and Odedokun (1991) a country is classified as a developed country, if it has a higher gross domestic product per capita in US dollars than the developed country with the lowest income per capita in these four studies; otherwise it is classified as developing country. Therefore the gross domestic product per capita was computed for the developed countries in Jung (1985), Addison et al. (1986), Katsimbris (1990), and Odedokun (1991) from the International Financial Statistics Yearbook 1995. Of these countries Spain turned out to have the lowest gross domestic product in the basis year 1980; it was only 5635 US dollars per capita. The gross domestic product per capita in Israel was 5614 US dollars per capita in 1980, and only 2862 US dollars per capita in South Africa. Thus, Israel and South Africa were classified as developing countries. Given this criterion, the remaining 29 countries not included in Jung (1985), Addison et al. (1986), Katsimbris (1990) or Odedokun (1991), were all classified as developing countries. The list of developed countries is available in appendix $4 \mathrm{~B}$ as well as an overview of which developed countries are included in the various Lucas variability studies; appendix $4 \mathrm{C}$ provides the same for the group of developing countries.

To get a first glance of the difference between developed and developing countries, the variance of nominal demand shocks, $\sigma_{\Delta x}^{2}$, the variance of inflation, $\sigma^{2}$, and the inflation-output parameter, $\pi$, were taken for each country in each of the studies. Then these data were averaged over the set of developed countries, developing countries, and all countries for each individual study. The results are listed in Tables $4.1,4.2$, and 4.3 respectively. They show that in general the average variance of demand shocks as well as the variance of inflation is smaller for developed countries than for developing countries, and that the effect of a nominal demand change on cyclical output, $\pi$, is larger for developed countries than for developing countries. Thus, developed countries are more sensitive to active demand policies.

2 Ceylon and Upper Volta are officially renamed as Sri Lanka (1972) and Burkina Faso (1984) respectively; therefore all observations for Ceylon or Upper Volta are considered as observations for Sri Lanka or Burkina Faso respectively.

3 See: International Financial Statistics Yearbook, IMF, 1994. 
Table 4.1 Cross-section averages of $\sigma^{2}$ for developed countries, developing countries, and all countries (developed and developing countries)

\begin{tabular}{lrrr} 
& $\begin{array}{r}\text { Developed } \\
\text { countries }\end{array}$ & $\begin{array}{r}\text { Developing } \\
\text { countries }\end{array}$ & All countries \\
\cline { 2 - 3 } Lucas (1973) & 0.00080 & 0.00902 & \\
Koskela and Viren (1980) & 0.00084 & 0.01518 & 0.00354 \\
Alberro (1981) & 0.00095 & 0.01964 & 0.00562 \\
Ram (1984) & 0.00128 & 0.02119 & 0.01277 \\
Jung (1985) & 0.00163 & 0.01894 & 0.01640 \\
Addison et al. (1986), 1955-1966 & 0.00106 & 0.00314 & 0.01307 \\
Addison et al. (1986), 1967-1980 & 0.00210 & 0.00860 & 0.00204 \\
Ball et al. (1988) & 0.00262 & 0.02284 & 0.00516 \\
Ram (1990), 1960-1973 & 0.00158 & 0.01114 & 0.01391 \\
Ram (1990), 1973-1986 & 0.00167 & 0.04385 & 0.00964 \\
Katsimbris (1990) & 0.00160 & 0.03032 & 0.03709 \\
Odedokun (1991) & 0.00235 & 0.02240 & 0.01632 \\
Note: & & 0.01861
\end{tabular}

Note: the variance of demand shocks, $\sigma_{\Delta x}^{2}$, was taken for each country from each invidual study; then for each study these were averaged for the set of developed and developing countries as well as for all countries (see appendices $4 \mathrm{~B}$ and $4 \mathrm{C}$ ).

Table 4.2 Cross-section averages of $\sigma^{2}$ for developed conntries, developing countries, and all countries (developed and developing countries)

\begin{tabular}{|c|c|c|c|}
\hline & $\begin{array}{r}\text { Developed } \\
\text { countries }\end{array}$ & $\begin{array}{r}\text { Developing } \\
\text { coumtries }\end{array}$ & All countries \\
\hline Lucas (1973) & 0.00041 & 0.00907 & 0.00330 \\
\hline Koskela and Viren (1980) & 0,00019 & 0.01453 & 0.00497 \\
\hline Alberro (1981) & 0.00047 & 0.01916 & 0.01223 \\
\hline Ram (1984) & 0.00055 & 0.01913 & 0.01466 \\
\hline Jung (1985) & 0.00189 & 0.04359 & 0.02944 \\
\hline Addison et all (1986), $1955-1966$ & 0.00057 & 0.00254 & 0.00150 \\
\hline Addison et al. $(1986), 1967-1980$ & 0.00207 & 0.00960 & 0.00560 \\
\hline Ball et al. (1988) & 0,00281 & 0.02601 & 0.01576 \\
\hline $\operatorname{Ram}(1990), 1960-1973$ & 0.00287 & 0.01697 & 0.01476 \\
\hline $\operatorname{Ram}(1990), 1973-1986$ & 0.00121 & 0.04129 & 0.03487 \\
\hline Katsimbris $(1990)$ & 0.00207 & 0.03182 & 0.01733 \\
\hline Odedokun (1991) & 0.00186 & 0.01896 & 0.01572 \\
\hline
\end{tabular}


Table 4.3 Cross-section averages of $\pi$ for developed countries, developing countries, and all countries (developed and deweloping countries)

\begin{tabular}{lrrr} 
& $\begin{array}{r}\text { Developed } \\
\text { countries }\end{array}$ & $\begin{array}{r}\text { Developing } \\
\text { conntries }\end{array}$ & All countries \\
\cline { 2 - 3 } & 0.579 & 0.366 & 0.508 \\
Lucas (1973) & 0.561 & 0.326 & 0.482 \\
Koskela and Viren (1980) & 0.648 & 0.355 & 0.463 \\
Alberro (1981) & 0.498 & 0.243 & 0.304 \\
Ram (1984) & 0.286 & 0.128 & 0.182 \\
Jung (1985) & 0.554 & 0.448 & 0.504 \\
Addison et al $(1986), 1955-1966$ & 0.398 & 0.099 & 0.257 \\
Addison et al. (1986), 1967-1980 & 0.314 & 0.186 & 0.243 \\
Ball et al. (1988) & 0.336 & 0.411 & 0.400 \\
Ram (1990), 1960-1973 & 0.268 & 0.281 & 0.279 \\
Ram (1990), 1973-1986 & 0.420 & 0.192 & 0.303 \\
Katsimbris (1990) & 0.318 & 0.232 & 0.248 \\
Odedokun (1991) & & &
\end{tabular}

Note: the inflation motput parameter, $\pi$, was taken for each country from each invidual study; then for each study these were averaged for the set of developed and developing countries as well as for all countries (see appendices $4 \mathrm{~B}$ and $4 \mathrm{C}$ ).

To see whether there is also a difference in the validity of the Lucas variability hypotheses between developed and developing countries, simple correlations were calculated for these three hypotheses given the data for $\sigma_{\Delta x}^{2}, \sigma^{2}$, and $\pi$ for each country from each study. These correlation have been calculated in this chapter for each study for developed countries, developing countries, and the whole set of countries. These are reported in Tables 4.4, 4.5, and 4.6 respectively. Comparison. of these tables shows that in general the correlation between the variances of inflation and demand shocks, $r\left(\sigma^{2} \sigma^{2}{ }_{\Delta x}\right)$, is lower for developed than for developing countries; the evidence for the other two correlation, however, is not uniform.

To investigate whether the correlations are higher for developed or developing counties, the simple cross-country correlations in Tables 4.4 to 4.6 were averaged across the various studies. The average simple correlations are reported in Table 4.7. It shows that the average correlation between the inflation-output parameter and the variance of inflation, $r\left(\pi, \sigma^{2}\right)$, is significantly negative, both for the group of developed countries, the group of developing countries and their combination. Similarly, the average correlation between the variances of demand shocks and inflation, $r\left(\sigma^{2}, \sigma_{A x}^{2}\right)$, is significantly positive in all three cases. The average correlation between the inflation-output parameter and the variance of demand shocks, $\mathrm{r}\left(\pi, \sigma_{\Delta x}^{2}\right)$, is negative and marginally significant for the total sample of countries, but marginally insignificant for both the groups of developing and developed countries separately. 
Table 4.4 Simple cross-country correlations for developed conntries

Lucas (1973)

Koskela and Viren (1980)

Alberro (1.981)

$\operatorname{Ram}(1984)$

Jung (1985)

Addison et al. (1986), 1955-1966

Addison et al. (1986), 1967-1980

Ball et al. (1988)

Ram (1990), 1960-1973

Ram (1990), 1973-1986

Katsimbris (1990)

Odedokun (1991)

\begin{tabular}{|c|c|c|}
\hline $\mathrm{r}\left(\pi, \sigma^{2}\right)$ & $\mathbb{r}\left(\sigma^{2} \sigma^{2}{ }^{2}\right)$ & $r\left(\pi_{i} \sigma^{2}{ }_{a x}\right)$ \\
\hline$-0.737^{* * *}$ & 0.287 & -0.126 \\
\hline-0.768 & 0.456 & 0.048 \\
\hline$-0.492 \ldots$ & $0.802^{* * * *}$ & -0.257 \\
\hline$-0.798^{* * *}$ & $0.775^{1 * * *}$ & $-0.490^{\circ}$ \\
\hline-0.608 & $0.826^{\ldots * *}$ & $-0.412^{\circ}$ \\
\hline$-0.654^{* 0}$ & 0.504 & -0.221 \\
\hline-0.394 & $0.983^{* \ldots * *}$ & -0.280 \\
\hline-0.364 & 0.992 & -0.306 \\
\hline$-0.164 .$. & $0.959^{\circ}$ & -0.036 \\
\hline-0.506 & $0.962^{\circ \ldots}$ & $-0.378^{\circ}$ \\
\hline-0.604 & 0.757 & $-0.509^{\circ}$ \\
\hline$-0.405^{\circ}$ & $0.984^{\circ}$ & -0.307 \\
\hline
\end{tabular}

Notes: *,**, *** denote that a coefficient is significant at the $10 \%, 5 \%$ and $1 \%$ level respectively. The correlations are calculated on the reported statistics of $\pi, \sigma^{2}, \sigma^{2}{ }_{\Delta x}$ in each of the studies; the computed simple correlations differ in some cases, however, slightly from those reported in the various studies. The $t$-values for the correlations are calculated as $\frac{r \sqrt{n-2}}{\sqrt{1-r^{2}}}$ where $\mathrm{r}$ is the simple correlation coefficient and $n$ the number of observations; this statistic has a t-distribution. with $n-2$ degrees of freedom (see Kendall and Stuart, 1977:412-416).

Table 4.5 Simple cross-country correlations for developing countries

Lucas (1973)

Koskela and Viren (1980)

Alberro (1981)

Ram (1984)

Jung (1985)

Addison et al. (1986), 1955-1966

Addison et al. (1986), 1967-1980

Ball et al. (1988)

Ram (1990), 1960-1973

Ram (1990), 1973-1986

Katsimbris (1990)

Odedokun (1991)

\begin{tabular}{|c|c|c|}
\hline$r\left(\pi, \sigma^{2}\right)$ & $\mathrm{I}\left(\sigma^{2}, \sigma_{\Delta \mathrm{K}}^{2}\right)$ & $\mathrm{r}\left(\pi, \sigma_{\Delta x}^{2}\right)$ \\
\hline$-0.849^{\circ *}$ & $0.986^{\circ \ldots *}$ & $-0.792^{*}$ \\
\hline-0.714 & $1.000^{* * * * *}$ & 0.712 \\
\hline-0.278. & $0.999^{\circ * * *}$ & -0.260 \\
\hline$-0.284^{* *}$ & $0,998^{* * * *}$ & $-0.257^{\circ}$ \\
\hline-0.223 & $0.973 \ldots$ & -0.253. \\
\hline$-0.627^{* * *}$ & $0.982^{\circ}$ & $-0.615^{\circ}$ \\
\hline$-0.513^{* *}$ & $0.993^{* * *}$ & $-0.475^{\circ}$ \\
\hline-0.485 & $0.997^{* * *}$ & $-0.437^{\circ}$. \\
\hline $.0 .215^{\circ "}$ & $0.992^{\circ *}$ & $-0.162^{\circ}$ \\
\hline$-0.179^{\circ}$ & $0.999^{\ldots * \ldots}$ & $-0.165^{\circ}$ \\
\hline-0.251 & 0.999 & -0.229 \\
\hline$-0.340^{\circ *}$ & $0.961^{* * *}$ & $-0.197^{\circ}$ \\
\hline
\end{tabular}

Notes: ${ }^{*}, *$ denote that a coefficient is significant at the $10 \%, 5 \%$ and $1 \%$ level respectively.

See Table 4.4 for the calculation of the correlations and the t-statistics. 
Table 4.6 Simple cross-country correlations for all countries

Lucas (1973)

Koskela and Viren (1980)

Alberro (1981)

Ram (1984)

Jung (1985)

Addison et al (1986), 1955-1966

Addison et al $(1986), 1967-1980$

Bail et all. (1988)

Ram (1990), 1960-1973

Ram (1990), 1973-1986

Katsimbris (1990)

Odediokun (1991)

Notes: * denote that a coefficient is significant at the $10 \%, 5 \%$ and $1 \%$ level respectively. See Table 4.4 for the calculation of the correlations and the t-statistics.

Table 4.7 Average simple correlations across studies

\begin{tabular}{lccc}
\hline & $\mathrm{r}\left(\pi, \sigma^{2}\right)$ & $\mathrm{r}\left(\sigma^{2}, \sigma_{\Delta x}^{2}\right)$ & $\mathrm{r}\left(\pi, \sigma^{2}{ }_{\Delta x}\right)$ \\
Developed countries & $-0.541^{*}$ & $0.774^{* * *}$ & -0.267 \\
Developing countries & $(-2.986)$ & $(3.405)$ & $(-1.546)$ \\
& $-0.413^{\circ}$ & $0.990^{* \cdots *}$ & -0.379 \\
All countries & $(-1.952)$ & $(83.241)$ & $(-1.784)$ \\
& $-0.357^{*}$ & $0.990^{* * *}$ & $-0.329^{*}$ \\
& $(-2.154)$ & $(78.753)$ & $(-2.015)$
\end{tabular}

Notes: * * * denote that a coefficient is significant at the $10 \%, 5 \%$ and $1 \%$ level respectively; the $t$-values are reported between parentheses and are calculated as the average simple correlation divided by its standurd deviation.

To test the equality of the average correlations between developed and developing countries Behrens-Fischer tests are performed (see Lindgren, 1976: 352-353). Table 4.8 shows that both $\mathrm{r}\left(\pi, \sigma^{2}\right)$ and $\mathrm{r}\left(\sigma^{2}{ }^{\prime} \sigma^{2}{ }_{A x}\right)$ differ significantly between developed and developing countries. However, the equality of $\mathrm{r}\left(\pi, \sigma_{\Delta x}^{2}\right)$ for developed and developing countries cannot be rejected. Overall, $r\left(\pi, \sigma^{2}\right)$ is higher for the developed countries than for developing countries in absolute terms; thus, high inflation variability reduces the effects of demand policy significantly more in

\footnotetext{
* Besides the Behrens-Fischer test paired means tests were performed too, but the results were quite comparable with the Behrens-Fischer test, so that they are left out.
} 
developed countries than in developing countries. Second, $r\left(\sigma_{,}^{2} \sigma_{\Delta x}^{2}\right)$ is higher for the developing countries than for the developed countries. A potential explanation is the fact that very high and variable inflation has been primarily a developing world phenomenon over the past decades. In combination with the boundedness of real growth variability in al countries, it implies that inflation variability accounts for a larger share of nominal demand variability in developing countries on average.

Based on the results for $\mathrm{r}\left(\pi, \sigma^{2}\right)$ and $r\left(\sigma^{2}, \sigma^{2}{ }_{A x}\right)$, we would expect to find both a significantly negative average correlation between the inflation-output parameter and the variance of demand shocks for developed and developing countries, and a significant difference in the magnitude of this correlation for developed and developing countries. The results in Tables 4.7 and 4.8 do not confirm these predictions, however.

Table 4.8 Behrens-Fischer tests on simple correlations

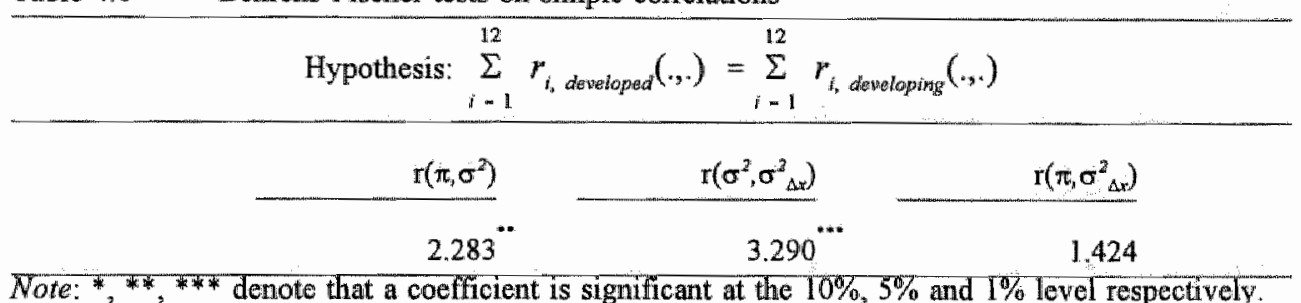

\subsection{A correction for supply responses}

A reason for the marginal insignificance of $\mathrm{r}\left(\pi, \sigma^{2}{ }_{4 x}\right)$ for both developing and developed countries and for the insignificant difference between the two groups of countries, is the inappropriateness of the assumption that the economic structure does not vary over the countries included in the cross-country analysis. This assumption is reflected in the model by the hypothesized cross-country equality of the variance of market specific demand shocks, $\tau^{2}$, as well as the supply response, $\gamma$ (see Addison et al., 1986). To correct for differences in economic structure, partial correlations are calculated conditional on the supply response $\gamma$ instead of simple correlations (see Jung, 1985, and Katsimbris, 1990). For example, the partial correlation between the variance of demand shocks and the inflation-output parameter conditional on the supply response, $\operatorname{t}\left(\sigma_{\Delta x}^{2}, \pi \mid \gamma\right)$, is defined as follows: ${ }^{5}$

\footnotetext{
5. The other two partial correlations, that between the variance of inflation and the variance of demand shocks given the supply response, and between the variance of inflation and the inflationoutput parameter given the supply response, are calculated likewise.
} 


$$
r\left(\sigma_{\Delta x}^{2}, \pi \mid \gamma\right)=\frac{r\left(\sigma_{A x}^{2}, \pi\right)-\gamma\left(\sigma_{A x}^{2}, \gamma\right) r(\pi, \gamma)}{\sqrt{\left(1-r\left(\sigma_{A x}^{2}, \gamma\right)^{2}\right)\left(1-r(\pi, \gamma)^{2}\right)}},
$$

where the supply response parameter $\gamma$ is defined as $\gamma=(1 / \theta)(\pi /(1-\pi))$. Given an estimate of $\pi, \gamma$ can be obtained for any given value of $\theta$. Jung (1985) found that the specific choice of $\theta$ does not significantly influence the conditional partial correlations. Following Jung (1985), therefore $\theta$ is also assumed to be equal to $2 / 3$. Given the fact that the response of output to a demand shock, $\pi$, is higher for developed countries than for developing countries (see Table 4.3), the supply responise is higher for developed countries than for developing countries. ${ }^{6}$ Thus there is reason to bellieve that economic structure is different.

For each study the three partial correlations were calculated for the set of developed countries, developing countries, and all countries. Then these partial correlations were averaged across all studies. The results are displayed in Table 4.9. The main difference in comparison with Table 4.7 is that the correlation between the inflation-output parameter and the variance of demand shocks decreases in absolute magnitude for the group of developed countries and becomes strongly insignificant. The correlation $\mathrm{r}\left(\pi, \sigma^{*}\right)$ is reduced in absolute value as well for the developed countries, but remains (marginally) significant. All other correlations stay virtually the same. The Behrens-Fisher test results in Table 4.10 show that the average of $\mathrm{r}\left(\pi, \sigma_{\alpha x}^{2}\right)$ now is significantly different between develloped and developing countries, in contrast to Table 4.8. Thus, if differences in supply response are taken into account, then the link between the output response of a demand shock and the variance of inflation is significantly stronger for developing countries than for developed countries.

\footnotetext{
6. An explanation for this difference may be that in developed countries suppliers can judge the expected real price for their products better than in developing countries because information about the expected aggregate price level is more accessable; therefore they adjust their supply more if the expected real price for their product changes than in developing countries.
} 
Table 4.9

Average partial comelations across studies

\begin{tabular}{|c|c|c|c|}
\hline & $\mathrm{r}\left(\pi, \sigma^{2} \| \gamma\right)$ & $r\left(\sigma^{2}, \sigma_{\Delta r}^{2} \mid \gamma\right)$ & $\mathrm{r}\left(\pi_{0} \sigma^{2}{ }_{t, x} \mid \gamma\right)$ \\
\hline Developed countries & $\begin{array}{c}-0.445^{\circ} \\
(-1.830)\end{array}$ & $\begin{array}{c}0.764 \\
(3.166)\end{array}$ & $\begin{array}{r}-0.153 \\
(-0.691)\end{array}$ \\
\hline Developing countries & $\begin{array}{l}-0.389^{\circ} \\
(-1.834)\end{array}$ & $\begin{array}{c}0.990 \cdots \\
(90.299)\end{array}$ & $\begin{array}{l}-0.353 \\
(-1.723)\end{array}$ \\
\hline All countries & $\begin{array}{l}-0.356^{\circ} \\
(-1.969)\end{array}$ & $\begin{array}{c}0.990^{* \cdots} \\
(88.117)\end{array}$ & $\begin{array}{c}-0.327^{\circ} \\
(-1.849)\end{array}$ \\
\hline
\end{tabular}

Nores: ***, *** denote that a coefficient is significant at the $10 \%, 5 \%$ and $1 \%$ level respectively; the t-values are reported between parentheses and are calculated as the average partial correlation divided by its standard deviation; $y$ is based on $\theta=2 / 3$.

Table 4.10 Behrens-Fischer tests on partial correlations

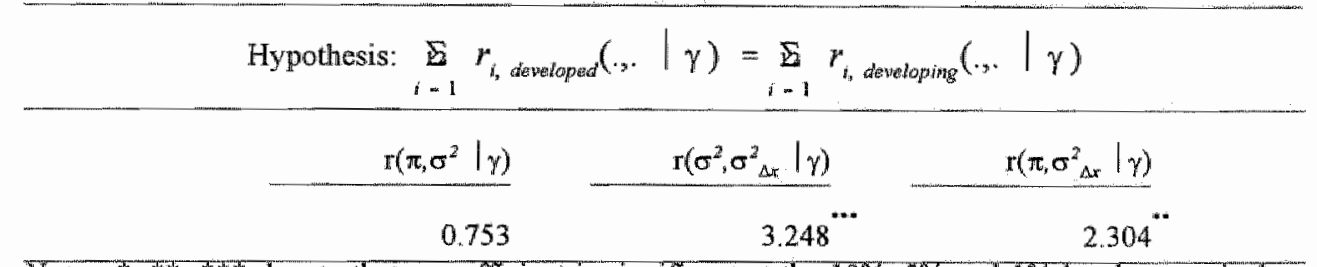

Notes: $* * *$ *** denote that a cocfficient is significant at the $10 \%, 5 \%$ and $1 \%$ level respectively and $y$ is based on $\theta=2 / 3$.

\subsection{Conclusion}

When adequate account is taken of structural differences between developing and developed countries, the prediction of the Lucas model that higher nominal demand variability leads to a lower inflation-output trade-off must be rejected for the group of developed countries. This does not imply that developed countries can use active demand policies without their short-run inflation-output trade-off deteriorating.

More realistically, the result suggests that nominal demand variability is an inadequate indicator of demand shocks for the group of developed countries. This may be due to relatively low inflation levels and variability in the developed countries. When real and nominal shocks both contribute significantly to nominal demand variability, the latter become a noisy and unreliable indicator of demand shocks. For the developing countries where nominal (infllationary) shocks dominate as witnessed by the average value of $\mathrm{r}\left(\sigma^{2}, \sigma^{2}{ }_{\Delta x}\right)$, this may be less of a problem.

Our conclusion is supported by the evidence on $r\left(\pi, \sigma^{2}\right)$. For both groups of countries it is significantly negative and of similar magnitude, indicating that countries with predominantly nominal (inflationary) shocks face a deterioration of their inflation-output trade-off. 


\section{Appendix 4A Estimation periods of Lucas variability studies}

\begin{tabular}{lr} 
& Estimation Period \\
\cline { 2 - 2 } Lucas (1973) & $1953-1967$ \\
Koskell and Viren (1980) & $1952-1967$ \\
Alberro (1981) & $1953-1969$ \\
Ram (1984) & $1960-1978$ \\
Jung (1985) & $1950-1981$ \\
Addison et al. (1986) & $1955-1966$ \\
ibidem & $1967-1980$ \\
Ball et al. (1988) & $1948-1986$ \\
Ram (1990) & $1960-1973$ \\
ibidem & $1973-1986$ \\
Katsimbris (1990) & $1953-1986$ \\
Odedokun (1991) & $1958-1985$ \\
\hline
\end{tabular}

Note: for some studies the period slightly differs across countries. 


\section{Appendix 4B Developed countries in Lucas variability studies}

\begin{tabular}{|c|c|c|c|c|c|c|c|c|c|c|c|c|c|}
\hline & LU & KV & $A B$ & $\mathrm{Rl}$ & JG & $\mathrm{ACl}$ & $\mathrm{AC2}$ & $\mathrm{B}$ & R2I & $\mathrm{R} 22$ & $\mathrm{~K}$ & OD & TOT \\
\hline Australia & 0 & 0 & 1 & 1 & 1 & 1 & 1 & 1 & $\mathbb{1}$ & 1 & 1 & 1 & 10 \\
\hline Austria & 1 & 1 & 1 & 1 & 1 & 1 & 1 & 1 & 1 & 1 & 1 & 1 & 12 \\
\hline Belgium & 1 & 1 & 1 & 1 & 1 & 1 & 1 & $\mathbb{1}$ & 1 & 1 & 1 & 1 & 12 \\
\hline Canada & 1 & 1 & 1 & 1 & 1 & 1 & 1 & $\mathbb{1}$ & 1 & 1 & 1 & 1 & 12 \\
\hline Denmark & 1 & 1 & 1 & 1 & 1 & 1 & 1 & 1 & 1 & $\mathbb{1}$ & 1 & 1 & 12 \\
\hline Finland & 0 & 0 & 1 & 1 & 1 & 1 & 1 & ] & 1 & 1 & 1 & 1 & 10 \\
\hline France & 0 & 0 & 1 & $\mathbb{1}$ & 1 & 1 & $\mathbb{1}$ & 1 & 1 & 1 & $\Downarrow$ & 1 & 10 \\
\hline Germany & 1 & 1 & 1 & 1 & 1 & 1 & 1 & 1 & 1 & $\mathbb{1}$ & 1 & 1 & 12 \\
\hline Iceland & 0 & 0 & 1 & 0 & 0 & 1 & 1 & 1 & 1 & 1 & 0 & 1 & 7 \\
\hline Ireland & 1 & 1 & 1 & 1 & 1 & 1 & 1 & 1 & 1 & 1 & 1 & I. & 12 \\
\hline Italy & 1 & 1 & 1 & 1 & 1 & 1 & 1 & 1 & 1 & 1 & 1 & 1 & 12 \\
\hline Japan & 0 & 0 & 1 & 1 & 1 & 1 & 1 & 1 & 1 & 1 & 1 & 1 & 10 \\
\hline Luxembourg & 0 & 0 & 0 & 0 & 0 & 0 & 0 & 0 & 1 & 1 & 0 & $\|$ & 3 \\
\hline Netherlands & 1 & 1 & 1 & 1 & 1 & 1 & 1 & 1 & 1 & 1 & $\mathbb{1}$ & 1 & 1.2 \\
\hline New Zealand & 0 & 0 & 0 & 1 & 1 & 0 & 0 & 0 & 1 & 1 & 1 & 1 & 6 \\
\hline Norway & $\mathbb{1}$ & 1 & 1 & 1 & 1 & 1 & 1 & $\mathbb{1}$ & 1 & 1 & 1 & 1 & 12 \\
\hline Spain & 0 & 0 & 0 & $\mathbb{1}$ & 1 & 0 & 0 & 1 & 1 & 1 & 1 & 1 & 7 \\
\hline Sweden & 1 & 1 & 1 & 1 & 1 & 1 & 1 & $\mathbb{1}$ & 1 & 1 & 1 & 1 & 12 \\
\hline Switzerland & 0 & 0 & 1 & 1 & 1 & 1 & 1 & 1 & 1 & 1 & 1 & 1 & 10 \\
\hline United Kingdom & 1 & $\mathbb{1}$ & 1 & 1 & 1 & 1 & 1 & 1 & 1 & 1 & 1 & 1 & 12 \\
\hline United States & 1 & 1 & 1 & 1 & 1 & 1 & 1 & 1 & 1 & 1 & 1 & 1 & 12 \\
\hline
\end{tabular}

Notes: I denotes that a country is included in a study; 0 denotes that it is not included LU $\equiv$ Lucas (1973); $K V=$ Koskela and Viren (1980); $A B=$ Alberro (1981); $R 1=\operatorname{Ram}(1984) ; J G=$ Jung (1985); $\mathrm{ACl}=$ Addison et al. (1986), 1955-1966; $\mathrm{AC2}=$ Addison et al. (1986), 1967-1980; $\mathrm{B}$ $=$ Ball et al. (1988), R21 $=\operatorname{Ram}(1990), 1960-1973 ; \mathrm{R} 22=\operatorname{Ram}(1990), 1973-1986 ; \mathrm{K}=\mathrm{Katsim}-$ bris (1990); $\mathrm{OD}=$ Odedokun (1991); and TOT states how may studies include a specific country. 


\section{Appendix $4 \mathrm{C}$ Developing countries in Lucas variability studies}

\section{LU KV AB RI JG ACl AC2 B R21 R22 K OD TOT}

\begin{tabular}{|c|c|c|c|c|c|c|c|c|c|c|c|c|c|}
\hline Afghanistan & 0 & 0 & 0 & 1 & 0 & 0 & 0 & 0 & 1 & 0 & 0 & 0 & 2 \\
\hline Algeria & 0 & 0 & 0 & 1 & 0 & 0 & 0 & 0 & I & 1 & 0 & $\mathbb{1}$ & 4 \\
\hline Angolat & 0 & 0 & 0 & 0 & 0 & 0 & 0 & 0 & 1 & 1 & 0 & 0 & 2 \\
\hline Antigua & 0 & 0 & 0 & 0 & 0 & 0 & 0 & 0 & 1 & 1 & 0 & 0 & 2 \\
\hline Argentina & 1 & $\mathbb{1}$ & 1 & 1 & 1 & 0 & 0 & 1 & 1 & 1 & 0 & 1 & 9 \\
\hline Bafamas & 0 & 0 & 0 & 0 & 0 & 0 & 0 & 0 & 1 & 1 & 0 & I & 3 \\
\hline Bangladesh & 0 & 0 & 0 & 1 & 0 & 0 & 0 & 0 & 1 & 1 & 0 & 1 & 4 \\
\hline Barbados & 0 & 0 & 0 & 0 & 0 & 0 & 0 & 0 & 1 & 1 & 0 & 1 & 3 \\
\hline Belize & 0 & 0 & 0 & 0 & 0 & 0 & 0 & 0 & 1 & 1 & 0 & 1 & 3 \\
\hline Benin & 0 & 0 & 0 & 1 & 0 & 0 & 0 & 0 & 1 & 1 & 0 & 1 & 4 \\
\hline Bermuda & 0 & 0 & 0 & 0 & 0 & 0 & 0 & 0 & 1 & 1 & 0 & 0 & 2 \\
\hline Bolivia & 0 & 0 & 0 & 1 & 1 & 0 & 0 & 1 & I & 1 & 1 & 1 & 7 \\
\hline Botswana & 0 & 0 & 0 & 0 & 0 & 0 & 0 & 0 & 1 & $\Perp$ & 0 & 1 & 3 \\
\hline Brazil & 0 & 0 & 1 & 1 & 1 & 0 & 0 & $\mathbb{1}$ & 1 & 1 & 0 & 1 & 7 \\
\hline Burkina Faso & 0 & 0 & 0 & 1 & 0 & 0 & 0 & 0 & 1 & 1 & 0 & 1 & 4 \\
\hline Burma & 0 & 0 & 0 & 1 & 0 & 0 & 0 & 0 & 1 & 1 & 1 & 1 & 5 \\
\hline Burumdi & 0 & 0 & 0 & 0 & 0 & 0 & 0 & 0 & 1 & 1 & 0 & 1 & 3 \\
\hline Cameroon & 0 & 0 & 0 & 1 & 0 & 0 & 0 & 0 & 1 & 1 & 0 & 1 & 4 \\
\hline Centr. Afr. Rep. & 0 & 0 & 0 & 1 & 0 & 0 & 0 & 0 & 1 & 1 & 0 & 1 & 4 \\
\hline Chad & 0 & 0 & 0 & 1 & 0 & 0 & 0 & 0 & 1 & 1 & 0 & 0 & 3 \\
\hline Chile & 0 & 0 & 1 & 0 & 0 & 0 & 0 & 0 & 1 & 1 & 0 & 1 & 4 \\
\hline China & 0 & 0 & 0 & 0 & 0 & 0 & 0 & 0 & $\mathbb{1}$ & 1 & 0 & 1 & 3 \\
\hline Colombia & 0 & 0 & 1 & 1 & 1 & 1 & 1 & 1 & 1 & 1 & 1 & 1 & 10 \\
\hline Congo & 0 & 0 & 0 & 1 & 0 & 0 & 0 & 0 & 1 & 1 & 0 & 1 & 4 \\
\hline Costa Rica & 0 & 0 & 0 & 1 & 1 & 0 & 0 & $\mathbb{1}$ & $\mathbb{1}$ & 1 & 0 & 1 & 6 \\
\hline Cyprus & 0 & 0 & 1 & 0 & 0 & 0 & 0 & 0 & 1 & $\mathbb{1}$ & 1 & 1 & 5 \\
\hline Domican Rep. & 0 & 0 & 1 & 1 & 1 & 0 & 0 & 1 & 1 & 1 & 1 & 1 & 8 \\
\hline Dominica & 0 & 0 & 0 & 0 & 0 & 0 & 0 & 0 & I & 1 & 0 & 0 & 2 \\
\hline Ecuador & 0 & 0 & 1 & 0 & 1 & 1 & 1 & 1 & 1 & 1 & 1 & 1. & 9 \\
\hline Egypt & 0 & 0 & 0 & 1 & 1 & 0 & 0 & 0 & 1 & 1 & 0 & 1 & 5 \\
\hline El Salvador & 0 & 0 & 0 & 1 & 1 & 0 & 0 & 1 & 1 & 1 & 1 & $\mathbb{1}$ & 7 \\
\hline Ethiopia & 0 & 0 & 0 & 0 & 1 & 0 & 0 & 0 & $\mathbb{1}$ & 1 & 0 & 1 & 4 \\
\hline Fiji & 0 & 0 & 0 & 0 & 0 & 0 & 0 & 0 & 1 & $\mathbb{1}$ & 0 & 1 & 3 \\
\hline Fremch Guinea & 0 & 0 & 0 & 0 & 0 & 0 & 0 & 0 & 1 & 1 & 0 & 0 & 2 \\
\hline Gabon & 0 & 0 & 0 & 0 & 0 & 0 & 0 & 0 & 1 & 1 & 0 & 0 & 2 \\
\hline Gambia & 0 & 0 & 0 & 0 & 0 & 0 & 0 & 0 & 1 & 1 & 0 & 0 & 2 \\
\hline Ghana & 0 & 0 & 0 & 1 & 0 & 0 & 0 & 0 & $\mathbb{1}$ & 1 & 0 & 1 & 4 \\
\hline Greece & 0 & 0 & 1 & $\downarrow$ & 1 & $\mathfrak{l}$ & $\mathbb{1}$ & 1 & 1 & 1 & 1 & 1 & 10 \\
\hline Gremada & 0 & 0 & 0 & 0 & 0 & 0 & 0 & 0 & 1 & 1 & 0 & 0 & 2 \\
\hline Guadelonpe & 0 & 0 & 0 & 0 & 0 & 0 & 0 & 0 & 1 & 1 & 0 & 0 & 2 \\
\hline Guatemala & 1 & 1 & 1 & 1 & $\mathbb{1}$ & 1 & 1 & 1 & 1 & 1 & 1 & 1 & 12 \\
\hline Guinea & 0 & 0 & 0 & 1 & 0 & 0 & 0 & 0 & 1 & 1 & 0 & 0 & 3 \\
\hline Guyyana. & 0 & 0 & 0 & 0 & 1 & 0 & 0 & 0 & 1 & 1. & 0 & 1 & 4 \\
\hline
\end{tabular}




\section{$\begin{array}{llllllllllllll}\mathrm{LU} & \mathrm{KV} & \mathrm{AB} & \mathrm{RI} & \mathrm{IG} & \mathrm{ACl} & \mathrm{AC} 2 & \mathrm{~B} & \mathrm{R} 21 & \mathrm{R} 22 & \mathrm{~K} & \mathrm{OD} & \mathrm{TOT}\end{array}$}

\begin{tabular}{|c|c|c|c|c|c|c|c|c|c|c|c|c|c|}
\hline Haiti & 0 & 0 & 0 & $\mathbb{1}$ & 0 & 0 & 0 & 0 & 1 & 1 & 0 & 1 & 4 \\
\hline Honduras & 1 & 1 & 1 & 1 & 1 & 1 & 1 & 0 & 1 & 1 & 1 & 1 & $\mathbb{1}$ \\
\hline Hong Kong & 0 & 0 & 0 & 1 & 0 & 0 & 0 & 0 & 1 & 1 & 0 & 0 & 3 \\
\hline Hungary & 0 & 0 & 0 & 0 & 0 & 0 & 0 & 0 & 1 & 1 & 0 & 1 & 3 \\
\hline India & 0 & 0 & 1 & 1 & 1 & 0 & 0 & 0 & 1 & 1 & 0 & ! & 6 \\
\hline Indonesia & 0 & 0 & 1 & I & $\mathbb{1}$ & 0 & 0 & 0 & 1 & 1 & 0 & 1 & 6 \\
\hline Iran & 0 & 0 & 0 & 0 & 1 & 0 & 0 & 1 & 1 & 1 & 0 & 1 & 5 \\
\hline Iraq & 0 & 0 & 1 & 1 & 0 & 0 & 0 & 0 & $\mathbb{1}$ & 0 & 0 & 0 & 3 \\
\hline Israel & 0 & 0 & 1 & 1 & 1 & 1 & 1 & 1 & 1 & 1 & 0 & 1 & 9 \\
\hline Ivory Coast & 0 & 0 & 0 & 1 & 0 & 0 & 0 & 0 & 1 & 1 & 0 & 1 & 4 \\
\hline Jamaica & 0 & 0 & 1 & 1 & 1 & 0 & 0 & 1 & 1 & 1 & 0 & 1 & 7 \\
\hline Jordan & 0 & 0 & 0 & 0 & 0 & 0 & 0 & 0 & 0 & 0 & 0 & 1 & 1 \\
\hline Kenya & 0 & 0 & 0 & 0 & 1 & 0 & 0 & 0 & 1 & 1 & 0 & 1 & 4 \\
\hline Korea & 0 & 0 & 1 & 0 & 1 & 1 & $\mathbb{1}$ & 0 & $\mathbb{1}$ & 1 & 1 & 1 & 8 \\
\hline Kuwait & 0 & 0 & 0 & 0 & 0 & 0 & 0 & 0 & 1 & 1 & 0 & 1 & 3 \\
\hline Lebanon & 0 & 0 & 0 & 0 & 0 & 0 & 0 & 0 & 1 & 0 & 0 & 0 & 1 \\
\hline Lesotho & 0 & 0 & 0 & 0 & 0 & 0 & 0 & 0 & 1 & 1 & 0 & 0 & 2 \\
\hline Liberia & 0 & 0 & 0 & 1 & 0 & 0 & 0 & 0 & 1 & 1 & 0 & 1 & 4 \\
\hline Libya & 0 & 0 & 0 & 1 & 0 & 0 & 0 & 0 & 1 & 1 & 0 & I & 4 \\
\hline Madagascar & 0 & 0 & 0 & 0 & 0 & 0 & 0 & 0 & 1 & 1 & 0 & 1 & 3 \\
\hline Malawi & 0 & 0 & 0 & 0 & 0 & 0 & 0 & 0 & 1 & 1 & 0 & 1 & 3 \\
\hline Malaysia & 0 & 0 & 0 & 1 & 0 & 0 & 0 & 0 & 1 & 1 & 0 & 1 & 4 \\
\hline Mali & 0 & 0 & 0 & 1 & $a$ & 0 & 0 & 0 & 0 & 0 & 0 & 0 & 1 \\
\hline Malta & 0 & 0 & 0 & 0 & 0 & 0 & 0 & 0 & 1 & 1 & 0 & 1 & 3 \\
\hline Martinique & 0 & 0 & 0 & 0 & 0 & 0 & 0 & 0 & 1 & 1 & 0 & 0 & 2 \\
\hline Mauritania & 0 & 0 & 0 & 1 & 0 & 0 & 0 & 0 & 1 & 1 & 0 & 0 & 3 \\
\hline Mauritius & $\theta$ & 0 & 0 & 0 & 0 & 0 & 0 & 0 & 1 & 1 & 0 & 1 & 3 \\
\hline Mexico & 0 & 0 & 1 & 1 & 1 & 1 & 1 & 1 & 1 & 1 & 1 & 1 & 10 \\
\hline Morocco & 0 & 0 & 1 & 1 & 1 & 0 & 0 & 0 & 1 & I & 0 & 1 & 6 \\
\hline Nepal & 0 & 0 & 0 & 0 & 0 & 0 & 0 & 0 & 1 & I & 0 & 1 & 3 \\
\hline Neth. Antulles & 0 & 0 & 0 & 0 & 0 & 0 & 0 & 0 & 1 & 1 & 0 & 0 & 2 \\
\hline Nicaragua & 0 & 0 & 0 & 1 & 0 & 0 & 0 & 1 & 1 & 1 & 0 & 1 & 5 \\
\hline Niger & 0 & 0 & 0 & 1 & 0 & 0 & 0 & 0 & 1 & $\mathbb{1}$ & 0 & 1 & 4 \\
\hline Nigeria & 0 & 0 & 1 & 1 & 1 & 0 & 0 & 0 & 1 & 1 & 0 & 1 & 6 \\
\hline Oman & 0 & 0 & 0 & 0 & 0 & 0 & 0 & 0 & 1 & $\mathbb{1}$ & 0 & 0 & 2 \\
\hline Pakistan & 0 & 0 & 1 & 1 & $\mathbb{1}$ & a & 0 & 0 & 1 & 1 & 0 & 1 & 6 \\
\hline Panama & 0 & 0 & 0 & 1 & 0 & 1 & 1 & 1 & 1 & 1 & 1 & 1 & 8 \\
\hline Papua $\mathrm{N}$. Guinea & 0 & 0 & 0 & 1 & 0 & 0 & 0 & 0 & 1 & 1 & 0 & 1 & 4 \\
\hline Paraguay & 1 & 1 & 1 & 1 & 1 & 1 & 1 & 0 & 1 & 1 & 1 & $\mathbb{1}$ & 11 \\
\hline Peru & 0 & 0 & I & 1 & 1 & 0 & 0 & 1 & 1 & $\mathbb{1}$ & 0 & 1 & 7 \\
\hline Philippines & 0 & 0 & 1 & $\mathbb{1}$ & 1. & 0 & 0 & l & 1 & 1 & 1 & 1 & 8 \\
\hline Portugal & 9 & 0 & 1 & 1 & 1 & 1 & 1 & 1 & l & 1 & 0 & 1 & 9 \\
\hline Puerto Rico & 1 & 1 & 1 & 0 & 0 & 0 & 0 & 0 & 0 & 0 & 0 & 0 & 3 \\
\hline Rwanda & 0 & 0 & 0 & 0 & 0 & 0 & 0 & 0 & $\mathbb{1}$ & 1 & 0 & $\mathbb{1}$ & 3 \\
\hline Saudi Arabia & 0 & 0 & 0 & 0 & 0 & 0 & 0 & 0 & 1 & 1 & 0 & 1 & 3 \\
\hline Senegal & 0 & 0 & 0 & 1 & 0 & 0 & 0 & 0 & 1 & 1 & 0 & 1 & 4 \\
\hline
\end{tabular}




\section{$\begin{array}{llllllllllll}\mathrm{LU} & \mathrm{KB} & \mathrm{R} 1 & \mathrm{JG} & \mathrm{ACl} & \mathrm{AC} 2 & \mathrm{~B} & \mathrm{R} 21 & \mathrm{R} 22 & \mathrm{~K} & \mathrm{OD} & \mathrm{TOT}\end{array}$}

$\begin{array}{llllllllllllll}\text { Seychelles } & 0 & 0 & 0 & 0 & 0 & 0 & 0 & 0 & 1 & 1 & 0 & 0 & 2 \\ \text { Sierra Leone } & 0 & 0 & 0 & 0 & 0 & 0 & 0 & 0 & 1 & 1 & 0 & 1 & 3 \\ \text { Singapore } & 0 & 0 & 0 & 1 & 0 & 0 & 0 & 1 & 1 & 1 & 0 & 1 & 5 \\ \text { Solomon Islands } & 0 & 0 & 0 & 0 & 0 & 0 & 0 & 0 & 1 & 1 & 0 & 0 & 2 \\ \text { Somalia } & 0 & 0 & 0 & 0 & 0 & 0 & 0 & 0 & 1 & 1 & 0 & 0 & 2 \\ \text { Soutli Africa } & 0 & 0 & 0 & 0 & 1 & 1 & 1 & 1 & 1 & 1 & 1 & 1 & 8 \\ \text { Srí Lankat } & 0 & 0 & 1 & 1 & 1 & 1 & 1 & 0 & 1 & 1 & 1 & 1 & 9 \\ \text { St. Kitts-Nevis } & 0 & 0 & 0 & 0 & 0 & 0 & 0 & 0 & 1 & 1 & 0 & 0 & 2 \\ \text { Sit. Lucia } & 0 & 0 & 0 & 0 & 0 & 0 & 0 & 0 & 1 & 1 & 0 & 1 & 3 \\ \text { St. Vincent } & 0 & 0 & 0 & 0 & 0 & 0 & 0 & 0 & 1 & 1 & 0 & 1 & 3 \\ \text { Sudan } & 0 & 0 & 0 & 0 & 0 & 0 & 0 & 0 & 1 & 1 & 0 & 0 & 2 \\ \text { Swaziland } & 0 & 0 & 0 & 0 & 0 & 0 & 0 & 0 & 1 & 1 & 0 & 0 & 2 \\ \text { Syria } & 0 & 0 & 0 & 1 & 0 & 0 & 0 & 0 & 1 & 1 & 0 & 1 & 4 \\ \text { Taiwan } & 0 & 0 & 1 & 1 & 1 & 0 & 0 & 0 & 0 & 0 & 0 & 0 & 3 \\ \text { Tarnzania } & 0 & 0 & 0 & 0 & 0 & 0 & 0 & 0 & 1 & 1 & 0 & 1 & 3 \\ \text { Thailand } & 0 & 0 & 1 & 1 & 1 & 1 & 1 & 0 & 1 & 1 & 1 & 1 & 9 \\ \text { Togo } & 0 & 0 & 0 & 1 & 0 & 0 & 0 & 0 & 1 & 1 & 0 & 1 & 4 \\ \text { Trinidad } & & & & & & & & & & & & & \end{array}$

Trinidad and

Tobago

Tunisia

"Turkey

Uganda

United Arab

Emirates

Uruguay

Virgin Islands

Venezuela

West Samoa

Yemen

Yugoslavia

Zaire

Zambia

$\begin{array}{lll}0 & 0 & 0 \\ 0 & 0 & 0 \\ 0 & 0 & 1 \\ 0 & 0 & 0\end{array}$

$\begin{array}{lll}0 & 0 & 0 \\ 1 & 0 & 0 \\ 1 & 1 & 1 \\ 0 & 0 & 0\end{array}$

Zimbabwe

$\begin{array}{lllll}0 & 0 & 0 & 0 & 0 \\ 0 & 0 & 1 & 1 & 1\end{array}$

\begin{tabular}{llllllll}
0 & 0 & 0 & 0 & 0 & 0 & 1 & 1 \\
0 & 0 & 0 & 1 & 1 & 0 & 1 & 6 \\
0 & 0 & 0 & 1 & 1 & 0 & 0 & 2 \\
1 & 1 & 1 & 1 & 1 & 1 & 1 & 12 \\
0 & 0 & 0 & 0 & 0 & 0 & 1 & 1 \\
0 & 0 & 0 & 0 & 0 & 0 & 1 & 1 \\
0 & 0 & 0 & 1 & 1 & 0 & 1 & 4 \\
0 & 0 & 1 & 1 & 1 & 0 & 1 & 4 \\
0 & 0 & 0 & 1 & 1 & 0 & 1 & 3 \\
0 & 0 & 0 & 1 & 1 & 0 & 1 & 3 \\
\hline
\end{tabular}

$\begin{array}{lllllllllllll}6 & 6 & 31 & 60 & 37 & 16 & 16 & 24 & 113 & 110 & 20 & 90 & 529\end{array}$

Notes: 1 denotes that a country is included in a study; 0 denotes that it is not included. $L U \equiv$ Lucas (1973); $\mathrm{KV}=$ Koskela and Viren (1980); $\mathrm{AB}=\mathrm{Alberro}(1981) ; \mathrm{R} 1=\mathrm{Ram}(1984) ; \mathrm{JG}=$ Jung (1985); $\mathrm{ACl}=$ Addlison et all (1986), 1955-1966; $\mathrm{AC2}=$ Addison et al. (1986), 1967-1980; $\mathrm{B}$ - Ball et al. (1988), R21 = Ram (1990), 1960-1973; R22 = Ram (1990), 1973-1986; K = Katsimbris (1990); $\mathrm{OD}=$ Odedakun (1991); and TOT states how may studies include a specific country. 


\section{The Effects of Systematic Policy in a Price Stickiness Model: The Alogoskoufis Model Revisited}

\subsection{Introduction}

In the flexible price, misperception model that lies behind chapters 3 and 4 , aggregate demand policy can only affect output by aggregate demand shocks, and thus only unexpected or unsystematic policy can influence the real economy. The empirical evidence of chapter 3 , however, shows that systematic policy can influence output growth as the expected terms of trade significantly affect economic growth in the United States, and expected nominal demand growth significantly influences economic growth in Germany (see Tables 3.5 and 3.6 respectively). This conclusion is supported by other empirical evidence (see section 3.1 for the references).

An explanation for this result may be that prices are to some degree sticky, instead of purely flexible as in the price misperception models. If prices are sticky, then systematic policy can affect economic growth. However, there are only a few models that show how changes in systematic policy, for example changes in the rules for adjusting money supply or the exchange rate, affect output and inflation. Models that do show such effects are the price stickiness models of Dornbusch (1982), Parkin (1986), Alogoskoufis and Smith (1991), and Alogoskoufis (1992). A closer look to these models can explain why changes in systematic policy have real effects and how these are transmitted. Furthermore, this can show how inflation is affected by changes in systematic policy.

Of these four models, this chapter concentrates on the Alogoskoufis and Smith (1991), and the Alogoskoufis (1992) models. The reasons for this choice are twofold. First, to investigate the effects of a change in the degree of exchange rate accommodation on output and inflation, a two-country model should be used instead of a one-country model because in an international setting, one should focus on the question whether the persistence of relative inflation clianges, not whether the persistence of inflation in one country changes. Dornbusch (1982), however, investigates the effects of a change in systematic exchange rate policy in a one-country whereas Alogoskoufis and Smith (1991) and Alogoskoufis (1992) use a two-country models. Second, a change in systematic monetary policy affects the persistence of average inflation, and a change in systematic exchange rate policy the persistence of relative inflation. Dornbusch (1982) shows only the latter relation whereas 
Parkin (1986) does not show even one of these relations. Alogoskoufis and Smith (1991) and Alogoskoufis (1992) do show both relations.

Nevertheless, three remarks must be made with respect to Alogoskoufis and Smith (1991) and Alogoskoufis (1992). First, they do not pay attention to the transmission channels in their models. If they had done this, this would have helped to understand the transmission of systematic policy. A close examination of their models shows that there are three transmission channels: the real exchange rate channel, the real interest rate channel, and the wage cost channel. According to the real exchange rate channel a higher degree of exchange rate accommodation increases relative economic growth, but this comes at the cost of increased persistence of inflation. Second, the real interest rate channel states that a higher degree of monetary (exchange rate) accommodation also increases economic growth at the cost of a higher persistence of average (relative) inflation. Third, the wage cost channel states that a higher degree of exchange rate accommodation increases the impact of the wage rate on prices and reduces the persistence of relative inflation. Note that systematic monetary policy changes are transmitted only through the real interest rate channel whereas systematic exchange rate policy changes are also transmitted through the other two channels.

Second, comparison of Alogoskoufis and Smith (1991) and Alogoskoufis (1992) with Dornbusch (1982) shows a crucial difference. Whereas Dornbusch (1982) finds that the relation between the persistence of inflation and the degree of exchange rate accommodation is not strictly positive, Alogoskoufis and Smith (1991) and Alogoskoufis (1992) suggest that it is strictly positive. In Dornbusch (1982) this is due to the fact that the increase in inflation persistence through the real exchange rate channel may be dominated by the decrease in persistence due to the wage cost channel. Recalculation of the models of Alogoskoufis and Smith (1991) and Alogoskoufis (1992), however, shows that they make a serious mistake in their derivations. If these mistakes are corrected, then the relation between the persistence of relative inflation and the degree of exchange rate accommodation is also not strictly positive, as in Dornbusch (1982).

Third, Alogoskoufis and Smith (1991) and Alogoskoufis (1992) do not show the output effects of changes in systematic policies. The explanation therefore is that these models cannot be solved for output growth. A graphical analysis, however, can provide these effeets.

The purpose of this chapter is to provide the correct solutions for the Alogoskoufis and Smith (1991) and Alogoskoufis (1992) models, to show how a change in systematic policy affects output growth by way of a graphical analysis, to derive the effects of a change in systematic monetary and exchange rate policy on the persistence of average and relative inflation respectively, and to explain why the relation between the persistence of relative inflation and the degree of exchange rate accommodation is not strictly positive given the transmission mechanisms. It is found that, similar to Dornbusch (1982), this link can be negative if the effect of a 
change on the persistence of relative inflation via the wage cost channel dominates the effect via the real exchange rate channel and the real interest rate channel.

This chapter is arranged as follows. Section 5.2 analyses the Alogoskoufis-Smith (1991) model, starting with the basic model. In order to show the consequences of varying the degree monetary accommodation for output and inflation, the model is solved as an average model in section 5.3. Section 5.4 concentrates on the effects of changing the degree of exchange rate accommodation; therefore the basic model is solved as a relative model. Section 5.5 briefly compares the slightly different model in Alogoskoufis (1992) with Alogoskoufis and Smith (1991). As the theoretical results for the average and the relative model of Alogoskoufis (1992) are comparable, these have been omitted from the main text. They are available in appendices $5 \mathrm{D}$ and $5 \mathrm{E}$ for the interested reader. The conclusions are reported in section 5.6 .

\subsection{Alogoskoufis-Smith (1991) model}

To clarify the Alogoskoufis-Smith (1991) model, the demand for goods is explained in section 5.2.1, the price-setting behaviour of firms in section 5.2.2, the demand for money and the supply of money in sections 5.2.3 and 5.2.4 respectively, and the demand for labour and the supply of labour in sections 5.2.5 and 5.2.6 respectively. Given the prices that firms set for their products, aggregate demand determines output. Furthermore in the money market and the international bonds market supply and demand are equal. And finally the employment level is determined in the labour market by labour demand. These equilibrium conditions are mentioned in section 5.2.7. Note that the whole model is stated in terms of first differences compared to Alogoskoufis and Smith (1991). This has the advantage that the model become clearer; especially the monetary policy rule becomes more intuitive. As a result, the model changes only slightly: first, a change in systematic policy now has symmetric instead of asymmetric effects on output growth (see appendix 5A); second, the interpretation of the shocks changes: whereas the shocks were assumed to behave like random walks with drift in the presentation of Alogoskoufis and Smith (1991), taking first differences of all equations make the shocks white noise terms. ${ }^{2}$

1 To save space only the basic equations for country $j$ are reported; the same modlel holds for country $h$. In that case $j$ and $h$ are rewersed.

2 Consider for example a demand shock $\tau_{j, t}$. In the model of Alogoskoufis and Smith (1991) it is assumed to behave like a random walk with drift. Thus: $\tau_{j, t}=\tau_{j, t-1}+c+f_{1}$, where $c$ is the drift term and $f_{t}$ a white noise term. If the equations in the Alogoskoufis and Smith (1991) model are differenced, the shocks must be differenced too. The new demand shock, $v_{j, t}$, is simply delined as: $v_{j, r}=\tau_{j, t}-\tau_{j, r-1}=c+f_{r}$. We interpret $c$ as the intercept in the real demand for goods; this intercept is nonmalized to zero. Thus the shocks in our model are white noise terms. 


\subsubsection{The demand for goods}

The real aggregate demand equation is based on the national income identity. Suppose that consumption as well as investment depends on the real interest rate, and on real income, government expenditures are exogenous, and the current account depends on the real exchange rate and domestic real income. Then, the growth rate of aggregate real demand in country $j, \Delta y_{j, t}^{d}$, is of the form: ${ }^{3}$

$$
\begin{gathered}
\Delta y_{j, t}^{d}=-\alpha\left(\Delta i_{j, t}-E_{t} \Delta p_{j, t+1}+\Delta p_{j, t}\right)+\beta\left(\Delta e_{j h, t}+\Delta p_{t, t}-\Delta p_{j, t}\right)+v_{j, t}, \\
\alpha, \beta>0,
\end{gathered}
$$

where $\Delta i_{j, t}$ is the change in nominal interest rate in country $j, \Delta p_{j, t}$ the inflation rate in country $j, \Delta e_{j h, t}$ the change in the nominal exchange rate between country $j$ and $h$ (in units of country $j$ per unit of country $h$ ), $v_{j, t}$ a white noise aggregate demand shock in country $j$, and $E$ the expectations operator. The higher the real interest rate, the more attractive it is for consumers to save and the less attractive it is for firms to invest. Consequently, an increase in the real interest rate will lower real demand for goods. If the real exchange rate for country $j$ depreciates, it is more profitable to export and less profitable to import. Thus, a real exchange rate depreciation increases the real demand for goods in country $j$.

\subsubsection{Price-setting behaviour of firms}

It is assumed that prices are sticky because firms have to make costs if they want to adjust their prices. ${ }^{4}$ These costs of changing prices depend on the size of the deviation of the firm's product price from the firm's optimal price level, and on the cost of market response. ${ }^{5,6}$ The more the firm's price deviates from this optimal price, the lower profits are, and the more costly this deviation is. These costs can be lowered by adjusting the firm's price towards the optimal price level. However, the

3 Note that all variables are stated in natural logs except for the nominal interest rates $\left(i_{j, t}\right.$ and $\left.i_{h_{i}, l}\right)$, and the real interest rates $\left(r_{\eta_{1},}\right.$ and $\left.r_{h_{1},}\right)$.

4 In the Alogoskoufis (1992) model price stickiness is introduced by assuming staggered wages (see section 2.6.2) instead of price adjustment costs as in Alogoskoufis and Smith (1991). This is the only point on which both models differ (see section 5.5).

5 The costs of market response are the costs that accrue from the reactions of customers and other suppliers due to changes of the supply price of the firm (see section 2.6.1).

6 The optimal price is the price that would prevail if there were no price-adjustment costs and firms maximize their profits. Alogoskoufis and Smith assume that these optimal prices are equal to a constant mark-up over unit labour costs (see appendix 5A). 
larger the price change is, the more customers switch between suppliers and the more aggressive is competition, and thus the larger the costs of market response are. Thus firms have to make an optimal choice between both costs.

To calculate the optimal pricing policy, the adjustment costs must be minimized over time. Therefore an intertemporal loss function is constructed in which the deviation of the firm's price from its optimal price is given a unit weight and the costs of market response a weight $\theta$ (see appendix $5 \mathrm{~A}$ ). This weight $\theta$ measures the marginal costs of deviating from the optimal price relative to the costs of market response. The current and future price adjustment costs are discounted at the discount rate $\lambda$. Optimizing the intertemporal loss function over time and aggregating the inflation-equation over all firms, which are assumed to be identical, the following second-order stochastic difference equation results for country $j$ :

$$
\begin{gathered}
E_{t} \Delta p_{j, t+1}-\frac{1+\theta(1+\lambda)}{\lambda \theta} \Delta p_{j, t}+\frac{1}{\lambda} \Delta p_{j, t-1}=-\frac{1}{\lambda \theta}\left(\Delta w_{j, t}-\Delta q_{j, \theta}\right), \\
\theta>0, \quad 0<\lambda<1,
\end{gathered}
$$

where $\Delta w_{j, t}$ is nominal wage growth and $\Delta q_{j, t}$ the change in labour productivity. In the case that there are no price-adjustment costs, that is if $\theta=0$, the standard pricing formula of a constant mark-up over unit labour costs results. Given the aggregate price level, the aggregate demand equation determines how much is produced. $^{7}$

\subsubsection{The demand for money}

The real money demand growth, $\Delta m_{j, t}{ }^{d}-\Delta p_{j, t}$, depends upon the change in real income, $\Delta y_{j, r}$, the change in the nominal interest rate, $\Delta i_{j, r}$, and a white noise aggregate money demand shock in country $j, k_{f, t}$ :

$$
\Delta m_{j, t}^{d}-\Delta p_{j, t}=\Delta y_{j, t}-\gamma \Delta i_{j, t}+k_{j, t} \quad \gamma>0
$$

where $\gamma$ represents the interest rate elasticity of real money demand. According to equation (5.3), real money demand growth rises in a one-to-one relation with real income growth, and falls by a coefficient $\gamma$ if the nominal interest rises.

Implicitly it is assumed that there are no inventories of produced goods and that the production capacity is sufficient to produce the amount of goods demanded. 


\subsubsection{The supply of money}

In general, in a two-country model the supply of money in one country can be dependent oi independent with respect to the money supply in the other country. If both monetary policies are fully independent, money supply is specified for each country separately. Then the relative supply of money determines the exchange rate. In this model, however, both monetary policies are dependent. This dependency can be modelled asymmetrically and symmetrically. In the case of an asymmetric monetary policy rulle, the leader determines its own monetary policy and the follower pegs its exchange rate and lets its money stock growth at the same rate as that of the leader. In the case of a symmetric monetary policy rule, both countries coordinate monetary policy decisions. First, they decide how large world money growth should be. Then, this growth is divided between both countries by their exchange rate policy.

In this model the monetary policy is symmetric. ${ }^{8}$ More specifically, the monetary policy rule states that growth of world money supply, $\Delta m_{j, t}{ }^{8}+\Delta m_{h, s}{ }^{8}$, is determined by average world inflation, $\Delta p_{j, t}+\Delta p_{h, t}$, and an exogenous component of monetary accommodation, $\mu_{t}$ :

$$
\Delta m_{j, t}^{s}+\Delta m_{h, t}^{s}=\psi\left(\Delta p_{j, s}+\Delta p_{h, s}\right)+\mu_{t} \quad 0 \leq \psi \leq 1
$$

where $\psi$ is the degree of monetary accommodation. How large this monetary accommodation must be, is decided by the monetary authorities of countries $j$ and $h$. It is assumed that the upper limit for the degree of monetary accommodation is unity to exclude hyperinflation policies.

Compared to the original monetary accommodation equation in Alogoskoufis and Smith (1991), equation (5.4) is stated in first differences. This has the advantage that growth rates are added on both sides of equation (5.4); however, if the model would be stated instead in levels, then on the left-hand side of equation (5.4) the log of money supply in country $j$ and the log of money supply in country $h$ are summed. The disadvantage of the latter is that it this sum is hard to interpret.

Nevertheless, two comments should be made. First, world money supply as well as world inflation in equation (5.4) ought to be measured in a common unit and therefore the bilateral exchange rate should be added. However, as long as the bilateral exchange rate between country $j$ and $h$ does not change much, equation

\footnotetext{
* In fact the distinction between symmetric and asymmetric international monetary regimes is not important in this model. Whether or not the international monetary regime is symmetric or asymmetric only matters if the degree of accommodation is different under symmetric and asymmetric regimes (see Alogoskoufis (1992), footnote 4).
} 
(5.4) is an appropriate approximation. ${ }^{9}$ Second, a lag in the response of world money supply to changes in the world inflation rate would be more appropriate; this would take into account the time needed to coordinate monetary policies.

As monetary policies are coordinated according to equation (5.4), the growth in world money stock must be divided between country $j$ and $h$. Therefore relative monetary policies are expressed by exchange rate policy; more specifically it is assumed that monetary authorities decide on the degree to which the exchange rate is adjusted to the inflation differrential:

$$
\Delta e_{j h, t}=\phi\left(\Delta p_{j, t}-\Delta p_{h, s}\right) \quad 0 \leq \phi \leq 1,
$$

where $\phi$ represents the degree of exchange rate accommodation. The central banks of countries $j$ and $h$ determine jointly how large this exchange rate accommodation will be. If they choose a flexible exchange rate regime, the degree of exchange rate accommodation will be between zero and unity; if they opt for a fixed exchange rate regime the degree of exchange rate accommodation is equal to zero. Alternatively, relative monetary policy could in principle be expressed by assuming a different degree of monetary accommodation for each country; however, in that case the average as well as the relative model cannot be solved anymore. Therefore, this alternative was not chosen.

\subsubsection{The demand for labour}

The change in the demand for labour, $\Delta l_{j, t}^{d}$, is assumed to be proportional to the change in output:

$$
\Delta l_{j, t}^{d t}=\Delta y_{j, d}-\Delta q_{j, s} .
$$

Equation (5.6) implies that all labour demand is employed in the production of goods. Thus, there is no labour hoarding and consequently hiring and firing costs are neglected.

The wage rate demanded by employees is determined by the search theory of unemployment (see Mortensen, 1970): ${ }^{10}$

\footnotetext{
Furthermore, it is not desirable to include the change in the exchange rate because this would introduce relative inflation in the average model; consequently, the average model cannot be solved anymore.

10 The change in labour supply minus the change in labour demand, $\Delta l_{j, t}^{*}-\Delta l_{j, t}^{d}$, approximates the change in rate of unemployment.
} 


$$
\begin{gathered}
\Delta w_{j, t}=E_{r-1}\left[\delta \Delta p_{j, r}+(1-\delta)\left(\Delta e_{j h, t}+\Delta p_{h, j}\right)-\varepsilon\left(\Delta l_{j, s}^{s}-\Delta l_{j, s}^{\alpha}\right)\right]+\Delta \omega_{j, r}, \\
0<\delta<1, \varepsilon>0,
\end{gathered}
$$

where $\varepsilon$ is the response of real wage to a change in unemployment, $\Delta l_{j, r}^{s}$ the change in labour supply, and $\Delta \omega_{j, t}$ an exogenous real wage growth target. According to equation (5.7) wages rise in line with expected consumer price inflation and with the real wage growth target. If unemployment is higher, this will lower wage inflation. Note that the wage demanded by employees is set given the expected demand for labour and thus given the expected output; output, however, is determined given the prices set by firms. These prices, in turn are set given the wage level (see equation (5.2)). Thus, the ultimate solution for output and unemployment should be determined by an iterative interaction between the goods market and the llabour market.

\subsubsection{The supply of labour}

Finally the change in the supply of labour supply is assumed to be exogenous:

$$
\Delta l_{j, t}^{s}=\Delta n_{j, t}
$$

\subsubsection{Equilibrium conditions}

The equilibrium conditions for this model are:

$$
\begin{gathered}
\Delta y_{g, t}=\Delta y_{g, t}^{d} \quad g=j, h, \\
\Delta m_{j, t}^{d}+\Delta m_{h, t}^{d}=\Delta m_{j, t}^{d}+\Delta m_{h, t}^{s}=\Delta m_{j, t}+\Delta m_{h, t}, \\
\Delta l_{g, t}=\Delta l_{g, t}^{d} \quad g=j, h, \\
\Delta j_{j, t}=\Delta i_{h, t}+E_{t} \Delta e_{j h, t+1}-\Delta e_{j h, t} .
\end{gathered}
$$

Equation (5.9) shows that aggregate output is equal to aggregate demand in countries $j$ and $h$. Next, in equation (5.10), the world money market is assumed to clear. The intuition behind this equation is that the central banks of countries $j$ and $h$ jointly set world money supply. This world money supply is distributed over countries $j$ and $h$ under the condition that the sum of money demand in countries $j$ and $h$ is equal to the world money supply. If for example the money supply in country $j$ is higher than money demand, the interest rate will fall in country $j$, and money will flow to country $h$ as long as money supply and money demand are unequal in 
country $j$. This capital mobility is assumed to take place so fast that money markets will clear in both countries. Furthermore, the change in employment, $\Delta l_{g, t}$, is determined by the change in labour demand (equation (5.11)). Finally, the international bond market equilibrium is represented by an uncovered interest parity condition in equation (5.12).

The model for country $j$ consists of equations (5.1) to (5.12); that for country $h$ can be obtained by replacing $j$ by $h$ and vice versa. This two-country model can be solved as an average model (section 5.3), and as a relative model (section 5.4). The average model focuses on the effects of monetary accommodation for output growth and inflation on the world level; thus, no distinction is made between both countries. The relative model, in the contrary, concentrates on the impact of exchange rate accommodation for relative output growth and inflation; consequently it tries to explain differences in, for example, output growth and inflation between both countries. In the average model a change in monetary accommodation is transmitted through the real interest rate channel; in the relative model a change in exchange rate accommodation is transmitted through the real exchange rate channel and the wage cost channel also.

\subsection{Average model}

In this section the basic model of section 5.2 is solved as an average model. Therefore equations (5.1) to (5.8) are averaged over countries $j$ and $h$ and the equilibrium conditions (5.9) to (5.12) are assumed hold. This gives the following set of equations in terms of average variables: ${ }^{11}$

1 Assuming that countries $j$ and $h$ are exact symmetrical, awerage output growth $\Delta \bar{y}$, is defined as $\left(\Delta y_{j, t}+\Delta y_{h_{t},}\right) / 2$ and this holds for all other average variables except for $\bar{\mu}_{t}$ that is defined as $\mu_{t} / 2$. Note that $\Delta e_{j h, t}=-\Delta e_{h, i, t}$ and that the average of equation (5.5) drops out. 


$$
\begin{gathered}
\Delta \bar{y}_{t}=-\alpha\left(\Delta \bar{y}_{t}-E_{t} \Delta \bar{p}_{t+1}+\Delta \bar{p}_{t}\right)+\bar{v}_{t}, \\
E_{t} \Delta \bar{p}_{t+1}-\frac{1+\theta(1+\lambda)}{\lambda \theta} \Delta \bar{p}_{t}+\frac{1}{\lambda} \Delta \bar{p}_{t+1}=-\frac{1}{\lambda \theta}\left(\Delta \bar{w}_{t}-\Delta \bar{q}_{t}\right), \\
\Delta \bar{m}_{t}-\Delta \bar{p}_{t}=\Delta \bar{y}_{t}-\gamma \Delta \overline{\bar{t}}_{t}+\bar{k}_{t}, \\
\Delta \bar{m}_{t}=\psi \Delta \bar{p}_{t}+\bar{\mu}_{t}, \\
\Delta \bar{l}_{t}=\Delta \bar{y}_{t}-\Delta \bar{q}_{t}, \\
\Delta \bar{w}_{t}=E_{t-1}\left[\Delta \bar{p}_{t}-\varepsilon\left(\Delta \bar{n}_{t}-\Delta \bar{l}_{t}\right)\right]+\Delta \bar{\omega}_{t} .
\end{gathered}
$$

Equation (5.13) represents the goods market equilibrium, or $I S$ curve. The average real interest rate in equation $(5.13)$ represents the real interest rate channel. Then the money market equilibrium, or $L M$ curve, is defined by equations (5.15) and (5.16). The link between inflation and unemployment is provided by substituting (5.18) into (5.14). Finally, equation (5.17) represents the link between unemployment and economic growth as labour supply growth is exogenous.

A formal solution for output and unemployment, however, cannot be obtained because of the quadratic nature of the price adjustment cost equation (5.14). Therefore, a graphical analysis is performed to understand the output effects of a change in systematic monetary policy. In Figure 5.1 the $I S$ curve, the $L M$ curve, the link between average economic growth and average employment, as well as the inflation-unemployment trade-off $(I U)$ are drawn. Note that the trade-off between inflation and unemployment is shown as a linear curve. This is due to the fact that the loss function that lies behind equation (5.14) is symmetric, that is, firms adjust their pricing policy to the same extent in case of a decrease and an increase in demand (see appendix 5A).

The effects of a change in systematic monetary policy can be analysed with Figure 5.1. Suppose that the average real interest rate, $\Delta \bar{r}$, is initially $\Delta \bar{r}_{0}$, average output growth $\Delta \bar{y}_{0}$, and average inflation $\Delta \bar{p}_{0}$. Then an increase in the degree of monetary rate accommodation causes an increase in the real money supply growth and thus decreases the average real interest rate to $\Delta \bar{r}_{1}$ as the $L M$ curve shifts outward to $\mathrm{LM}^{\prime}$. Consequently, average real economic growth increases to $\Delta \bar{y}_{1}$ and unemployment decreases to $\Delta \bar{u}_{1}$. This lower average unemployment rate raises average inflation to $\Delta \bar{p}_{1}$. This decreases real money supply growth, and thus the $L M$ curve shifts back to, for example, $L M^{\prime \prime}$. Furthermore, the higher degree of monetary accommodation increases expected inflation. Therefore, the inflationunemployment trade-off, $I U$, shifts outwards to $I U^{r}$. This increases average inflation 
to $\Delta \bar{p}_{2}$ and therefore shifts the $L M$ curve even further to the left. In the end, average inflation fully adjusts to the new degree of monetary accommodation; consequently, average output growth, average unemployment, and the average real interest rates return to the original rates $\Delta \bar{y}_{0}, \Delta \bar{u}_{0}$, and $\Delta \bar{r}_{0}$; inflation, however, ends up higher at, for example, $\Delta \bar{p}_{3}$.

Besides an increase in systematic monetary policy, also the effects of shocks in, for example, goods demand, $\bar{v}_{t}$, money demand, $\bar{k}_{t}$, and money supply, $\vec{\mu}_{t}$, can be analysed using Figure 5.1. A positive shock in the aggregate demand for goods, shifts the $I S$ curve to the right, increases the average real interest rate, the average output growth, as well as the average rate of inflation; for a negative shock in aggregate demand for goods the effects are reverse. A negative money demand or a positive money supply shock shifts the $L M$ curve downward, and thus decreases the average real interest rate, but increases average economic growth as well as average inflation; the effects for a positve money demand or a negative money supply supply are exactly the opposite.

From this analysis of a change in systematic monetary policy, several properties of the average model become clear. First of all, a change in systematic monetary policy has real effects in the short run, but not in the long run. This is due to the fact that prices are sticky in the short run. Second, the shape of the inflation-unemployment trade-off is linear. This implies that a decrease in the degree of monetary accommodation has the same effects on average economic growth as an increase. Thus, systematic monetary policy has symmetric effects on economic growth. Note that this symmetric effect is a result of the transformation of the Alogoskoufis and Smith (1991) to first differences. This transformation makes the loss-function symmetric (see appendix 5A); consequently, the shape of the inflation-unemployment trade-off is linear. If the loss-function would be stated in levels, then systematic policy has asymmetric effects on output growth. Third, even if the change in systematic policy is expected, it will have real effects as long as prices do not have the opportunity to adjust. Finally, a change in systematic monetary policy has persistent effects on real economic growth, that is, a change in the degree of monetary accommodation not only affects real economic growth in the period when this change is made, but also in later periods. 


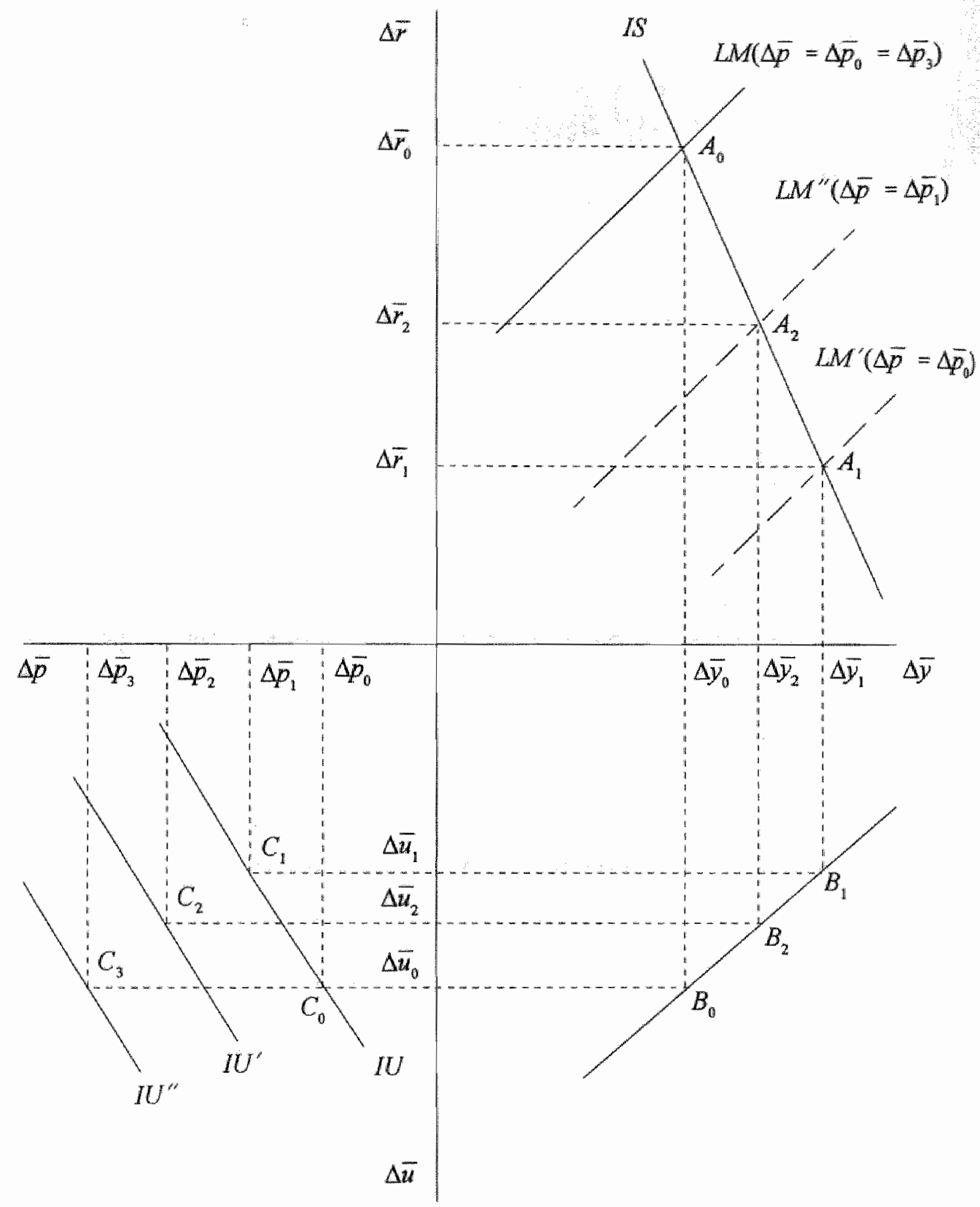

Figure 5.1 Output effects of a change in systematic monetary policy in the average Alogoskoufis-Smith (1991) model 
Besides these effects on average real output growth, a change in the degree of monetary accommodation also influences average inflation. For that purpose model (5.13)-(5.18) must be simplified. This gives a second order stochastic difference equation in terms of average inflation (see appendix $5 \mathrm{~B}$ ): $:^{13,13}$

$$
\left[F^{2}-\left(\rho_{1}+\rho_{2}\right) F+\rho_{1} \rho_{2}\right] L E_{t-1} \Delta \bar{p}_{t}=0
$$

with

$$
\begin{gathered}
\rho_{1}+\rho_{2}=1+\frac{\theta(\alpha+\gamma)+\varepsilon \alpha(1-\psi)}{\lambda \theta(\alpha+\gamma)+\varepsilon \alpha \gamma}, \\
\rho_{1} \rho_{2}=\frac{\theta(\alpha+\gamma)}{\lambda \theta(\alpha+\gamma)+\varepsilon \alpha \gamma},
\end{gathered}
$$

and where $F$ is the forward operator and $L$ the lag operator.

Under the assumption that degree of monetary accommodation, $\psi$, is strictly smaller than unity, the restrictions on the roots $\rho_{l}$ and $\rho_{2}$ in equation (5.19) imply that one of the roots $\rho_{1}$ and $\rho_{2}$ is below unity and the other above unity; $\rho_{1}$ is presumed to be the stable root $\left(\rho_{1}<1\right)$ and $\rho_{2}$ the unstable root $\left(\rho_{2}>1\right)$. Furthermore, the parameter restrictions in the model imply that both roots are real and positive. Consequently, a saddlepath solution results.

Given this saddlepath solution, equation (5.19) can be re-arranged as:

$$
E_{t-1} \Delta \bar{p}_{t}=\rho_{1} \Delta \bar{p}_{t-1},
$$

where $\rho_{I}$ represents the degree of persistence of average inflation. Alogoskoufis and Smith (1991) show that this persistence is positively related to the degree of monetary accommodation $(\psi)$ : the higher the degree of monetary accommodation, the higher the persistence of average inflation. To check whether this result indeed is true, we state the characteristic equation of equation (5.19) as

$$
z^{2}+b z+c \quad b=-\left(p_{1}+\rho_{2}\right) \quad c=p_{1} \rho_{2},
$$

and calculate the first derivative of $\rho_{\perp}$ with respect to $\psi$ :

12 Note that equation $(5.19)$ is different from equation [25] in Alogoskoufis and Smith (1991) due to some small miscalculations in Alogoskoufis and Smith (1991).

${ }^{13}$ It is assumed that the exogenous variables $\Delta \bar{q}_{n}, \bar{\mu}_{t}, \Delta \bar{\omega}_{n}$, and $\Delta \bar{n}_{p}$ are equal to an intercept plus a white noise term. Here these intercepts are normalized to zero. 


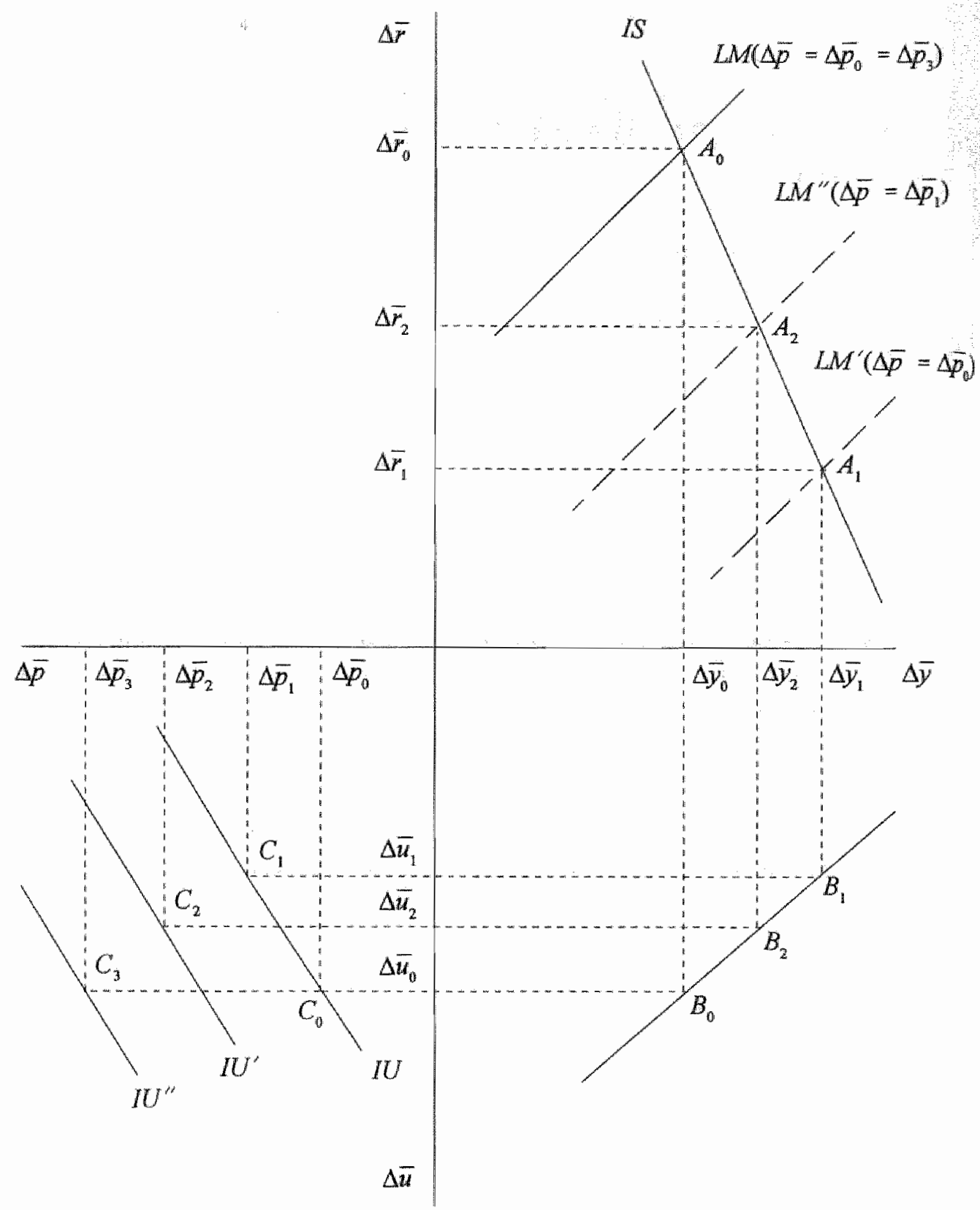

Figure $5.1 \quad$ Output effects of a change in systematic monetary policy in the average Alogoskoufis-Smith (1991) model 
Besides these effects on average real output growth, a change in the degree of monetary accommodation also influences average inflation. For that purpose model (5.13)-(5.18) must be simplified. This gives a second order stochastic difference equation in terms of average inflation (see appendix $5 B$ ): $:^{12,13}$

$$
\left[F^{2}-\left(\rho_{1}+\rho_{2}\right) F+\rho_{1} \rho_{2}\right] L E_{r-1} \Delta \bar{p}_{t}=0
$$

with

$$
\begin{gathered}
\rho_{1}+\rho_{2}=1+\frac{\theta(\alpha+\gamma)+\varepsilon \alpha(1-\psi)}{\lambda \theta(\alpha+\gamma)+\varepsilon \alpha \gamma}, \\
\rho_{1} \rho_{2}=\frac{\theta(\alpha+\gamma)}{\lambda \theta(\alpha+\gamma)+\varepsilon \alpha \gamma},
\end{gathered}
$$

and where $F$ is the forward operator and $L$ the lag operator.

Under the assumption that degree of monetary accommodation, $\psi$, is strictly smaller than unity, the restrictions on the roots $\rho_{l}$ and $\rho_{2}$ in equation (5.19) imply that one of the roots $\rho_{1}$ and $\rho_{2}$ is below unity and the other above unity; $\rho_{1}$ is presumed to be the stable root $\left(\rho_{1}<1\right)$ and $\rho_{2}$ the unstable root $\left(\rho_{2}>1\right)$. Furthermore, the parameter restrictions in the model imply that both roots are real and positive. Consequently, a saddlepath solution results.

Given this saddlepath solution, equation (5.19) can be re-arranged as:

$$
E_{t-1} \Delta \bar{p}_{t}=\rho_{1} \Delta \bar{p}_{t-1},
$$

where $\rho_{I}$ represents the degree of persistence of average inflation. Alogoskoufis and Smith (1991) show that this persistence is positively related to the degree of monetary accommodation $(\psi)$ : the higher the degree of monetary accommodation, the higher the persistence of average inflation. To check whether this result indeed is true, we state the characteristic equation of equation (5.19) as

$$
z^{2}+b z+c \quad b=-\left(\rho_{1}+\rho_{2}\right) \quad c=\rho_{1} \rho_{2},
$$

and calculate the first derivative of $\rho_{1}$ with respect to $\psi$ :

\footnotetext{
12 Note that equation (5.19) is different from equation [25] in Alogoskoufis and Smith (1991) due to some small miscalculations in Alogoskoufis and Smith (1991).

13 It is assumed that the exogenous variables $\Delta \bar{q}_{t}, \bar{\mu}_{t}, \Delta \bar{\omega}_{r}$, and $\Delta \bar{n}_{t}$ are equal to an intercept plus a white noise term. Here these intercepts are normalized to zero.
} 


$$
\frac{\partial \rho_{1}}{\partial \psi}=-\frac{1}{2}\left[1+b\left(b^{2}-4 c\right)^{-\frac{1}{2}}\right] \frac{\varepsilon \alpha}{\lambda \theta(\alpha+\gamma)+\varepsilon \alpha \gamma}>0 .
$$

Equation (5.21) indeed shows that the higher monetary accommodation is, the higher the persistence of average inflation becomes. An increase in the degree of monetary accommodation lowers the average real interest rate; this in turn increases average economic growth through the real interest rate channel. The higher rate of average economic growth implies more demand for goods, and thus a higher rate of average inflation. And as the increase in the degree of monetary accommodation has a persistent effect on average economic growth, average inflation will keep rising. Consequently, the persistence of average inflation increases.

\subsection{Relative model}

Whereas the average model analysed the consequences of a change in systematic monetary policy for average output growth and inflation, the relative model focuses on the effects of a change in systematic exchange rate policy on relative output growth and inflation. The relative model can be obtained by subtracting the basic equations (5.1)-(5.8) for country $h$ from those for country $j$ and imposing the equilibrium conditions (5.9)-(5.12); the difference of a variable between two countries is denoted by adding a hat to the variable; for example, the difference in output growth, $\Delta \hat{y}_{1}$, is defined as $\Delta y_{j, r}-\Delta y_{h, t}$. The relative model consists of the following equations: ${ }^{14}$

\footnotetext{
14 Note that taking differences across countries $j$ and $h$ causes the monetary accommodation equation $(5.4)$, to drop out whereas the exchange rate accommodation equation $(5.5)$, and the uncovered interest rate parity condition $(5.12)$ remain unchanged.
} 


$$
\begin{aligned}
& \Delta \hat{y}_{t}=-\alpha\left(\Delta \hat{i}_{r}-E_{r} \Delta \hat{p}_{t+1}+\Delta \hat{p}_{t}\right)+2 \beta\left(\Delta e_{j k_{t}}-\Delta \hat{p}_{t}\right)+\hat{v}_{i} \\
& E_{t} \Delta \hat{p}_{t+1}-\frac{1+\theta(1+\lambda)}{\lambda \theta} \Delta \hat{p}_{n}+\frac{1}{\lambda} \Delta \hat{p}_{n-1}=-\frac{1}{\lambda \theta}\left(\Delta \dot{\omega}_{n}-\Delta q\right) \\
& \Delta \hat{m}_{t}-\Delta \hat{p}_{t}=\Delta \hat{y}_{t}-\gamma \Delta \hat{i}_{i}+\hat{k}_{t} \\
& \Delta e_{j t_{t}, t}=\phi \Delta p_{r} \\
& \Delta \hat{l}_{t}=\Delta \hat{y}_{t}-\Delta \hat{q}_{i} \\
& \Delta \hat{w}_{t}=E_{t-1}\left[(2 \delta-1) \Delta \hat{p}_{t}+2(\mathbb{1}-\delta) \Delta e_{j h_{t}}-\varepsilon\left(\Delta \hat{n}_{t}-\Delta \hat{l}\right)\right]+\Delta \hat{\omega}_{t}, \\
& \Delta \hat{i}_{t}=E_{,} \Delta e_{j h, t+1+1}-\Delta e_{j h, t} \text {. }
\end{aligned}
$$

As in the average model, equation (5.22) represents the relative $I S$ curve. However, there is one difference. Besides the relative real interest differential, equation $(5.22)$ includes the change in the real exchange rate whereas equation (5.13) does not. This represents the real exchange rate channel of systematic exchange rate policy. The relative $L M$ curve is described by equation (5.24). The trade-off between relative inflation and relative unemployment is obtained by substituting equation (5.27) in (5.23). Note that equation (5.27) includes the change in the nominal exchange rate, whereas equation (5.18) does not; this is the wage cost channel of systematic exchange rate policy. Furthermore equation (5.26) links relative unemployment and relative economic growth. Finally, equation (5.25) defines the changes in the exchange rate and equation (5.28) the uncovered interest rate parity condition.

To see the output effects of a change in systematic exchange rate policy more clearly, the relative $I S$ curve, the relative $L M$ curve, the production technology and the trade-off between inflation and unemployment $(I U)$ are drawn in Figure 5.2 . Assume that the relative real interest rate, $\Delta \hat{r}$, is initially $\Delta p_{0}$, relative output growth $\Delta \hat{y}_{0}$, relative unemployment $\Delta \hat{u}_{0}$, and relative inflation $\Delta \hat{p}_{0}$. Given an increase in the degree of exchange rate accommodation, the relative $1 S$ curve shifts outward to $I S^{\prime \prime}$ due to the real devaluation of the currency of country $j$ in terms of the currency of country $h$. Then relative output growth increases to $\Delta \hat{p}_{1}$ and relative inflation rises to $\Delta \hat{p}_{1}$. This rise in inflation causes the real exchange rate to appreciate again, and thus the relative $I S$ curve shifts down to $I S^{\prime \prime}$. Furthermore, the increase in the degree of exchange rate accommodation causes a rise in the expected inflation differential and thus the inflation-output trade-off $I U$ shifts outward to $I U^{\prime}$. This causes a further inward shift of the relative $I S$ curve. In the end, the 
economy fully adjusts to the change in systematic monetary policy and relative output growth, relative unemployment, and the relative real interest rate will return to their initial positions $\left(\Delta \hat{y}_{0}, \Delta \hat{x}_{0}\right.$, and $\left.\Delta \hat{r}_{0}\right)$; relative inflation will be $\Delta \hat{p}_{3}$ and is thus higher in the long run. Like in the average model, Figure 5,2 can be used also to show the effects of shocks in, for example, relative aggregate demand, relative money demand, and relative money supply. As these effects are comparable to those in the average model, they are not repeated here.

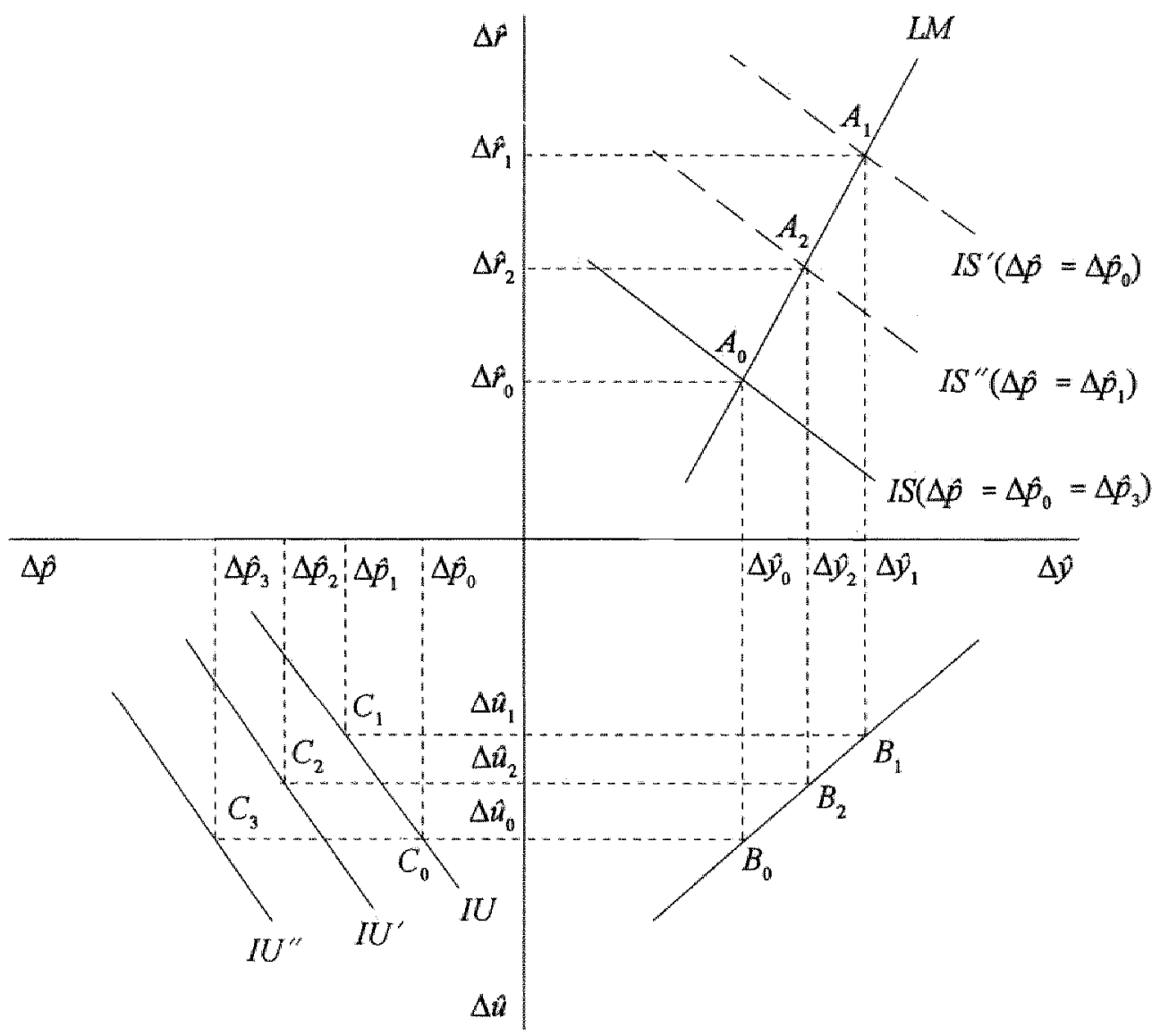

Figure 5.2 Output effects of a change in systematic exchange rate policy in the relative Alogoskoufis-Smith (1991) model 
Figure 5.2 shows that a change in systematic exchange rate policy has a number of effects on relative output growth. First, a change in systematic exchange rate policy has real effects only in the short run; not in the long run. Second, the linear shape of the inflation-unemployment trade-off implies that a decrease in the degree of exchange rate accommodation has the same effect on economic growth as an increase. Thus, systematic policy changes have symmetric effects on relative output growth. Note again that this symmetry is due to the symmetric price adjustment function (5.23), see appendix 5A. Third, an expected increase in exchange rate accommodation has real effects if inflation rates in both countries have not yet had the chance to adjust to the new exchange rate policy. Finally, the decrease in exchange rate accommodation has persistent effects on relative output growth, that is it has not only an effect on economic growth and unemployment in the period when systematic exchange rate policy is changed, but also in later periods.

The differences with the average model are twofold. First, a change in systematic monetary policy is represented by an outward shift of the $L M$ curve, whereas a change in systematic exchange rate policy shifts the IS curve outward. Second, the change in systematic policy is transmitted in the relative model by two additional channels: the real exchange rate channel and the wage cost channel.

In addition to these effects on relative output, a change in systematic exchange rate policy has also consequences for the behaviour of relative inflation. To derive these properties, model (5.22)-(5.28) must be solved. This gives a second order stochastic difference equation in terms of relative inflation (see appendix $5 \mathrm{C}$ ) $!^{13,16}$

$$
\left[F^{2}-\left(\zeta_{1}+\zeta_{2}\right) F+\zeta_{1} \zeta_{2}\right] L E_{i-1} \Delta \hat{p}_{1}=0
$$

with

$$
\begin{gathered}
\zeta_{1}+\zeta_{2}=1+\frac{\theta+2(1-\phi)(1-\delta+\varepsilon \beta)}{\lambda \theta+\varepsilon \alpha(1-\phi)}, \\
\zeta_{1} \zeta_{2}=\frac{\theta}{\lambda \theta+\varepsilon \alpha(1-\phi)},
\end{gathered}
$$

and where $F$ is the forward operator and $L$ the lag operator.

\footnotetext{
15 Note that equation (5.29) is different from equation [34] in Alogoskoufis and Smith (1991) due to a mistake in their relative wage inflation equation [32] (see Appendix 5C) and some other small miscalculations in Alogoskoufis and Smith (1991).

16 The exogenous variables $\Delta \hat{q}_{t}, \Delta \hat{\omega}_{t}$, and $\Delta \hat{n}_{t}$ are assumed to be equal to an intercept plus a white noise term; here these intercepts are normalized to zero.
} 
Under the assumption that the degree of exchange rate accommodation, $\phi$, is strictly smaller than unity, the restrictions on the roots $\zeta_{\gamma}$ and $\zeta_{2}$ in equation (5.29) imply that one of the roots $\zeta_{1}$ and $\zeta_{2}$ is below unity and the other above unity; it is presumed that $\zeta_{1}$ is the stable root $\left(\zeta_{I}<1\right)$ and that $\zeta_{2}$ the unstable root $\left(\zeta_{1}>1\right)^{17}$ ? Furthermore the parameter restrictions in the model imply that both roots are real and positive. Consequently, a saddlepath solution is obtained.

Given this saddlepath solution, equation (5.29) can be re-arranged as:

$$
E_{t-1} \Delta \hat{p}_{\imath}=\zeta_{1} \Delta \hat{p}_{t-1},
$$

where $\zeta_{1}$ is the degree of persistence of relative inflation. Alogoskoufis and Smith (1991) show that this persistence is positively related to the degree of exchange rate accommodation ( $\phi)$ : the higher the degree of exchange rate accommodation, the higher the persistence of relative inflation. To check whether this result indeed is true, we state the characteristic equation of equation (5.29) as

$$
z^{2}+b z+c \quad b=-\left(\zeta_{1}+\zeta_{2}\right) \quad c=\zeta_{1} \zeta_{2},
$$

and calculate the first derivative of $\zeta_{1}$ with respect to $\phi$ :

$$
\begin{gathered}
\frac{\partial \zeta_{1}}{\partial \phi}=-\frac{1}{2}\left[1+b\left(b^{2}-4 c\right)^{-\frac{1}{2}}-\frac{2 \theta \varepsilon \alpha\left(b^{2}-4 c\right)^{-\frac{1}{2}}}{\chi_{1}}\right] \frac{\chi_{1}}{(\lambda \theta+\varepsilon \alpha(1-\phi))^{2}}, \\
\chi_{1}=\theta[2 \lambda(1-\delta+\varepsilon \beta)-\varepsilon \alpha] .
\end{gathered}
$$

Inspection of (5.31) shows that there is no strict positive relation between the persistence of relative inflation and the degree of exchange rate accommodation. The explanation for this result is the following. An increase in the degree of exchange rate accommodation causes a rise in the persistence of relative inflation via the real interest rate and the real exchange rate channel, but a decrease via the wage cost channel. Thus, the total effect of an increase in the degree of exchange rate accommodation on the persistence of relative inflation is undetermined. This is in line with Dornbusch (1982).

17 Note that the restriction of a less than unit degree of exchange rate accommodation implies that the real exchange will depreciate endlessly. Empirical evidence suggests, however, that there is a slow mean reversion of the real exchange rate towards purchasing power parity (see Rogoff, 1996, for example). The Alogosklkoufis-Smith model, nevertheless, lacks this mean reversion property. 
Given equation (5.31), a necessary condition for having a positive relation is that $\chi_{1}$ $>0$. A sufficient condition for a positive relation is $\alpha=0$. This implies in Figure 5.2 that the relative $I S$ curve becomes vertical. This vertical $I S$ curve makes relative economic growth more stable, and thus increases the persistence of relative inflation. This increase in inflation persistence is so large that the effect via the real exchange rate on relative inflation persistence dominates the effect via the wage cost channel. Consequently, the relation between the persistence of relative inflation and the degree of exchange rate accommodation is strictly positive. This can be seen directly from equation (5.31) by substituting $\alpha=0$ :

$$
\left.\frac{\partial \zeta_{1}}{\partial \phi}\right|_{\alpha=0}=-\left[1+b\left(b^{2}-4 c\right)^{-\frac{1}{2}}\right] \frac{1-\delta+\varepsilon \beta}{\lambda \theta}>0 .
$$

Another sufficient condition for a strictly positive relation between the degree of exchange rate accommodation and the persistence of relative inflation is to assume that the response of real wages to unemployment is zero: $\varepsilon=0$. This implies in Figure 5.2 that the inflation-unemployment becomes independent of the rate of unemployment. Therefore the relation between the persistence of relative inflation and the degree of exchange rate accommodation becomes strictly positive. This can be seen by setting $\varepsilon=0$ in equation (5.31):

$$
\left.\frac{\partial \zeta_{1}}{\partial \phi}\right|_{\delta=0}=-\left[1+b\left(b^{2}-4 c\right)^{-\frac{1}{2}}\right] \frac{1-\delta}{\lambda \theta}>0 .
$$

For reasonable parameter values, that is if the real interest rate elasticity of aggregate demand, $\alpha$, and the unemployment elasticity of wages, $\varepsilon$, are rather low, then $\chi_{1}$ is positive, and thus the relation between the persistence of relative inflation and the degree of exchange rate accommodation is positive.

\subsection{Alogoskoufis (1992) model}

In this section the Alogoskoufis (1992) model is compared with that of Alogoskoufis and Smith (1991). The main difference of the Alogoskoufis (1992) model is that other assumptions are made about the determination of prices and wages. ${ }^{18}$ Whereas Alogoskoufis and Smith (1991) assume convex adjustment costs of supply prices

\footnotetext{
1. Another difference is that Alogoskoufis (1992) is presented as a world-model, whereas Alogoskoufis and Smith (1991) is a two-country model. Here the attention is restricted to the two-country version of Alogoskoufis (1992) as the results in the world-version are equal to those in the twocountry version.
} 
and reopening of the labour market every period, Alogoskoufis (1992) assumes instead that prices are set as a constant mark-up over unit labour costs, and wages are determined by a staggered wage contracts approach, that is by the average contract wage increase of the contracts still not renewed:

$$
\begin{gathered}
\Delta p_{j, t}=\Delta w_{j, t}-\Delta q_{j, s}, \\
\Delta w_{j, t}=(1-\xi) \sum_{s=0}^{\infty} \xi^{*} \Delta x_{j, t \rightarrow t}=\frac{1-\xi}{1-\xi L} \Delta x_{j, t} \quad 0<\xi<1,
\end{gathered}
$$

where $\Delta x_{j, t}$ is the change in the contract wage rate and $\xi$ is the proportion of wage contracts not reopened. Substituting (5.33) into (5.32) and rearranging gives the equation for inflation:

$$
\Delta p_{j, t}=\xi \Delta p_{j, t-1}+(1-\xi) \Delta x_{j, t}-\Delta q_{j, t}+\xi \Delta q_{j, t-1}
$$

The contract wage inflation, $\Delta x_{\hat{h}, t}$, is determined by a staggered wage contracts approach. More specifically, the contract wage growth is determined by the expected future inflation, the expected change in unemployment, and the expected future real wage target growth: ${ }^{19}$

$$
\begin{aligned}
\Delta x_{j, t}= & (1-\xi) E_{t-1} \sum_{j=0}^{\infty} \xi^{\prime}\left[\delta \Delta p_{j, t+1}+(1-\delta)\left(\Delta e_{j h, t+i}+\Delta p_{h, t+t}\right)-\varepsilon\left(\Delta n_{j, t+t}-\Delta l_{j, t+t}\right)+\Delta \omega_{j, t+1}\right]= \\
& =\frac{1-\xi}{1-\xi F} E_{t-1}\left[\delta \Delta p_{j, t}+(1-\delta)\left(\Delta e_{j h, t}+\Delta p_{h, t}\right)-\varepsilon\left(\Delta n_{j, t}-\Delta l_{j, t}\right)+\Delta \omega_{j, t}\right] .(5.35)
\end{aligned}
$$

The total basic model of Alogoskoufis (1992) consists of equations (5.11), (5.34), (5.3)-(5.6), (5.35), and (5.8)-(5.12). This model can be solved as an average model and as a relative model. As the results are comparable to those obtained for the Alogoskoufis and Smith (1991) model that we discussed in section 5.2, we refer to appendices $5 \mathrm{D}$ and $\mathrm{SE}$ for the explicit results.

19 Alogoskoufis and Smith (1991) implicitly assume that the labour market is re-opened every period, so that $\xi=0$. Substituting this condition into (5.33) and (5.34) gives equation (5.7). The only difference that is equation (5.35) includes the expected real wage target growth, $E_{t-1} \Delta \omega_{j_{s} t}$, under the assumption that $\xi=0$, whereas equation (5.7) includes the real wage target growth $\Delta \omega_{j, t}$ itself. This difference is not significant as in the solution of both models expectations are taken conditional on the information awailable on $t-1$; then this difference disappears. Note that as the labour market is re-opened every period, there is no need to make a distinction between the contract wage growth $\Delta x_{j, t}$ and wage growth $\Delta w_{j, t}$. This can be seen by substituting $\xi=0$ in equation (5.33). 


\subsection{Conclusion}

In this chapter the price adjustment cost model of Alogoskoufis and Smith (1991) and the staggered wage model of Alogoskoufis (1992) were re-interpreted. In both models the effects of systematic monetary and exchange rate policy for output growth and inflation have been analysed. Systematic monetary policy changes are transmitted through the real interest rate channel and systematic exchange rate policy changes are also transmitted through the real exchange rate channel and the wage cost channel.

With respect to output growth both the average and the relative models show that a change in systematic policy has real effects only in the short run; in the long run there are no real effects. Second, an increase in monetary or exchange rate accommodation has the same effects on economic growth as a decrease. Thus, a change in systematic policy has symmetric effects on real economic growth. Note, however, that this result depends on the fact that the model is stated in first differences; if it would have been stated in levels, like in Alogoskoufis and Smith (1991) and Alogoskoufis (1992), systematic policy changes have asymmetric effects on output growth. Third, as long as firms have not adjusted their pricing policy to a change in systematic policy, a change in systematic policy has real effects even if it is already expected. Finally, due to the time needed for firms to adjust their pricing policy to a change in systematic policy, the real effects persist for some while. Thus, the change in systematic policy has persistent effects on real economic growth.

Finally, this chapter showed the effects of changes in systematic monetary and exchange rate policy on inflation. With respect to systematic monetary policy it is found that an increase in the degree of monetary accommodation causes an increase in the persistence of average inflation via the real interest rate channel. With respect to systematic exchange rate policy it is found that an increase in the degree of exchange rate accommodation does not have a strictly positive effect on the persistence of relative inflation. The explanation for this result is the following. A change in the degree of exchange rate accommodation is transmitted through the real interest rate channel, the real exchange rate channel, and the wage cost channel. An increase in the degree of exchange rate accommodation causes an increase the persistence of relative inflation via the real interest rate channel and the real exchange rate channel, but a decrease via the wage cost channel. The total effect of the increase in accommodation on the persistence of average and relative inflation depends on the strength of the various channels. As a result, the relation between the degree of exchange rate accommodation and the persistence of relative inflation is ambiguous, in line with Dornbusch (1982). Under reasonable parameter values, that is if the real interest rate elasticity of aggregate demand and the unemployment elasticity of wages are rather low, the relation will be positive. 


\section{Appendix 5A Price adjustment cost model}

The price stickiness model in Alogoskoufis-Smith (1991) is based on the Rotemberg (1982) model. It assumes that price adjustment costs are due to deviations of the actual change in supply prices of firm $i, \Delta p_{i, t}$, from the optimal price change that would come about if there were no price adjustment costs, $\Delta \tilde{p}_{i, 4}$, and from the change in pricing policy, $\Delta p_{i, t}-\Delta p_{i, t-1}$. Both adjustment costs are included in an intertemporal loss function $L_{i, 1}$ :

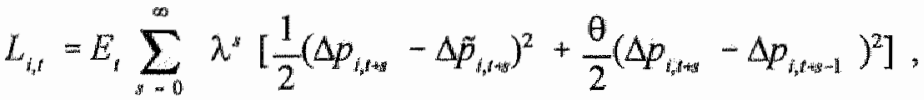

$$
\begin{aligned}
& \theta>0 \quad 0<\lambda<1 \text {. }
\end{aligned}
$$

Furthermore, the optimal price change is assumed to follow unit labour costs. Thus:

$$
\Delta \tilde{p}_{i, t}=\Delta w_{i, t}-\Delta q_{i, t} .
$$

where $\Delta w_{t, t}$ is the wage growth in firm $i$, and $\Delta q_{i, t}$ the productivity growth in firm i. Given the optimal price change formula (5A.2), firms are assumed to minimize the intertemporal loss function (5A.1). This gives the following pricing formula:

$$
E_{t} \Delta p_{i, t+1}-\frac{1+\theta(1+\lambda)}{\lambda \theta} \Delta p_{i, t}+\frac{1}{\lambda} \Delta p_{i, t-1}=-\frac{1}{\lambda \theta}\left(\Delta w_{i, t}-\Delta q_{i, t}\right) .
$$

If it is furthermore assumed that all firms $i$ are identical, equation (5.2) follows directly from (5A.3)

Note that equation (5A.1) is a symmetric loss function, that is, an increase in inflation causes the same loss as a decrease in inflation; thus the price adjustment cost equation (5A.3) is also symmetric. The original loss function in Alogoskoufis and Smith (1991), however, compares the change in price with a constant reference rate of inflation; therefore, their loss function is asymmetric and their price adjusment cost is asymmetric. If such an asymmetry should be built in the first differences model, the loss function would be: 


$$
\begin{gathered}
L_{i, t}=E_{t} \sum_{s=0}^{\infty} \lambda^{s}\left[\frac{1}{2}\left(\Delta p_{i, t, s}-\Delta \tilde{p}_{i, t, s}\right)^{2}+\frac{\theta}{2}\left(\Delta p_{i, t \omega s}-\Delta p_{i, t, s-1}-\pi\right)^{2}\right], \\
\theta>0 \quad 0<\lambda<1,
\end{gathered}
$$

where $\pi$ is a positive constant. This would, however, change the pricing formula and therefore this is left for future research.

\section{Appendix 5B Solution of the average Alogoskoufis-Smith (1991) model}

Model (5.13)-(5.18) is solved as follows. First, equation (5.17) is substituted into (5.15) and expressed in terms of the change in average interest rate $\Delta \bar{i}_{q}$. This gives:

$$
\Delta \bar{i}_{t}=\frac{1-\psi}{\gamma} \Delta \bar{p}_{t}+\frac{1}{\gamma} \Delta \bar{y}_{t}+\frac{1}{\gamma}\left(\bar{k}_{t}-\bar{\mu}_{t}\right) .
$$

Then, equation (5B.1) is substituted into (5.13) and rearranged as:

$$
\Delta \bar{y}_{t}=\frac{1}{\alpha+\gamma}\left[\alpha \gamma E_{r} \Delta \bar{p}_{t+1}-\alpha(1-\psi+\gamma) \Delta \bar{p}_{t}-\alpha\left(\bar{k}_{t}-\bar{\mu}_{t}\right)+\gamma \bar{p}_{t}\right] .
$$

Second, equations (5.17) and (5B.2) are substituted into (5.18). This gives:

$$
\begin{aligned}
& \Delta \bar{w}_{t}=\left(1-\frac{\varepsilon \alpha(1-\psi+\gamma)}{\alpha+\gamma}\right) E_{t-1} \Delta \bar{p}_{t}+\frac{\varepsilon \alpha \gamma}{\alpha+\gamma} E_{t-1} \Delta \bar{p}_{t+1} \\
& -\varepsilon E_{t-1}\left[\Delta \bar{n}_{t}+\Delta \bar{q}_{t}+\frac{\alpha}{\alpha+\gamma}\left(\bar{k}_{t}-\bar{\mu}_{t}\right)-\frac{\gamma}{\alpha+\gamma} \bar{v}_{t}\right]+\Delta \bar{\omega}_{t} .
\end{aligned}
$$

Finally, equation (5B.3) is substituted in (5.14) and expectations are taken conditional upon the information available at time $t-1$. This equation can be rearranged as $(5.19)$. 


\section{Appendix 5C Solution of the relative Alogoskoufis-Smith (1991) model}

Model (5.22)-(5.28) is solved as follows. First, equation (5.28) and (5.25) are substituted in equation $(5,22)$. This gives:

$$
\Delta \hat{y}_{t}=\alpha(1-\phi) E_{t} \Delta \hat{p}_{t+1}-(\alpha+2 \beta)(1-\phi) \Delta \hat{p}_{i}+\hat{v}_{t} .
$$

Next the exchange rate equation $(5.25)$ is substituted in equation $(5.27):^{20}$

$$
\Delta \hat{w}_{t}=E_{t-1}\left[(2 \delta-1+2(1-\delta) \phi) \Delta \hat{p}_{t}-\varepsilon\left(\Delta \hat{n}_{i}-\Delta \hat{l}_{l}\right)\right]+\Delta \hat{\omega}_{t}
$$

Then the relative wage equation in terms of expected inflation is obtained by substituting equations (5.26) and (5C.1) in (5C.2):

$$
\begin{gathered}
\Delta \hat{w}_{t}=E_{t-1}\left[(2 \delta-1+2(1-\delta) \phi-\varepsilon(\alpha+2 \beta)(1-\phi)) \Delta \hat{p}_{t}+\varepsilon \alpha(1-\phi) \Delta \hat{p}_{t+1}\right. \\
\left.-\varepsilon\left(\Delta \hat{n}_{t}+\Delta \hat{q}_{t}-\hat{w}_{t}\right)\right]+\Delta \hat{\omega}_{t} .
\end{gathered}
$$

Finally substituting (5C.3) into (5.23) and taking expectations conditions upon the information available at time $t-1$ results in equation (5.29).

20 Note that equation (5C.2) is different from [32] in Alogoskoufis and Smith (1991). This difference is expressed by a different term in front of $E_{t-1} \Delta \hat{p}_{t}$. In Alogoskoufis and Smith (1991) this term is $\delta-(1-\delta) \phi$ whereas it should be $2 \delta-1+2(l-\delta) \phi$ as in (5C 2). Alogoskoufis and Smith (1991) use this false relative wage equation to derive the price difference equation [34], which is therefore false too. 


\section{Appendix 5D Solution of the average Alogoskoufis (1992) model}

In this appendix the average Alogoskoufis (1992) model is recalculated. The average contract-wage and price equations in this model are derived from (5.34) and $(5.35)$ :

$$
\begin{gathered}
\Delta \bar{p}_{t}=\xi \Delta \bar{p}_{t-1}+(1-\xi) \Delta \bar{x}_{t}-\Delta \bar{q}_{t}+\xi \Delta \bar{q}_{t-1} \\
\Delta \bar{x}_{t}=\frac{1-\xi}{1-\xi F} E_{t-1}\left[\Delta \bar{p}_{t}-\varepsilon\left(\Delta \bar{n}_{t}-\Delta \bar{l}_{t}\right)+\Delta \bar{\omega}_{t}\right] .
\end{gathered}
$$

The average model for the two-country version of Alogoskoufis (1992) consists of equations (5.13), (5D.1), (5.15)-(5.18), and (5D.2). It is solved as follows. First, equations (5.13), (5.15) and (5.16) are solved for $\Delta \bar{y}_{s}$ giving equation (5B.2), see appendix 5B. Then equations (5.17) and (5B.2) are substituted in (5D.2). The resulting equation is substituted in (5D.1) and then expectations are taken based on the information available on time $t-1$. After rearranging this equation we obtain the following second order stochastic difference equation. ${ }^{21}$

$$
\left[F^{2}-\left(\rho_{1}+\rho_{2}\right) F+\rho_{1} \rho_{2}\right] L E_{i-1} \Delta \bar{p}_{t}=0
$$

with

$$
\begin{gathered}
\rho_{1}+\rho_{2}=1+\frac{\xi(\alpha+\gamma)+(1-\xi)^{2} \varepsilon \alpha(1-\psi)}{\xi(\alpha+\gamma)+(1-\xi)^{2} \varepsilon \alpha \gamma}, \\
\rho_{1} \rho_{2}=\frac{\xi(\alpha+\gamma)}{\xi(\alpha+\gamma)+(1-\xi)^{2} \varepsilon \alpha \gamma} .
\end{gathered}
$$

Making the same assumptions about the roots $\rho_{1}$ and $\rho_{2}$ as in section 5.3 , the first derivative of $\rho_{1}$ with respect to $\psi$ turns out to be:

$$
\frac{\partial \rho_{1}}{\partial \psi}=-\frac{1}{2}\left[1+b\left(b^{2}-4 c\right)^{-\frac{1}{2}}\right] \frac{\varepsilon \alpha(1-\xi)^{2}}{\xi(\alpha+\gamma)+(1-\xi)^{2} \varepsilon \alpha \gamma}>0
$$

Thus, the higher the degree of monetary accommodation, the higher the persistence of average inflation. This is the same result we obtained in section 5.3 .

21 It is assumed that the exogenous variables $\Delta \bar{q}_{t}, \bar{\mu}_{t}, \Delta \bar{\omega}_{t}$, and $\Delta \bar{n}_{f}$ are equal to an intercept plus a white noise term; here the intercepts are normalized to zero. 


\section{Appendix 5E Solution of the relative Alogoskoufis (1992) model}

The relative contract-wage and price equations in the Alogoskoufis (1992) model are derived from (5.34) and (5.35):22

$$
\begin{gathered}
\Delta \hat{p}_{i}=\xi \Delta \hat{p}_{j-1}+(1-\xi) \Delta \hat{x}_{i}-\Delta \hat{q}_{i}+\xi \Delta \hat{q}_{i-1}, \\
\Delta \hat{x}_{i}=\frac{1-\xi}{1-\xi \bar{F}} E_{i-1}\left[(2 \delta-1) \Delta \hat{p}_{i}+2(1-\delta) \Delta e_{j k, t}\right. \\
\left.-\varepsilon\left(\Delta \hat{n}_{i}-\Delta \hat{l}_{i}\right)+\Delta \hat{\omega}_{t}\right] .
\end{gathered}
$$

The relative model for the two-country version of Alogoskoufis (1992) consists of equations (5.22), (5E.1), (5.24)-(5.26), (5E.2), and (5.28). It is solved as follows. First equations (5.25) and (5.28) are substituted in (5.22), giving (5C.1). Then equation (5.25), (5.26) and (5C.1) are substituted into (5E.2). The resulting equation is substituted in $(5 \mathrm{E} .1)$ and expectations are taken based on the information available at time $t-1$. After rearranging this equation we obtain the following second order stochastic difference equation: ${ }^{23,24}$

$$
\left[F^{2}-\left(\zeta_{1}+\zeta_{2}\right) F+\zeta_{1} \zeta_{2}\right] L E_{t-1} \Delta \hat{p}_{1}=0
$$

with

$$
\begin{gathered}
\zeta_{1}+\zeta_{2}=\frac{1+\xi^{2}-(1-\xi)^{2}(2 \delta-1+2(1-\delta) \phi-\varepsilon(\alpha+2 \beta)(1-\phi))}{\xi+(1-\xi)^{2} \varepsilon \alpha(1-\phi)}, \\
\zeta_{1} \zeta_{2}=\frac{\xi}{\xi+(1-\xi)^{2} \varepsilon \alpha(1-\phi)} .
\end{gathered}
$$

Under the same conditions for $\zeta_{1}$ and $\zeta_{2}$ as in section 5.4, the first derivative of $\zeta_{1}$ with respect to the degree of exchange rate accommodation $\phi$ becomes:

\footnotetext{
22. Note that this relatiwe contract wage equation is different from equation [29] in Alogoskoufis (1992) due to miscalculations in Alogoskoufis (1992).

23 Note that there are some minor differences with Alogoskoufis (1992) due to miscalculations in the latter.
}

24 It is assumed that the exogenous variables $\Delta \hat{q}_{t}, \Delta \hat{\omega}_{t}$, and $\Delta \hat{h}_{t}$ are equal to an intercept plus a white noise term; the intercepts are normalized to zero. 


$$
\begin{gathered}
\frac{\partial \zeta_{1}}{\partial \phi}=-\frac{1}{2}\left[1+b\left(b^{2}-4 c\right)^{-\frac{1}{2}}\right. \\
\left.-\frac{2\left(b^{2}-4 c\right)^{-\frac{1}{2}} \varepsilon \alpha \xi(1-\xi)^{2}}{\chi_{2}}\right] \frac{x_{2}}{\left(\xi+(1-\xi)^{2} \varepsilon \alpha(1-\phi)\right)^{2}}, \\
\chi_{2}=(1-\xi)^{2} \xi[2(1-\delta)+\varepsilon(2 \beta-\alpha)] .
\end{gathered}
$$

Again, we find that the relation between the persistence of relative inflation and the degree of exchange rate accommodation is not strictly positive. This is consistent with the result in section 5.4. The necessary condition for a positive relation is that $\chi_{2}>0$. This implies $\alpha=0$ or $\varepsilon=0$ is a sufficient condition for a positive relation. This can be seen from (5E.4):

$$
\begin{gathered}
\left.\frac{\partial \zeta_{1}}{\partial \phi}\right|_{\alpha=0}=-\left[1+b\left(b^{2}-4 c\right)^{-\frac{1}{2}}\right] \frac{(1-\xi)^{2}(1-\delta+\varepsilon \beta)}{\xi}>0, \\
\left.\frac{\partial \zeta_{1}}{\partial \phi}\right|_{\varepsilon=0}=-\left[1+b\left(b^{2}-4 c\right)^{-\frac{1}{2}}\right] \frac{(1-\xi)^{2}(1-\delta)}{\xi}>0 .
\end{gathered}
$$

The explanation for these effects is the same as in section 5.4 for the Alogoskoufis and Smith (1991) model. 


\section{Chapter 6}

\section{The Effects of Systematic Policy in a Price-Misperception Model}

\subsection{Introduction}

In chapter 5 the price adjustment cost model of Alogoskoufis and Smith (1991) and the staggered wage model of Alogoskoufis (1992) were re-examined. These models investigated the effects of changes in systematic policy on output growth and inflation. It was found that an increase in the degree of monetary as well as exchange rate accommodation has effects on real output growth only in the short run, not in the long run. Furthermore, these changes have symmetric effects on real output growth; they are non-neutral, and persist for some while due to price stickiness. With respect to inflation it was found that an increase the degree of monetary accommodation increases the persistence of average inflation and that an increase in the degree of exchange rate accommodation has an ambiguous effect on the persistence of relative inflation. Given that it is not clear whether the trade-off between inflation and unemployment is due to price adjustment costs, staggered wages, or imperfect information, it is interesting to know how a change in systematic policy affects output growth and inflation in a flexible price, misperception model. Are the effects the same as in the price adjustment cost model and the staggered wage model in chapter 5 , or are they different?

The purpose of this chapter is to build such a flexible price, misperception model and to investigate the effects of systematic policy changes for output growth and inflation. To keep this new model comparable to the Alogoskoufis models in chapter 5 , these models are converted to a price-misperception model. Therefore a number of changes are necessary.

First of all, the assumption of price adjustment costs or staggered wages is replaced by flexible prices. If prices are flexible instead of sticky, output is determined by the interaction of aggregate supply and demand. In the price stickiness model of chapter 5 , however, aggregate supply could not be determined by maximizing profit given production technology because technology was implicitly assumed to have constant returns to scale. To solve this problem decreasing returns to scalle are assumed here. In that case an aggregate surprise supply equation results from profit maximization. This aggregate supply equation replaces the price adjustment equation, the labour demand equation, and the wage equation in the price stickiness model of chapter 5. This has two consequences: first, the wage cost channel disap- 
pears because it operated through the wage equation; second, the labour supply equation becomes superfluous and therefore it is deleted.

Besides these changes, two additional changes are made. First, the response of world money growth is lagged one period in order to obtain a strictly positive relation between the persistence of average inflation and the degree of monetary accommodation in the average model. This change can be defended by arguing that it takes time to coordinate monetary policies between countries; therefore, a lagged response is more appropriate than an immediate response.

Second, it is assumed that the real exchange rate reverts to purchasing power parity in order to solve the relative model. This change can be justified by noting that the Alogoskoufis models imply that the real exchange rate can appreciate or depreciate without boundary whereas empirical evidence suggests that there is a tendency in the short run that the real exchange rate returns to purchasing power parity, or what is the same, there is a small mean reversion in the real exchange rate (see, for example, Rogoff, 1996).

This chapter is arranged as follows. In section 6.2 the basic alternative model is presented. To analyse the consequences of systematic monetary policy, the model is solved in section 6.3 as an average model; section 6.4 derives the relative model in order to investigate systematic exchange rate policy. Finally, section 6.5 contains the main conclusions.

\subsection{Basic model}

In the flexible price, misperception model, the goods market and the money market are distinguished. Furthermore the model is stated for two countries with identical structures. ${ }^{1}$ The basic equations for this alternative model are presented in sections 6.2 .1 to 6.2 .5 and the equilibrium conditions in section 6.2 .6 . Finally, because the flexible price, misperception model in this chapter is close to the price stickiness model in chapter 5 , the corresponding equations in chapter 5 are denoted in square brackets in order to make the comparison easier.

\subsubsection{The demand for goods}

The growth in the demand for goods in country $j, \Delta y_{j, t}^{d}$, depends negatively on the change in the real interest rate and positively on the real exchange rate change:

To save space we only report the basic equations for country $j$; the same model holds for country $h$. In that case $j$ and $h$ are reversed. All variables are expressed in logs, except the interest rates. 


$$
\Delta y_{j, t}^{d}=-\alpha\left(\Delta i_{j, t}-E_{t} \Delta p_{j, t+1}+\Delta p_{j, t}\right)+\beta \Delta e r_{j h, t}+v_{j, t} \quad \alpha, \beta>0
$$

where $\Delta i_{j, t}$ is the change in the nominal interest rate in country $j, \Delta p_{j, t}$ is the inflation rate in country $j, \Delta e r_{j, t}$ is the change in the real exchange rate, $v_{j, t}$ is a white noise aggregate demand shock in country $j$, and $E$ is the expectations operator. The change in the real exchange rate, $\Delta e r_{j, t}$, is defined as:

$$
\Delta e r_{j h, t}=\Delta e_{j h, t}+\Delta p_{h, t}-\Delta p_{j, t},
$$

where $e_{g h,}$ is the nominal exchange rate between countries $j$ and $h$ (in unit of country $j$ per unit of country $h$ ). A rise in $e r_{j h, t}$ is a real depreciation and a fall a real appreciation.

\subsubsection{The supply of goods}

If there are decreasing instead of constant returns to scale for labour in the production function and the stock of capital is fixed in the short run, maximizing profit given production technology, yields a Lucas surprise supply function (see appendix 6A):

$$
\Delta y_{j, t}^{s}=\Delta y n_{j, t}+\eta\left(\Delta p_{j, t}-E_{x-1} \Delta p_{j, t}\right) \quad \eta>0
$$

where $\Delta y_{j, t}^{s}$ is the growth of the supply of goods, and $\Delta y n_{j, t}$ the natural output growth in country $j$. This equation states that real supply growth will be higher than the natural growth rate if inflation is higher than expected; it replaces the price adjustment equation, the labour demand equation, and the wage equation in chapter 5 , that is, equation (5.2), (5.6), and (5.7) respectively.

\subsubsection{The demand for money}

The growth of the real demand for money, $\Delta m_{j, t}{ }^{d}-\Delta p_{j, t}$, depends on real income growth, $\Delta y_{j, t}$, the change in nominal interest rate, $\Delta i_{j, r}$, and a white noise money demand shock $k_{j, t}$ :

$$
\Delta m_{j, t}^{d}-\Delta p_{j, t}=\Delta y_{j, t}-\gamma \Delta i_{j, t}+k_{j, t} \quad \gamma>0,
$$

where $\gamma$ is the interest elasticity of real money demand. 


\subsubsection{The supply of money}

In this model money supply is coordinated between country $j$ and $h$. The world money supply growth, $\Delta m_{j, r}{ }^{f}+\Delta m_{j, t}$, is determined by the average world inflation, $\Delta p_{j, t}+\Delta p_{h, t}$, and an exogenous component of monetary accommodation $\mu_{t}$ :

$$
\Delta m_{j, t}^{s}+\Delta m_{h_{i, t}}^{s}=\psi\left(\Delta p_{j, t-1}+\Delta p_{h, t-1}\right)+\mu_{t} \quad 0 \leq \psi \leq 1
$$

where $\psi /$ represents the degree of monetary accommodation. Note that in equation (6.5) world inflation is lagged one period compared to equation (5.4) to account for the time needed to coordinate monetary policies.

\subsubsection{The nominal and the real exchange rate}

The change in the nominal exchange rate, $\Delta e r_{j, t}$, simply depends on the inflation differential between country $j$ and $h$ :

$$
\Delta e_{j h, t}=\phi\left(\Delta p_{j, t}-\Delta p_{h, t}\right) \quad 0 \leq \phi \leq 1,
$$

where $\phi$ is the degree of exchange rate accommodation. In a managed floating exchange rate regime, the degree of exchange rate accommodation lies between zero and unity $(0<\phi \leq 1)$, and in a fixed exchange rate regime it is zero. As equation (6.6) is a monetary approach to the exchange rate, a change in the degree of exchange rate accommodation reflects a change in relative monetary policy.

Another change in the model is to assume that the real exchange rate returns to purchasing power parity with speed $\chi$ (see Dumas, 1992; Rogoff, 1996):

$$
E_{t} \Delta e r_{j h, t+1}=-\chi \Delta e r_{j h, 1} \quad \chi>0 .
$$

Consequently, the real exchange rate cannot appreciate or depreciate in the long run without boundary.

\subsubsection{Equilibrium conditions}

Finally the equilibrium conditions for this model are: 


$$
\begin{gathered}
\Delta y_{g, t}^{d}=\Delta y_{g, t}^{s}=\Delta y_{g, t} \quad g=j, h, \\
\Delta m_{j, t}^{d}+\Delta m_{h, t}^{d}=\Delta m_{j, t}^{s}+\Delta m_{h, t}^{s}=\Delta m_{j, t}+\Delta m_{h, t}, \\
\Delta i_{j, t}=\Delta i_{h, t}+E_{t} \Delta e_{j h_{s} t+1}-\Delta e_{j h, t},
\end{gathered}
$$

where equation (6.8) shows that the domestic goods market in countries $j$ and $h$ clear, and equation (6.9) that the world money market clears. As in section 5.2.7 it is assumed that capital mobility is so fast that the domestic money markets in countries $j$ and $h$ clear also. ${ }^{2}$ Finally, equation (6.10) states the uncovered interest parity condition; it implies equilibrium in international bond markets.

\subsection{Average price-misperception model}

In this section the model presented in section 6.2 is solved as an average model. The focus of the average model is to investigate the effects of changes in the degree of monetary accommodation on average economic growth and inflation; thus the consequences for both countries together are analysed instead of the difference between both countries. Therefore equations (6.1)-(6.7) are averaged over countries $j$ and $h$ and the equilibrium conditions (6.8) to (6.10) are assumed to hold. This gives the following set of equations in terms of average variables: ${ }^{3}$

2 A drawback of this model is that the money supply in countries $j$ and $h$ are not identified. This problem can be solved by specifying the change in the nominal exchange rate as a function of relative money supply growth:

$$
\Delta e_{j h, t}=\phi\left(\Delta m_{j, t}^{s}-\Delta m_{h, t}^{*}\right) .
$$

In this case the growth of money supply in countries $j$ and $h$ are identified because equation (6.5) determines world money supply growth and equation (6.6a) determines relative money supply growth. Replacing equation (6.6) by (6.6a) does not change the average model in this chapter; with respect to the relative model there is still a strictly positive relation between the persistence of relative inflation and the degree of monetary accommodation, see appendix $6 \mathrm{~B}$. The disadvantage of replacing equation (6.6) by equation $(6.6 \mathrm{a})$ is that the interpretation of the degree of exchange rate accommodation, $\phi$, changes.

3 Note that $\Delta e_{j h, t}=-\Delta e_{h j, t}$, that the averages of (6.2), (6.6), and (6.7) drop out, and that equation $(6.10)$ is not relevant in the average model. Average output growth $\Delta \bar{y}_{t}$ is defined as $\left(\Delta y_{f, 1}+\Delta y_{h, t}\right) / 2$ and this holds for all other average variables except for $\bar{\mu}_{t}$ which is defined as $\mu_{1} / 2$. 


$$
\begin{gathered}
\Delta \bar{y}_{t}=-\alpha\left(\Delta \bar{i}_{t}-E_{t} \Delta \bar{p}_{t+1}+\Delta \bar{p}_{t}\right)+\bar{v}_{t}, \\
\Delta \bar{y}_{t}=\Delta \bar{n}_{t}+\eta\left(\Delta \bar{p}_{t}-E_{i-1} \Delta \bar{p}_{t}\right), \\
\Delta \bar{m}_{t}-\Delta \bar{p}_{t}=\Delta \bar{y}_{t}-\gamma \bar{i}_{t}+\bar{k}_{t}, \\
\Delta \bar{m}_{t}=\psi \Delta \bar{p}_{t-1}+\bar{\mu}_{t} .
\end{gathered}
$$

Equation (6.11) is the goods market equilibrium, or IS curve. The aggregate surprise supply function (6.12) represents the trade-off between inflation and output growth (1O); it replaces equations $(5.14),(5.17)$, and (5.18) in chapter 5. The money market equilibrium or $L M$ curve is defined by equations (6.13) and (6.14).

To understand the output effects of a change in systematic monetary policy, the IS curve, the $L M$ curve, and the trade-off between inflation and output growth (IO)

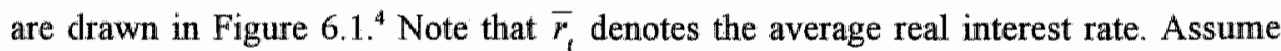
that the economy is initially in equilibrium in point $A_{0}$ in Figure 6.1. Then an increase in the degree of monetary accommodation causes the $L M$ curve to shift to the right from $L M$ to $L M^{\prime}$. This causes an increase in real average economic growth to $\Delta \bar{y}_{1}$ and an increase in average inflation to $\Delta \bar{p}_{1}$. Consequently, average inflation is expected to increase and therefore the inflation-output trade-off shifts down to $I O^{\prime}$. Furthermore, the rise in average inflation decreases average real money growth, and thus the $L M$ curve shifts back to $L M^{\prime \prime}$. Given the shift of the inflation-output trade-off from $I O$ to $1 O^{*}$, average inflation will then be $\Delta \bar{p}_{2}$ instead of $\Delta \bar{p}_{1}$. This increase in inflation will decrease real money growth even further, and thus the $L M$ curve shifts again to the left. In the end, the $L M$ curve returns to its original position and average output growth will be again equal to the average rate of natural output growth, $\Delta \bar{y}$, and average inflation will converge to a higher rate, for example, $\Delta \bar{p}_{3}$.

From this analysis several properties of the price-misperception model follow. First of all, a change in systematic monetary policy has real effects in the short run, but not in the long run. Second, a decrease and an increase in the degree of monetary accommodation have the same effect on economic growth; thus, a change in systematic policy has symmetric effects on economic growth. Third, expected changes in systematic monetary policy are non-neutral because money supply

\footnotetext{
Alternatively, a change in systematic monetary policy can be analysed in an aggregate supply, aggregate demand framework.
} 
responds with a lag to inflation. Finally, a change in systematic monetary policy has persistent effects on average output growth, that is, a change in systematic monetary policy causes not only a change in average economic growth in the period when the change in systematic policy is made, but also in later periods. The explanation for the prolonged effect is that the convergence to the long-run equilibrium average inflation rate takes time due to the lag in the money supply process. Thus, the output effect in the price-misperception model in this chapter are the same as those in the price stickiness model.

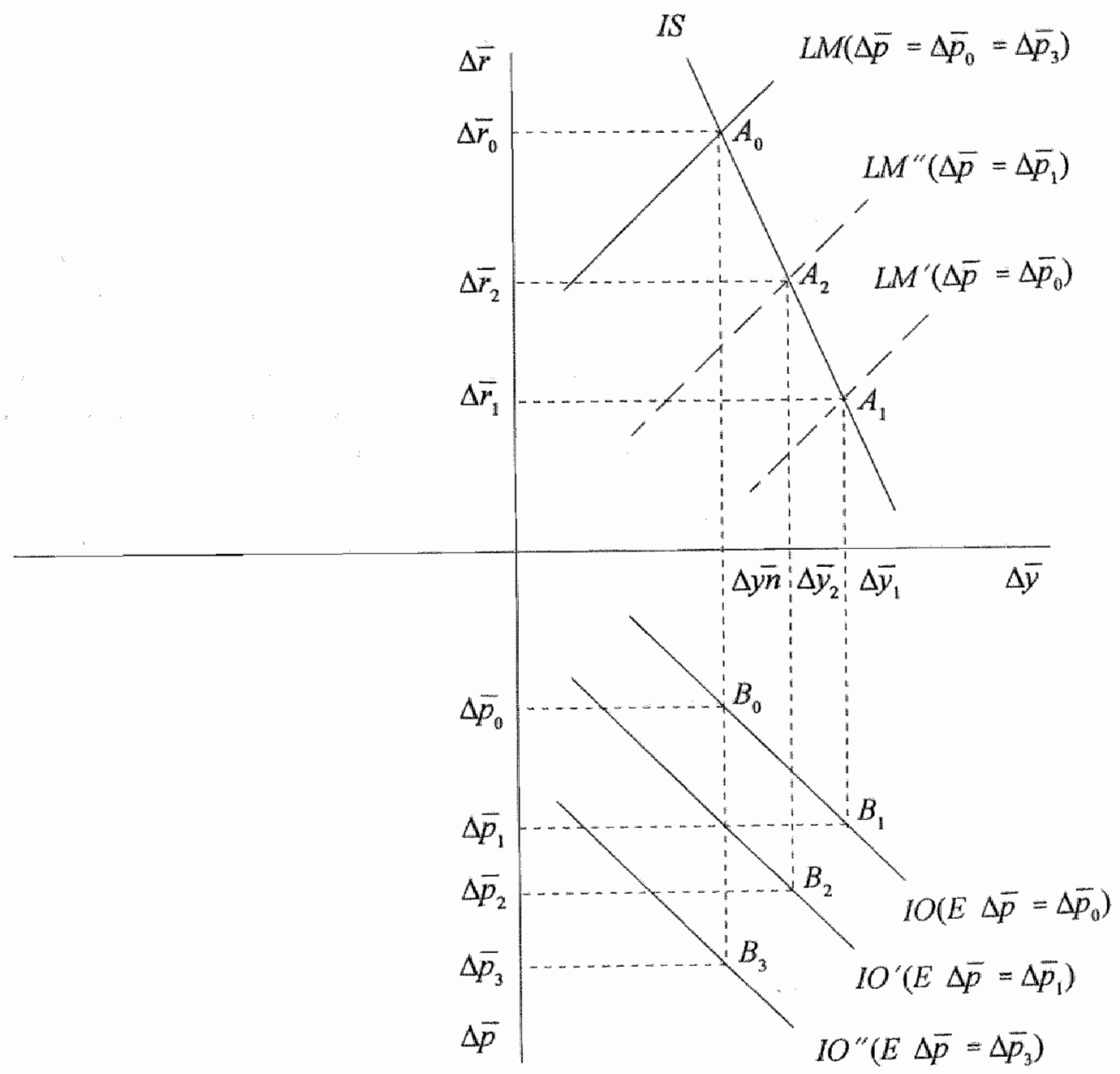

Figure 6.1 Output effects of a change in systematic monetary policy in the price-misperception model 
A change in systematic monetary policy also affects average inflation besides average output growth. For this purpose the model is solved in terms of average inflation (see appendix 6C). This gives a second order stochastic difference equation in average inflation: ${ }^{5}$

$$
\left[F^{2}-\left(\rho_{1}+\rho_{2}\right) F+\rho_{1} \rho_{2}\right] L E_{t-1} \Delta \bar{p}_{t}=0
$$

with

$$
\begin{gathered}
\rho_{1}+\rho_{2}=\frac{1+\gamma}{\gamma}, \\
\rho_{1} \rho_{2}=\frac{\psi}{\gamma},
\end{gathered}
$$

and where $F$ is the forward operator and $L$ the lag operator.

To solve this second order equation, a saddlepath solution is assumed. This implies that both roots $\rho_{1}$ and $\rho_{2}$ are real and positive, and that one of them is below unity and the other above unity. This, however, lies restrictions on the interest elasticity of real money demand, $\gamma$, and on the degree of monetary accommodation, $\psi$. To analyse these restrictions, a grid search is performed on the parameter space of $\gamma$ and $\psi$ by investigating for which values of $\gamma$ and $\psi$ the saddlepath assumption is fulfilled. For this purpose the two restrictions on the roots of equation (6.15) are rewritten as:

$$
\rho_{1}^{2}-\omega_{1} \rho_{1}+\omega_{2}=0 \quad \text { with } \quad \omega_{1}=\frac{1+\gamma}{\gamma} ; \omega_{2}=\frac{\psi}{\gamma} .
$$

Solving the quadratic equation (6.16) for $\rho_{I}$, and assuming that $\rho_{l}$ is the stable root $\left(\rho_{1}<1\right)$ and $\rho_{2}$ the unstable root $\left(\rho_{2}>1\right)$, it follows that

$$
\begin{gathered}
\rho_{1}=\frac{\omega_{1}}{2}-\frac{1}{2} \sqrt{\omega_{1}^{2}-4 \omega_{2}}, \\
\rho_{2}=\omega_{1}-\rho_{1} .
\end{gathered}
$$

Given that the interest elasticity of the real demand for money, $\gamma$, has to be strictly positive, and that the degree of monetary accommodation, $\psi$, has to lie between s in chapter 5 it is assumed that the exogenous variables $\Delta y \bar{n}_{t}$ and $\bar{\mu}_{t}$ are equal to an inter-
cept plus a white noise term; here these intercepts are normalized to zero. 
zero and unity, it is investigated for which $\gamma$ and $\psi$ both $\rho_{b}$, is positive and strictly less than unity and $\rho_{2}$ is strictly larger than unity.

It is found that the combinations of $\gamma$ and $\psi$ that fulfil the saddlepath restrictions lie below the line in Figure 6.2 and have a degree of monetary accommodation that is strictly less than unity. Normally, the interest elasticity of money demand, $\gamma$, will be around 0.1-0.2, and the degree of monetary accommodation around 0.7-0.9. If $\gamma$ and $\psi$ are in these ranges, then Figure 6.2 shows that the saddlepath restrictions are fulfilled.

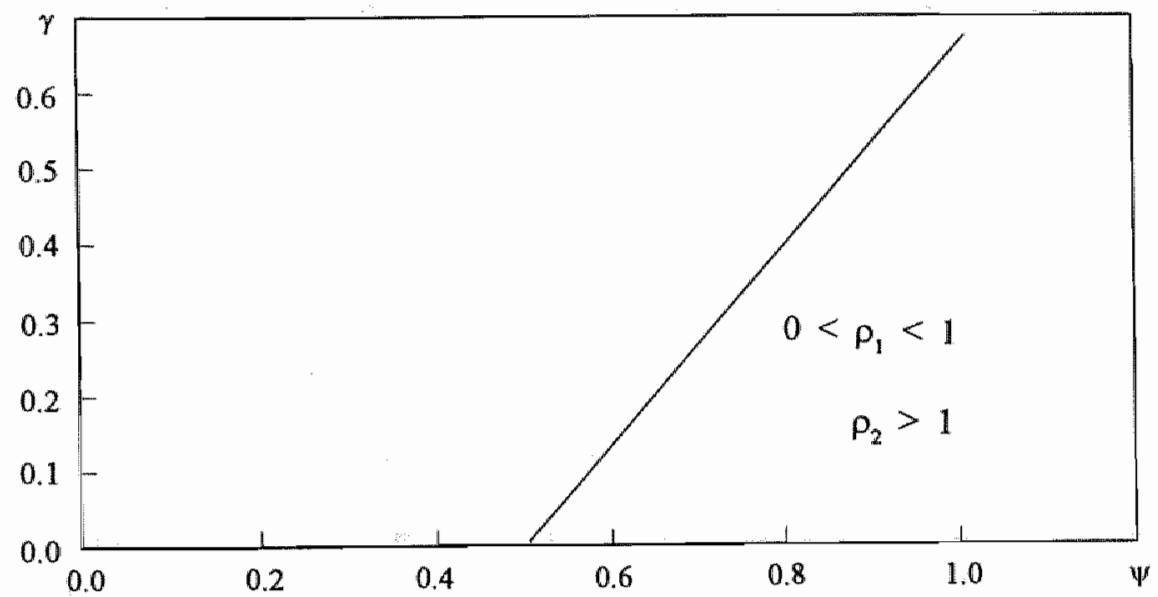

Figure 6.2 Restrictions in the average price-misperception model due to the saddlepath assumption

Given that the saddlepath assumption is fulfilled, equation (6.15) can be re-arranged as:

$$
E_{t-1} \Delta \bar{p}_{t}=\rho_{1} \Delta \bar{p}_{t-1},
$$

where $\rho_{1}$ represents the degree of persistence of average inflation. To check whether there is a strictly positive relation between the persistence of average inflation and the degree of monetary accommodation as in chapter 5 , the first derivative of $\rho_{1}$ with respect to the degree of monetary accommodation, $\psi$, is calculated from the characteristic equation of $(6.15)$ : 


$$
\frac{\partial \rho_{1}}{\partial \psi}=\left[1+\gamma(2-4 \psi)+\gamma^{2}\right]^{-\frac{1}{2}}>0 .
$$

Equation (6.20) indeed shows that the higher the degree of monetary accommodation, the more persistent average inflation is. The mechanism behind this result is the following. An increase in the degree of monetary accommodation lowers the average real interest rate and thus increases average economic growth through the real interest rate channel. This increase in average economic growth raises average inflation as the demand for goods is higher. And as an increase in the degree of monetary accommodation not only affects average economic growth in the period when the decision to increase the degree of monetary accommodation is taken, but also in later periods, average inflation has to keep increasing in order to maintain average economic growth above the average rate of natural output growth; consequently, a higher degree of monetary accommodation the persistence of average inflation increases the persistence of average inflation.

\subsection{Relative price-misperception model}

In this section the model of section 6.2 is solved as a relative model. The purpose of this analysis is to show the effects of changes in exchange rate accommodation for relative output growth and inflation. Whereas the average model focused on the consequences for both countries together, the relative model concentrates on the difference between both countries. This relative model is obtained by subtracting the basic equations (6.1)-(6.7) for country $j$ from those for country $h$, imposing the equilibrium conditions (6.8)-(6.9), and leaving (6.10) unchanged. A hat above a variable denotes the relative value of a variable, for example the difference in output growth, $\Delta \hat{y}_{t}$, is defined by $\Delta y_{j, t}-\Delta y_{h, t}$. The relative model consists of the following equations: ${ }^{6}$

6. Note that the difference of equation (6.5) between countries $j$ and $h$ drops out and that the differences of equation $(6.2),(6.6)$ and $(6.7)$ between countries $j$ and $h$ are unchanged. 


$$
\begin{gathered}
\Delta \hat{y}_{t}=-\alpha\left(\Delta \hat{i}_{t}-E_{t} \Delta \hat{p}_{t+1}+\Delta \hat{p}_{t}\right)+2 \beta \Delta e r_{j h, t}+\hat{v}_{r}, \\
\Delta e r_{j h, t}=\Delta e_{j h, t}-\Delta \hat{p}_{t}, \\
\Delta \hat{y}_{t}=\Delta y \hat{n}_{t}+\eta\left(\Delta \hat{p}_{t}-E_{t-1} \Delta \hat{p}_{t}\right), \\
\Delta \hat{m}_{t}-\Delta \hat{p}_{t}=\Delta \hat{y}_{t}-\gamma \Delta \hat{i}_{t}+\hat{k}_{t}, \\
\Delta e_{j h, t}=\phi \Delta \hat{p}_{t}, \\
E_{t} \Delta e r_{j h, t+1}=-\chi \Delta e r_{j h, t}, \\
\Delta \hat{i}_{t}=E_{t} \Delta e_{j h, t+1}-\Delta e_{j h, t} .
\end{gathered}
$$

Equations (6.21) is the goods market equilibrium or $I S$ curve. Note that, compared to equation (6.11), it includes the change in the real exchange rate. This represents the real exchange rate channel of systematic exchange rate policy. Then equation (6.22) defines the change in the real exchange rate and equation (6.23) is the aggregate surprise supply function; it replaces the relative price adjustment equation (5.23), the relative labour demand equation (5.26), and the relative wage equation (5.27) in chapter 5. Furthermore, equation (6.24) represents the money market equilibrium or $L M$ curve. Next equation (6.25) is the exchange rate accommodation equation, and equation (6.26) the mean reversion assumption with respect to the real exchange rate. Finally, equation (6.27) is the uncovered interest parity condition.

As in the average price-misperception model in section 6.3, the output effects of a change in the degree of exchange rate accommodation can also be explained by an $I S / L M$ analysis. ${ }^{7}$ Therefore the $I S$ curve, the $L M$ curve, and the trade-off between relative output growth and inflation are drawn in Figure 6.3. Suppose that the economy is initially in point $A_{*}$ with relative output growth equal to $\Delta y \hat{n}$, and relative inflation equal to $\Delta \hat{p}_{0}$. Then a higher the degree of exchange rate accommodation, causes an exchange rate depreciation and this shifts the $I S$ curve outward to $I S$. Consequently, relative economic growth increases to $\Delta \hat{y}_{\|}$and relative inflation becomes $\Delta \hat{p}_{1}$. Furthermore, the trade-off between inflation and output shifts

\footnotetext{
7 Alternatively, a change in systematic exchange rate policy can be analysed in an aggregate supply, aggregate demand framework.
} 


$$
\frac{\partial \zeta}{\partial \phi}=\frac{\eta}{\gamma} \frac{(1+\eta+\gamma) 2 \beta+(1+\chi)(\eta \gamma+\alpha(1+\eta+\gamma))}{[(1-\phi)(2 \beta+\alpha(1+\chi))+\eta]^{2}}>0 .
$$

Thus, there is a strictly positive relation between the degree of exchange rate accommodation and the persistence of relative inflation. The explanation for this result is the following. A higher degree of exchange rate accommodation increases relative economic growth through the real interest rate channel and the real exchange rate channel. This output effect, however, not only happens in the period in which this policy change is made, but also in later periods as the output effect is persistent. Then in order to keep relative output growth above the difference in natural output growth, relative inflation has to keep increasing. Thus, a higher degree of exchange rate accommodation increases the persistence of relative inflation.

Note that in contrast with the models of Alogoskoufis and Smith (1991) and Alogoskoufis (1992), there is a positive relation between the persistence of relative inflation and the degree of exchange rate accommodation in the price-misperception model instead of an ambiguous relation. This is due to the fact that an increase in the degree of exchange rate accommodation is transmitted only through the real interest rate channel and the real exchange rate channel, but not through the wage cost channel. This wage cost channel is absent here because the wage equation in chapter 5 , together with the price adjustment equation, and the labour demand equation, have been replaced in this chapter by the aggregate surprise supply equation. Because an increase in the degree of exchange rate accommodation causes an increase in the persistence of relative inflation through the real exchange rate channel as well as the real interest rate channel, is the total effect of an increase in the degree of exchange rate accommodation on the persistence of relative inflation strictly positive. 


\subsection{Conclusion}

In this chapter a price-misperception model has been built in which the effects of changes in systematic monetary and exchange policy have been investigated. The model is a flexible price, misperception variant of the price stickiness models of Alogoskoufis and Smith (1991) and Alogoskoufis (1992). It differs from these models on three points. First of all, the assumption of flexible prices implies that output comes about by the interaction of supply and demand. Because aggregate supply is undetermined in the price stickiness model of chapter 5 due to the implicit assumption of constant returns to scale, this assumption bas been replaced in this chapter by decreasing returns to scalle. In this case, maximizing profits given production technology gives an aggregate surprise supply function. This aggregate surprise supply function replaces the price adjustment equation, the labour demand equation, and the wage equation in chapter 5 . This has two effects: i) the wage cost channel disappears because it works through the wage equation; ii) the labour supply equation becomes superfluous.

Second, the response of world money supply growth to changes in world inflation is lagged one period in order to have a strictly positive relation between the degree of exchange rate accommodation and the persistence of average inflation in the average model. This change can be defended by arguing that it takes time to coordinate monetary policies between two countries. Third, the real exchange rate is assumed to return to purchasing power parity in order to be able to solve the relative model. This change can be defended by noting in the Alogoskoufis models the real exchange rate can devalue endlessly; empirical evidence, however, suggests that in the longer run the real exchange rate returns to purchasing power parity.

As in the sticky price models of Alogoskoufis and Smith (1991) and Alogoskoufis (1992), a change in systematic monetary and exchange rate policy has only a real effect in the short run. Second, a decrease in the degree of accommodation has exactly the opposite effect on output growth as an increase. Thus the effects on output growth are symmetric. Furthermore, an expected increase in the degree of accommodation does affect economic growth. Finally, a change in systematic policy has a persistent effect on economic growth. Thus, the conclusions for output growth with respect to systematic policy are the same as in the price stickiness model in chapter 5 .

With respect to systematic monetary policy it is found that a higher degree of monetary accommodation increases the persistence of average inflation in the pricemisperception model for reasonable values of the interest elasticity of real money demand and the degree of monetary accommodation. In the price stickiness model of chapter 5 a comparable result was found, however, the parameter restrictions were less strict as only the degree of exchange rate accommodation had to be strictly less than unity. 
Furthermore, with respect to systematic exchange rate policy it is found that a higher degree of exchange rate accommodation increases the persistence of relative inflation in the price-misperception model, whereas the link was ambiguous in the price-stickiness models. This difference is due to the fact that a change in the degree of exchange rate accommodation is only transmitted through the real interest rate channel and the real exchange rate channel. In the price-stickiness models it is also transmitted through wage cost channel. An increase in the degree of exchange rate accommodation increases the persistence of relative via the real interest rate channel, the real exchange rate channel and the imported inflation channel, but decreases via the wage cost channel: As this latter channel is absent in the pricemisperception model, the relation becomes strictly positive. Note, however, that a persistence of relative inflation between zero and unity implies serious restrictions on the parameter space in the price-misperception model; in the price stickiness model of chapter 5 only the degree of exchange rate accommodation has to be strictly less than unity to guarantee this. 


\section{Appendix 6A Derivation of aggregate supply function}

Given that technology is defined by a Cobb-Douglas production function with decreasing returns to scale in labour and a fixed capital stock, the production for country $j$ can be written in levels as:

$$
Y_{j, t}=Q_{j, t} L_{j, t}{ }^{\kappa} \quad 0<\kappa<1 .
$$

Assuming that profits $Z_{j, t}$ are defined as prices times output minus labour costs, that is:

$$
Z_{j, t}=P_{j, r} Y_{j, t}-W_{j, t} L_{j, r},
$$

then maximizing profits $Z_{j, t}$ given the production function (6A.1) and taking natural logs gives the following aggregate supply function:

$$
\ln Y_{j, r}^{s}=\frac{\kappa}{1-\kappa} \ln \kappa+\frac{1}{1-\kappa} \ln Q_{j, r}+\frac{\kappa}{\kappa-1} \ln W_{j, r}+\frac{\kappa}{1-\kappa} \ln P_{j, r}(6 \mathrm{~A} .3)
$$

Now taking first differences of (6A.3), and approximating wage growth by expected rate of inflation, $E_{t-1} \Delta p_{j, t}$, it can be rewritten as the Lucas surprise supply function (6.3):

$$
\Delta y_{j, t}^{s}=\Delta y n_{j, t}+\eta\left(\Delta p_{j, t}-E_{t-1} \Delta p_{j, t}\right) \quad \eta=\frac{\kappa}{1-\kappa}>0,
$$

where $\Delta y n_{j, t}$ is the natural output growth.

\section{Appendix 6B Derivation of the relative price-misperception mo- del given a modified exchange rate equation}

In this appendix it is shown that replacing the nominal exchange rate equation (6.6) by (6.6a) (see footnote 3 ) still generates a strictly positive relation between the persistence of relative inflation and the degree of exchange rate accommodation. The new basic model consists of equations (6.1)-(6.5), (6.6a), (6.7)-(6.8), (6.10) and the money market equilibrium condition:

$$
\Delta m_{g, t}^{d}=\Delta m_{g, t}^{s}=\Delta m_{g, r} \quad g=j, h .
$$

Equilibrium on the domestic money is assumed because money is identified for both countries. This basic model can be solved as an average model and as a rela- 
tive model. As replacing equation (6.6) by equation (6.6a) does not change the average model, its solution does not have to be repeated; it can be found in section 6.2 .

The relative model consists of equations $(6.21)-(6.24),(6.26)-(6.27)$, and the new equation for the change in the nominal exchange rate which follows from equation (6.6a):

$$
\Delta e_{j h, t}=\phi \Delta \hat{m}_{s}
$$

This relative model is solved as follows. First, equation (6.22) is substituted in equation (6.26). This gives:

$$
E_{s} \Delta e_{j h, t+1}=E_{t} \Delta \hat{p}_{t+1}-\chi \Delta e_{j h, t}+\chi \Delta \hat{p}_{g} .
$$

Then substituting equation (6B.3) into (6.27) gives:

$$
\Delta \hat{i}_{t}=E, \Delta \hat{p}_{t+1}-(1+\chi) \Delta e_{j h, t}+\chi \Delta \hat{p}_{t} .
$$

If equation (6B.2) and (6B.4) is filled into (6.21), relative output growth is defined by:

$$
\Delta \hat{y}_{1}=(2 \beta+\alpha(1+\chi)) \phi \Delta \hat{m}_{t}-(2 \beta+\alpha(1+\chi)) \Delta \hat{p}_{t}+\hat{v}_{t} .
$$

Next, substituting equation (6B.4) into (6.24) gives an expression for relative money growth:

$$
\Delta \hat{m}_{t}=\frac{1}{1-\gamma \phi(1+\chi)}\left[\Delta \hat{y}_{t}-\gamma E_{r} \Delta \hat{p}_{s+1}+(1-\gamma \chi) \Delta \hat{p}_{t}+\hat{k}_{t}\right] .
$$

Substituting (6B.6) into (6B.5) and re-arranging this expression results in:

$$
\begin{aligned}
\Delta \hat{y}_{t} & =K_{1}\left[(1-\gamma \chi) \Delta \hat{p}_{s}-\gamma E_{t} \Delta \hat{p}_{t+1}+\hat{k}_{t}\right] \\
& +K_{2}\left[\hat{v}_{t}-(2 \beta+\alpha(1+\chi)) \Delta \hat{p}_{t}\right]
\end{aligned}
$$

where 


$$
\begin{aligned}
& K_{1}=\frac{[2 \beta+\alpha(1+\chi)] \phi}{1-\phi[(\alpha+\gamma)(1+\chi)+2 \beta]}, \\
& K_{2}=\frac{1-\gamma \phi(1+\chi)}{1-\phi[(\alpha+\gamma)(1+\chi)+2 \beta]} .
\end{aligned}
$$

Now setting equation (6B.7) equal to equation (6.23), and re-arranging this expression, the following differential equation is obtained:

$$
\begin{gathered}
E_{r} \Delta \hat{p}_{t+1}+\frac{\eta-(1-\gamma \chi) K_{1}+(2 \beta+\alpha(1+\chi)) K_{2}}{\gamma K_{1}} \Delta \hat{p}_{t}-\frac{\eta}{\gamma K_{1}} E_{t-1} \Delta \hat{p}_{t}= \\
\frac{1}{\gamma K_{1}}\left[-\Delta y \hat{n}_{t}+K_{1} \hat{k}_{\mathrm{r}}+K_{2} \hat{\vartheta}_{\mathrm{r}}\right] .
\end{gathered}
$$

Now taking expectations based on the information available on time $t-1$ and assuming that $\Delta y \hat{n}_{t}$ behaves like a white noise, gives the following differential equation in relative inflation:

$$
E_{t-1} \Delta \hat{p}_{t+1}=\frac{(1-\gamma \chi) K_{1}-(2 \beta+\alpha(1+\chi)) K_{2}}{\gamma K_{1}} E_{t-1} \Delta \hat{p}_{\mathrm{r}}
$$

The persistence of relative inflation, $\zeta$, can be obtained from equation (6B.9):

$$
\zeta=\frac{\partial E_{t-1} \Delta \hat{p}_{t+1}}{\partial E_{t-1} \Delta \hat{p}_{t}}=\frac{\phi(\mathbb{1}+\gamma)-1}{\gamma \phi}
$$

Finally the link between the persistence of relation inflation turns out to be strictly positive with respect to the degree of exchange rate accommodation. This can be shown by calculating the derivative of $\zeta$ with respect to $\phi$ :

$$
\frac{\partial \zeta}{\partial \phi}=\frac{1}{\phi^{2}}>0 .
$$

Q.e.d. 


\section{Appendix $6 \mathrm{C}$ Solution of the average price-misperception model}

Model (6.11)-(6.14) is solved as follows. First, money growth is eliminated by substituting equation (6.14) into (6.13). This equation is rewritten in terms of the change in the average interest rate $\overline{\Delta i}$ :

$$
\Delta \bar{i}_{t}=\frac{1}{\gamma} \Delta \bar{p}_{t}-\frac{\psi}{\gamma} \Delta \overline{\bar{p}}_{t-1}+\frac{1}{\gamma} \Delta \bar{y}_{t}+\frac{1}{\gamma}\left(\bar{k}_{t}-\bar{\mu}_{t}\right) .
$$

Then substituting (6.12) into (6C.1) gives:

$$
\overrightarrow{\Delta i}_{t}=\frac{1}{\gamma} \Delta \bar{p}_{t}-\frac{\psi}{\gamma} \Delta \bar{p}_{t-1}+\frac{1}{\gamma}\left(\Delta y \bar{n}_{t}+\eta\left(\Delta \vec{p}_{t}-E_{t-1} \Delta \bar{p}_{t}\right)\right)+\frac{1}{\gamma}\left(\bar{k}_{t}-\bar{\mu}_{t}\right) .
$$

The next step is to substitute equation (6C.2) and (6.12) into (6.11). This gives the following expression for $\Delta \bar{p}$ :

$$
\begin{gathered}
\Delta \bar{p}_{t}=\frac{\gamma}{\eta(\alpha+\gamma)+\alpha(1+\gamma)}\left[-\frac{\alpha+\gamma}{\alpha} \Delta y \bar{n}_{t}+\frac{\eta(\alpha+\gamma)}{\gamma} E_{t-1} \Delta \bar{p}_{t}+\frac{\alpha \psi}{\gamma} \Delta \bar{p}_{t-1}\right. \\
\left.-\frac{\alpha}{\gamma}\left(\bar{k}_{t}-\bar{\mu}_{t}\right)+\alpha E_{t} \Delta \bar{p}_{t+1}+\bar{p}_{t}\right]
\end{gathered}
$$

Finally, expectations are taken of equation (6C.3) conditional on the information available on time $t-1$. This equation can then be re-arranged as equation (6.15).

\section{Appendix 6D Solution of the relative price-misperception model}

Model (6.21)-(6.27) is solved as follows. Using equations (6.22), (6.25), (6.26) and (6.27) the change in the interest differential $\Delta \hat{i}$, becomes:

$$
\Delta \hat{i}_{i}=E_{t} \Delta \hat{p}_{i+1}+[\chi-\phi(1+\chi)] \Delta \hat{p}_{t} .
$$

Then substituting (6.19) and (6D.1) into (6.21) gives: 


$$
\Delta \hat{y}_{i}=-(1-\phi)(2 \beta+\alpha(1+\chi)) \Delta \hat{p}_{i}+\hat{v}_{i}
$$

Substituting equation (6D.1) into (6.24), the expected inflation difference $E_{t-1} \Delta \hat{p}_{r}$ can be obtained:

$$
E_{t-1} \Delta \hat{p}_{t}=\frac{1}{\gamma} \Delta \hat{y}_{t-1}-\frac{1}{\gamma} \Delta \hat{m}_{t-1}+\left[\frac{1}{\gamma}-\chi+\phi(1+\chi)\right] \Delta \hat{p}_{t-1}+\frac{1}{\gamma} \hat{k}_{t-1} .
$$

By substituting (6D.3) into (6.23) and equating it to (6D.2), equation (6.28) is obtained after rearranging. 


\section{Inflation Convergence and Exchange Rate Policy: A Case Study for Spain and Italy}

\subsection{Introduction}

Aggregate demand policy can be divided into unsystematic and systematic policy. Unsystematic aggregate demand policy was the subject of chapters 3 and 4 , where it was explained that shocks, e.g. shocks in the money stock, have only a temporary effect on real output and that frequent use of demand shocks reduces the real effect of such a therapy. Chapters 5 and 6 focused on systematic aggregate demand policy. It was concluded that a change in systematic policy, for example an increase in the degree of monetary or exchange rate accommodation, can have only a short run effect on real output. In the long run a government cannot obtain a higher output volume by following expansionary aggregate demand policies, only a higher inflation will result.

Whereas systematic policy cannot achieve a higher output growth in the long run, chapters 5 and 6 show that it can be used to attain a lower inflation rate. More specifically, they state that the lower the degree of monetary accommodation is, the less persistent average inflation will be, and that the lower the degree of exchange rate accommodation is, the less persistent relative inflation becomes, and thus the faster inflation rates converge. The advantage of a disinflation policy is that it may improve the efficiency of the price system (see Friedman, 1977); especially if inflation is rather high, these gains can be large.

This chapter will empirically investigate which decisions with respect to systematic exchange rate policy did increase the speed of inflation convergence of Spain and Italy. ${ }^{2}$ In the mid-1970s Spain as well as Italy had difficulties in controlling inflation because it was difficult to stick to a strong exchange rate policy given that unemployment was rising rapidly and the central bank lacked political independen-

Unsystematic policy affects the real economy by shocks in, for example, government expenditures, the money stock or the exchange rate, whereas systematic policy affects the real economy by changes in the rules for these variables.

2 Attention is restricted here to systematic exchange rate policy because changes in systematic exchange rate policy can be observed more easily than changes in systematic monetary policy. 
$\mathrm{H}^{3}$

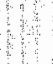

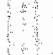

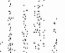

(3)

$\vdots$
$\vdots$
$\vdots$
$\vdots$

(1)

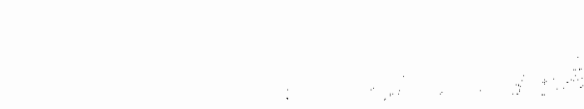

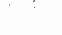




\section{Inflation Convergence and Exchange Rate Policy: A Case Study for Spain and Italy}

\subsection{Introduction}

Aggregate demand policy can be divided into unsystematic and systematic policy. ${ }^{1}$ Unsystematic aggregate demand policy was the subject of chapters 3 and 4 , where it was explained that shocks, e.g. shocks in the money stock, have only a temporary effect on real output and that frequent use of demand shocks reduces the real effect of such a therapy. Chapters 5 and 6 focused on systematic aggregate demand policy. It was concluded that a change in systematic policy, for example an increase in the degree of monetary or exchange rate accommodation, can have only a short run effect on real output. In the long run a government cannot obtain a higher output volume by following expansionary aggregate demand policies, only a higher inflation will result.

Whereas systematic policy cannot achieve a higher output growth in the long run, chapters 5 and 6 show that it can be used to attain a lower inflation rate. More specifically, they state that the lower the degree of monetary accommodation is, the less persistent average inflation will be, and that the lower the degree of exchange rate accommodation is, the less persistent relative inflation becomes, and thus the faster inflation rates converge. The advantage of a disinflation policy is that it may improve the efficiency of the price system (see Friedman, 1977); especially if inflation is rather high, these gains can be large.

This chapter will empirically investigate which decisions with respect to systematic exchange rate policy did increase the speed of inflation convergence of Spain and Italy. ${ }^{2}$ In the mid-1970s Spain as well as Italy had difficulties in controlling inflation because it was difficult to stick to a strong exchange rate policy given that unemployment was rising rapidly and the central bank lacked political independen-

Unsystematic policy affects the real econony by shocks in, for example, government expenditures, the money stock or the exchange rate, whereas systematic policy affects the real economy by changes in the rules for these variables.

2 Attention is restricted here to systematic exchange rate policy because changes in systematic exchange rate policy can be observed more easily than changes in systematic monetary policy. 
ce. From the end of the 1970 s both countries tried to lower domestic inflation with exchange rate policies. Both countries are investigated in this chapter because they have a quite different institutional setting but a comparable exchange rate performance vis-à-vis the Deutschmark.

There are two kinds of systematic exchange rate pollicy decisions that can increase the speed of inflation convergence. First of all, according to chapters 5 and 6 a country will obtain a higher speed of inflation convergence only if it opts for a hard official or unofficial peg to a low inflation currency like the Deutschmark. The harder the peg is, the longer the period of real appreciation of the high inflation currency is and the faster inflation converges to the German rate. Second, according to the borrowed credibility hypothesis a country can accelerate inflation convergence by joining a fixed exchange-rate regime like the Exchange Rate Mechanism (ERM) of the European Monetary System (EMS). Note, however, that participation in such an exchange rate mechanism does not imply that a currency gets a hard peg with respect to the Deutschmark. As long as a currency is devalued when the exchange rate parity cannot be maintained anymore, the peg keeps weak.

The purpose of this chapter is to test whether the speed of inflation convergence of Spain and Italy increased at the moment they joined the ERM or when they maintained a hard peg to the Deutschmark over the period 1975-1995. To investigate this question a structural break analysis is performed using the autoregressive model of order 1 for relative inflation that is implied by chapters 5 and 6 . It is found for Spain as well as Italy that the speed of inflation convergence increases only if a country commits itself to a hard peg with respect to the Deutschmark; entrance into the ERM does not increase convergence speed. This supports the model of chapters 5 and 6 , but rejects the borrowed credibility hypothesis.

This chapter is arranged as follows. Sections 7.2 and 7.3 describe the major economic developments in the period 1975-1995 for Spain and Italy respectively. In section 7.4.1 an inflation convergence model is constructed from the autoregressive process of relative inflation in chapters 5 and 6 . Section 7.4 .2 determines which points in time may be structural breaks in the process of inflation convergence; these points are taken from sections 7.2 and 7.3. The data-sources for the empirical analysis are reported in section 7.5. Then section 7.6 performs a structural break analysis for Spain on the inflation convergence model of section 7.4.1 given the possible breaks identified in section 7.4.2. In section 7.7 the analysis of section 7.6 is repeated for Italy. Finally, section 7.8 contains the main conclusions.

\subsection{Main economic developments in Spain during 1975-1995}

In the middle of the 1970s the Spanish economy faced two main problems. First, the economy was rigid and protected. For example, the labour market was highly regulated, heavy import restrictions existed and the financial sector was protected 
against foreign competition. Second, the monetary authorities had lost control over inflation. As a result of the rise in oil prices and accommodating monetary policy, inflation rose to 25 per cent in 1977. To tackle inflation, the central bank started at money targeting policy by slowly decreasing money growth targets (see Table 7.1), which signals the central banks intention to abstain from policy-induced money shocks and to reduce the degree of monetary accommodation. And in order to regain the ability to adjust to changing economic situations, the economy had to be revitalized. More specifically, the efficiency of production factor utilization had to be increased, more labour flexibility was necessary, the financial system had to be liberalized, and inflation had to be reduced to the level of competitors.

Table 7.1 Money growth targeting in Spain

\begin{tabular}{|c|c|c|c|c|c|c|c|c|}
\hline & \multirow[t]{2}{*}{$\begin{array}{r}\text { Targeted } \\
\text { series }\end{array}$} & \multicolumn{2}{|c|}{$\begin{array}{r}\text { M3 target range } \\
(\%)\end{array}$} & \multicolumn{2}{|c|}{$\begin{array}{l}\text { ALP target range } \\
(\%)\end{array}$} & \multirow{2}{*}{$\begin{array}{r}\text { M3 } \\
\text { growth } \\
(\%)\end{array}$} & \multirow{2}{*}{$\begin{array}{r}\text { ALP } \\
\text { growth } \\
(\%)\end{array}$} & \multirow[t]{2}{*}{$\begin{array}{l}\text { Target } \\
\text { achiewed }\end{array}$} \\
\hline & & $\begin{array}{l}\text { Lower } \\
\text { target }\end{array}$ & $\begin{array}{l}\text { Upper } \\
\text { target }\end{array}$ & $\begin{array}{l}\text { Lower } \\
\text { target }\end{array}$ & $\begin{array}{l}\text { Upper } \\
\text { target }\end{array}$ & & & \\
\hline 1978 & M3 & 14.5 & 19.5 & - & - & 21.7 & - & No \\
\hline 1979 & M3 & 15.0 & 20.0 & - & - & 17.2 & - & Yes \\
\hline 1980 & M3 & 16.0 & 20.0 & - & - & 20.4 & 21.0 & Nio \\
\hline 1981 & $M 3$ & 14.5 & 18.5 & - & - & 16.0 & 17.0 & Yes \\
\hline 1982 & ALP & 13.5 & 17.5 & 16.6 & 20.6 & 14.0 & 16.6 & Yes \\
\hline 1983 & ALP & 11.0 & 15.0 & 13.5 & 17.5 & 12.9 & 16,2 & Yes \\
\hline 1984 & ALP & 8.0 & 12.0 & 10.5 & 14.5 & 12.0 & 13.3 & Yes \\
\hline 1985 & ALP & - & - & 11.5 & 14.5 & 5.5 & 13.0 & Yes \\
\hline 1986 & ALP & - & - & 9.5 & 12.5 & 3.9 & 162 & No \\
\hline 1987 & ALP & - & - & 6.5 & 9.5 & 7.7 & 14.8 & Nó \\
\hline 1988 & ALP & - & - & 8.0 & 11.0 & 12.8 & 13.4 & No \\
\hline 1989 & $\mathrm{ALP}$ & - & - & 6.5 & 9.5 & 15.0 & 14.8 & No \\
\hline 1990 & ALP & - & - & 6.5 & 9.5 & 13.5 & 11.9 & No \\
\hline 1991 & ALP & - & - & 7.0 & 11.0 & 10.9 & 11.4 & No \\
\hline 1992 & ALP & - & - & 8.0 & 11.0 & 4.8 & 5.2 & Yes \\
\hline 1993 & ALP & - & - & 4.5 & 7.5 & 9.3 & 10.1 & No \\
\hline 1994 & ALP & - & - & 3.0 & 7.0 & 7,5 & 70 & Yes \\
\hline
\end{tabular}

In the first ten years until 1985, the Spanish central bank was able to bring inflation down to about 9 per cent at the cost of an enormous rise in unemployment from 5 per cent to 22 per cent in 1985 . This rise in unemployment was due not only to the 
money targeting policy, but also to low real economic growth, industrial restructuring, and the labour-saving nature of private investments. Whereas monetary policy was restrictive, fiscal policy was loose: the general government deficit increased steadily from an almost balanced budget to a deficit of about 7 per cent in 1985 . Given the inflation reduction that had been achieved, the central bank was able to shadow the Deutschmark from the middle of 1985 onwards (see Figure 7.1). The aim of this decision was to speed the convergence of the Spanish inflation towards the German rate and to prepare the entry of the peseta into the ERM.

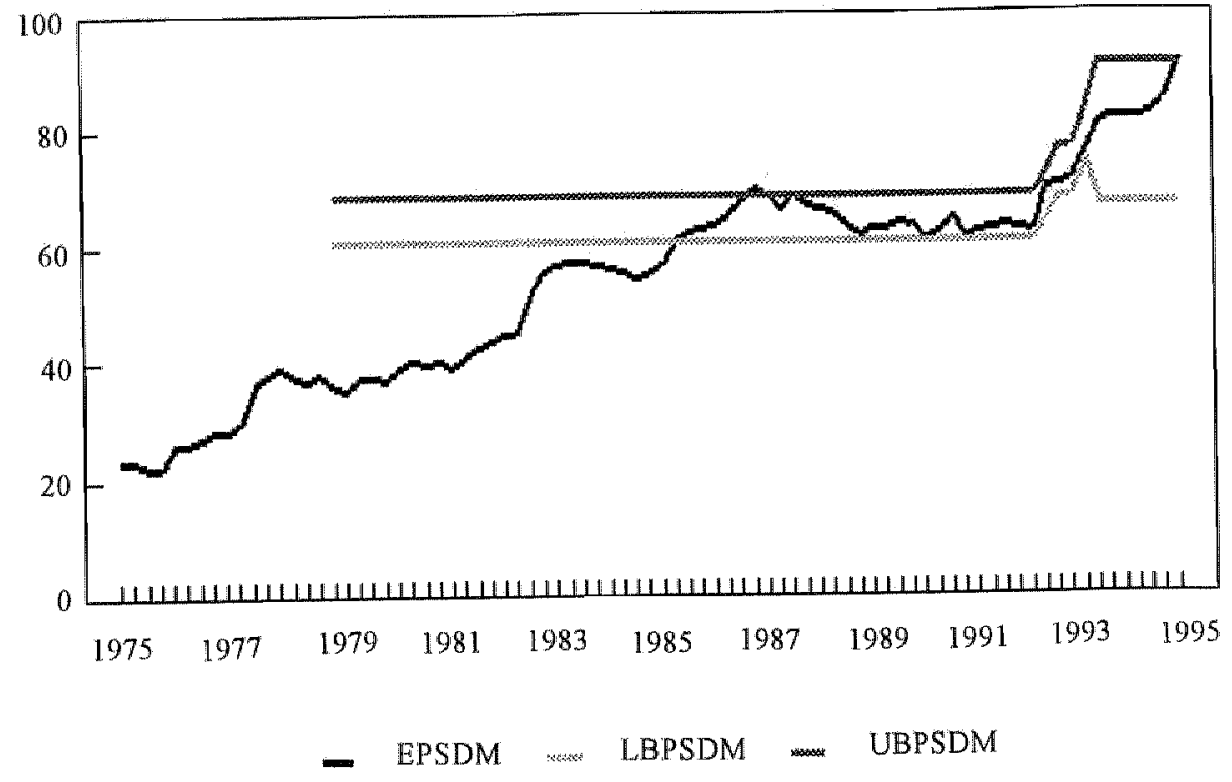

Figure 7.1 Exchange rate of the Spanish peseta per Deutschmark (EPSDM), the lower EMS band (LBPSDM), and the upper EMS band (UBPSDM)

As a result of the economic boom in the major industrial countries in the middle of the eighties, the growing openness of the Spanish economy, the entry into the European Community in January 1986, and the effect of the structural adjustment programmes ${ }^{3}$, the upward trend in unemployment was reversed: it dropped from

\footnotetext{
3 These programmes consisted of such actions as increasing labour market flexibility, industrial restructuring, lightening of the social security costs for employers and the dismantling of protection.
} 
nearly 21 per cent in 1986 to 17 per cent in 1989 . The increase in openness as measured by the increase in exports and imports relative to gross domestic product was, however, not limited to the goods market. The financial markets became more open too. Furthermore, given that Spanish interest rates were higher than German rates due to the restrictive Spanish monetary policy, and that the peseta was rather stable, it was very attractive for foreigners to invest in Spanish bonds. The capital inflows that resulted, together with the expansionary character of fiscal policy, impelled the central bank to tighten money supply in 1988 and 1989. Therefore the central bank was not able to achieve its money growth target (see Table 7.1). To control the pressure on the peseta, and to make anti-inflation policy even more credible, Spain decided in June 1989 to join the ERM. After the entry of the peseta, the speculation on a further appreciation of the peseta largely disappeared, but the interest rate differential remained high.

In the beginning of the nineties the sentiment in the currency markets was rather optimistic about the possibility that the exchange rate parities in the ERM did not have to be adjusted and that the EMS had become a quasi-monetary union (see Bakker, 1996) as the exchange rate parities had been unchanged since January 1987. After the rejection of the Maastricht Treaty by the Danish referendum in June 1992, this feeling was reversed. It was no longer certain that the exchange rate parities could remain unchanged and the market speculated on the devaluation of weak currencies in the EMS like the peseta and the lira. This sentiment was enforced by the increasing probability that the Maastricht treaty would be rejected in September 1992 by the French referendum. For Spain, there were also fundamental reasons for a speculative attack, namely higher current account deficits, decreased net foreign capital inflows and rising public deficits. In September 1992 the pressure on the EMS became so great that some of the exchange rate parities could not be defended anymore. The Italian lira and the British pound left the ERM, and the Spanish peseta was devalued. In November 1992 and in May 1993 the peseta had to be devalued again. And in August 1993 the band widths were adjusted to 15 per cent due to heavy exchange rate speculation. The Spanish peseta, however, remained inside the ERM. Due to renewed turbulence in international capital markets it was again necessary to devalue the peseta in March 1995.

The fact that the peseta is still in the ERM, in spite of the two EMS crises and the devaluation of March 1995, shows that Spain is eager to integrate into Europe and to meet the EMU criteria. This willingness was stressed in the March 1992 Convergence Programme for 1992-1996. ${ }^{4}$ The ambitious targets in this programme, however, have not been achieved; unemployment, for example, rose from 16 per cent in 1990 to over 24 per cent in 1994, and dropped only a little thereafter. This programme was renewed in 1994 and it aims to achieve the Maastricht criteria in

4 OECD, Economic Surveys, Spain, 1993: 30-31. 
1997 instead of 1996 as in the 1992 Convergence Programme. Another decision Spain made to show its commitment was to grant the Bank of Spain autonomy in June 1994. More specifically, the primary objective of the centrall bank was defined as price stability, and monetization of government debts was prohibited (see OECD, Economic Surveys, Spain, January 1996: 39-43).

\subsection{Main economic developments in Italy during 1975-1995}

In the second half of the seventies Italy faced serious problems in keeping inflation low. Whereas inflation was about 5 per cent in 1972, it rose to 17 per cent in 1975 . This large increase in inflation was the result of the first oil crisis, the swift rise in the price of raw materials, the strong depreciation of the lira, and the rapid increase in unit labour costs. Besides the difficulty in controlling inflation, the government had to deal with labour market rigidity, an unsuitable industrial structure for international competition and high government deficits. Given such a critical situation of the Italian economy and the worldwide decline in economic activity in the midseventies, unemployment started to increase year by year. The rise in unemployment was so serious that the government decided to counter the upward trend by aiming at an employment growth of four per cent a year. In order to achieve such a high employment growth, low wage inflation, a stabilization of the public sector deficit, and a reallocation of public expenditure towards investment were necessary.

By 1978 inflation had fallen to 12 per cent. This was due to a slower rise of import prices, strengthening of the lira, the drop in oil and raw material prices, and a partial budgetization of social security contributions. ${ }^{3}$ However, the decrease in inflation was only temporary. In order to lower inflation, Italy joined the Exchange Rate Mechanism (ERM) of the European Monetary System (EMS) in March 1979. The idea behind Italy's decision was that the country hoped to avert an inflationdepreciation spiral by pegging the lira to a strong currency. Inflation, however, rose further to around 21 per cent in 1980. This rise in inflation was due to the second oil crisis, increased public utility charges and higher rents. Furthermore, the government contributed to the inflation problem: the deficits that resulted from the attempts to stimulate the economy in the mid-seventies were so severe that they interfered with monetary policy.

It was difficult for Italy to maintain the initial exchange rate for the lira while domestic inflationary pressure rose, interest differentials were high, and the balance of payments deficits were severe. Therefore devaluations were necessary in March 1981, October 1981 and in June 1982 (see Figure 7.2). Exchange rate policy,

\footnotetext{
5 A budgetization of social security contributions slows down labour costs: given a progressive tax system an increase in nominal wage generates a more than proportional increase in wage taxes; the latter is used to finance the decrease in social security contributions (see Giavazzi and Spaventa, 1989).
} 
however, had become firmer than before the participation in ERM. ${ }^{6}$ The stronger exchange rate policy together with reductions of social security contributions, provided a stimulus for uncompetitive firms to rationalize and increase productivity and thus induced a huge restructuring and modemization of industry in the beginning of the eighties (see Giavazzi and Spaventa, 1989). This caused real growth to pick up as quickly as 1983, after the 1981-1982 recession. By July 1985, however, a devaluation was necessary to relieve the speculative pressure on the lira. Moreover, excessive current account and official reserves losses urged the central bank to stop capital outflow. Only in 1985 did the Italian government get a grip on fiscal policy. From then on the trend in the general government deficit was reversed and it decreased gradually from a high of 15 per cent in 1985 .

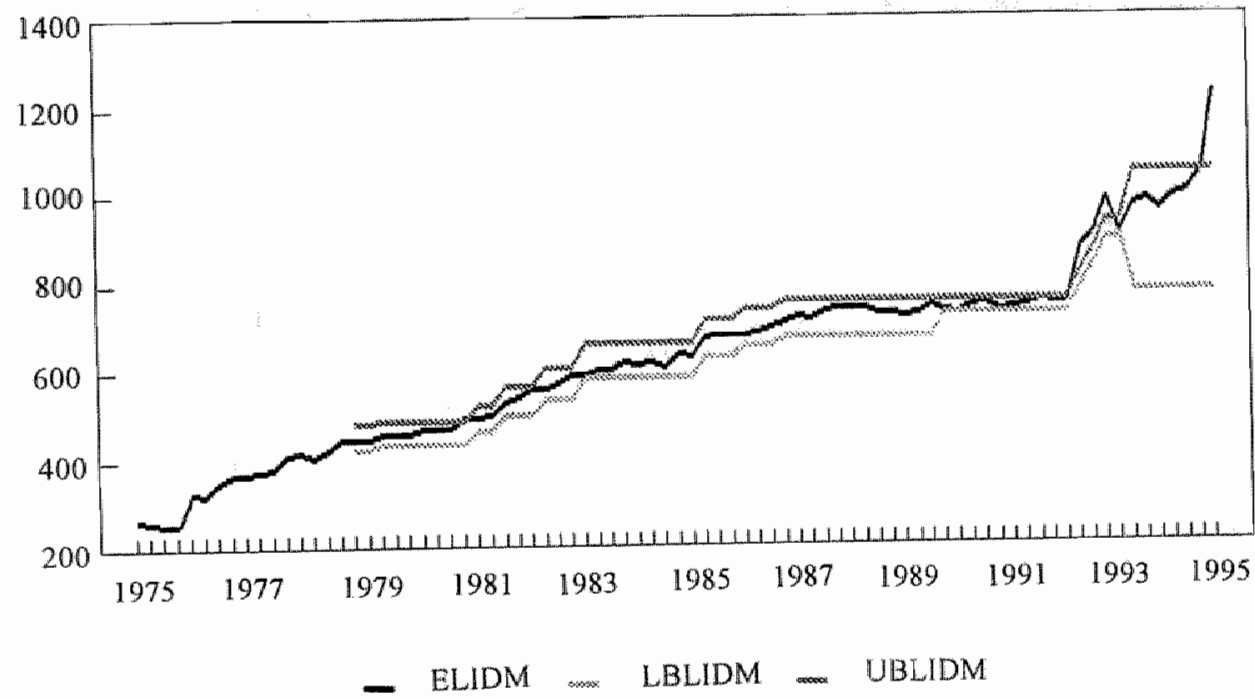

Figure 7.2 Exchange rate of the Italian lira per Deutschmark (ELIDM), the lower EMS band (LBLIDM), and the upper EMS band (UBLIDM)

In spite of the fact that Italy was not able to keep the exchange parity unchanged during the period 1980-1986 and the fact that the public deficits had not been

\footnotetext{
6 Before the ERM participation exchange rate policy rested on two pillars: holding import prices low by keeping the lira stable against the US dollar, and maintaining competitiveness of Italian exports by allowing a gradual depreciation against currencies that were appreciating against the US dollar (the Swiss franc, the Deutschmark, and the Yen).
} 
stabilized, its disinflation policy was rather successful. Whereas inflation was 21 per cent in 1980 , it had declined to about 5 per cent in 1986. The central bank realized that maintaining a hard peg to the Deutschmark would help Italian inflation converge to the German rate. This attitude led Italy not to devalue the lira in the April 1986 and January 1987 round of ERM realignments. As a result the lira got a hard peg with respect to the Deutschmark, whereas it had behaved like a managed floating currency until the end of 1986 (see Figure 7.2). The upward trend in unemployment that started in the mid-seventies only stopped in 1989 when it was about 12 per cent. Thereafter unemployment started to decline.

In January 1990 smaller band widths of 2.25 per cent were adopted to increase the credibility of the peg even more. At the same time the currency was again devalued such that the upper band did not increase (see Figure 7.2). Exchange rate speculation started in October 1991 due to the threat of larger budget deficits, excessive government spending and political instability. This set the stage for the September 1992 devaluation. On September 16, Italian monetary authorities suspended ERM participation as they could not defend the exchange rate parity anymore given the speculation against the lira. The exit from ERM, however, did not change the intention to be among the countries with the lowest inflation rates in Europe and to become a EMU member. Approximately four years later in November 1996, Italy joined the ERM again because the Maastricht Treaty requires that a country that wants to be a member of the European Monetary Union (EMU) as from January, 1, 1999 should have a stable exchange rate in the previous two years.

\subsection{Methodology}

\subsubsection{Model}

To empirically investigate whether ERM participation and a hard peg to the Deutschmark affected the speed of inflation convergence, this speed must be defined. In this chapter it is the speed at which the inflation in Spain or Italy converges to the core European inflation rate. It is represented by $\alpha_{1}$ in the following equation: ${ }^{7}$

$$
\Delta \pi_{j, t}=\alpha_{0}+\alpha_{1}\left(\pi_{e x r, t-1-1}-\pi_{j, t-1}\right)+\Delta \pi_{e w r, t}+u_{t} \quad u_{f} \sim N\left(0, \sigma_{u t}^{2}\right)
$$

where $\pi_{b, t}$ is the inflation rate in country $j, j=s p$, it for Spain and Italy respectively, and $\pi_{e u r, t}$ is the core European inflation rate. The speed of inflation convergence is

See appendix. 7A for the derivation of this inflation convergence model. 
assumed to lie between zero and unity; if it is strictly larger than unity, this would imply that inflation rates follow divergent trends.

Before the speed of inflation convergence is estimated, equation (7.1) is modified in two respects. First, to be able to test whether the coefficient of the change in core European inflation is indeed unity, this restriction is lifted. If it is unity, this implies that the Spanish or Italian inflation rate and the core European inflation go up and down in the same proportion, and thus the short-term dynamics do not help inflation rates to converge. If it is zero, monetary authorities in Spain or Italy have the freedom to deviate from the development of inflation in the core European countries. When Spain or Italy entered the Exchange Rate Mechanism or chose a hard peg with respect to the Deutschmark, the coefficient of the change in core European inflation may have fallen because such a change in exchange rate policy implies that inflation rates go up and down in the same proportion in the long run; in the short run, however, it allows a deviation between both inflation rates and thus the freedom to deviate from core European inflation in the short run may have increased.

Second, an increase in the degree of exchange rate accommodation not only affects the speed of inflation convergence, but also the real exchange rate and import prices. "These in turn affect domestic inflation: the higher the degree of exchange rate accommodation, the more the real exchange rate will depreciate, and the faster import prices will rise. Consequently, domestic inflation will be higher relative to foreign inflation. To investigate these effects, the real exchange rate, reer $_{t-1}$, and the import prices, pimp $p_{r-1}$, are included in equation (7.1). Both variables are added as second order differences, as the dependent variable is also a second order difference of the price level. Given these modifications, equation (7.1) becomes:

$$
\begin{aligned}
& \Delta \pi_{j_{0} t}=\alpha_{0}+\alpha_{1}\left(\pi_{e w r_{e}, t-1}-\pi_{j, t-1}\right)+\alpha_{2} \Delta \pi_{\text {eur }, t} \\
& +\alpha_{3} \Delta^{2} \text { reer } r_{t-1}+\alpha_{4} \Delta^{2} p i m p_{t-1}+u_{t} \\
& 0<\alpha_{1}<1, \alpha_{2} \geq 0, \alpha_{3} \geq 0, \alpha_{4} \geq 0, u_{t} \sim N\left(0, \sigma_{u}{ }^{2}\right) .
\end{aligned}
$$

The main hypothesis in this chapter is that the convergence speed, $\alpha_{i}$, increased when Spain and Italy joined the EMS or chose a harder exchange rate policy. This

\footnotetext{
8 In chapters 5 and 6 a change in systematic exchange rate policy is transmitted through the real exchange rate channel, the wage cost channel, and the real interest rate channel. Here the real exchange rate accounts for the real exchange rate channel, and the import prices for the wage cost channel.
} 
hypothesis is tested by means of a structural break analysis. Second, it is tested whether the coefficient of $\alpha_{2}$ is unity and whether it changes. Furthermore, it is tested whether the effect of the real exchange rate, $\alpha_{3}$, and imported inflation, $\alpha_{6}$, change. Finally if $\alpha_{3}$ as well as $\alpha_{4}$ is zero, then the steady state where both inflation rates are equal, is represented by $\alpha_{0}=0$.

\subsubsection{Structural breaks}

The possible structural breaks in the speed of inflation convergence may be caused by changes in actual exchange rate policy changes as well as by institutional changes like the entrance- and withdrawal decisions with respect to the ERM, as well as the changes in bandwidths. The actual exchange rate policy changes are identified by visual inspection of the exchange rate of the peseta and the lira with respect to the Deutschmark. These exchange rates are depicted in Figures 7.1 and 7.2 respectively. They show that there are two possible structural breaks in the exchange rate regime: until $1985 / 1986$ the lira and the peseta were depreciating with respect to the Deutschmark, thereafter they were stable until the EMS crisis in September 1992, and then they started to depreciate again. The institutional changes are taken from sections 7.2 and 7.3 .

For Spain the list of possible structural breaks consists of the start of the shadowing of the Deutschmark ${ }^{9}$, the participation of Spain in the ERM in June 1989, the end of the stable exchange rate period in September 1992 when the first crisis in the Exchange Rate Mechanism occurred, and the increase in the band-width to 15 per cent in August 1993. For Italy the list of possible structural breaks consists of the ERM participation in March 1979 , the change from a soft peg to a hard peg in January 1987, the change in bandwidth in January 1990, and the withdrawal of the Italy's ERM participation in September 1992.

\subsection{Data}

This study uses quarterly data which cover a period of approximately twenty years (1975:1-1995:1). The nominal exchange rate, the consumer price index (CPI), and the import price index are available from the International Financial Statistics (IFS) tape (line ae, line 64 and line 75 respectively). The real effective exchange rate is calculated as an export share weighted index of the real bilateral exchange rate with respect to nine countries; an increase in this index represents a real depreciation.

\footnotetext{
Given Figure 7.2 the start of this unofficial targeting is approximated as the moment at which the peseta-Deutschmark exchange rate first hits the band with which the peseta starts its ERM period in June 1989. The initial parity is 65 pesetas per Deutschmark and the band width is plus and minus 6 per cent. Given this band, we estimate the start of the unofficial targeting as the third quarter of 1985 .
} 
The core European price index is calculated according to Groeneveld, Koedijk and Kool (1996) as a real GDP weighted index of consumer prices in the Netherlands, France, Germany and Belgium. See appendix 7B for more explicit information on the real effective exchange rate and the European price index.

\subsection{Empirical results for Spain}

Before model (7.2) is estimated for Spain over the period 1975:1-1995:1, unit root tests and co-integration tests are carried out in section 7.6.1. Then the structural break analysis is performed in section 7.6.2. This is done in a sequential way. First, the depreciation period for the Spanish peseta (1975:1-1985:2) is analysed in section 7.6.2.1. Then in section 7.6.2.2 the period of analysis is extended to 1975:11992:3 by including the stable exchange rate period. Next, the whole period, $1975: 1-1995: 1$, is investigated in section 7.6.2.3. Finally, the main results are stated in section 7.6.2.4; moreover, it is investigated whether a joint Likelihood Ratio test yields the same model.

\subsubsection{Tests for unit roots and co-integration}

To investigate whether the variables in model (7.2) for Spain are stationary the number of unit roots in the basic series for Spain were determined by calculating the Augmented Dickey-Fuller statistic (ADF). The results of these tests are reported in Table 7.2. It shows that the Spanish consumer price index and the European price index are integrated of order 2 and the Spanish import price index and the real effective exchange rate index are integrated of order 1 . The significant ADFstatistic for the $\log$ of the Spanish consumer price index confuses it with a trendstationary series; this is in contradiction with the behaviour of this series. Thus this particular statistic was discarded.

Table 7.2 Augmented Dickey-Fuller tests for Spain with constant, trend, and four lags (1975: :-1995:1)

\begin{tabular}{|c|c|c|c|}
\hline & $\log (0$ & $\Delta \log ()$. & $\Delta^{*} \log ()$. \\
\hline $\mathrm{P}$ & $-4.36^{\cdots *}$ & -2.89 & $-5.52^{\ldots}$ \\
\hline PIMP & -1.74 & $-3.19^{*}$ & $-5.67^{* \ldots * *}$ \\
\hline PEUR & -1.41 & -1.83 & $-4,40^{* \ldots *}$ \\
\hline REER & -1.68 & -4.34 & -7.27 \\
\hline
\end{tabular}


Table 7.2 shows that the Spanish and the core European inflation rate are not stationary. This is not a problem, as long as the difference between the Spanish and the core European inflation rate is stationary: Figures 7.3 and 7.4 informally suggest that this is the case. In addition, co-integration tests were performed along the lines of MacKinnon (1991). These tests show that the difference between the Spanish and the core European inflation is indeed stationary.

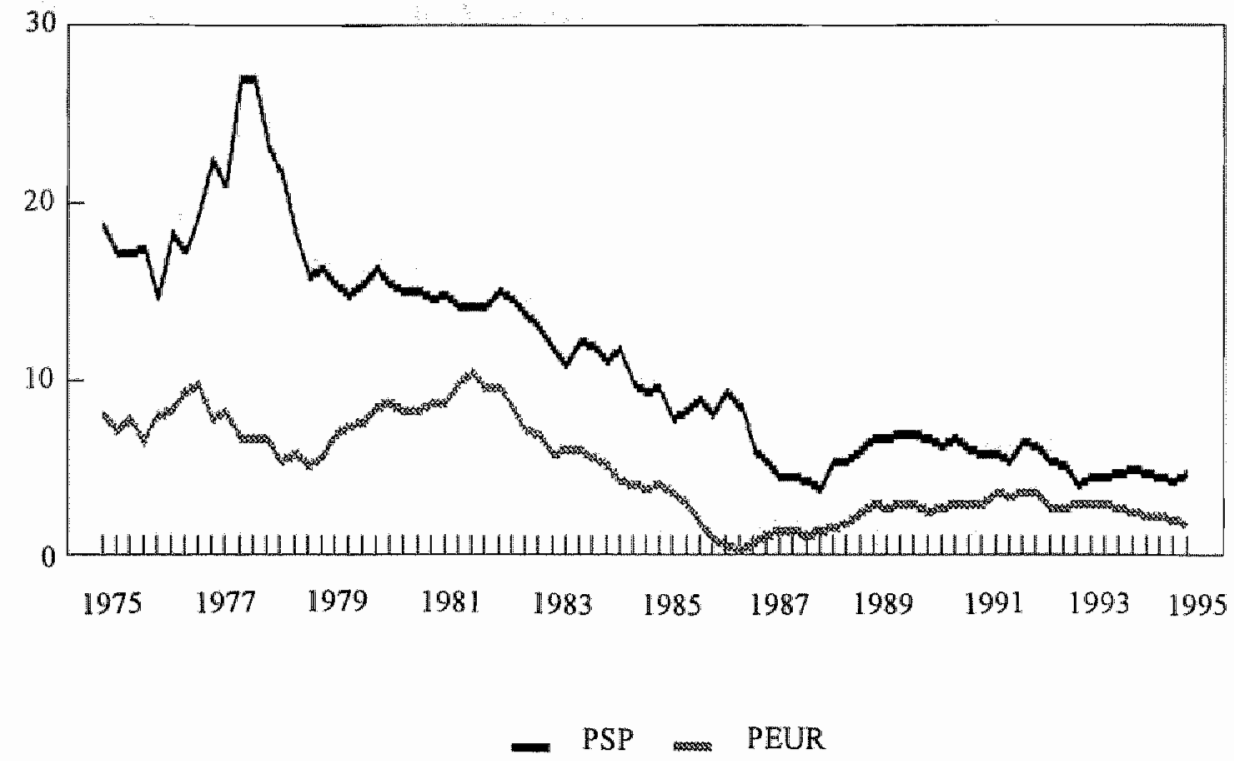

Figure 7.3 Spanish (PSP) and core European (PEUR) inflation (percentage price increase relative to the corresponding quarter of the previous year) 


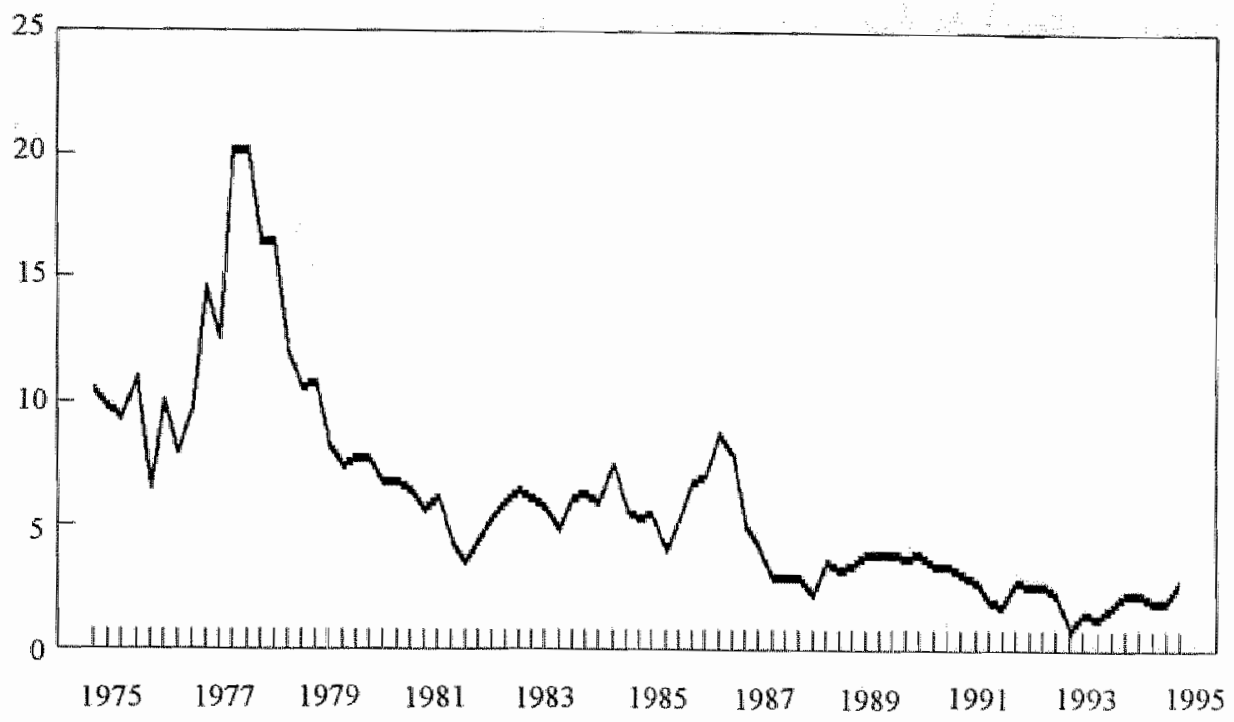

Figure 7.4 Difference between Spanish and core European inflation

\subsubsection{Structural break analysis}

\subsubsection{Depreciation period: 1975:1-1985:2}

The structural break analysis is started by estimating equation (7.2) over the period in which the peseta is depreciating with respect to the Deutschmark (1975:11985:2). Three dummies are added for the first, second, and third quarter (D1, D2 and D3) to allow for seasonal effects. Furthermore, to find a convenient lag structure the model is extended to contain up to five lags of $\Delta^{2}$ pimp $_{i k 1}, \Delta^{3}$ reer $_{t-1}$, and $\Delta \pi_{e u r, r}$. The model is reduced by first deleting insignificant variables, then checking whether in this model no diagnosis is found for residual autocorrelation, non-normality, heteroscedasticity and parameter instability. Finally, t-tests are performed to check whether the theoretical restrictions in (7.2) are true. The resulting model is reported in Table 7.3 as equation (7.3). It shows that even before the Deutschmark is targeted, the Spanish inflation is already converging to the European inflation rate with a speed of 0.40 . Furthermore, the hypothesis that $\alpha_{2}=1$ cannot be rejected and thus the Spanish inflation follows all short run developments in the core European rate of inflation. Finally, both the real exchange rate and the import prices affect the Spanish inflation; the coefficient for import prices, however, has the wrong sign. 


\subsubsection{Depreciation and stable period: 1975:1-1992:3}

The second step in the structural break analysis is to assume that model (7.3) is also valid in the stable exchange rate period (1985:3-1992:3) as well as in the depreciation period (1975:1-1985:2). If the estimation period of model (7.3) is extended to 1975:1-1992:3 and everything else is left unchanged, equation (7.4) in Table 7.3 is obtained. Whereas equation (7.4) shows that the model does not break down over the period 1975:1-1992:3, there are some signs that the estimated coefficients have changed. More specifically, the estimated coefficient for $\alpha_{2}$ decreases from 0.88 to 0.64 and becomes less significant, and the convergence speed slightly increases and becomes more significant. There are two structural breaks that may have caused these changes in the estimated model: i) the start of the shadowing period; and ii) the EMS participation.

First, it is investigated whether shadowing affects the model. Therefore a Chow test is performed for model (7.4) that compares the subperiods 1975:1-1985:2 and 1985:3-1992:3. The Chow statistic for this test is 2.64 and it is significant at the 5 per cent level. Thus, the start of the shadowing is indeed a structural break. To see how this influences the model, equation (7.4) is re-estimated by splitting each variable into two series: one for 1975:1-1985:2, and one for 1985:3-1992:3. It is tested whether the coefficients of a variable are equal between the two periods. If this hypothesis cannot be rejected, then the restriction was imposed; if it is restricted, then a variable only remained inside the model if its coefficient is significant. This results in model (7.5). It shows that from the moment Spain targeted the Deutschmark, the speed of inflation convergence doubled from 0.37 in the first subperiod (1975:1-1985:2) to 0.74 in the second subperiod (1985:3-1992:3); the null hypothesis that the convergence speed in both subperiods is equal must be rejected as we find an F-value of $6.26(0.015)$ for this test. Furthermore, the model shows that the increase in convergence speed went hand-in-hand with an increase in policy freedom. With respect to the period before the Deutschmark was shadowed the hypothesis that the Spanish inflation rate followed the core European inflation rate with a unit coefficient cannot be rejected; from the moment the Spanish central bank shadowed the Deutschmark it obtained the freedom to deviate from the core European inflation rate in the short run. Finally, the results show that whereas the real exchange rate and the import prices affected Spanish inflation in the depreciation period, they did not in the shadowing period. This combined with the fact that the constant term $\alpha_{0}$ is not significantly different from zero, implies that the inflation rates in the shadowing period corresponded to the steady state solution, whereas they did not in the earlier depreciation period. ${ }^{10}$

\footnotetext{
10 The results are not affected much if a later moment for the start of the shadowing period is chosen such as the first actual appreciation of the peseta with respect to the Deutschmark that took place in the first quarter of 1987.
} 
Then it is verified whether the other possible structural break - the decision to participate in the ERM in June 1989 - changes the estimated model. The Chow test for this break compares the subperiods 1975:1-1989:2 and 1989:3-1992:3. The Chow statistic of 0.41 is, however, not significant even at the 10 per cent level. The interpretation of this result is that the increase in inflation convergence had already been obtained by shadowing the Deutschmark; the official ERM participation only confirmed the willingness to maintain a hard currency.

\subsubsection{Whole period: 1975:1-1995:1}

The third stage of the examination is to assume that model (7.5) holds for the whole period 1975:1-1995:1. Estimating model (7.5) over this longer period gives equation (7.6). It confirms the previous findings: the convergence speed of inflation increases significantly at the moment Spain starts to shadow the Deutschmark. More specifically, the F-statistic for the equality between both convergence rates is $6.85(0.011)$ and thus the hypothesis that the convergence rates in the periods 1975:1-1985:2 and 1985:3-1995:1 are equal must be rejected at the 5 per cent significance level. Furthermore, from the start of the shadowing of the Deutschmark, the Spanish central bank gained the freedom to diverge from the core European inflation rate in the short run, whereas in the early depreciation period (1975:1-1985:2) Spanish inflation followed the European inflation with a coefficient that was not significantly different from unity.

Finally the last two structural breaks are analysed: i) did the end of the stable period during the first EMS-crisis affect the convergence of inflation?; and ii) did the change to widen margins ( \pm 15 per cent) affect inflation convergence? To test the first hypothesis a Chow test is performed that compares model (7.6) over the period 1975:1-1992:3 with 1992:4-1995:1. The computed Chow statistic of 0.35, however, is not significant even at the 10 per cent level; consequently, the first hypothesis is rejected. Thus, the speed of inflation convergence did not drop in the new depreciation period of the peseta that started after the September 1992 EMS crisis. The second hypothesis is also tested using a Chow test. This test compares model (7.6) for the periods 1975:1-1993:2 and 1993:3-1995:1. The computed Chow statistic of 0.15 is not significant and consequently the second hypothesis must be rejected too. An interpretation of these results may be that due to the long history of disinflation ( 7 years), the explicit intention to fully participate in the European Monetary Union, and the low-inflation from 1992 onwards, the speed of inflation convergence did not drop.

\subsubsection{Main results for Spain}

Given the structural breaks considered, only the decision to opt for a (unofficial) hard peg with respect to the Deutschmark, significantly increased the speed of infla- 
tion convergence." As Spain already showed its willingness to maintain an unofficial hard peg to the Deutschmark around 1985-1986, the ERM-participation in 1989 only confirmed this attitude, but did not increase the speed of inflation convergence. To visualize the increase in convergence speed, recursive coefficients for $\alpha_{1}$ are depicted in Figure 7.5. It shows that the speed of inflation convergence doubles when the peg to the Deutschmark becomes hard. Furthermore, it is found that from the moment Spain maintained a hard peg to the Deutschmark, it gained the freedom to deviate in the short run from the core European inflation, whereas it followed the changes in core European inflation with a unit coefficient before this hard peg was obtained. Finally, it is found that from the moment Spain shadowed the Deutschmark, the real exchange rate and the import price did not have anymore a significant effect on Spanish inflation. This, combined with the fact the constant term is zero, implies that from the start of the shadowing regime, the model is line with the steady state solution of equal inflation rates in Spain and Europe.

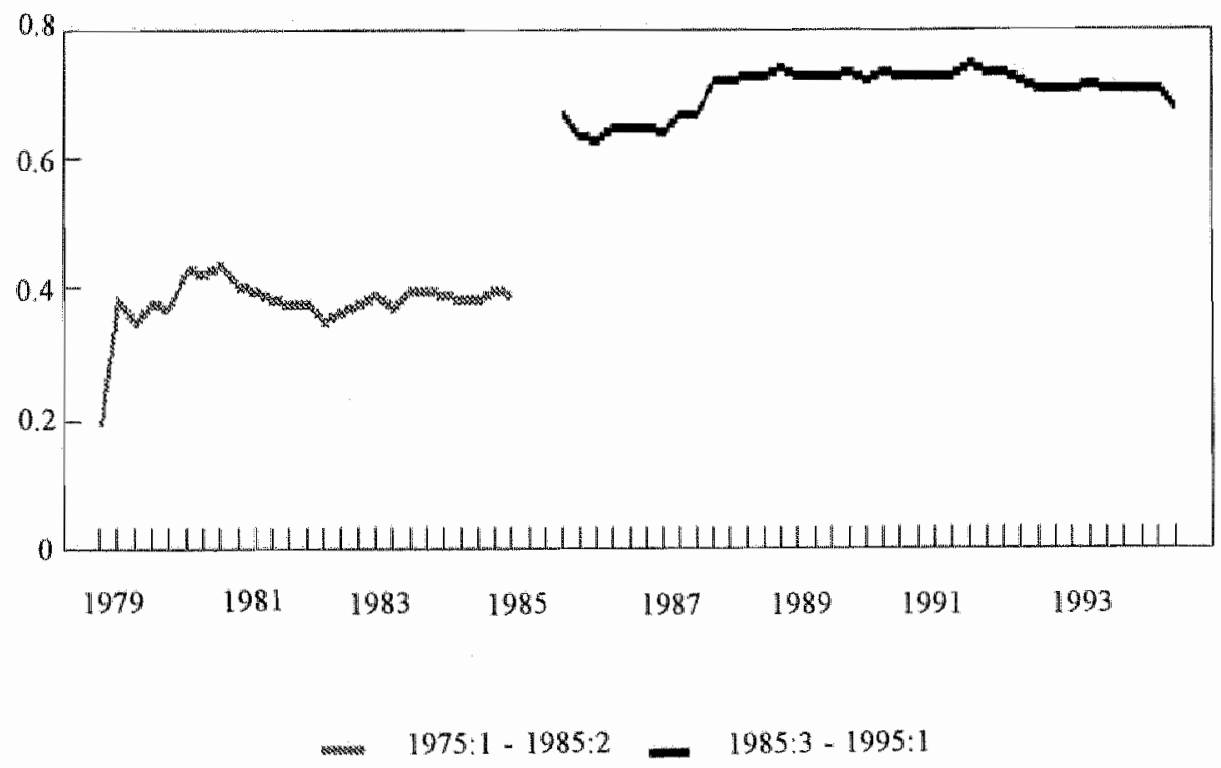

Figure 7.5 Recursive speed of inflation convergence for Spain (model (7.6))

"A joint likelihood ratio test of the possible structural breaks followed by a reduction generated model $(7.6)$ as well. Thus, the sequential character of the analysis in sections $7.6 .2 .1,7.6 .2 .2$, and 7.6.2.3 did not affect the results. 
Table 7.3 Models for the change in Spanish inflation $\left(\Delta \pi_{s p}\right)$

\begin{tabular}{|c|c|c|c|c|}
\hline & $(7.3)$ & $(7.4)$ & (7.5) & (7.6) \\
\hline Period & $75: 1-85: 2$ & $75: 1-92: 3$ & $75: 1-92: 3$ & $75: 1-95: 1$ \\
\hline Observations & 42 & $\pi 1$ & 71 & 81 \\
\hline constant & $\begin{array}{c}0.002 \\
(0.647)\end{array}$ & $\begin{array}{c}0.001 \\
(0.429)\end{array}$ & $\begin{array}{c}0.001 \\
(0.624)\end{array}$ & $\begin{array}{l}0.001 \\
(0.517)\end{array}$ \\
\hline 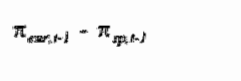 & $\begin{array}{l}0.399^{-3} \\
(3.215)^{--}\end{array}$ & $\begin{array}{c}0.420^{-} \\
(4.342)\end{array}$ & & \\
\hline 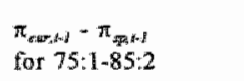 & & & $\begin{array}{l}0.374^{4 *} \\
(4.192)\end{array}$ & $\begin{array}{c}0.350^{-*} \\
(4.357)\end{array}$ \\
\hline 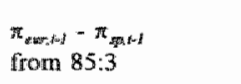 & & & $\begin{array}{l}0.739 \\
(4.304)\end{array}$ & $\begin{array}{c}0.709^{\text {mi* }} \\
(4.435)\end{array}$ \\
\hline 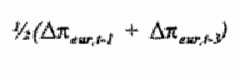 & $\begin{array}{l}0.882^{* *} \\
(2.646)\end{array}$ & $\begin{array}{c}0.639^{\circ} \\
(2.149)\end{array}$ & & \\
\hline 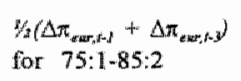 & & & $\begin{array}{l}0.920^{-7} \\
(3.224)\end{array}$ & $\begin{array}{l}0.962^{-0-} \\
(3.557)\end{array}$ \\
\hline$\Delta^{2} r e e r_{i-1}$ & $\begin{array}{l}0.082 \\
(3.147)\end{array}$ & $\begin{array}{c}0.061^{*} \\
(2.577)\end{array}$ & & \\
\hline $\begin{array}{l}\Delta^{*} \text { reer }_{k 1} \\
\text { for } 75: 1-85: 2\end{array}$ & & & $\begin{array}{l}0.077^{-1} \\
(3.333)\end{array}$ & $\begin{array}{c}0.078^{-} \\
(3.586)\end{array}$ \\
\hline$\Delta^{y}$ pimpp & $\begin{array}{c}-0.098 \\
(-3.402)\end{array}$ & $\begin{array}{l}-0.074 \\
(-3.436)\end{array}$ & & \\
\hline $\begin{array}{l}\Delta p^{4} \text { imp } p_{n-2} \\
\text { for } 75: 1-85: 2\end{array}$ & & & $\begin{array}{c}-0.108^{4-2} \\
(-4.237)\end{array}$ & $\begin{array}{c}-0.109^{-* *} \\
(-4.527)\end{array}$ \\
\hline$D I$ & $\begin{array}{c}0.014 \\
(3.817)\end{array}$ & $\begin{array}{c}0.012^{+\infty} \\
(4.540)\end{array}$ & $\begin{array}{l}0.013^{* *} \\
(5.094)\end{array}$ & $\begin{array}{c}0.012 \\
(5.564)\end{array}$ \\
\hline D3 & $\begin{array}{c}0.007^{*} \\
(1.964)\end{array}$ & $\begin{array}{l}0.008^{-*} \\
(2.891)\end{array}$ & $\begin{array}{c}0.0088^{+*} \\
(3.103)\end{array}$ & $\begin{array}{c}0.008^{--} \\
(3.285)\end{array}$ \\
\hline $\mathbb{R}_{\text {践 }}^{ \pm}$ & 0.705 & 0.631 & 0.693 & 0.683 \\
\hline DW & 2.1132 & 2.056 & 2.091 & 2.134 \\
\hline SEE & 0.009 & 0.009 & 0.008 & 0.008 \\
\hline Jarque-Bers & $\begin{array}{l}2.206 \\
(5.990)\end{array}$ & $\begin{array}{c}1.957 \\
(5.990)\end{array}$ & $\begin{array}{l}1.930 \\
(5.990)\end{array}$ & $\begin{array}{l}2.410 \\
(5.990)\end{array}$ \\
\hline $\mathrm{AR}(4)$ & $\begin{array}{c}0.435 \\
(0.782)\end{array}$ & $\begin{array}{c}1.645 \\
(0.180)\end{array}$ & $\begin{array}{l}0.820 \\
(0.524)\end{array}$ & $\begin{array}{c}0.797 \\
(0.537)\end{array}$ \\
\hline $\operatorname{AR}(8)$ & $\begin{array}{l}0.359 \\
(0.915)\end{array}$ & $\begin{array}{c}1.385 \\
(0.235)\end{array}$ & $\begin{array}{c}0.615 \\
(0.757)\end{array}$ & $\begin{array}{c}0.596 \\
(0.769)\end{array}$ \\
\hline Heteroscedasticity & $\begin{array}{l}1.008 \\
(0.495)\end{array}$ & $\begin{array}{c}0.617 \\
(0.861)\end{array}$ & $\begin{array}{c}1.035 \\
(0.469)\end{array}$ & $\begin{array}{c}0.818 \\
(0.728)\end{array}$ \\
\hline $\mathrm{ARCH}(4)$ & $\begin{array}{l}1.010 \\
(0.417)\end{array}$ & $\begin{array}{c}1.255 \\
(0.297)\end{array}$ & $\begin{array}{c}11.294 \\
(0.282)\end{array}$ & $\begin{array}{c}1.619 \\
(0.179)\end{array}$ \\
\hline
\end{tabular}

Notes: * ** "and ${ }^{*}$ indicate that the test-statistic is significant at the 10,5 , and the 1 per cent level; between parentheses the $t$-value is reported for the estimated coefficients, for the Jarque-Bera test the 5 perr cent critical walue, and for the other statistics the significarice level. 


\subsection{Empirical results for Italy}

This section estimates model (7.2) for Italy over the period 1975:1-1995:1. Before this is done, unit root tests and co-integration tests are conducted in section 7.7.1. Then the structural break analysis is performed in section 7.7.2. First, the depreciation period for the Italian lira (1975:1-1986:4) is analysed in section 7.7.2.1. Then in section 7.7.2.2 the period of analysis is extended to (1975:1-1992:3) by including the stable exchange rate period. Next, the whole period, 1975:1-1995:1, is investigated in section 7.7.2.3. Finally, the main results in section 7.7.2.4; to investigate whether the results are not affected by testing the possible structural breaks sequentially, a joint Likelihood Ratio test is performed to check whether this gives the same model.

\subsubsection{Tests for unit roots and co-integration}

To investigate whether the variables in model (7.2) for Italy are stationary the number of unit roots in the basic series for Italy are determined by calculating the augmented Dickey-Fuller statistics. Table 7.4 reports these statistics. The Italian consumer price index and the European price index turn out to be integrated of order 2 and the Italian import price index and the real effective exchange rate index integrated of order 1 .

As Table 7.4 shows that the Italian and the core European inflation rate are not stationary, this may introduce a non-stationary variable. Figures 7.6 and 7.7 give a first impression that the difference between Italian inflation and the core European inflation is stationary. However, this is not a formal test. Therefore co-integration tests were performed along the lines of MacKinnon (1991). These tests show that the difference between the Italian and the core European inflation is indeed stationary.

Table 7.4 Augmented Dickey-Fuller tests for Italy with constant, trend, and four lags $(1975: 1-1995: 1)$

\begin{tabular}{|c|c|c|c|}
\hline & $\log (0)$ & $\Delta \log ()$. & $\Delta^{2} \log ()$ \\
\hline $\mathbf{p}$ & -2.12 & -3.03 & $-4.70 \ldots$ \\
\hline PIMP & -2.28 & $-3.46^{4}$ & $-5.53 \ldots$ \\
\hline PEUR & -1.41 & -1.83 & $-4.40 \ldots$ \\
\hline REER & -1.78 & $-3.88^{* *}$ & $-6.79^{* * *}$ \\
\hline
\end{tabular}




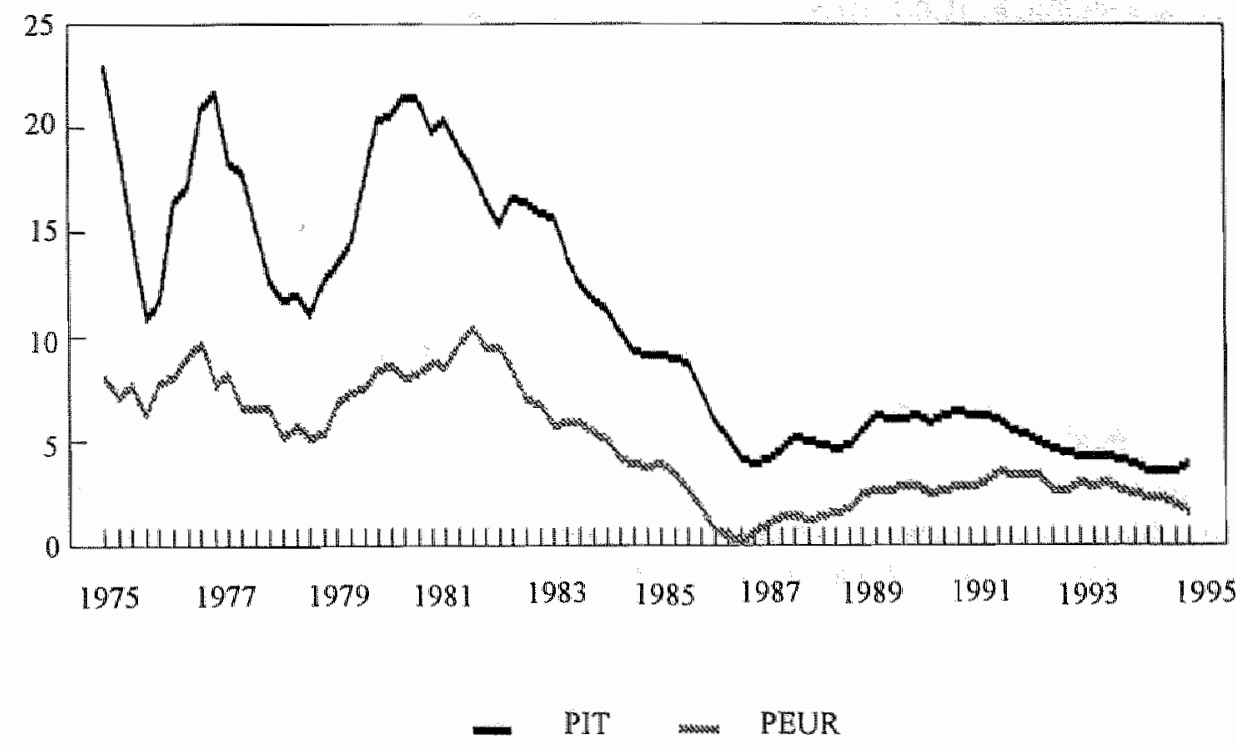

Figure 7.6 Italian (PIT) and core European (PEUR) inflation (percentage price increase relative to the corresponding quarter of the previous year)

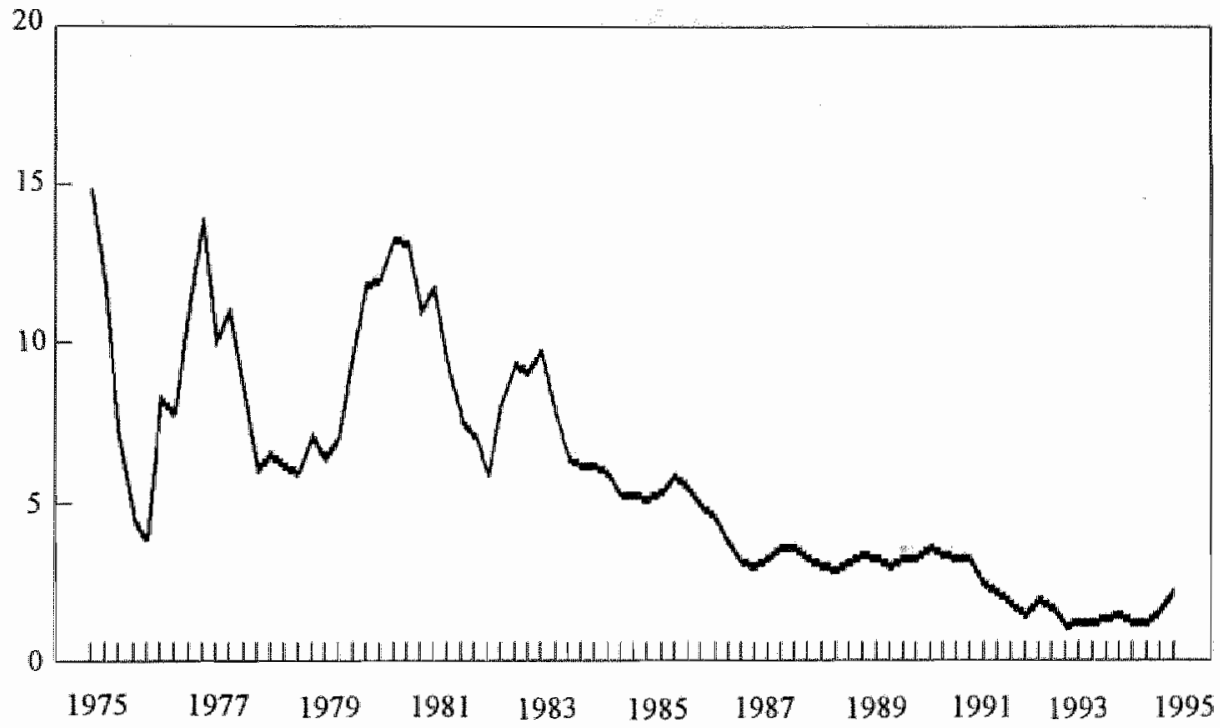

Figure 7.7 Difference between Italian and core European inflation 


\subsubsection{Structural break analysis}

\subsubsection{Depreciation period: 1975:1-1986:4}

The first step in the structural break analysis is to estimate model (7.2) over the period 1975:1-1986:4. As for Spain, seasonal dummies as well as up to five lags of $\Delta^{2}$ pimp $_{t-1}, \Delta^{3}$ reer $_{i-1}$, and $\Delta^{2} \pi_{e t r, i}$ were added. The reduction was carried out in the same manner. This resulted in model (7.7) in Table 7.5. It shows that Italian inflation converges to the core European rate at a speed of 0.53 . Furthermore, the hypothesis that $\alpha_{2}=1$ cannot be rejected; thus, Italian inflation follows all short run changes in the core European rate. Finally, the effect of the change in the real exchange rate on Italian inflation is small, but significant.

Within this depreciation period, Italy joined ERM in March 1979. This is the first possible structural break as listed in section 7.4.2. To investigate whether it affected the inflation convergence process a Chow statistic was calculated that compares the periods 1975:1-1979:1 and 1979:2-1986:4. The computed value of this statistic of 0.62 is not significant; consequently; the ERM participation is not a structural break. The interpretation of this result is that until the end of 1986 the lira was devalued every time the central bank faced serious difficulties to maintain the parity and thus the Italian lira behaved more like a managed floating currency than a fixed currency.

\subsubsection{Depreciation and stable period: 1975:1-1992:3}

The second step is to assume that model (7.7) is valid in the stable exchange rate period (1987:1-1992:3) as well as in the depreciation period (1975:1-1986:4). If the estimation period of model (7.7) is extended to 1975:1-1992:3 and everything else is left unchanged, model (7.8) is obtained. Comparison of the coefficients in modell (7.7) and (7.8) shows that the speed of inflation convergence is much lower in the second period ( 0.36 instead of 0.53$)$. Furthermore the estimated coefficient for $\alpha_{2}$ drops from 1.40 to 1.28 . This may be due to two possible structural breaks in the period 1975:1-1992:3: the change from a soft peg to a hard peg with respect to the Deutschmark in January 1987 and the change to small margins in January 1990.

First it is checked whether the change from a soft peg to a hard peg affects the model. Therefore a Chow test is performed for model (7.8) that compares the subperiods 1975:1-1986:4 and 1987:1-1992:3. The computed Chow statistic of 2.24 is significant at the 10 per cent level. Thus, the change from a soft peg to a hard peg is indeed a structural break. To investigate how this structural break affects the model, each variable is split into two periods: one for 1975:1-1986:4, and one for 1987:1-1992:3. The equality of the coefficients of the same variable between the two subperiods is tested, and imposed if the equality hypothesis could not be rejected. Furthermore, insignificant variables were deleted. This resulted in model 
(7.9). It shows that the speed of inflation convergence more than doubled in absolute terms from 0.48 in the first subperiod $(1975: 1-1986: 4)$ to 1.05 in the second subperiod (1987:1-1992:3); the null hypothesis that the convergence speed in both subperiods is equal must be rejected as we find an F-value for this test of 8.55 which is significant at the 1 per cent level. Italy also obtained more policy freedom to diverge from changes in European inflation. Furthermore, the model slows that this rise in convergence speed was accompanied by an increase in policy freedom. Whereas the hypothesis that Italy followed the core European inflation in the first subperiod with a unit coefficient could not be rejected, it gained the freedom to deviate from core European inflation in the second subperiod as the estimated coefficient is not significant. Furthermore, the real exchange rate affected Italian inflation only in the depreciation period, not in the stable exchange rate period. For Spain similar results were found. The only difference is that model (7.9) is not in line with a steady state solution where Italian and core European inflation are equal because the constant term in equation (7.9) is significantly different from zero.

Then it is investigated whether the change to small ERM margins affected the model. Therefore a Chow statistic was calculated that compares model (7.9) for the periods 1975:1-1989:4 and 1990:1-1992:3. The value of this statistic is equal to 0.83 , and thus insignificant. An interpretation of this result is that the effect of the smaller band widths was countered by the depreciation of the lira; consequently, no effect resulted for the convergence process.

\subsubsection{Whole periad: 1975:1-1995:1}

The third stage of the structural break analysis is to assume that model (7.9) is also valid in the new depreciation period that started in September 1992, just after the first EMS crisis. If the estimation period of model (7.9) is extended to 1975:11995:1 all else equal, model (7.10) is obtained. It shows again that the inflation convergence speed increases significantly at the moment the peg of the lira with respect to the Deutschmark becomes a hard peg. The F-statistic for the equality of the convergence speed in both subperiods is 8.16 and it is significant at the 1 per cent level. Furthermore, from the start of the shadowing of the Deutschmark, Italy gained the freedom to diverge in the short run from the core European inflation. Furthermore, the real exchange rate only affected Italian inflation in the first depreciation period (1975:1-1986:4), not in the later periods. Finally, model (7.10) does not correspond to the steady state solution as the constant term is significantly different from zero.

Only one possible structural break is left: the withdrawal from the ERM in September 1992. To find out whether this break affected the speed of inflation convergence a Chow test is performed that compares model (7.10) over the period 1975:11992:3 with 1992:4-1995:1. The Chow statistic is 0.87 and thus is not significant even at the 10 per cent level. Thus the speed of inflation convergence in Italy did 
not drop after the withdrawal of the participation in the ERM, in spite of the actual depreciation of the lira that occurred after the EMS crisis in September 1992. This can be attributed to long period of disinflation (six years), the explicit intention to be among the countries with the lowest inflation rates within Europe and to become an EMU member, and finally the low-inflation and low-money growth performance from 1987 on.

\subsubsection{Main results for Italy}

Given the four possible structural breaks considered, only the decision to choose a hard peg with respect to the Deutschmark, significantly increased the speed of inflation convergence. ${ }^{12}$ Whereas Italy was among the initiators of the ERM in March 1979, it devalued the lira until 1987 each time it became difficult to maintain the peg. Consequently, the lira behaved more like a managed floating currency than like a fixed currency. From 1987 ltaly tried to maintain a more fixed exchange rate with respect to the Deutschmark. This resulted in an increase in the convergence speed. To visualize this increase, recursive coefficients of $\alpha$, are plotted in Figure 7.8. This causes an increase in the speed of inflation convergence from about 0.5 to 1.3. However, as time passed, part of this increase got lost, especially from 1991 on. Furthermore, it is found that from the moment that Italy maintained a hard peg with respect to the Deutschmark in 1987, it gained the freedom to deviate in the short run from the core European inflation rate, whereas it followed the changes in core European inflation quite closely until 1987 . Finally, the real exchange rate and the import prices do not significantly affect the change in Italian inflation anymore from the moment when the lira got a hard peg. As the constant term is significantly different from zero, this implies that the model is not in line with the steady state solution of equal inflation rates in Italy and Europe.

12 A joint likelihood ratio test of the breakpoints followed by a reduction generated the same model. Thus, the sequential character of the analysis in sections 7.7.2.1, 7.7.2.2, and 7.7.2.3 did not affect the results. 


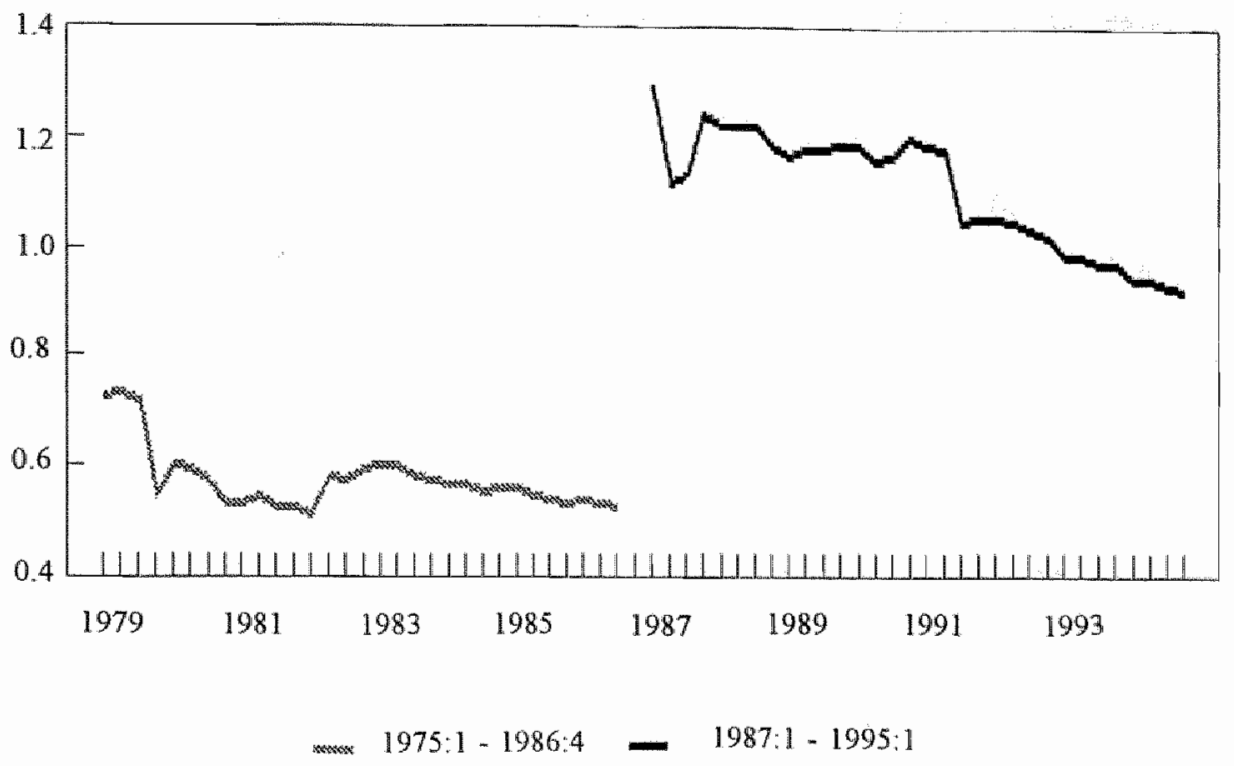

Figure 7.8 Recursive speed of inflation convergence for Italy (model (7.10)) 
Table 7.5. Models for the change in Italian inflation $\left(\Delta \pi_{i, i}\right)$

\begin{tabular}{|c|c|c|c|c|}
\hline & $(7.7)$ & $(7.8)$ & (7.9) & $(7.10)$ \\
\hline Period & $75 \cdot 1 \cdots 6: 4$ & $75: 1 \cdot 92.3$ & $75: 1.92: 3$ & $75: 1-95: 1$ \\
\hline Observations & 48 & 71 & 71 & 81 \\
\hline constant & $\begin{array}{l}0.015^{-} \\
(5.982)\end{array}$ & $\begin{array}{l}0.010^{-} \\
(6.022)\end{array}$ & $\begin{array}{l}0.013^{-} \\
(6.945)\end{array}$ & $\begin{array}{c}0.011 \\
(6.789)\end{array}$ \\
\hline 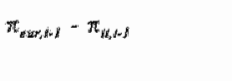 & $\begin{array}{l}0.528 \\
(4.469)\end{array}$ & $\begin{array}{l}0.359^{-} \\
(4.144)\end{array}$ & & \\
\hline 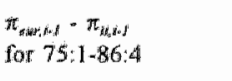 & & & $\begin{array}{l}0.481 \\
(5.311)^{-}\end{array}$ & $\begin{array}{l}0.400^{--} \\
(5.034)\end{array}$ \\
\hline 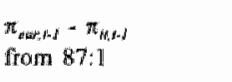 & & & $\begin{array}{l}1.056^{-0 *} \\
(4.256)\end{array}$ & $\begin{array}{c}0.9299^{-\cdots} \\
(4.076)\end{array}$ \\
\hline 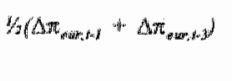 & $\begin{array}{l}1.3999^{-*} \\
(4.951)\end{array}$ & $\begin{array}{c}1.277^{-4 *} \\
(5.249)\end{array}$ & & \\
\hline 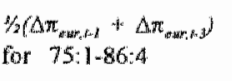 & & & $\begin{array}{c}1.362 \\
(5.579)\end{array}$ & $\begin{array}{c}1.356^{-} \\
(5.709)\end{array}$ \\
\hline 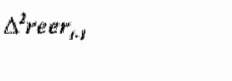 & $\begin{array}{l}0.0844^{-} \\
(3.682)\end{array}$ & $\begin{array}{l}0.099^{-*} \\
(5.215)\end{array}$ & & \\
\hline $\begin{array}{l}\Delta^{*} r e e r_{1-1} \\
\text { for } 75: 1.86: 4\end{array}$ & & & $\begin{array}{c}0.090^{--} \\
(4.704)\end{array}$ & $\begin{array}{l}0.099^{-3} \\
(5.467)\end{array}$ \\
\hline$D 2$ & $\begin{array}{l}0.010^{* *} \\
(-3.923)\end{array}$ & $\begin{array}{l}-0.009 \\
(-4.746)\end{array}$ & $\begin{array}{l}-0.008^{* * *} \\
(-4.801)\end{array}$ & $\begin{array}{l}-0,008^{-} \\
(-5.160)\end{array}$ \\
\hline$D 3$ & $\begin{array}{l}0.014 \\
(-5.283)\end{array}$ & $\begin{array}{l}-0.011^{-} \\
(-5.948)\end{array}$ & $\begin{array}{c}-0.012^{-3} \\
(-6.371)\end{array}$ & $\begin{array}{c}-0.010^{-} \\
(-6.279)\end{array}$ \\
\hline $\mathrm{R}_{\mathrm{udj}}^{2}$ & 0.714 & 0.663 & 0.693 & 0.669 \\
\hline DW & 1.825 & 1.808 & 1.852 & 1.884 \\
\hline SEE & 0.007 & 0.006 & 0.006 & 0.006 \\
\hline Jarque-Bera & $\begin{array}{r}0.427 \\
(5.990)\end{array}$ & $\begin{array}{l}2,606 \\
(5.990)\end{array}$ & $\begin{array}{c}2.674 \\
(5.990)\end{array}$ & $\begin{array}{l}2.259 \\
(5.990)\end{array}$ \\
\hline$A R(4)$ & $\begin{array}{l}0.843 \\
(0.513)\end{array}$ & $\begin{array}{c}0.995 \\
(0.420)\end{array}$ & $\begin{array}{c}0.814 \\
(0.528)\end{array}$ & $\begin{array}{c}0.669 \\
(0.617)\end{array}$ \\
\hline$A R(8)$ & $\begin{array}{c}1.568 \\
(0.221)\end{array}$ & $\begin{array}{c}1.212 \\
(0.319)\end{array}$ & $\begin{array}{c}1.402 \\
(0.258)\end{array}$ & $\begin{array}{c}1.442 \\
(0.221)\end{array}$ \\
\hline Helereseedasticity & $\begin{array}{c}1.138 \\
(0.382)\end{array}$ & $\begin{array}{c}1,343 \\
(0.211)\end{array}$ & $\begin{array}{c}0.760 \\
(0.777)\end{array}$ & $\begin{array}{c}0.873 \\
(0.654)\end{array}$ \\
\hline $\mathrm{ARCH}(4)$ & $\begin{array}{l}0.225 \\
(0.923)\end{array}$ & $\begin{array}{c}0.740 \\
(0.568)\end{array}$ & $\begin{array}{c}0.435 \\
(0.783)\end{array}$ & $\begin{array}{c}0.884 \\
(0.478)\end{array}$ \\
\hline
\end{tabular}

Nofes: * * and *** indicate that the test-statistic is significant at the 10,5 , and the 1 per cent level; between parentheses the $t-$ walue is reported for the estimated coefficients, for the Jarque-Bera test the 5 per cent critical value, and for the other statistics the significance level. 


\subsection{Conclusion}

According to chapter 5 and 6 an increase in the speed of inflation convergence can only be obtained if a high inflation country wants to maintain a hard peg with respect to a low inflation currency. The borrowed credibility hypothesis, however, states that it is enough to join a fixed exchange-rate regime like the Exchange Rate Mechanism (ERM) of the European Monetary System (EMS) to obtain such an increase in the speed of inflation convergence. In this chapter it is empirically investigated which of these two hypotheses is true for Spain and Italy. It is found for Spain as well as Italy that only a hard peg to a low inflation currency increases the speed of inflation convergence; joining and leaving ERM, and changing band widths did not affect the convergence speed significantly. This supports the hypothesis of chapter 5 and 6 , but rejects the borrowed credibility hypothesis.

Spain and Italy got such a hard around 1986/1987. This roughly doubles the speed of inflation convergence. However, for Spain this meant a permanent increase in the convergence speed; for Italy part of this increase in convergence speed has disappeared, especially since 1991 . Furthermore it is found that Spain and Italy got the freedom to deviate from the core European inflation rate at the moment the peseta and the lira got a hard peg with respect to the Deutschmark, whereas they followed the changes in core European inflation with a unit coefficient before this period. At the end of the stable exchange rate period, that is around the first EMS crisis in August 1992, both the effect for the speed of inflation convergence as well as the short-run inflation dynamics did not significantly change. A possible explanation for this result is that financial markets did believe that central banks of Spain and Italy still wanted to join the European Monetary Union and therefore would not let inflation go out of control. 


\section{Appendix 7A Derivation of the inflation convergence model}

The relative models of chapters 5 and 6 show that relative inflation behaves as an autoregressive process of order 1 :

$$
\hat{\pi}_{t}=\alpha_{\theta}+\zeta \hat{\pi}_{t-1}+u_{t} \quad 0<\zeta<1 \quad u_{t} \sim N\left(0, \sigma_{u}^{2}\right),
$$

where the inflation differential, $\tilde{\pi}_{r}$, is defined as:

$$
\hat{\pi}_{j, t}=\pi_{j, t}-\pi_{\text {eur, }} .
$$

Combining (7A.1) and (7A.2) gives:

$$
\pi_{j, t}=\alpha_{0}+\pi_{e u r, t}+\zeta \pi_{j, t=1}-\zeta \pi_{e u r, t w-1}+u_{f} .
$$

Now subtracting $\pi_{j, t-1}$ on the left hand side and the right hand side, adding and subtracting $\pi_{e w, t-1}$ on the right hand side, and defining $\alpha_{1}=1-\zeta$, that is the speed of inflation convergence is 1 minus the persistence of relative inflation, equation (7A.3) can be rearranged as equation (7.1).

\section{Appendix 7B Construction of the real exchange rate and the European price index}

In calculating the real effective exchange rate for the Spanish peseta, first the bilateral exchange rates [domestic rates] with respect to the Belgian franc, the Danish kroner, the French franc, the German mark, the Italian lira, the Japanese yen, the British Pound sterling, the US dollar and the Dutch guilder are calculated. Second, these exchange rates are multiplied by the ratio of consumer price indices to calculate real bilateral exchange rates. Third, the real exchange rates are normalized to $1972=100$. Fourth, the shares of Spanish exports going to each of these nine countries separately in the sum of the Spanish exports going to these nine countries together are computed. Multiplying these export shares by the normalized real bilateral exchange rates gives the real effective exchange rates. The real effective exchange rate for the Italian lira is calculated likewise. The additional exchange rate data (end of period) are obtained from DATASTREAM and from the Main Economic Indicators, OECD, October 1995. The additional consumer price indices are 
from line 64 in the International Financial Statistics and completed with the Main Economic Indicators of the OECD. The export shares (yearly frequency) are calculated from the Direction of Trade Statistics, IMF.

The European price-index is computed according to the formula:

$$
\text { PEUR }=\sum_{i}^{n} \frac{\left(\frac{Y_{i}}{E_{i}}\right) P_{i}}{\sum_{i}^{n}\left(\frac{Y_{i}}{E_{i}}\right)},
$$

in which $Y_{i}$ is the real GDP in country $i$ in domestic currency, $P_{i}$ is the domestic consumer price index, and $E_{i}$ is the number of domestic currency units per unit of German marks, see Groeneveld, Koedijk and Kool (1996). The European price index is calculated using data for the Netherlands, France, Belgium and Germany. The additional real GDP data for Germany and France are obtained from the International Financial Statistics of the IMF (line 99) and completed with real GDP data from the Main Economic Indicators of the OECD. The real GDP data (yearly frequency) for Belgium are obtained from the International Financial Statistics Yearbook 1994, the Main Economic Indicators of the OECD and the Economic Outlook 57, June 1995; the yearly data are distributed over the quarters. The real GDP data for the Netherlands are combined from the Dutch Central bank's Kwartaalconfrontatie van middelen en bestedingen (1986), the Quarterly Accounts (CBS), and the Main Economic Indicators, OECD. 


\section{Summary and Suggestions for Further Research}

\subsection{Summary and conclusions}

This thesis investigates two main kinds of explanations for the existence of a shortrun trade-off between inflation and output growth: the price-misperception theories and the price stickiness theories; in the long run the trade-off is absent in both theories (see chapter 2). According to the price-misperception theories, there is a short-run trade-off between inflation and output growth because suppliers have imperfect information about the nature of the shock in the demand for their products; they are uncertain whether the relative demand for their products has risen or whether the average price level has risen. The more a shock is thought to be real, the more suppliers will adjust output. According to the price stickiness theories, there is a short-run trade-off between inflation and output growth because the competition in goods market is imperfect and there are costs associated to changing prices or other nominal rigidities like strategic complementarity or staggered wages. In this case a higher aggregate demand will cause an increase in output as prices and wages are not adjusted immediately.

The price-misperpection theories contain predictions for two types of aggregate demand policies: unsystematic and systematic policy. Unsystematic policy is defined as the occurrence of shocks in, for example, government expenditures, the money stock or the exchange rate, whereas systematic policy refers to changes in the rules for these variables. In the price-misperception theories only unsystematic policy can affect real output growth; systematic policy is neutral because an expected change in policy is already taken into account by economic agents. In the price stickiness theories unsystematic as well as systematic policy can affect output growth; then systematic policy can influence real economic growth due to the fact that it takes time for firms to adjust their pricing strategy.

\section{Theoretical output effects of unsystematic and systematic policy}

The theoretical effects on output growth of unsystematic as well as systematic policy which the price-misperception theories and the price stickiness theories imply have been summarized in Table 8.1. It shows that the effect of both an expansionary unsystematic and a systematic policy change on output growth is positive in the short run, but zero in the long run. Second, the type of aggregate demand policy and the theoretical explanations underlying the trade-off affect the 
shape of the short-run trade-off, and determine whether expected policy does affect output growth or not and whether the output effects are persistent or not. A symmetric short-run trade-off implies that an expansionary policy has the same effect on economic growth as a contractionary policy whereas they are different in case of an asymmetric short-run trade-off; a persistent effect on output growth implies that a policy change influences output growth not only in the period of the policy change, but also in later periods.

Now Table 8.1 shows that the price-misperception models and the price stickiness models have exactly the opposite predictions for unsystematic policy with respect to the shape of the short-run trade-off, the output effect of expected policy changes, and the length of the output effect. Whereas the price-misperception theories state that an aggregate demand shock has symmetric effects on output growth, the price stickiness models predict that they are asymmetric. The main explanation for this asymmetric trade-off is the existence of price adjustment costs (see Caballero and Engel, 1993; Tsiddon, 1993; and Ball and Mankiw, 1994). Given a positive rate of inflation, the price adjustment cost theories imply that a firm will adjust a price more frequently in the case of a demand increase than in the case of a demand decrease. Consequently, the output effect will be larger with a decrease in demand than with an increase in demand. Second, the price-misperception theories imply that an expected change in aggregate demand is neutral whereas it is not neutral in the price stickiness theories. If prices are sticky, it takes time to accommodate prices to a new level given an expected change in demand; therefore, expected policy changes do affect output growth. If prices are flexible, as in the price-misperception model, prices can be adjusted immediately and thus an expected change in demand is neutral. Third, shocks in aggregate demand are not persistent in the price-misperception model whereas they are persistent in the price stickiness models. In the price-mispercep-tion models a shock disappears one period after its initiation because the publication of the general price level eliminates the uncertainty about the relative prices; in the price stickiness models persistence is due to strategic complementarity, staggered wages, replenishment of the inventory of produced goods, or lags in the acquisition of information (see section 3.3.3).

Furthermore Table 8.1 shows that the output effects with respect to systematic policy are the same in the price-misperception model of chapter 6 and the price stickiness model of chapter 5: the shape of the short-run trade-off is symmetric, expected policy changes do affect output growth, and policy changes are persistent. Note that in chapter 6 expected policy changes do influence output because the nominal interest rate affects the real demand for money, the money supply responds with a lag to inflation changes, and the real exchange rate slowly reverts to purchasing power parity. In the price stickiness models of chapter 5 the last two causes are absent, but instead price adjustment costs or staggered wages are assumed. 
Table 8.1 Theoretical output effects of unsystematic and systematic policy

\begin{tabular}{|c|c|c|c|c|}
\hline & \multicolumn{2}{|c|}{ Price-misperception models } & \multicolumn{2}{|c|}{ Price stickiness models } \\
\hline & $\begin{array}{l}\text { Unsystematic } \\
\text { policy } \\
\text { (chapter 3) }\end{array}$ & $\begin{array}{l}\text { Systematic } \\
\text { policy } \\
\text { (chapter 6) }\end{array}$ & $\begin{array}{l}\text { Unsystematic } \\
\text { policy } \\
\text { (chapter 3) }\end{array}$ & $\begin{array}{l}\text { Systematic } \\
\text { policy } \\
\text { (chapter 5) }\end{array}$ \\
\hline $\begin{array}{l}\text { Short-run } \\
\text { output effect of ex- } \\
\text { pansionary policy }\end{array}$ & positive & positive & positive & positive \\
\hline $\begin{array}{l}\text { Long-run } \\
\text { output effect of ex- } \\
\text { pansionary policy }\end{array}$ & zero & zero & zero & zero \\
\hline $\begin{array}{l}\text { Shape of the } \\
\text { short-run } \\
\text { trade-off }\end{array}$ & symmetric & symmetric & asymmetric & symmetric \\
\hline $\begin{array}{l}\text { Output effect of } \\
\text { expected expan- } \\
\text { sionary policy }\end{array}$ & zero & positive & positive & positive \\
\hline $\begin{array}{l}\text { Length of } \\
\text { output efiect }\end{array}$ & not persistent & persistent & persistent: & persistent \\
\hline
\end{tabular}

\section{Empirical output effects of unsystematic policy}

Table 8.1 shows that the shape of the short-run trade-off, the output effect of expected expansionary policy, and the length of the output effect are different for unsystematic policy between the price-misperception models and the price stickiness models. This allows one to test whether the empirical evidence favours the pricemisperception models or the price stickiness models. For that purpose the symmetry-hypothesis, the structural neutrality hypothesis and the non-persistence hypothesis have been tested against the alternatives of asymmetry, non-neutrality and persistence respectively in chapter 3. It is found for the United States and Germany over the period 1973:1-1992:4 that the evidence with respect to the asymmetry hypothesis is mixed; the structural neutrality hypothesis and the non-persistence

The symmetric response of systematic policy in the price stickiness models results from the fact that the Alogoskoufis models in chapter 5 have been stated in first differences instead of in levels; if they are stated in levels, these models imply an asymmetric short-run trade-off. 
hypothesis, however, could not be rejected against the alternatives of non-neutrality and persistence respectively. So, it is hard to reject the price-misperception model.

From a policy point of view, however, it is hard to interpret the actual shocks in, for example, nominal demand growth as changes in policy. These may have resulted not only from changes in policy, but also from change in, for example, the behaviour of consumers and producers, and financial institutions. In order to analyse policy changes these must be separated from other changes.

\section{Theoretical effects of unsystematic policy on the short-run trade-off}

If unsystematic policy is used more frequently, the price-misperception theories and the price stickiness theories predict that this has a detrimental effect on the shortrun trade-off between inflation and output growth; the more it is applied, the lower the real effect of a shock becomes. Table 8.2 summarizes the theoretical effects of unsystematic policy on the short-run trade-off. It shows that according to the pricemisperception theories a higher variance of inflation or a higher variance of aggregate demand shocks lowers the output response of an aggregate demand shock. These effects are known as the Lucas variability hypotheses. The price stickiness model of Ball, Mankiw and Romer (1988) implies the same relations. Thus, these two relations cannot be used to discriminate between the price-misperception theories and the price stickiness theories.

Nevertheless, a different response does appear with respect to inflation. Whereas the price-misperception theories do not predict a relation between the slope of the short-run trade-off and the rate of inflation, it is negative in the price stickiness theories because prices are adjusted more frequently if inflation is higher, and thus the output response to a demand shock is smaller. Normally, however, there is a strong correlation between the rate of inflation and the variance of inflation; consequently, a negative relation between the slope of the short-run trade-off and inflation does not provide evidence for the price stickiness theories.

Finally, Table 8.2 shows that both inflation-output theories predict a different response to changes in the variance of relative prices. Whereas there is a positive relation between the variance of relative price and the slope of the short-run tradeoff in the price-misperception theories, it is negative in the price-stickiness theories. The relation is positive in the price-misperception theories because a higher variance of relative prices increases the proportion of shocks that are misperceived as real shocks; according to the price stickiness theories it is negative because a higher variance of relative prices increases the frequency of price adjustment and thus decreases the output effect of an aggregate demand shock. However, it is difficult to distinguish the variance of relative prices from the variance of absolute prices; consequently, it is hard to verify whether empirical evidence provides support for the price-misperception theories or for the price stickiness theories. 
Table 82 Theoretical effects of unsystematic policy on the slope of the short-run inflationoutput trade-off:

\section{Price-misperception theories Price stickiness theories}

Increase in the variance of inflation $\left(\sigma^{2}\right)$

negative

negative

Increase in the variance of

aggregate demand shocks $\left(\sigma_{\Delta x}{ }^{2}\right)$ negative negative

Increase in inflation $(\Delta p)$ absent negative

Increase in the variance of

relative prices $\left(\tau^{2}\right) \quad$ positive negative

Empirical effects of the variance of inflation and the variance of aggregate demand shocks on the short-run trade-off

While chapter 3 tested the symmetry hypothesis, the structural neutrality hypothesis, and the non-persistence hypothesis empirically, chapter 4 tested the effect of unsystematic policy on the slope of the short-run trade-off by investigating the Lucas variability hypotheses. Because the evidence in previously published Lucas variability studies is mixed concerning the question whether these cross-country predictions differ between developed and developing countries, a meta-study of ten of those studies has been performed. If a correction is made for differences in supply response, it is found that the hypothesis that a higher variance of demand shocks leads to a steeper short-run trade-off must be rejected for the group of developed countries. Thus, the price-misperception theories fail in some respects to explain empirical results. This may be also due to endogeneity in demand shocks as these are measured as changes in nominal income.

\section{Theoretical inflation effects of systematic monetary and exchange rate policy}

Neither unsystematic nor systematic policy can be used to affect real economic growth permanently. Moreover, frequent use of unsystematic policy even deprives such a policy from its short-run real effects. Therefore, it can be questioned whether such policies are of any use. However, the theoretical models of chapters 5 and 6 show that systematic policies can be of use to decrease inflation. The theoretical effects found in both chapters have been summarized in Table 8.3. It shows that according to the price-misperception model of chapter 6 a higher degree of monetary accommoda-tion increases the persistence of average inflation. A higher degree of exchange rate accommodation decreases the average real interest rate which in 


\section{Empirical effects of systematic exchange rate policy}

Given reasonable parameter values, chapters 5 and 6 imply that a country can only obtain an increase in the speed of inflation convergence by maintaining a hard peg with respect to a low inflation currency. Alternatively, the borrowed credibility hypothesis suggests that it is enough to join a fixed-exchange rate regime like the Exchange Rate Mechanism (ERM) of European Monetary System (EMS). In chapter 7 it has been empirically investigated which of these two hypotheses is true for Spain and Italy over the period 1975:1-1995:1. The results show for both countries that only the hard peg to the Deutschmark increased the speed of inflation convergence; joining and leaving ERM, and changing band widths did not affect the speed of inflation convergence significantly. This provides support for the hypothesis of chapters 5 and 6 , but rejects the borrowed credibility hypothesis.

\section{Overall conclusions}

This thesis has shown that the two explanations for a short-run trade-off between output and inflation, the price-misperception theories and the price stickiness theories, predict that the short-run output effect of both an expansionary unsystematic and a systematic policy is positive and that their long-run effects are zero. However, both theories have different predictions for unsystematic policy with respect to the shape of the short-run trade-off, the output effect of expected policy, and the length of the output effect. According to the price-misperception theories the shortrun trade-off is symmetric, the output effect of an expected policy change is zero, and demand shocks are not persistent; according to the price stickiness theories, the short-run trade-off is asymmetric, the output effect of an expected policy change in not zero, and demand shocks are persistent. The empirical evidence in this thesis shows that it is hard to reject the price-misperception model. For systematic policy, both theories have the same theoretical prediction: the shape of the short-run tradeoff is symmetric, the output effect of an expected expansionary policy is positive, and demand shocks are persistent:

If unsystematic policy is used frequently, this deteriorates the short-run tradeoff. Whereas the new-Keynesian theories suggest two tests to distinguish between the price-misperception theories and the price-stickiness theories, these tests suffer from a measurement problem. If the average inflation is correlated with the variance of inflation, it is hard to interpret a negative relation between the slope of the short-run trade-off and the rate of inflation as resulting from price stickiness. Furthermore, if the variance of relative prices is correlated with the variance of absolute prices, it is not sure anymore whether a negative relation between the variance of relative prices results from price-misperception or price stickiness.

Finally, whereas neither unsystematic nor systematic policy can be used to increase output growth permanently, the theoretical price-misperception model of 
chapter 6 and the price stickiness model of chapter 5 predict that systematic monetary and exchange rate policy can be used to reduce inflation permanently. The empirical evidence of chapter 7 shows for Spain and Italy that a hard exchange rate policy indeed increases the speed of inflation conwergence as implied by the models of chapters 5 and 6 ; joining an exchange rate mechanism as the ERM is not enough to obtain an increase in the speed of inflation convergence as suggested by the borrowed credibility hypothesis.

\subsection{Suggestions for further research}

With respect to the new-Keynesian explanations for the trade-off, only a few empirical investigations have been performed. Improvements in this area can be achieved by constructing relative and absolute price variance in such a way that they are orthogonal based on disaggregated data. In that case, the relative price variability test of Ball, Mankiw, and Romer (1988) can be used to distinguish the price-misperception theory and the price stickiness theory. Furthermore, expected aggregate demand growth must be specified more carefully instead of assuming that it is equal to the long-run average growth. Such an assumption generates quite inefficient estimates of expected aggregate demand growth while more efficient procedures like Box-Jenkins models and Kalman filters are available. Finally, in order to investigate such trade-offs from a cross-country perspective, it is rather rigid to use all available countries without making any distinction in, for example, their stage of development. The more developed they are, the less the effect of a change in policy may be. In chapter 4 developed and developing countries were distinguished, but a more flexible classification may provide more insight into the data; such a classification can be obtained by using different non-parametric techniques.

A final suggestion for future research is to investigate the inflation convergence model with the expected inflation differentials instead of the realized differentials. This would be closer to chapter 5. Finally, as a parallel to the inflation convergence, interest convergence should be investigated. It can be investigated whether the same shifts occur in the interest rate convergence; furthermore, this analysis can be extended to more European countries. 


\section{References}

Addison, J.T., Chappell, H.W., Castro, A.C., Output-inflation tradeoffs in 34 countries, Journal of Economics and Business, 38, 1986, 353-360.

Ahmed, S., Wage Stickiness and the Non-Neutrality of Money: A Cross-Industry Analysis, Journal of Monetary Economics, 20(1), 1987, 25-50.

Akerlof, G.A., Yellen, J.L., A Near-Rational Model of the Business Cycle, with Wage and Price Inertia, Quarterly Journal of Economics, 100, 1985, 823-838.

Akerlof, G.A., Rose, A., Yellen, J.L., The New Keynesian Economics and the Output-Inflation Trade-off: Comments and Discussion, Brookings Papers on Economic Activity, 1988, 1, 66-75.

Alberro, J., The Lucas Hypothesis on the Phillips Curve: Further International Evidence, Journal of Monetary Economics, 7, 1981, 239-250.

Alogoskoufis, G.S., Monetary Accommodation, Exchange Rate Regimes and Inflation Persistence, Economic Journal, 102(412), 1992, 461-480.

Alogoskoufis, G.S., Smith, R., The Phillips Curve, the Persistence of Inflation, and the Lucas Critique: Evidence from Exchange-Rate Regimes, American Economic Review, 81(5), 1991, 1254-1275.

Argy, V., Spitaller, E., The Joint Determination of Changes in Output and Prices in the Seven Main Industrial Countries, Weltwirtschaftliches Archiv, 116, 1980, 87113.

Attfield, C.L.F, Duck, N.W., The Influence of Unanticipated Money Growth on Real Output: Some Cross-Country Estimates, Journal of Money, Credit and Banking, 15(4), 1983, 442-454.

Attwood, T., The Remedy; or, Thoughts on the Present Distresses, London, 1816.

Bakker, A.F.P., The Liberalization of Capital Movements in Europe: The Monetary Commitree and Financial Integration, 1958-1994, Kluwer, Dordrecht, 1996.

Ball, L., Mankiw, N.G., Asymmetric Price Adjustment and Economic Fluctuations, Economic Journal, 104(2), 1994, 247-261.

Ball, L., Mankiw, N.G., Romer, D., The New Keynesian Economics and the Output-Inflation Trade-off, Brookings Papers on Economic Activity, 1988, 1-65.

Ball, L., Romer, D., Real Rigidities and the Non-neutrality of Money, Review of Economic Studies, 57(2), 1990, 183-203.

Barro, R.J., Rational Expectations and the Role of Monetary Policy, Journal of Monetary Economics, 2, 1976, 1-32.

Begg, D.K.H., Rational Expectations and the Non-neutrality of Systematic Monetary Policy, Review of Economic Studies, 47, 1980, 293-303.

Bils, M., Pricing in a Customer Market, Quarterly Journal of Economics, 104(4), 1989, 699-718. 
Blanchard, O.J., Price Ansynchronization and Price Level Inertia, in: Dornbusch, R., Simonsen, M.H. (ed), Inflation, Debt, and Indexation, MTT Press, 1983, 324.

Blanchard, OJ., Kiyotaki, N., Monopolistic Competition and the Effects of Aggregate Demand, American Economic Review, 77(4), 1987, 647-666.

Blinder, A.S., Fischer, S., Inventories, Rational Expectations, and the Business Cycle, Journal of Monetary Economics, 8, 1981, 277-304.

Brown, A.J., The Great Inflation, 1939-1951, Oxford University Press, London, 1955.

Caballero, R.J, Engel, E.M.R.A., Price Rigidities, Asymmetries, and Output Fluctuations, National Bureau of Economic Research, Working Paper, 4091, 1992.

Caplin, A.S., Leahy, J., State-Dependent Pricing and the Dynamics of Money and Output, Quarterly Journal of Economics, 106(3), 1991, 683-708.

Caplin, A.S., Spulber, D.F., Menu costs and the neutrality of money, Quarterly Journal of Economics, 102(4), 1987, 703-725.

Cecchetti, S.G., Staggered Contracts and the Frequency of Price Adjustment, Quarterly Journal of Economics, 100, 1985, 935-959.

Cecchetti, S.G., Testing Short-run Neutrality: International Evidence, Review of Economics and Statistics, 69, 1987, 135-140.

Centraal Bureau voor de Statistiek, Kwartaalrekeningen, 's-Gravenhage, Staatsuitgeverij.

Christensen, M., Paldam, M., Some Further International Evidence on OutputInflation Tradeoffs: The Lucas Variability Hypothesis Reexamined, Weltwirtschaftiches Archiv, 126, 1990, 222-238.

Christensen, M., Palldam, M., Shooting fish in the barrel? Examining the standard test of the Lucas variability hypothesis, Applied Economics, 23, 1991, 18111818.

Collignon, S., Bofinger, P., Johnson, C., Maigret, B. de, Europe's Monetary Futwre, Pinter Publishers, London, 1994.

Cover, J.P., Asymmetric Effects of Positive and Negative Money-Supply Shocks, Quarterly Journal Economics, 107 (4), 1992, 1261-1282.

Darrat, A.F., The Policy Ineffectiveness Proposition: Some Further Tests, Economics Letters, 25, 1987, 117-122.

Darrat, A.F., Policy Impacts under Rational Expectations, Journal of Banking and Finance, 15, 1991, 257-271.

DeFina, R.H., International Evidence on a New Keynesian Theory of the OutputInflation Trade-off, Joumal of Money, Credit, and Banking, 23(3), 1991, 410422.

De Grauwe, P., The Economics of Monetary Integration, second edition, Oxford University Press, Oxford, 1994. 
De Long, J.B., Summers, L.H., How Does Macroeconomic Policy Affect Output?; Brookings Papers on Economic Activity, 1988(2), 433-494.

Demery, D., Aggregate Demand, Rational Expectations and Real Output: Some new Evidence for the UK: 1963.2-1982.2, Economic Joumal, 94, december, 1984 , 847-862.

De Nederlandsche Bank, Kwartaalconfrontatie van middelen en bestedingen 195\%1984, Kluwer, Deventer, 1986.

Diamond, P.A., Aggregate Demand Management in Search Equilibrium, Journal of Political Economy, 90(5), 1982, 881-894.

Dixon, H., Rankin, N., Imperfect Competition and Macroeconomics: A Survey, Oxford Economic Papers, 46(2), 1994, 171-199.

Dornbusch, R., PPP Exchange-Rate Rules and Macroeconomic Stability, Journal of Political Economy, 1982, 90(1), 158-165.

Driscoll, M.J., Ford, J.L., Mullineux, A.W., Sen, S., Money, Output, Rational Expectations and Neutrality: Some Econometric Results for the UK, Economica, $50,1983,259-268$.

Dumas, B., Dynamic Equilbrium and the Real Exchange Rate in a Spatially Separated World, Review of Financial Studies, 5(2), 1992, 153-180.

Fischer, S., Long-Term Contracts, Rational Expectations, and the Optimal Money Supply Rule, Journal of Political Economy, 85(1), 1977, 191-205.

Fischer, S., On Activist Monetary Policy with Rational Expectations, in: Fischer, S., (ed.), Rational Expectations and Economic Policy, University of Chicago Press, Chicago, 1980, 211-247.

Fisher, I., A Statistical Relation between Unemployment and Price Changes, International Labour Review, 13(6), 1926, 785-792; reprinted in: Journal of Political Economy, 81(2), 1973, 496-502.

Fratianni, M., Nabli, M., Inflation and Output with Rational Expectations in Open Economies, Welrwirtschaftliches Archiv, 121, 1985, 33-52.

Friedman, M., The Role of Monetary Policy, American Economic Review, 58(1), 1968, 1-17.

Friedman, M., Unemployment versus Inflation? An Evaluation of the Phillips Curve, Institute of Economic Affairs, 1975.

Friedman, M., Inflation and Unemployment, Journal of Political Economy, 85(3), 1977, 451-472.

Frisch, J., Theories of Inflation, Cambridge University Press, Cambridge, 1983.

Froyen, R.T., Waud, R.N., Demand. Variability, Supply Shocks and the OutputInflation Tradeoff, Review of Economics and Statistics, 67, 1985, 9-15.

Giavazzi, F., Pagano, M., The Advantage of Tying One's Hands: EMS Discipline and Central Bank Credibility, European Economic Review, 32, 1988, 10551082. 
Giavazzi, F., Spaventa, L. Italy: The Real Effects of Inflation and Disinflation, Economic Policy: A European Forum, 8, 1989, 135-171.

Groeneveld, H.M., Koedijk, K.G., Kool, C.J.M., Monetary Interdependencies in the "Core" ERM Countries: The P-Star Approach, in: Alders, K., Koedijk, K., Kool, C., Winder, C., Monetary Policy in a Converging Europe, Kluwer, Dordrecht, $1996,39-60$.

Gros, D., Thygesen, N., European Monetary Integration: From the European Monetary System to European Monetary Union, Longman, London, 1992.

Haltiwanger, J., Waldman, M., Limited Rationality and Strategic Complements: The Implications for Macroeconomics, Quarterly Journal of Economics, 104(3), $1989,463-483$.

Hume, D., Of Money, 1752. Reprinted in: Rotwein, E. (ed.), Writings on Economics, University of Wisconsin, Madison, 1970.

Humphrey, T.M., From Trade-offs to Policy Ineffectiveness: A History of the Phillips Curve, Federal Reserve Bank of Richmond, October 1986.

Jung, W.S., Output-Inflation Tradeoffs in Industrial and Developing Countries, Journal of Macroeconomics, 7(1), 1985, 101-113.

Katsimbris, G.M., Output-inflation trade-Offs in industrial and developing countries: A comment and additional evidence, Journal of Macroeconomics, 12(3), 1990, 483-499.

Katsimbris, G.M., Miller, S., The new-Keynesian Economics and the Output-Inflation Trade-off, Applied Economics Letters, 3(9), 1996, 599-602.

Kempf, H., Irregular Staggered Contracts and Monetary Policy, European Economic Review, 31(6), 1987, 1247-1266.

Kendall, M.G., Stuart, A., The Advanced Theory of Statistics, volume 1, Distribution Theory, fourth edition, Griffin, London, 1977.

Kenen, P.B., Economic and Monetary Union in Europe: Moving beyond Maastricht, Cambridge Uniwersity Press, Cambridge, 1995.

Kim, J., Testing in Modern Economics: the Case of Job Search Theory, in: Marchi, N. de, Blaug, M., Appraising Economic Theories, Edward Elgar, Aldershot, $1991,105-136$.

Klein, L.R., Goldberger, A.S., An Econometric Model of the United States 19291952, North-Holland, Amsterdam, 1955.

Konienczny, J.D., Inflation, Output and Labour Productivity when Prices are Changed Infrequently, Economica, 57(2), 1990, 201-218.

Konieczny, J.D., Variable Price Adjustment Costs, Economic Inquiry, 31, 1993, 488-498.

Kool, CJ.M., Multiwariate Multi State Kalman Filter Method: General Description and User's Guide, State University Limburg, Maastricht, January 1993.

Kormendi, R.C., Meguire, P.G., Cross-Regime Evidence of Macroeconomic Rationality, Journal of Political Economy, 92 (5), 1984, 875-908. 
Koskela, E., Viren, M., New international evidence on output-inflation tradeoffs, Economics Letrers, 6, 1980, 233-239.

Kremers, J.J.M., Gaining Policy Credibility for a Disinflation: Ireland's Experience in the EMS, LMF Staff Papers, 37(1), 1990, 116-145.

Laidler, D., Some Macroeconomic Implications of Price Stickiness, in: Laider, D., Taking Money Seriously and Other Essays, Philip Allan, New York, 1990, 7995.

Lawrence, C., Rational Expectations, Supply Shocks And the Stability of the Inflation-Output Tradeoff, Joumal of Monetary Economics, 11(3), 1983, 225-245.

Leeson, R., Does the Expectations Trap render the Natural-Rate Model invalid in the Disinflationary Zone, Cambridge Journal of Economics, 21(1), 1997, 95101 .

Leiderman, L., Expectations and Output-Inflation Tradeoffs in a Fixed-ExchangeRate Economy, Journal of Political Economy, 87(6), 1979, 1285-1306.

Lindgren, B.W., Statistical Theory, MacMillan, New York, third edition, 1976.

Lipsey, R.G., The Relation between Unemployment and the Rate of Change ofMoney Wages in the United Kingdom, 1862-1957: A Further Analysis, Economica, 27, 1960, 1-31.

Lucas, R.E., Econometric Testing of the Natural Rate Hypothesis, in: Eckstein, O. (ed.), Conference on the Econometrics of Price Determination, Washington, 1972, 50-59. Reprinted in: Lucas, R.E., Studies in Business-Cycle Theory, Basil Blackwell, Oxford, 1981, 90-103.

Lucas, R.E., Some International Evidence on Output-Inflation Tradeoffs, American Economic Review, 63(3), 1973, 326-334.

Lucas, R.E., An Equilibrium Model of the Business Cycle, Journal of Political Economy, 83(6), 1975, 1113-1144.

Lucas, R.E., Rapping, L.A., Real Wages, Employment, and Inflation, Journal of Political Economy, 77(2), 1969a, 721-754.

Lucas, R.E., Rapping, L.A., Price Expectations and the Phillips Curve, American Economic Review, 59, 1969b, 342-350.

Lucke, B., Do Small Menu Costs Explain Large Business Cycles?, Economics Letters, 47(2), 1995, 185-192.

Lye, J.N., Sibly, H., Testing for Pricing Asymmetries in Customer Markets, Australian Economic Papers, 33(63), 1994, 239-252.

MacKinnon, J., Critical Values of Cointegration Tests, in: Engle, R.F., Granger, C.W.J., Long-run economic relationships: Readings in Cointegration, Oxford University Press, Oxford, 1991, 267-276.

Mankiw, N.G., Small Menu Costs and Large Business Cycles: A Macroeconomic Model of Monopoly, Quarterly Journal of Economics, 100(3), 1985, 529-537.

Mill, J.S., The Currency Juggle, Tait's Edinburg Magazine, 1833. Reprinted in: Mill, J.S., Dissertations and Discussions, Vol. 1, Boston, 1865. 
Mishkin, F.S., Does Anticipated Monetary Policy Matter? An Econometric Investigation, Joumal of Political Economy, 90(1), 1982a, 22-51.

Mishkin, F.S., Does Anticipated Aggregate Demand Policy Matter? An Econome tric Investigation, American Economic Review, 72(4), 1982b, 788-802.

Modigliani, F., The Monetarist Controversy or, Should We Forsake Stabilization Policies?, American Economic Review; 67(2), 1977, 1-19.

Modigliani, F., The Debate over Stabilization Policy, Cambridge University Press, London, 1986, 3-39:

Mortensen, D.T., Job Search, the Duration of Unemployment, and the Phillips Curve, American Economic Review, 60(5), 1970, 847-862.

Musgrave, R.A., Musgrave, P.B., Public Finance in Theory and Practice, Fifth Edition, McGraw-Hill, New York, 1989.

Naish, H.F.s Price Adjustment Costs and the Output-Inflation Trade-off, Economica, $53,1986,219-230$.

Naish, H.F., Imperfect Competition; Price Adjustment Costs, and the Long-Run Phillips Curve, Journal of Macroeconomics, 10(1), 1988, 103-124.

Neumann, M.J.M., von Hagen, J., An Aggregate Supply Function for the Open Economy With Flexible Exchange Rates, Journal of Institutional and Theoretical Economics, 144(4), 1988, 658-670.

Nishimura, K.G., Customer Markets and Price Sensitivity, Economica, 56(222), $1989,187-198$.

Odedokun, M.O., Evidence on Inflation-Output Trade-Off in Developing and Industrial Countries, Applied Economics, 23, 1991, 731-742.

OECD, Economic Outlook, December 1993 - June 1995.

OECD, Economic Surveys, Italy, 1979 - 1995.

OECD, Economic Surveys, Spain, 1979 - 1996.

Oh, S., Waldman, M., Strategic Complementarity Slows Macroeconomic Adjustment to Temporary Shocks, Economic Inquiry, 32, 1994, 318-329.

Okun, A.M., Inflation: Its Mechanics and Welfare Cost, Brookings Papers on Economic Activity, 2, 1975, 351-401.

Okun, A.M., Prices and Quantities: A Macroeconomic Analysis, Basil Blackwell, Oxford, 1981.

Padoa-Schioppa, T., The European Monetary System: A Long-Term View, in: Giavazzi, F., Micossi, S., Miller, M., ed., The European Monetary System, Cambridge University Press, Cambridge, 1988.

Parkin, M., The Output-Inflation Trade-off When Prices Are Costly to Change, Journal of Political Economy, 94(1), 1986, 200-224.

Parkin, M., Bentley, B., Fader, C., Some International Evidence on Output-Inflation Trade-Offs: A Reappraisal, in: Flanders, M.J., Razin, A., Development in an inflationary World, Academic Press, New York, 1981, 131-152. 
Phelps, E.S., Phillips curves, expectations of inflation and optimal unemployment over time, Economica, 34, 1967, 254-281.

Phelps, E.S., Money-Wage Dynamics and Labor-Market Equilibrium, Joumal of Political Economy, 76, 1968, 678-711.

Phelps, E.S., Introduction: The New Microeconomics in Employment and Inflation Theory, in: Phelps, E.S., et al., Microeconomic Foundations of Employment and Inflation Theory, Norton, New York, 1970, 1-23.

Phelps, E.S., Taylor, J.B., Stabilizing Powers of Monetary Policy under Rational. Expectations, Joumal of Political Economy, 85(1), 1977, 163-190.

Phelps, E.S., Winter, S.G., Optimal Price Policy under Atomistic Competition, in: Phelps, E.S., et al., Microeconomic Foundations of Employment and Inflation Theory, Norton, New York, 1970, 309-337.

Phillips, A.W., The Relation Between Unemployment and the Rate of Change of Money Wage Rates in the United Kingdom, 1861-1957, Economica, 25, 1958, 283-299.

Ram, R., Further international evidence on inflation-output trade-offs, Canadian Journal of Economics, 17, 1984, 523-540.

Ram, R., Another look at intemational evidence on inflation-output trade-offs, Indian Economic Journal, 37(3), 1990, 71-83.

Rankin, N., Imperfect Competition, Expectations and the Multiple Effects of Monetary Growth, Economic Journal, 102(413), 1992, 743-753.

Rhee, W., Rich, R.W., Inflation and the Asymmetric Effects of Money on Output Fluctuations, Journal of Macroeconomics, 17(4), 1995, 683-702.

Rogoff, K., The Purchasing Power Parity Puzzle, Journal of Economic Literature, 34(2), 1996, 647-668.

Rotemberg, J.J., Sticky Prices in the United States, Journal of Political Economy, 90(6), 1982, 1187-1211.

Samuelson, P.A., Solow, R.M., Problem of Achieving and Maintaining a Stable Price Level: Analytical Aspects of Anti-Inflation Policy, American Economic Review, 50, 1960, 177-194.

Santomero, A.M., Seater, J.J., The Inflation-Unemployment Trade-off: A Critique of the Literature, Journal of Economic Literature, 16, 1978, 499-544.

Sargent, T.J., Wallace, N., "Rational" Expectations, the Optimal Monetary Instrument, and the Optimal Money Supply Rule, Journal of Political Economy,83(2), $1975,241-254$.

Sheffrin, S.M., Unanticipated Money Growth and Output Fluctuations, Economic Inquiry, 17, 1979, 1-13.

Shelley, G.L., Wallace, F.H., A Reexamination of Mishkin's Neutrality Test, Journal of Economics and Business, 47(3), 1995, 255-265.

Sheshinski, E., Weiss, Y., Inflation and Costs of Price Adjustment, Review of Economic Studies, 44, 1977, 287-303. 
turn increases the demand for goods. This increase in demand for goods raises average inflation. And as the output effect is persistent (see Table 8.1), average inflation will keep rising in order to keep average output growth above the average rate of natural output growth. In the price-stickiness model of chapter 5 allso a strictly positive relation has been found between the persistence of average inflation and the degree of monetary accommodation. The explanation for this result is comparable to that of the price-misperception model of chapter 6 .

With respect to systematic exchange rate policy, it is found in the price-misperception model of chapter 6 that a higher degree of exchange rate accommodation increases the peristence of rellative inflation. A higher degree of exchange rate accommodation increases relative economic growth through the real interest rate channel and the real exchange rate channel. As this increase in the demand for goods is persistent (see Table 8.1), relative inflation must keep rising in order to maintain relative output growth above the relative growth rate of natural output. As a result, a higher degree of exchange rate accommodation increases the persistence of relative inflation, and thus decreases the speed of inflation convergence. In the price stickiness model of chapter 5 , however, it is found that the relation between the degree of exchange rate accommodation and the persistence of relative inflation is not strictly positive. This is due to the fact that a change in the degree of exchange rate accommodation is transmitted through three channels: the real interest rate channel, the real exchange rate channel, and the wage cost channel. A higher degree of exchange rate accommodation causes an increase in the persistence of rellative inflation through the real interest rate channel and the real exchange rate channel, but a decrease through the wage cost channel. As a result, the relation is not strictly positive. This is in line with Dombusch (1982). Under reasonable parameter values, however, the relation is positive. In that case, the inflation effects cannot be used to distinguish between price-misperception and price stickiness.

Table 8.3 Theoretical inflations effects of systematic monetary and exchange rate policy

Price-misperception model

(chapter 6)

Effect on the persistence of average inflation of an increase in the degree of monetary accommodation

positive

positive

Effect on the persistence of re-

lative inflation of an increase in the degree of exchange rate accommodation
Price stickiness model

(chapter 5) 
Sheshinski, $\mathbb{E}$. Weiss, Y, Optimum Pricing Policy Under Stochastic Inflation, Review of Economic Studies, 50, 1983, 513-530.

Sidrauski, M., Rational Choice and Patterns of Growth in a Monetary Economy, American Economic Review, 67(2), 534-544.

Slade, ME., Price Wars in Price-setting Supergames, Economica, 56, 1989, 295 310.

Slade, M.E, Strategic Pricing Models and Interpretation of Price-War Data, European Economic Review, 34, 1990, 524-537.

Taylor, J.B., Staggered Wage Setting in a Macro Model, American Economic Review, 69(2), 1979, 108-113.

Taylor, J.B., Aggregate Dynamics and Staggered Contracts, Journal of Political Economy, 88(1), 1980, 1-23.

Thornton, H., An Enquiry into the Nature and Effects of the Paper Credit of Great Britain, 1802. Edited with an introduction by F.A. von Hayek, Rinehart and Company, New York, 1939.

Tinbergen, J., An Economic Policy for 1936, in: Klaassen, L.H., Koyck, M., Witteveen, H.J., Selected Papers, North-Holland, Amsterdam, 1959.

Tsiddon, D., On the Stubbornness of Sticky Prices, International Economic Review, 32(1), 1991, 69-75.

Tsiddon, D., The (Mis)Behaviour of the Aggregate Price Level, Review of Economic Studies, 60, 1993, 889-902.

Turnovsky, S.J., An Introduction to Stabilization Theory and Policy, in: Turnovsky, S.J., Macroeconomic analysis and stabilization policy, fourth revised edition, Cambridge University Press, Cambridge, 1981, 307-328.

Zaretsky, A.M., Coughlin, C.C., An Introduction to the Theory and Estimation of a Job-Search Model, Federal Reserve Bank of St. Louis Review, 77(1), January/February, 1995, 53-65. 


\section{Samenvatting}

Met het naderen van de totstandkoming van de Europese Monetaire Unie vrezen landen zoals Frankrijk, Italië en Spanje dat het Europese monetaire beleid zo strikt zal zijn dat het een recessie zal veroorzaken. Vanuit de literatuur is bekend dat een minder strikt monetair beleid de werkloosheid op de korte termijn kan verlagen, maar op de lange termijn alleen de inflatie zal verhogen. Of een dergelijke uitruil tussen inflatie en economische groei benut moet worden met behulp van monetair beleid of meer in het algemeen met vraag-beleid, hangt van een aantal omstandigheden af. Niet alleen de omvang en de duur van de effecten van expansief beleid op de werkloosheid en de economische groei, maar ook de mate waarin inflatie stijgt, spelen een rol bij deze beslissing. En als het aankondigen van beleidswijzigingen het effect daarvan beïnvloedt, is dit eveneens van belang. Bovendien kunnen de effecten van vraag-beleid op inflatie en economische groei anders zijn als de verklaring voor de uitruil anders is en als het soort vraag-beleid verschilt.

Dit proefschrift onderzoekt twee verklaringen voor het bestaan van een uitruil tussen inflatie en economische groei: prijs-misperceptie theorieën en prijs-starheidstheorieën (zie hoofdstuk 2). Alleen op de korte termijn bestaat er in deze theorieën een uitruil tussen inflatie en economische groei; op de lange termijn is er geen uitruil. Volgens de prijs-misperceptie theorieën is er een korte termijn uitruil tussen inflatie en economische groei omdat aanbieders imperfecte informatie hebben over de aard van de schokken in de vraag naar hum producten. Ze zijn er onzeker over of de relatieve vraag naar hun producten is gestegen of dat het gemiddelde prijspeil is gestegen. Hoe meer de aanbieder denkt dat een schok reèel is, hoe meer hij zijn productie zal aanpassen. Volgens de prijs-starheidstheorieèn is er een korte termijn uitruil tussen inflatie en economische groei omdat de concurrentie op de goederenmarkt imperfect is en er prijsaanpassingskosten zijn of andere nominale rigiditeiten, zoals strategische complementariteit en overlappende looncontracten. In dat geval zal een hogere vraag naar goederen een toename van de productie veroorzaken omdat lonen en prijzen niet onmiddellijk reageren.

Het vraag-beleid wordt onderverdeeld in niet-systematisch en systematisch beleid. Niet-systematisch beleid betreft het optreden van schokken in bijvoorbeeld overheidsuitgaven, de geldhoeveelheid, of de wisselkoers; systematisch beleid is gericht op het veranderen van de aanpassingsregels voor deze variabelen. In de prijs-misperceptie theorieên heeft alleen niet-systematisch beleid invloed op de reële economische groei; systematisch beleid is neutraal omdat economische agenten al rekening hebben gehouden met de verwachte verandering in beleid In de prijs- 
starheidstheorieën heeft echter ook systematisch beleid invloed op de economische groei; dit effect vloeit voort uit het feit dat het tijd kost voor bedrijven om hun prijsstrategie aan te passen aan een verandering in systematisch beleid.

of de uitruil tussen inflatie en economische groei benut kan worden, hangt af van de effecten van niet-systematisch en systematisch beleid voor economische groei en inflatie. Zowel de prijsmisperceptie modellen als de prijs-starheidsmodellen in hoofdstuk 3, 5 en 6 doen hier een uitspraak over. Beide typen modellen voorspellen dat zowel expansief niet-systematisch als systematisch beleid alleen op de korte termijn de economische groei vergroot; op de lange termijn heeft een dergelijk beleid geen effect op de economische groei. Bovendien is de vorm van de korte termijn uitruil, het effect van verwacht beleid op de economische groei en de duur van de productie-effecten afhankelijk van het type vraag-beleid en de verklaring voor de uitruil.

In het geval van niet-systematisch beleid hebben de prijs-misperceptie modellen en de prijs-starheidsmodellen tegengestelde eigenschappen met betrekking tot de vorm van de korte termijn uitruil, de productie-effecten van verwachte beleidswijzigingen, en de duur van de productie-effecten. Waar de prijs-misperceptie modellen stellen dat positieve en negatieve vraagschokken hetzelfde effect hebben op de economische groei, voorspellen de prijs-starheidsmodellen dat de effecten van negatieve schokken op de economische groei juist groter zijn dan die van positieve schokken. De belangrijkste verklaring voor een dergelijke asymmetrische uitruil is het bestaan van prijsaanpassingskosten (zie Caballero en Engel, 1993; Tsiddon, 1993; en Ball en Mankiw, 1994). Gegeven een positieve inflatievoet impliceren de prijsaanpassingstheorieën dat een bedrijf een prijs vaker zal aanpassen in het geval van een toename van de vraag dan in het geval van een afname van de vraag. Het gevolg hiervan is dat het productie-effect groter is bij een afname van de vraag dan bij een toename van de vraag.

Ten tweede impliceren de prijs-misperceptie modellen dat een verwachte verandering in de geaggregeerde vraag geen effect heeft op de economische groei (structurele neutraliteit), terwijl dit wel het geval is in de prijs-starheidsmodellen (nietneutraliteit). In de prijs-misperceptie modellen komt dit door het feit dat prijzen zich onmiddellijk aanpassen gegeven de verwachte verandering in de geaggregeerde vraag; in de prijs-starheidsmodellen kost het juist tijd om de prijzen aan te passen en dus hebben verwachte beleidswijzigingen wel effect op de economische groei.

Ten derde zijn schokken in de geaggregeerde vraag niet persistent in de prijsmisperceptie modellen, maar wel in de prijs-starheidsmodellen. Een persistent effect op de groei van de productie wil zeggen dat beleidswijzigingen de economische groei niet alleen beïnvloeden op het moment van de beleidswijziging, maar ook daarna. In de prijs-misperceptie modellen is een schok niet persistent omdat de publicatie van het algemene prijspeil de onzekerheid over de relatieve prijzen oplost en zo de schok elimineert; in de prijs-starheidsmodellen zijn schokken wel persistent als gevolg van strategische complementariteit, overlappende looncontracten, het 
aanvullen van de voorraad geproduceerde goederen, of vertragingen bij het verzamelen van informatie.

De prijs-misperceptie modellen en de prijs-starheidsmodellen kunnen dus worden onderscheiden met behulp van de vorm van de korte termijn uitruil, de productie-effecten van verwachte beleidswijzigingen, en de duur van de productie-effecten. In hoofdstuk 3 is onderzocht of empirisch bewijs voor de Verenigde Staten en Duitsland de prijsmisperceptie-modellen ondersteunen of juist de prijs-starheidsmodellen. Om dat te onderzoeken zijn de symmetrie-hypothese, de structurele neutraliteitshypothese en de hypothese van geen persistentie getoetst tegen de alternatieve hypotheses van respectievelijk asymmetrie, niet-neutraliteit en persistentie. Voor zowel de Verenigde Staten en Duitsland is het bewijs niet eenduidig met betrekking tot de asymmetrie-hypothese; de hypotheses van structurele neutraliteit en geen persistentie konden echter niet verworpen worden en dus is het moeilijk om het prijsmisperceptie model te verwerpen. Een punt van kritiek met betrekking tot deze empirische toetsen is dat waargenomen schokken in bijvoorbeeld de groei van het nominale inkomen niet zonder meer aangemerkt kunnen worden als wijzigingen in het beleid. Deze schokken zijn niet alleen het resultaat van beleidswijzigingen, maar ook van veranderingen in het gedrag van consumenten, producenten, en financiële instituten. Om beleidswijzigingen te onderzoeken moeten deze eigenlijk worden onderscheiden van de andere wijzigingen.

Een groot bezwaar tegen het voeren van niet-systematisch beleid is dat zowel de prijs-misperceptie modellen als de prijs-starheidsmodellen voorspellen dat veelvuldig gebruik ervan het effect van schokken op de economische groei verminderen. Dit effect wordt weergegeven met behulp van een aantal relaties. Ten eerste impliceren beide soorten modellen dat een hogere variantie van inflatie of een hogere variantie van vraagschokken het effect van een vraagschok op de economische groei vermindert; dit zijn de Lucas variabiliteitshypotheses. Omdat deze twee relaties hetzelfde zijn voor de prijs-misperceptie modellen en de prijs-starheidsmodellen, kunnen ze niet worden gebruikt om empirisch een onderscheid te maken tussen beide theorieèn. Het beschikbare bewijs voor deze variabiliteitshypotheses is echter niet eenduidig voor ontwikkelde en ontwikkelende landen. Daarom is in hoofdstuk 4 een meta-studie verricht over de tien beschikbare studies waarin de Lucas variabiliteitshypotheses zijn onderzocht. Als er gecorrigeerd wordt voor verschillen in aanbod-reactie, geven deze studies aan dat de hypothese dat een hogere variantie van vraagschokken tot een steilere korte termijn uitruil leidt moet worden verworpen voor de groep van ontwikkelde landen. Dus, de prijs-misperceptie theorieën slagen er niet in alle empirische resultaten te verklaren. Dit kan ook te wijten zijn aan endogeniteit van de vraag-schokken omdat deze gemeten worden als veranderingen in nominaal inkomen.

Daarnaast zijn er nog twee andere relaties die in eerste instantie wel geschikt lijken om een dergelijk onderscheid te maken. Zo voorspellen de prijs-misperceptie modellen dat er geen relatie is tussen inflatie en de helling van de korte termijn 
uitruil tussen productie en inflatie; de prijs-starheidsmodellen voorspellen echter een negatief verband omdat een hogere inflatie tot een hogere frequentie van prijsaanpassingen leidt en dus een kleiner effect van een vraagschok op de economische groei. Gewoonlijk is er echter een hoge correlatie tussen de inflatievoet en de variantie van inflatie. In dat geval verschaft een negatieve relatie tussen de helling van de korte termijn uitruil en de inflatievoet geen bewijs voor de prijs-starheidstheorieèn. Ten slotte voorspellen de prijs-misperceptie theorieën een positieve relatie tussen de helling van de korte termijn uitruil en de variantie van relatieve prijzen terwijl de prijs-starheidstheorieèn juist een negatieve relatie voorspellen. In de prijs-misperceptie theorieên is deze relatie positief omdat een hogere variantie van relatieve prijzen de mate waarin schokken ten onrechte worden waargenomen als reéle schokken verhoogt; in de prijs-starheidstheorieèn is de relatie negatief omdat een hogere variantie van relatieve prijzen de frequentie van prijsaanpassingen verhoogt en dus het effect van een vraag-schok op de economische groei vermindert. Het is echter moeilijk om de variantie van relatieve prijzen te onderscheiden van de variantie van absolute prijzen; dit heeft tot gevolg dat ook de relatie tussen de variantie van relatieve prijzen en de helling van de korte termijn uitruil tussen inflatie en economische groei niet gebruikt kan worden om empirisch prijs-misperceptie te onderscheiden van prijs-starheid.

In het geval van systematisch beleid hebben de prijsmisperceptie modellen en de prijs-starheidsmodellen juist dezelfde eigenschappen met betrekking tot de vorm van de korte termijn uitruil, de productie-effecten van verwachte beleidswijzigingen, en de duur van de productie-effecten. Het prijs-misperceptie model van hoofdstuk 6 en de prijs-starheidsmodellen van hoofdstuk 5 laten zien dat de korte termijn uitruil tussen inflatie en economische groei symmetrisch is, dat verwachte beleidswijzigingen de economische groei beïnvloeden, en dat beleidswijzigingen persistent zijn. Het feit dat verwachte beleidswijzigingen in het prijs-misperceptie model in hoofdstuk 6 toch de economische groei beïnvloeden wordt veroorzaakt door het feit dat de reele vraag naar geld afhankelijk is van de nominal rente, dat het geldaanbod met een vertraging reageert op veranderingen in de inflatie, en dat de reële wisselkoers langzaam terugkeert naar koopkrachtpariteit. In de prijs-starheidsmodellen van hoofdstuk 5 ontbreken de laatste twee redenen, maar in plaats daarvan worden of prijsaanpassingskosten of overlappende looncontracten verondersteld.

Omdat noch niet-systematisch beleid, noch systematisch beleid gebruikt kan worden om de economische groei permanent te verhogen, en frequent gebruik van niet-systematisch beleid het effect van vraag-schokken op de economische groei vermindert, moet het nut van vraagbeleid om de economische groei te vergroten betwijfeld moet worden. Systematisch beleid wel kan worden gebruikt om de inflatie te verminderen. Zo laat het prijs-misperceptie model van hoofdstuk 6 zien dat een hogere mate van monetaire accommodatie de persistentie van de inflatie laat stijgen. Een hogere monetaire accommodatie laat de reële interest voet dalen wat de vraag naar goederen doet toenemen. Deze hogere vraag naar goederen veroorzaakt 
een toename in de inflatie. En ondat het effect op de economische groei persistent is, moet de inflatie blijven stijgen om de economische groei boven de groei van de natuurlijke productie te houden. In het prijs-starheidsmodel van hoofdstuk 5 is er eveneens een strict positieve relatie tussen the persistentie van inflatie en de mate van monetaire accommodatie. De verklaring hiervoor is vergelijkbaar met die van het prijs-misperceptie model van hoofdstuk 6 .

Met betrekking tot systematisch wisselkoers-beleid laat het prijs-misperceptie model van hoofdstuk 6 zien dat een hogere mate van wisselkoers accommodatie het verschil in inflatie tussen twee landen persistenter maakt. Een hogere mate van wisselkoersacccommodatie laat de relatieve economische groei toenemen via het reële interest kanaal en het reële wisselkoers kanaal. En omdat de toename in de vraag naar goederen persistent is, moet de relatieve inflatie blijven stijgen om de relatieve productie groei boven de relatieve groei van de natuurlijke productie te houden. In het prijs-starheidsmodel van hoofdstuk 5 is de relatie tussen de mate van wisselkoersaccommodatie en de persistentie van relatieve inflatie niet strikt positief. Dit ligt aan het feit dat de transmissie van een verandering in de mate van wisselkoersaccommodatie langs drie kanalen plaatsvindt: het reële interest kanaal, het reële wisselkoers kanaal, en het loonkosten kanaal. Een hogere mate van wisselkoersaccommodatie veroorzaakt een toename in de persistentie van relatieve inflatie via het reële interest kanaal en het reële wisselkoers kanaal, maar een afname via het loonkosten kanaal. Het gevolg hiervan is dat de relatie niet strikt positief is; dit is in overeenstemming met Dornbusch (1982). Echter onder redelijke waarden voor de parameters, is de relatie toch positief. In dat geval kan met behulp van de effecten van systematisch beleid geen onderscheid gemaakt worden tussen prijs-misperceptie en prijs-starheid als verklaring voor de korte termijn uitruil tussen inflatie en economische groei.

Gegeven dat de parameters in hoofdstukken 5 redelijke waarden aannemen, impliceren zowel hoofdstuk 5 als 6 dat een land alleen een toename in de snelheid van inflatie-convergentie kan bewerkstelliggen als het een harde wisselkoers weet vast te houden ten opzichte van een munt met een lage inflatie. De geleende geloofwaardigheidshypothese suggereert echter dat het toetreden tot een vast wisselkoerssysteem zoals het het Europees Monetair Stelsel voldoende is om de snelheid van inflatie-convergentie te laten stijgen. Om dit te onderzoeken welke van de twee hypotheses waar is, is in hoofdstuk 7 voor zowel Spanje als Italië een structurele breukenanalyse uitgevoerd met betrekking tot de snelleid van inflatie-convergentie over de periode 1975:1-1995:1. De resultaten laten zien dat de snelheid van inflatieconvergentie alleen toeneemt wanneer hun munten een harde wisselkoers krijgen ten opzichte van de Duitse mark; het toefreden, het uittreden, en het veranderen van de bandbreedtes heeft geen effect of de snelheid van inflatie-convergentie. Dit resultaat ondersteunt de modellen van hoofdstuk 5 en 6, maar niet de geleende geloofwaardigheidshypothese. 
De conclusie van dit proefschrift is dat de effecten van niet-systematisch vraagbeleid op de economische groei in de prijs-misperceptie modellen en de prijs-starheidsmodellen werschillen met betrekking tot hun implicaties voor de vorm van de korte termijn uitruil, de productie-effecten van verwachte beleidswijzigingen, en de duur van de productie-effecten. De empirische resultaten voor de Verenigde Staten en Duitsland geven aan dat het moeilijk is om de prijs-misperceptie modellen te verwerpen. De effecten wan systematisch vraagbeleid op de economische groei verschillen daarentegen niet tussen de prijs-misperceptie modellen en de prijs-starheidsmodellen. En hoewel het effect van systematisch anti-inflatie beleid via de intermediaire doelstelling van een harde wisselkoers niet eenduidig is in de prijs-starheidsmodellen maar wel in de prijs-misperceptie modellen, is dit verschil afwezig onder redelijke aannames voor parameters in het prijs-starheidsmodel. Dus, de effecten van systematisch anti-inflatie beleid kunnen ook niet gebruikt worden om prijs-misperceptie van prijs-starheid te onderscheiden.

Met betrekking tot het gebruik van vraag-beleid kan geconcludeerd worden dat vanuit een theoretisch perspectief noch niet-systematisch, noch systematisch vraagbeleid op lange termijn om de economisch groei kan vergroten en dat frequent gebruik van niet-systematisch beleid het effect van vraag-schokken op de economische groei vermindert. Het meta-onderzoek van hoofdstuk 4 laat echter zien dat voor het laatste verband geen empirisch bewijs is voor ontwikkelde landen. Systematisch vraag-beleid kan echter wel gebruikt wordlen om de inflatie te verlagen. Het empirisch onderzoek in hoofdstuk 7 voor Spanje en Italië bevestigt de voorspelling van hoofdstuk 5 en 6 dat een systematisch anti-inflatie-beleid met behulp van het vasthouden aan een harde wisselkoers helpt om de inflatie in een versneld tempo terug te brengen. Voor de alternatieve hypothese dat het deelnemen aan het Europees Monetair Stelsel voldoende zou zijn om de snelheid van inflatie-convergentie

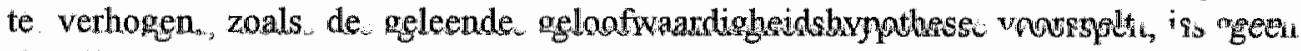
bewijgs gevonden. 


\section{Curriculum Vitae}

Allex Lammertsma was born on July 15 th 1970 in Heerlen (the Netherlands). From 1982 to 1988 he attended secondary school at the Romboutscollege in Brunssum. From September 1988 to August 1993, he studied Economics and Quantitative Economics at the Faculty of Economics and Business Administration at Maastricht University. In August 1993 he received his Master's degree with distinction. Immediately thereafter he started his $\mathrm{Ph} . \mathrm{D}$. thesis while working as a research assistant at the Economics department of Maastricht University; in August 1997 he completed this thesis.

Alex Lammertsma werd geboren op 15 juli 1970 in Heerlen. Van 1982 to 1988 volgde hij een Atheneum opleiding aan het Romboutscollege te Brunssum. Vanaf september 1988 tot en met augustus 1993 studeerde hij algemene en kwantitatieve economie aan de Faculteit der Economische Wetenschappen en Bedrijfskunde van de Universiteit Maastricht. In augustus 1993 studeerde hij cum laude af. Onmiddellijk daarna trad hij voor vier jaar in dienst als Assistent in Opleiding (AiO) bij dezelfde universiteit. Gedurende deze periode heeft hij dit proefschrift voltooid. 